\title{
Degradation of Beta Cloth Covering for a Battery Orbital Replacement Unit in Low Earth Orbit
}

James R. Gaier and Deborah L. Waters

Glenn Research Center, Cleveland, Ohio

Sammantha Baldwin and Angela D. Folz

Glenn Research Center, Cleveland, Ohio

Alyssa Loos

Manchester University, North Manchester, Indiana 


\section{NASA STI Program . . . in Profile}

Since its founding, NASA has been dedicated to the advancement of aeronautics and space science. The NASA Scientific and Technical Information (STI) Program plays a key part in helping NASA maintain this important role.

The NASA STI Program operates under the auspices of the Agency Chief Information Officer. It collects, organizes, provides for archiving, and disseminates NASA's STI. The NASA STI Program provides access to the NASA Technical Report Server-Registered (NTRS Reg) and NASA Technical Report ServerPublic (NTRS) thus providing one of the largest collections of aeronautical and space science STI in the world. Results are published in both non-NASA channels and by NASA in the NASA STI Report Series, which includes the following report types:

- TECHNICAL PUBLICATION. Reports of completed research or a major significant phase of research that present the results of NASA programs and include extensive data or theoretical analysis. Includes compilations of significant scientific and technical data and information deemed to be of continuing reference value. NASA counter-part of peer-reviewed formal professional papers, but has less stringent limitations on manuscript length and extent of graphic presentations.

- TECHNICAL MEMORANDUM. Scientific and technical findings that are preliminary or of specialized interest, e.g., "quick-release" reports, working papers, and bibliographies that contain minimal annotation. Does not contain extensive analysis.
- CONTRACTOR REPORT. Scientific and technical findings by NASA-sponsored contractors and grantees.

- CONFERENCE PUBLICATION. Collected papers from scientific and technical conferences, symposia, seminars, or other meetings sponsored or co-sponsored by NASA.

- SPECIAL PUBLICATION. Scientific, technical, or historical information from NASA programs, projects, and missions, often concerned with subjects having substantial public interest.

- TECHNICAL TRANSLATION. Englishlanguage translations of foreign scientific and technical material pertinent to NASA's mission.

For more information about the NASA STI program, see the following:

- Access the NASA STI program home page at http://www.sti.nasa.gov

- E-mail your question to help@sti.nasa.gov

- $\quad$ Fax your question to the NASA STI Information Desk at 757-864-6500

- Telephone the NASA STI Information Desk at 757-864-9658

- Write to:

NASA STI Program

Mail Stop 148

NASA Langley Research Center Hampton, VA 23681-2199 


\section{Degradation of Beta Cloth Covering for a Battery Orbital Replacement Unit in Low Earth Orbit}

James R. Gaier and Deborah L. Waters

Glenn Research Center, Cleveland, Ohio

Sammantha Baldwin and Angela D. Folz

Glenn Research Center, Cleveland, Ohio

Alyssa Loos

Manchester University, North Manchester, Indiana

Prepared for the

SPACE 2016

sponsored by AIAA

Long Beach, California, September 13-16, 2016

National Aeronautics and

Space Administration

Glenn Research Center

Cleveland, Ohio 44135 


\section{Acknowledgments}

The authors gratefully acknowledge the contributions of J. Caruso and P. Dalton (NASA Glenn Research Center) for making the ORU samples available to us and answering our many questions about the history of the samples. B.A. Banks (SAIC) suggested and performed the hyperthermal asher test.

Level of Review: This material has been technically reviewed by technical management.

Available from

NASA STI Program

Mail Stop 148

NASA Langley Research Center

Hampton, VA 23681-2199
National Technical Information Service 5285 Port Royal Road Springfield, VA 22161 703-605-6000

This report is available in electronic form at http://www.sti.nasa.gov/ and http://ntrs.nasa.gov/ 


\title{
Degradation of Beta Cloth Covering for a Battery Orbital Replacement Unit in Low Earth Orbit
}

\author{
James R. Gaier and Deborah L. Waters \\ National Aeronautics and Space Administration \\ Glenn Research Center \\ Cleveland, Ohio 44135 \\ Sammantha* Baldwin and Angela D. Folz ${ }^{*}$ \\ National Aeronautics and Space Administration \\ Glenn Research Center \\ Cleveland, Ohio 44135 \\ Alyssa Loos \\ Manchester University \\ North Manchester, Indiana 46962
}

\begin{abstract} the material over a temperature range of 300 to $700 \mathrm{~K}$ was essentially unchanged.

\section{Nomenclature}

$\begin{array}{ll}\alpha & \text { integrated absorptance } \\ \alpha(\lambda) & \text { absorptivity } \\ \text { AO } & \text { atomic oxygen } \\ \mathrm{B}(\lambda, \mathrm{T}) & \text { normalized blackbody irradiance } \\ \text { EDS } & \text { Energy-Dispersive X-ray Spectroscopy } \\ \varepsilon & \text { integrated emittance } \\ \varepsilon(\lambda) & \text { emissivity } \\ \text { FEP } & \text { fluorinated ethylene propylene } \\ \text { FESEM } & \text { Field Emission Scanning Electron Microscopy } \\ \text { ISS } & \text { International Space Station } \\ \text { IR } & \text { mid-infrared spectrum }(2.5 \text { to } 25 \mu \mathrm{m}) \\ \lambda & \text { wavelength } \\ \text { LEO } & \text { low Earth orbit } \\ \text { LDEF } & \text { Long Duration Exposure Facility } \\ \text { ORU } & \text { Orbit Replaceable Unit } \\ \text { MISSE-7 } & \text { seventh Materials International Space Station Experiment } \\ \text { PEC } & \text { passive experiment container } \\ \text { PGA } & \text { pressure garment assembly } \\ \text { PTFE } & \text { polytetrafluoroethylene }\end{array}$
\end{abstract}

Samples from the beta cloth cover for a battery orbit replaceable unit from the International Space Station (ISS) were characterized using optical and electron microscopy, UV-vis-NIR spectrophotometry, and $\mathrm{x}$-ray energy dispersive spectroscopy. Results showed that in areas where the fabric was exposed to solar radiation the absorptance increased by as much as 20 percent, and the peak difference was in the ultraviolet, indicating that the increased absorptance may have been due to radiation. The emissivity of

*Undergraduate Student Research Program 
$S(\lambda) \quad$ air mass zero solar spectrum

UV-vis-NIR ultraviolet-visible-near infrared spectrum (250 to $2500 \mathrm{~nm}$ )

\subsection{Introduction}

NASA is actively planning missions that will take humans into deep space for long periods of time. These may include returning to the moon, visiting a near-Earth asteroid, or undertaking a human mission to Mars. Mission lengths have been estimated to last from 6 months to 3 years. These long missions will require spacesuits to be exposed to the solar radiation environment for much longer periods of time than they have been heretofore. To date the most exposure to the space environment spacesuits have seen is a few tens of hours. A spacesuit used during any of the planned extended missions will likely see many more hours than that.

In an attempt to quantify what damage might occur to spacesuit fabrics during a long mission, the Spacesuit Fabrics Exposure Experiment was included as part of the Materials International Space Station Experiment-7 (MISSE-7). The results of this experiment have been described previously (Ref. 1), and are briefly summarized here. Pristine and dust-abraded samples of outer layer spacesuit fabrics were flown on the wake side passive experiment container (PEC) for approximately eighteen months, from November 2009 to May 2011. They were exposed to the space radiation environment of low Earth orbit (LEO), which is similar to that of the moon, though reduced in particle radiation because many of the solar wind ions are captured by the van Allen radiation belts, well above International Space Station (ISS) orbit. It was hoped that the long-term exposure in LEO will shed light on the extent to which spacesuit fabrics will degrade in long-term exposure on the moon, and how dust abrasion affects it.

The fabric samples were characterized using optical microscopy, Field Emission Scanning Electron Microscopy (FESEM), energy dispersive x-ray spectroscopy (EDS), optical spectroscopy and tensile testing after exposure on the ISS. Comparison of pre- and post-flight characterizations showed that space radiation darkened and reddened all six fabrics. On space exposure, the $\alpha$ of FEP fabric of the type used during the Apollo missions increased by 27 percent, and that of the modern Ortho-fabric increased by 38 percent. The $\alpha$ of FEP fabric abraded with JSC-1A lunar simulant increased by 7 percent, and JSC-1A abraded Ortho-fabric increased 9 percent. In both cases most of their spectra could be explained as a linear addition of the fabric and the dust, though the correlation did not hold in the visible and UV wavelengths for the Ortho-fabric. Spectroscopically, the lunar dust-laden fabric sample from Alan Bean's Apollo 12 suit darkened, but did not appreciably redden, though it appears redder to the eye. No evidence of contamination was seen in the EDS results, suggesting that the discoloration was due to radiation damage. Even though the samples were positioned on the wake side, because the ISS periodically reoriented to accommodate the docking of the Space Shuttle, the samples were exposed to the equivalent of about 38 days of ram AO. Evidence for this was seen in the oxidation of silver-coated fasteners and the etching of fabric fibers. The erosion seen in the fibers was qualitatively consistent with previously reported values for the erosion yields of the materials. Space exposure decreased the ultimate tensile strength and elongation to failure of the Alan Bean Apollo 12 space suit fibers by a factor of four and increased the elastic modulus by a factor of two. The severity of the degradation of the fabric samples over the 18 month exposure period demonstrates the necessity to find ways to prevent or mitigate radiation damage to spacesuits when planning extended missions to the moon.

In order to get some indication of how the fabric degradation might progress over longer periods of time, the $\beta$-cloth from a battery orbital replacement unit (ORU) that had been exposed to the space environment for 8.6 years was analyzed. A battery ORU is a replaceable set of rechargeable nickel hydrogen batteries used to power the ISS when it is not in direct sunlight (Fig. 1). The batteries are then recharged by the solar arrays each time the ISS orbit takes them into the sun. The ORU was protected by a scrim cloth covered by 21 layers of perforated vapor deposited aluminized Kapton ${ }^{\circledR}$ sheet covered by a 


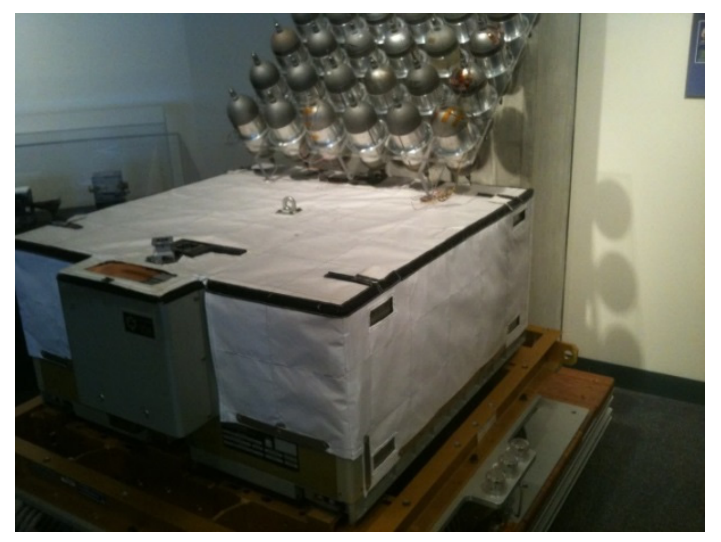

(a)

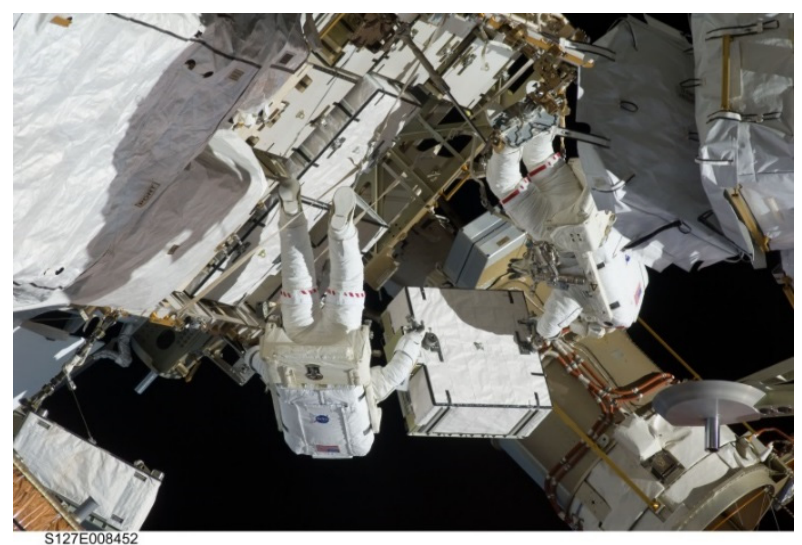

(b)

Figure 1.-(a) A battery ORU and the array of nickel hydrogen batteries it contains and (b) astronauts installing a battery ORU on the ISS.

second scrim cloth, with the beta cloth (PTFE-coated fiberglass) outer layer. The layers were stitched together with embedded wire for grounding. The ORU also has black trim made from carbon loaded PTFE. Although the material is not the same as either the Apollo or present spacesuit materials, all of them have a PTFE or FEP surface, and so should react similarly to the space environment. Samples were taken from battery ORU S/N 15, one of the first set of six battery ORUs flown on ISS.

The durability of $\beta$-cloth on long-term space exposure has been evaluated before. It was included in the Long Duration Exposure Facility (LDEF), a large cylindrical facility that was placed in orbit by the Space Shuttle Challenger in April 1984 and retrieved by Space Shuttle Columbia in January 1990. The $\beta$-cloth sample was exposed for 5.7 years in a constant orientation of $22^{\circ}$ off of ram and was analyzed by Linton (Ref. 2). The environmental exposure was characterized as including 8,680 estimated sun hours of UV radiation, AO exposure of $8.17 \times 10^{21}$ atom $/ \mathrm{cm}^{2}$, a proton fluence $(0.05$ to $200 \mathrm{MeV})$ of $10^{9} / \mathrm{cm}^{2}$, an electron fluence of $10^{12} / \mathrm{cm}^{2}$ for $50 \mathrm{keV}$ to $10^{8} / \mathrm{cm}^{2}$ for $3.0 \mathrm{MeV}$, and about 32,000 thermal cycles. They found that the more exposure $\beta$-cloth had to $\mathrm{AO}$, the darker it became. They attributed this to increased light absorption from the more highly textured surface and the exposed glass in the surface. They also found that the PTFE polymer erosion did not release glass fibers. In addition, the glass fibers prevented further erosion of the PTFE. The backside of the samples did not change appreciably from the starting material.

The fortuitous opportunity to evaluate the ORU $\beta$-cloth provided an opportunity to confirm the results of the LDEF sample. Because this ORU was not part of a space exposure experiment, the environment was not characterized. Nor was the orientation controlled, or even constant. But the exposure was some 20 percent longer, and the variation in the orientation more indicative of realistic spacesuit exposure.

The battery ORU S/N 15 was one of six installed on the P6 truss was launched November 30, 2000 on the Space Shuttle Endeavor (STS 97). Endeavor docked with the ISS on December 2, and the next day installed the P6 integrated truss segment onto the Z1 segment (Fig. 2). P6 supported the first set of solar arrays and the supporting battery ORUs, including S/N 15. The ORU was oriented such that it faced the starboard side of the truss, orthogonal to the ram and zenith directions. It remained in this position 2520 days $(6.9 \mathrm{yr})$.

On October 28, 2007 the P6 truss was removed from the Z1 segment to the ISS robotic arm. On October 29, the P6 truss was moved to Space Shuttle Discovery's (STS 120) robotic arm, and on October 30, it was installed at the end of the P5 truss (Fig. 3). After installation at the end of P5 the ORU faced the zenith direction when the Beta Gimbal was set at zero. However, as the ISS orbits the Earth, the gimbal continuously rotates, so the ORU was subjected to a continuous cycling through zenith, ram, nadir, and wake directions.

After 632 days, on July 24, 2009, the six battery P6 truss ORUs were returned to Endeavor's bay (STS-127). Battery ORU S/N 15 was returned to Earth on July 31, 2009 after being exposed to the LEO environment for 3156 days (8.6 years). 


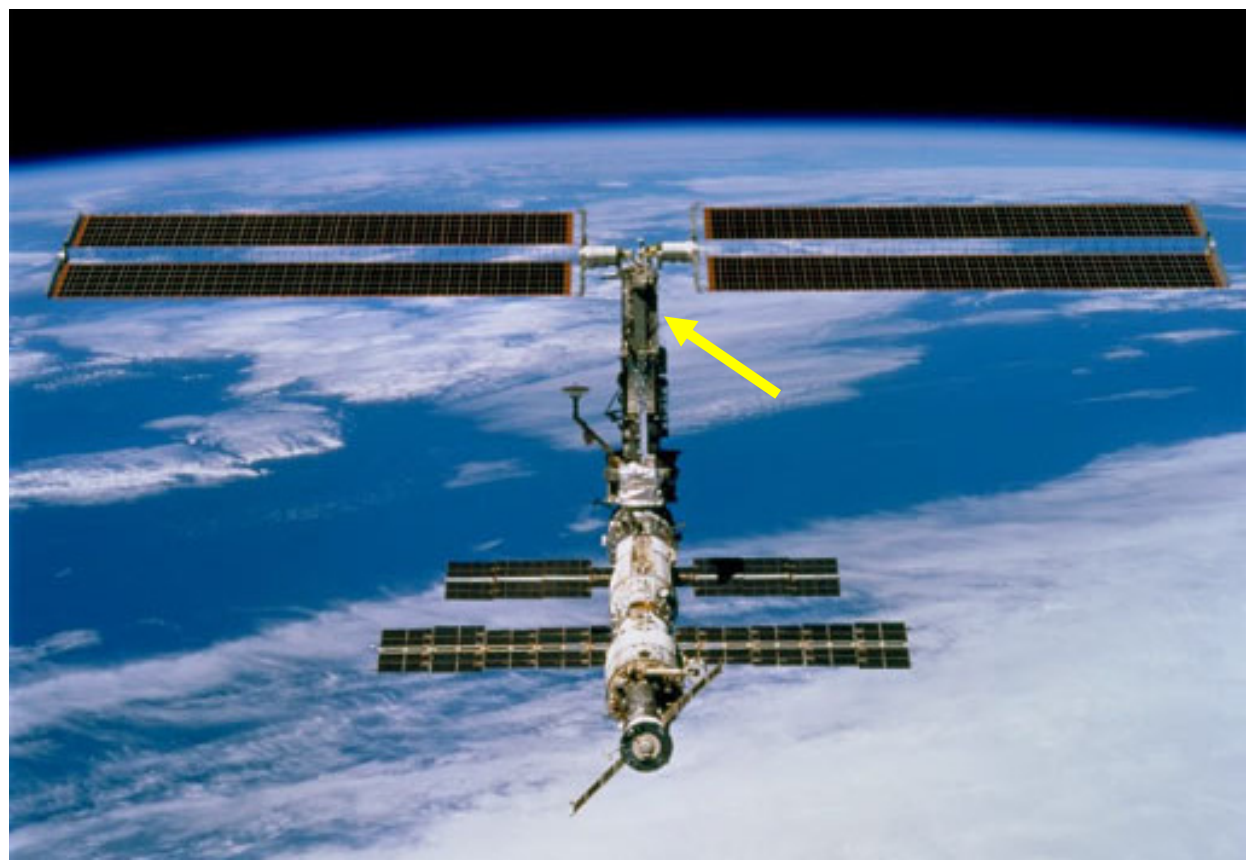

Figure 2.-Configuration of the ISS when battery ORU S/N 15 was first attached to the P6 integrated truss segment. The motion of the ISS is away from the camera, and the arrow shows the approximate location of the ORU.

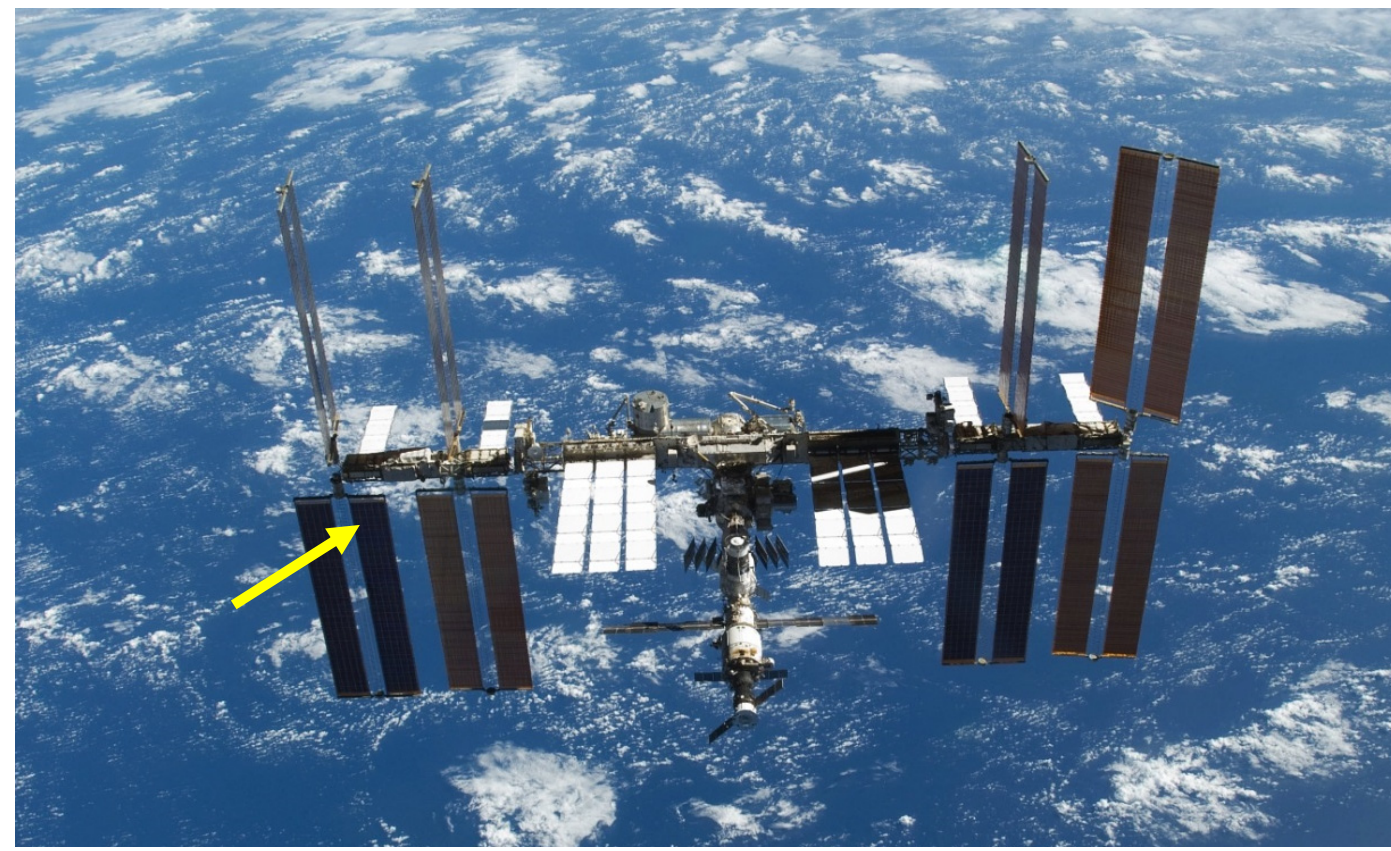

Figure 3.-Configuration of the ISS after the P6 integrated truss segment containing battery ORU S/N 15 was moved to the end of the P5 integrated truss segment. The motion of the ISS is away from the camera, and the arrow shows the approximate location of the ORU. 


\subsection{Methods}

The ORU was returned to the NASA Glenn Research Center to be put in storage at Plumbrook Station. But before storage, pieces were cut from each of the five accessible sides, bagged, and set aside for analysis. The five sides were labeled A through E, with side A facing roughly in the wake direction and the other sides orthogonally oriented as illustrated in Figure 4. Although the orientation of this ORU is not known, since sides B and D saw more degradation than sides C and D, it is speculated that it was in the orientation shown in Figure 4. If so, side E would have been zenith facing as it faces the radiator panel which likewise is oriented zenith for optimum heat rejection.

Seven samples were cut from the ORU cover, two each from sides A and B (one from the lightest spot (A1, B1) and one from the darkest spot (A2, B2)), and one each from other sides (C1, D1, and E1). In addition, two samples were cut from black trim on sample B1, one from a more eroded region (grey) and one from a less eroded (black). The pieces from the five ORU sides showing where they were sampled are shown in Figure 5. The samples were trimmed to $15 \mathrm{~mm} \times 17 \mathrm{~mm}$ and placed in sample handlers (Fig. 6). This enabled the samples to be transported among the microscopes and analytical instruments without being directly handled.

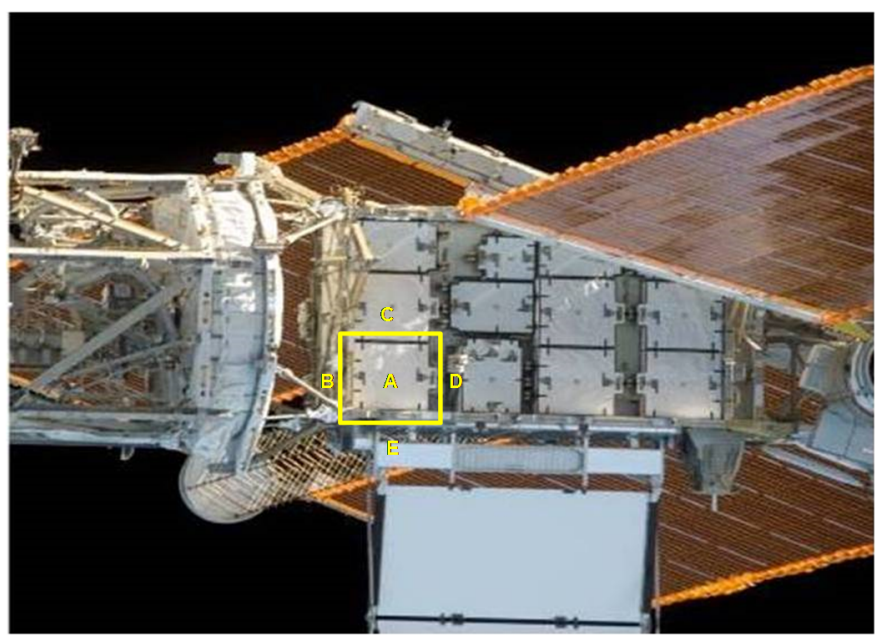

Figure 4.-Battery ORUs located near a solar array beta gimbal illustrating their flight orientation. The "A" surface is facing the viewer, with the B, C, D, and E surfaces located in the 9:00, 12:00, 3:00, and 6:00 positions, respectively.
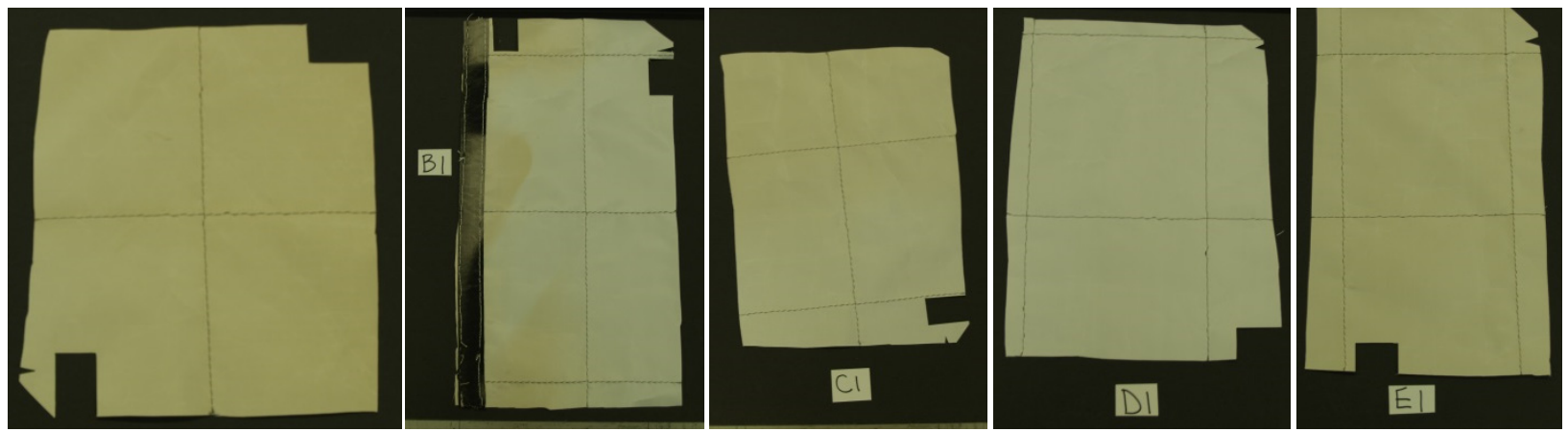

Figure 5.-Pieces from the five ORU sides show where each was sampled. In addition, two samples were cut from black trim on sample B1, one from a more eroded region (grey) and one from a less eroded (black). 


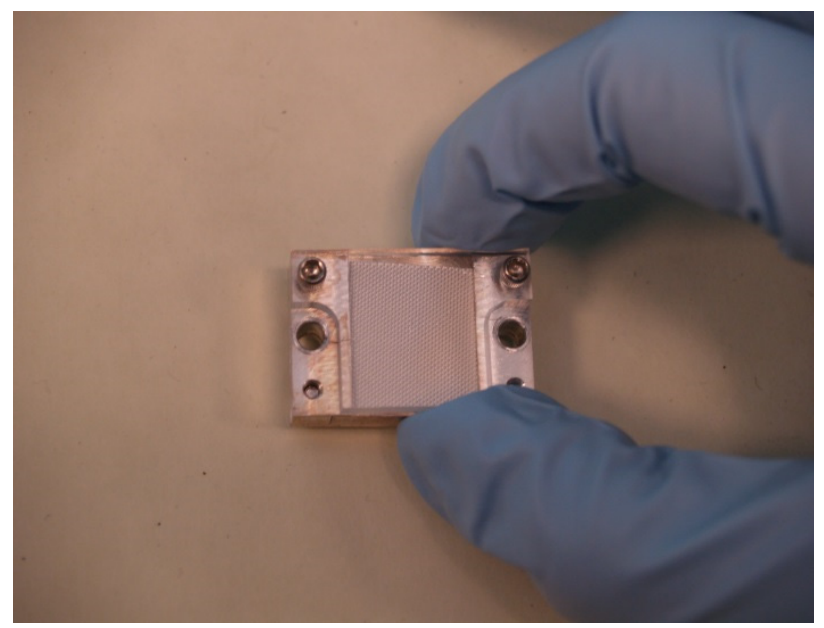

Figure 6.-Sample handler of the type the seven ORU samples were mounted.

The exposed outer side and the unexposed inner side of each sample was imaged using a Leica MZ16 optical microscope fitted with digital image capture at $7.1 \times$ magnification with the same white balance to show color changes of the fabric. They were then imaged at 5 positions: center and $3 \mathrm{~mm}$ north, south, east, and west of center. At each position, images were taken at $10 \times, 25 \times, 50 \times$, and $100 \times$ magnification. The samples were also imaged using a Hitachi Model S-4700 Field Emission Scanning Electron Microscope (FESEM) using $1 \mathrm{keV}$ electrons at the same 5 positions. At each position, images were taken at 50×, 100×, $250 \times$, and $1000 \times$ magnification. Some positions were imaged at higher magnifications as well.

The total integrated reflectance as a function of wavelength $(250$ to $2500 \mathrm{~nm})$ of the front and back of each sample was measured using a Varian Cary 5000 UV-vis-NIR Spectrophotometer equipped with an integrating sphere. These data were used to determine the total integrated solar absorptance of the fabrics as well. It was assumed that the color of the backs of the samples was the same as the original color, since it is unlikely that radiation penetrated to the back of the fabric.

The total reflectivity $(\rho(\lambda))$ in the mid-infrared region (wavelength 2.5 to $25 \mu \mathrm{m}$ ) was measured using an iS50 Nicolet Spectrophotometer (ThermoFisher) equipped with a Pike integrating sphere measured on a deuterated triglycine sulfate (DTGS) detector. Data were collected using OMNIC software. Since all of the incident energy must be transmitted, reflected, or absorbed, assuming the samples were opaque, their absorptivities $(\alpha(\lambda))$ can be calculated using Equation (1).

$$
\alpha(\lambda)=(1-\rho(\lambda))
$$

The total integrated absorptance $(\alpha)$ can be obtained by integrating the $\alpha(\lambda)$ over all values of $\lambda$, and convoluting that with the air mass zero solar spectrum $(S(\lambda))$. In practice nearly all of the solar energy is emitted between 250 and $2500 \mathrm{~nm}$, so the following approximation can be made with little loss of accuracy.

$$
\alpha \approx \sum_{250 \mathrm{~nm}}^{2500 \mathrm{~nm}} \alpha(\lambda) S(\lambda)
$$

Kirchhoff's law of thermal radiation leads to the expression for the emissivity $(\varepsilon(\lambda))$ below, Equation (3).

$$
\varepsilon(\lambda)=\alpha(\lambda)
$$


The total integrated emittance $(\varepsilon)$ was approximated by summing the $\varepsilon(\lambda)$ times the normalized blackbody irradiance values for a given wavelength and temperature $(B(\lambda, T))$ over the wavelength range of the spectrum, Equation (4). There is little lost in approximating $\varepsilon$ over the temperature range of 300 to $700 \mathrm{~K}$ by using $\lambda$ from 2.5 to $25 \mu \mathrm{m}$.

$$
\varepsilon \approx \sum_{25 \mu \mathrm{m}}^{25 \mu \mathrm{m}} \varepsilon(\lambda) B(\lambda, T)
$$

It is important to note that, because of the limited range of the wavelength region probed by the IR spectra, there is a corresponding limited temperature range for which this analysis is valid. Temperatures below about $300 \mathrm{~K}$ or above about $700 \mathrm{~K}$ would require input over a wider wavelength range. This study did not attempt to calculate $\varepsilon$ outside of the 300 to $700 \mathrm{~K}$ window.

After imaging, half of each of the A1, A2, B1, and B2 samples was gold coated in order to measure the energy dispersive spectroscopy (EDS) spectra, and higher magnification imaging. The coating enabled the use of higher energy electron beams so that more chemical species could be identified without melting or burning the nonconductive fabric. EDS spectra were measured using an AMETEK EDAX JSM-6360 EDS Detector in the exposed area of the sample and to determine whether the samples had been contaminated.

\subsection{Results and Discussion}

\subsection{Optical Microscopy}

One of the most obvious effects noted even before optical micrographs were taken, was that four of the seven samples (A1, A2, B2, and E1) had darkened, and reddened. Note the pattern of darkening that shows up in the survey photos in Figure 5. Sample B showed particularly dramatic color differences, and a pattern that indicated shadowing either of radiation or contamination. This will be discussed in more detail below, but Figure 7 illustrates the extent of the color change. Photomicrographs of samples B1, C1, and D1 showed little darkening and so might be considered indicative of material that was neither strongly contaminated nor radiation damaged.

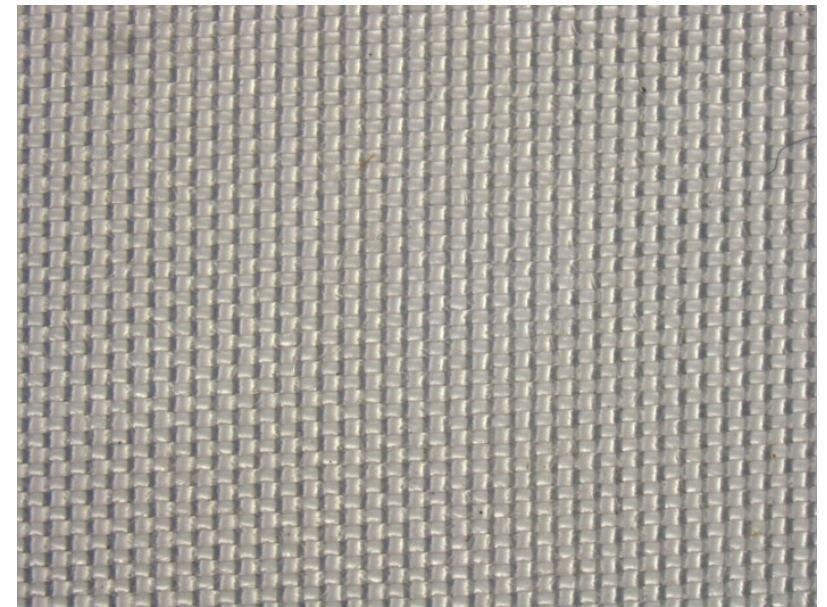

(a)

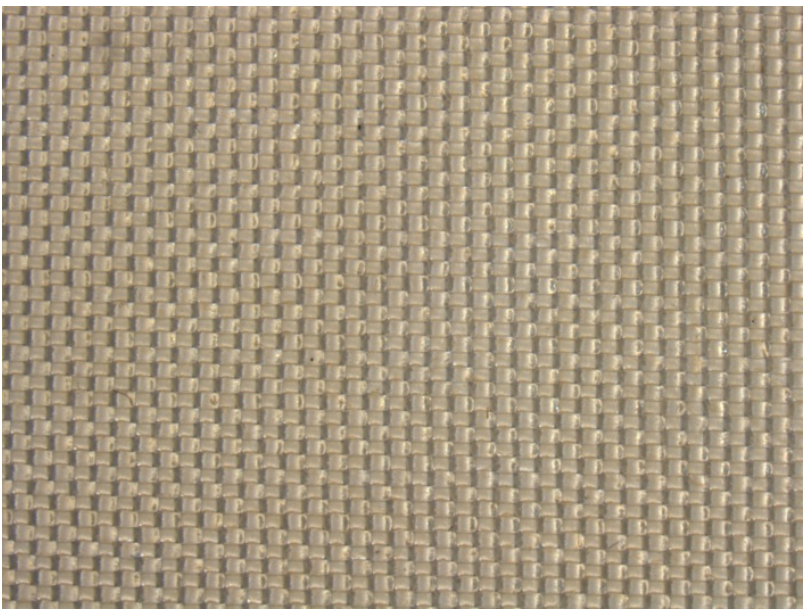

(b)

Figure 7.-(a) The back of sample A2 at $7.1 \times$ is assumed to be the original color of the ORU. (b) The space exposed side of sample A2 appears darker and redder. 
Linton attributed darkening of the $\beta$-cloth to increased surface texture and to the erosion of the PTFE to reveal the darker fiberglass below. In the present study, evidence for darkening of the fiberglass was found as well. High magnification optical microscopy revealed that there appears to be no or little damage to the individual filaments. Figure 8 shows an image of the center of the sample in Figure 7(b) at 100×. The glass fibers seen beneath the clear PTFE layer appeared to be undamaged. However, where the $\beta$-cloth was stitched together several of the fibers were pulled free of the PTFE. As can be seen clearly in Figure 9(a) this fiber has darkened markedly.

In order to investigate this further, an additional sample from D1 was placed in a hyperthermal asher operated at $35 \mathrm{~W}$ with an air plasma for $165 \mathrm{hr}$. Under these severe conditions the PTFE was oxidized away leaving only the glass fibers. The asher also generates a high flux of UV light. The result, shown in Figure 9(b), was no darkening of the fibers. Thus UV darkening of the fiberglass is unlikely the major contributor to the overall darkening of the $\beta$-cloth. It seems likely that ionizing radiation (high energy protons and electrons) are responsible for darkening the fiberglass when $\mathrm{AO}$ erosion is severe enough to expose it.

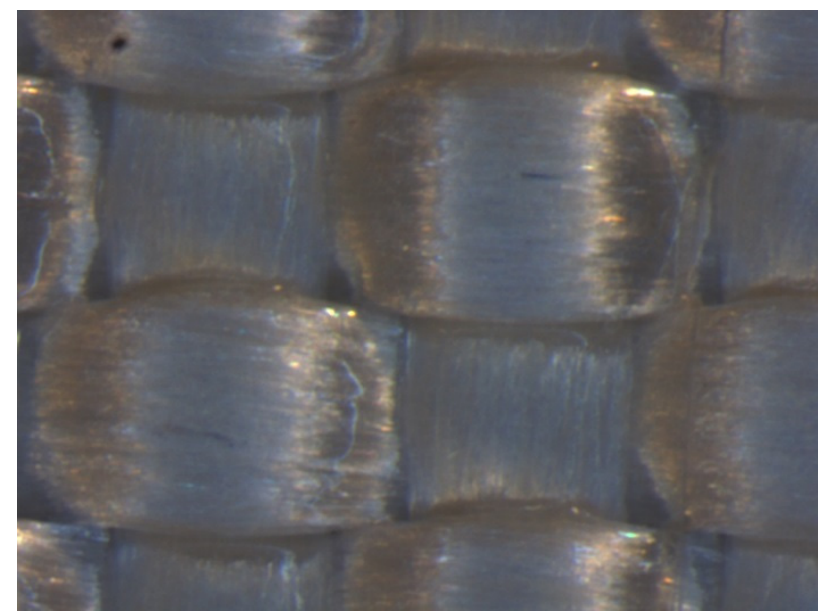

Figure 8.-A photomicrograph of the space exposed side of sample $A 2$ at $100 \times$ shows no indications of fiber damage or contamination.
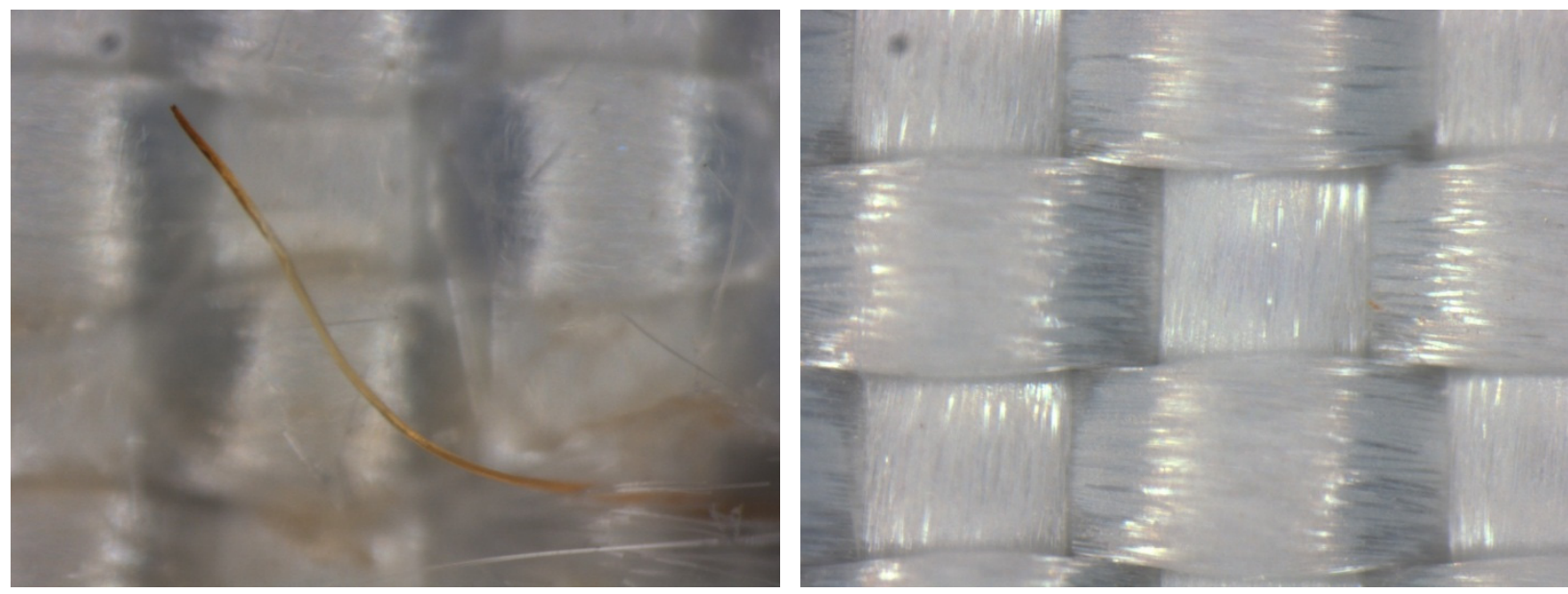

Figure 9.-Photomicrographs of (a) the space exposed side of sample B2 at 100x showing a glass fiber which was pulled from the $\beta$-cloth during the stitching. It has been dramatically darkened compared to those shown in the background. (b) A sample exposed to $165 \mathrm{hr}$ of a $35 \mathrm{~W}$ hyperthermal air plasma. 


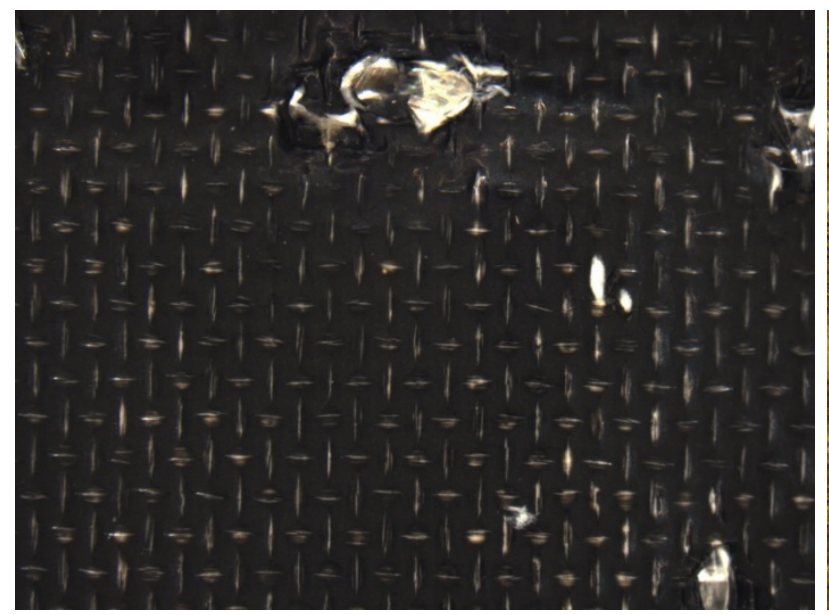

(a)

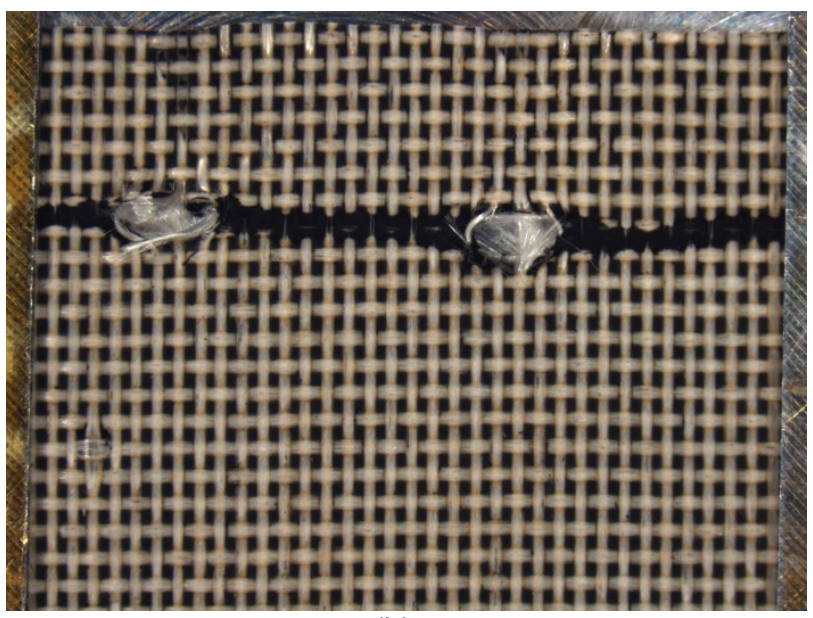

(b)

Figure 10.- The space exposed sides of the black trim of sample B1 at $7.1 \times$ in a (a) black region and a (b) grey region shows that the fibers are intact, but much of the black resin has been eroded away in the grey sample. The larger yarns seen in the upper portion of the photographs are the thread used to attach the trim to the ORU.

Unlike the MISSE-7 fabrics, there was no evidence of splotches of discoloration that might be indicative of contamination. Figure 10 shows two areas from the space-exposed side of the black trim at a magnification of 7.1×. One appeared black to the eye and the other grey (as can be seen in Fig. 5). At this magnification it was clear that the difference is that in the grey sample the entire top layer of the black resin has been eroded from the trim piece. The erosion of the grey sample was likely due to ram atomic oxygen, and the black regions were shadowed from it. The full set of optical images at $10 \times, 25 \times, 50 \times$, and $100 \times$ are found in Appendix A.

\subsection{Scanning Electron Microscopy and Energy Dispersive Spectroscopy}

Samples B1, C1, and D1, which showed little darkening, were imaged in the FESEM. After initial imaging, sample B1 was gold coated to reduce sample charging in the microscope and improve the image clarity. At a magnification of $500 \times, \mu \mathrm{m}$-sized holes were evident in the PTFE coating. At $2000 \times$ there were areas where the PTFE had apparently eroded all of the way through to the glass fibers (Fig. 11(a)). The full set of FESEM images at 100×, 500×, 1000×, and 2000× are found in Appendix B.

The greatest erosion was seen on sample B2, where the material was discolored. It was noted that sample A2, which was also discolored, showed little or no erosion. This would seem to indicate that the process that darkened the fabric was distinct from that which eroded it. Previous studies of the effects of fluorocarbons suggest that the erosion was likely due to atomic oxygen attack (Ref. 3).

Although there was evidence of texture on the PTFE, it was not as well developed as the texture on the MISSE-7 samples which were exposed for only 18 months. In general there seemed to be less damage to the ORU surface, despite its longer exposure. However, it was difficult to judge how much PTFE has eroded away since there were no areas protected from atomic oxygen.

Photomicrographs of the black trim samples confirmed the optical microscope observation that the gray areas were much more highly eroded than the black areas. Figure 12 shows that the black areas showed even less erosion than the main body of the ORU, possibly because of the extra thickness of the black coating. The grey areas, however were more highly eroded than the main body. This was not surprising given that the $\mathrm{AO}$ erosion yield for carbon is much higher than that of PTFE in the LEO environment (Ref. 4). 


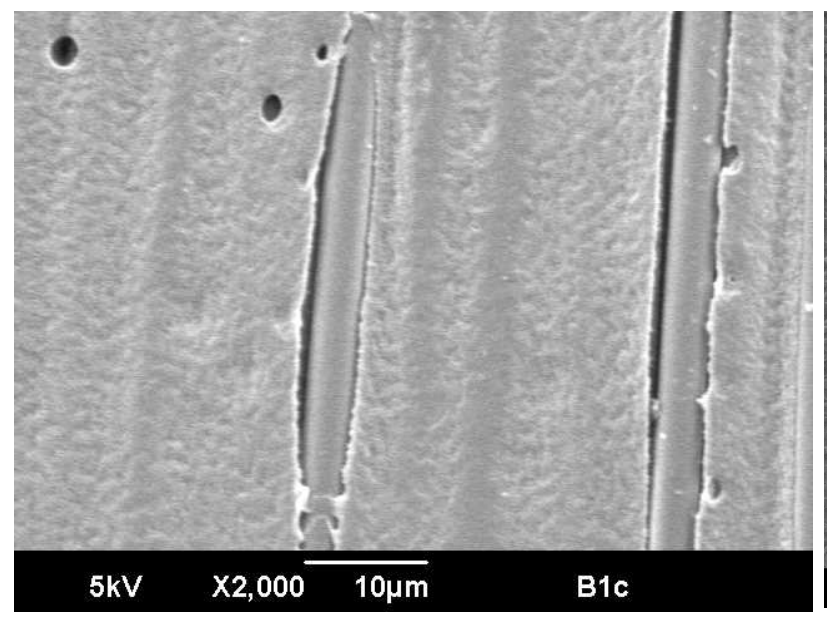

(a)

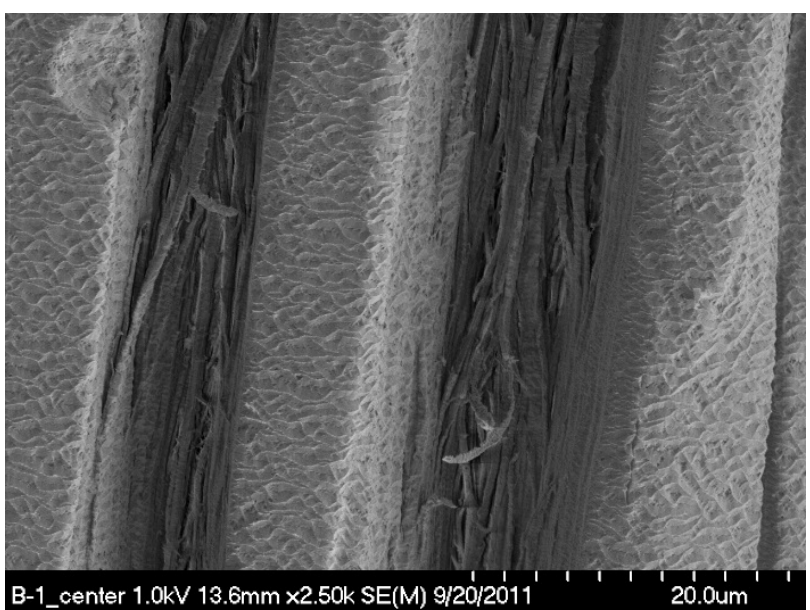

(b)

Figure 11.-Battery ORU degradation after $8.6 \mathrm{yr}$ (a) compare with FEP fabric degradation after $1.5 \mathrm{yr}$ exposure on the wake side of MISSE-7 (Ref. 4).

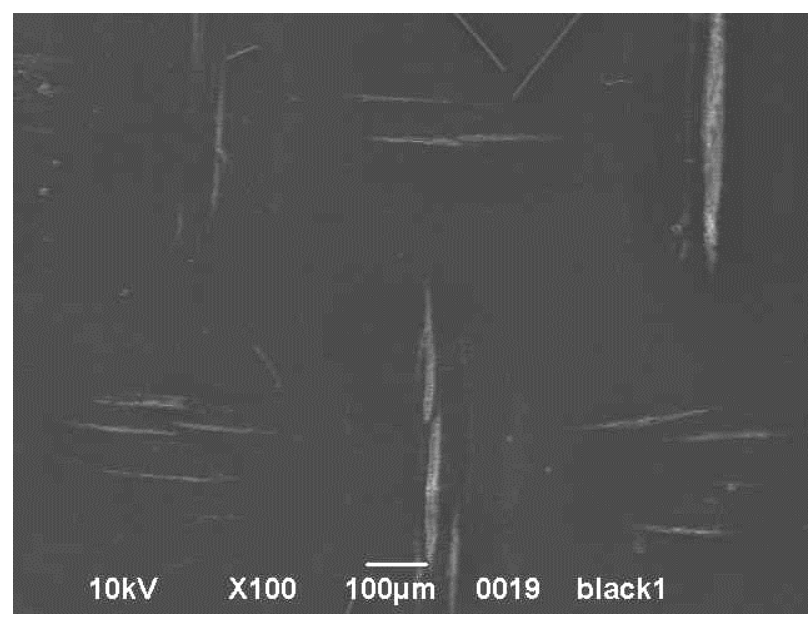

(a)

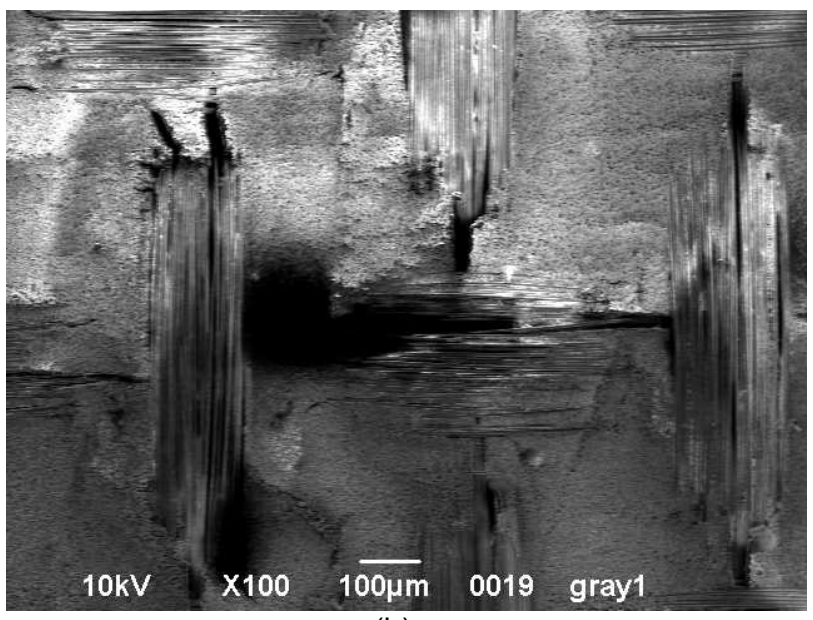

(b)

Figure 12.-Black trim of the ORU degradation after $8.6 \mathrm{yr}$ exposure varies from no discernable degradation (a) to "grey" areas where the coating was eroded down to the fibers (b).

\subsection{Spectroscopy}

Figure 13(a) shows the reflectance spectrum of sample E1 in the region of maximum solar absorptance ( 250 to $2500 \mathrm{~nm}$ ) for the front and back sides. Figure 13(b) shows the difference between these two spectra which was a single broad peak centered near $370 \mathrm{~nm}$. The other samples were similar, although B1, C1, and D1 had much smaller difference peaks. The full set of UV-vis-NIR spectra are found in Appendix C. These results were consistent with radiation-caused degradation of the mechanical properties of FEP on the Hubble Space Telescope (Ref. 5). The difference peak for all of the samples was in the UV, between 360 and $375 \mathrm{~nm}$, which indicated that darkening of the PTFE may be due to unsaturated bonds induced by UV radiation.

The sample taken from the B side also included a black trim piece. It can be seen in Figure 5 that the area of the degradation of the black to grey spatially corresponds to area of darkening in the main body of the sample. It is reasonable to ask whether that darkening was caused by contamination by the degrading black trim. However, the spectral lightening of the gray trim showed no spectral features corresponding to the $370 \mathrm{~nm}$ peak exhibited in difference spectrum of the darkened B1 sample. In addition, the difference peak was the same as that seen in the A1 and E1 samples, suggesting that they were all degraded by a 


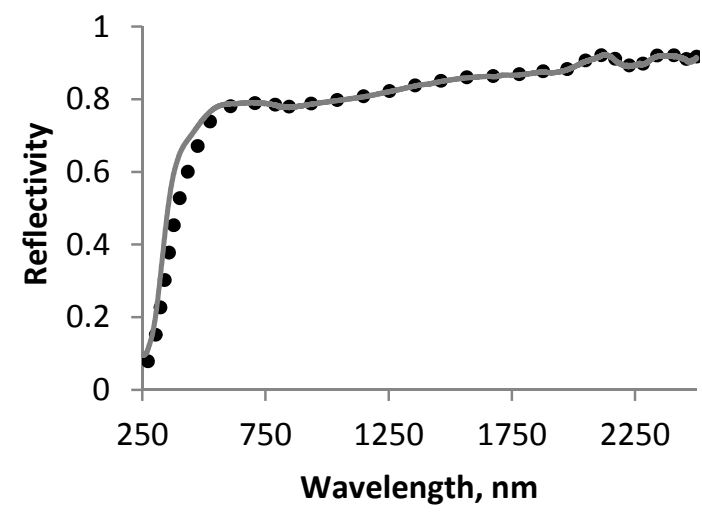

(a)

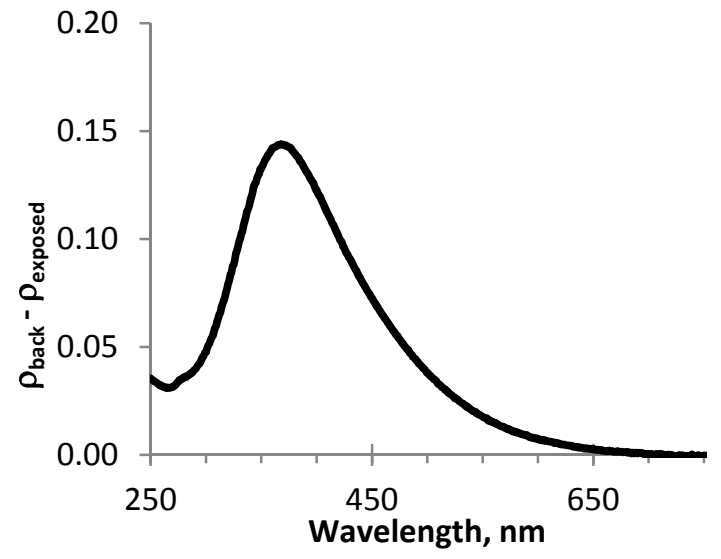

(b)

Figure 13.-(a) Total reflectivity of sample E1 comparing the back, unexposed side (solid grey line) with the exposed side (black dotted line), and (b) their difference spectrum.

similar mechanism. In addition, there was no correlation between the amount of darkening, as measured either by the total $\alpha$ degradation or the difference peak height. Thus, contamination by the black trim piece was ruled out as a dominant mechanism for the darkening of the ORU surfaces.

EDS of selected areas of all samples showed no evidence of contamination from external sources either. In areas that showed minimal erosion there were only peaks at $277 \mathrm{eV}$ (carbon) and $677 \mathrm{eV}$ (fluorine). These peaks were expected in the PTFE coating which has a nominal chemical composition of $\left(\mathrm{C}_{2} \mathrm{~F}_{4}\right)_{\mathrm{n}}$. In areas where the fibers were exposed there were also significant peaks at 525 and $1740 \mathrm{eV}$, corresponding to oxygen and silicon that make up the major component of the glass fibers. Small peaks were also identified in the fiber exposed regions at 1040, 1486, and $3690 \mathrm{eV}$, corresponding to sodium, aluminum, and calcium respectively, and presumed to be minor constituent of the glass fibers as well. The EDS spectra of the black trim stripe and eroded grey areas had very similar EDS spectra. One conspicuous difference was that the ratio of carbon to fluorine was about 0.78 in the black region, and about 0.60 in adjacent white regions. This was believed to be due to carbon black added to the PTFE coating to make the trim black. Selected EDS spectra are found in Appendix D.

The UV-vis-NIR reflectance spectra of the samples show that the darkening was characteristic of PTFE degradation in LEO. Table 1 lists the $\alpha$ for each of the seven samples taken from uncovered regions of the ORU in order of least to most darkening. The back side $\alpha$ was $0.248 \pm 0.005$, with a range of 0.015 . The front side $\alpha$ was $0.267 \pm 0.020$ with a range of 0.018 . This value is consistent with the $\alpha$ of $0.22 \pm 0.02$ that Linton measured after 5.7 years LEO exposure on LDEF (Ref. 2). Note that, for the most part, those samples with darker front surfaces also had darker back surfaces. A least squares fit of the data reveals that about 62 percent of the variation in the front side $\alpha$ can be explained variation in the back side. However, since there were no preflight reflectivity measurements it was not clear whether there was a 2 percent variation in material on launch, or whether the process that darkened the front side darkened the back side also. The mean $\alpha$ was about 21 percent higher than the $0.22 \pm 0.02$ reported for the LDEF exposed samples and were exposed 21 percent longer, reinforcing the idea that $\alpha$ of the $\beta$-cloth increases linearly with time.

It was clear that the A side of the ORU was most affected by the space environment. This is consistent with the A side being most directly exposed to the LEO environment (as seen in Fig. 4). Similarly, the E side was fully exposed to the LEO environment and was also darkened. Side D showed no change in $\alpha$, and the change in side $\mathrm{C}$ was nominal. The exposure of side $\mathrm{B}$ was less uniform as reflected in both the photograph in Figure 5, and the $\alpha$ values in Table 1. 
TABLE 1.-INTEGRATED SOLAR ABSORPTANCE OF ORU SAMPLES

\begin{tabular}{|l|c|c|c|c|}
\hline & $\alpha_{\text {back }}$ & $\alpha_{\text {front }}$ & $\alpha_{\text {front/back }}$ & $\alpha_{\text {front/under back }}$ \\
\hline D1 & 0.247 & 0.246 & 1.00 & 1.33 \\
\hline B1 & 0.240 & 0.242 & 1.01 & 1.30 \\
\hline E1 & 0.246 & 0.253 & 1.03 & 1.36 \\
\hline B2 & 0.255 & 0.277 & 1.09 & 1.49 \\
\hline A1 & 0.251 & 0.275 & 1.10 & 1.48 \\
\hline A2 & 0.246 & 0.274 & 1.11 & 1.48 \\
\hline Black & 0.253 & 0.299 & 1.18 & 1.61 \\
\hline Grey & 0.963 & 0.939 & 0.98 & ---- \\
\hline Under B & 0.963 & 0.711 & 0.74 & ---- \\
\hline Under G & 0.185 & 0.199 & 1.07 & ---- \\
\hline
\end{tabular}

The $\alpha$ of two samples taken from the black trim strap on Side B was also measured. Portion of this strap appear light grey, and portions black (Fig. 5). It was noted that the lighter grey regions were adjacent to the darkened areas of B. Measurements were made of the black and the grey parts of the strap, and of the surfaces underneath those two areas. Since the original sample (as represented by the back side) had a very high $\alpha$, degradation tended to lighten these samples, rather than darken them. The reason for this is shown clearly in the optical micrographs (Fig. 10(b)) which shows erosion of the black matrix material exposes the lighter glass fibers.

Samples taken of the fabric underneath the black and grey samples had somewhat lower $\alpha$ values than the backside of the other samples. It was expected that they would have $\alpha$ similar to the back sides of the other samples. But since the $\alpha$ 's were lower it implies that they were better protected from the environment. If these $\alpha$ are taken as representative of the original $\alpha$ of the ORU $\beta$-cloth, then the degradation was much greater than that calculated using the ratio of the front to back of each sample, ranging from 30 to 60 percent. The $\alpha$ of backside of the cloth even decreased by 29 to 37 percent.

But the infrared spectra of the backside of the samples were identical, bolstering the assumption that these surfaces were not substantially altered by the space environment, or at least that they were altered only by a uniform process that is not dependent on characteristics of the space environment that are known to vary locally, such as solar radiation or atomic oxygen exposure. The only new spectral features that occurred on the front side (space exposed) spectra were a grouping of weak peaks centered near 8.1, 8.25 , and $8.7 \mu \mathrm{m}\left(1235,1210\right.$, and $\left.1150 \mathrm{~cm}^{-1}\right)$ shown in Figure 14. Although this is in the region of C-F bond motions, no specific structural features could be assigned to these peaks. It should be noted that the silicone is a common space contaminant that can darken upon UV exposure, but the $\mathrm{Si}_{-} \mathrm{CH}_{3}$ stretch occurs at $7.94 \mu \mathrm{m}\left(1260 \mathrm{~cm}^{-1}\right)$, somewhat higher energy. And since the LDEF results also showed darkening, this was not considered to be strong evidence of contamination. The full set of IR spectra are found in Appendix E.

The $\varepsilon$ of the backside of the samples decreased nearly monotonically from $0.922 \pm 0.001$ at $300 \mathrm{~K}$ to $0.655 \pm 0.006$ at $700 \mathrm{~K}$ (Fig. 15). Space exposure did not appreciably change the $\varepsilon$ of any of the samples over this temperature range, with deviations from the backside being less than 1 percent, within the error of the measurement. The $\varepsilon$ of the LDEF sample was reported to be $0.89 \pm 0.02$, as measured by a GierDunkle reflectometer, presumably at ambient temperature and so about 3.5 percent lower (Ref. 2).

There was, however, a substantial change in the $\varepsilon$ of the black trim fabric. The back side of the trim showed a nearly monotonic increase of $\varepsilon$ from 0.901 at $300 \mathrm{~K}$ to 0.932 at $700 \mathrm{~K}$. The part of the trim that still appears black had a $\varepsilon$ that was nearly constant at 0.932 over the 300 to $700 \mathrm{~K}$ temperature range. But the $\varepsilon$ of that part that appeared grey dropped nearly monotonically from 0.937 at $300 \mathrm{~K}$ to 0.817 at $700 \mathrm{~K}$. 
Thus, the lightening in color due to removal of the black pigment that was evident in the visible spectrum, also had consequences in the thermal infrared. (It should be noted, however, that only a very small fraction of the surface area of the ORU was covered by this black trim, so the thermal performance of the $\beta$-cloth would be dominated by the white PTFE outer layer.)

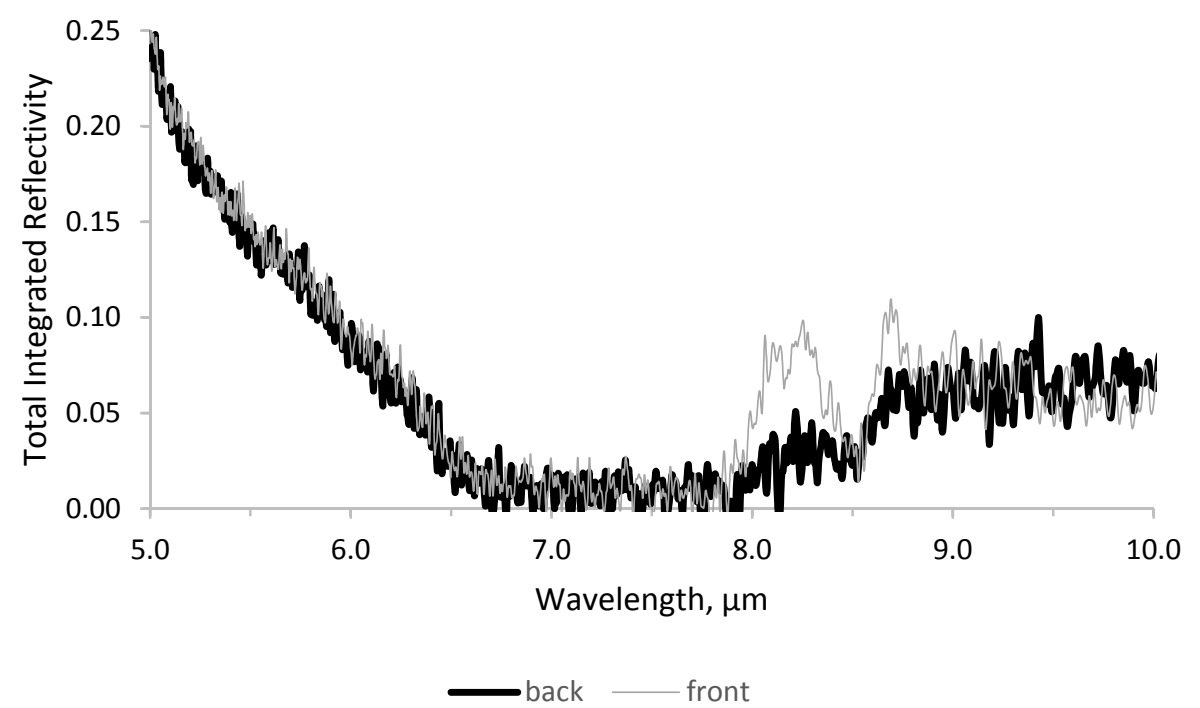

Figure 14.-A blow up of the 5 to $10 \mu \mathrm{m}$ portion of the infrared spectrum of B2 showing the three small peaks that occurred in all of the space exposed ORU samples. No other spectral features were observed.

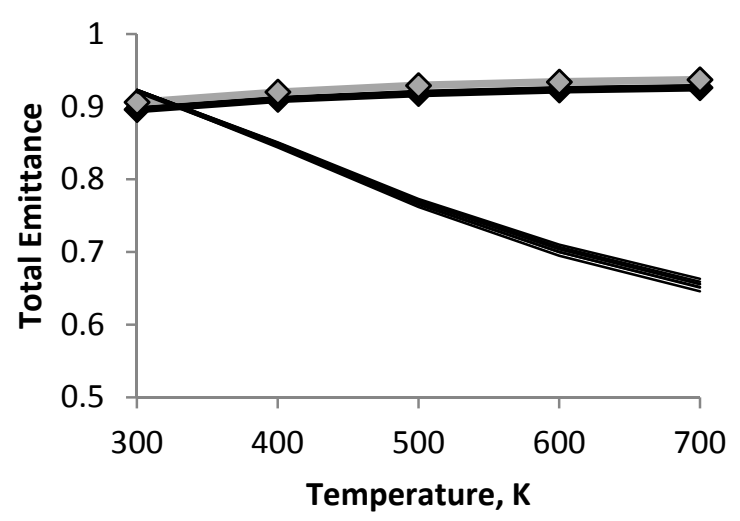

(a)

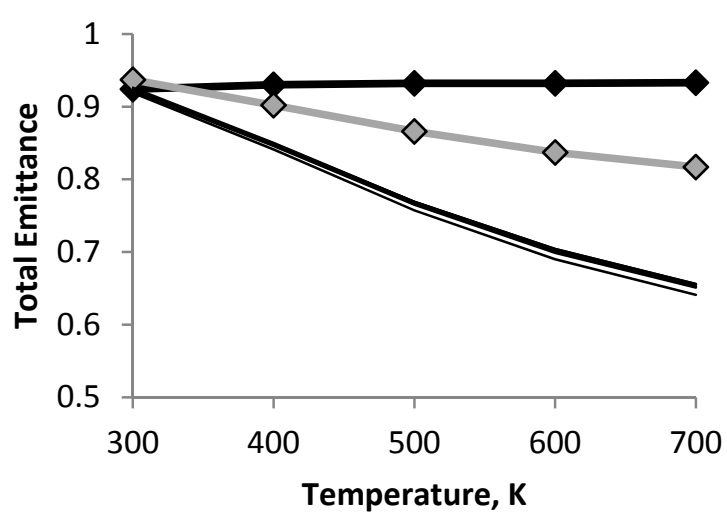

(b)

Figure 15.-The $\varepsilon$ of (a) the backside, and (b) the space exposed side of ORU samples as a function of temperature. Thin black lines show ORU $\beta$-cloth $\varepsilon$ (which are so similar as to lay over top of each other), the thick black line shows the $\varepsilon$ of the black material, and the thick grey line that of the "grey" material. 


\subsection{Conclusion}

Optical microscopy of the MISSE-7 Space Suit Fabric Exposure Experiment samples showed that all six fabrics darkened during exposure in LEO. ORU results confirmed that PTFE darkens during exposure in LEO. FESEM analysis indicated that atomic oxygen texturing was not as deeply developed as was seen on the MISSE-7 spacesuit fabric experiment. However, there were regions where the PTFE layer was completely eroded, revealing the glass fibers underneath. It was found that exposed fiberglass darkened upon space exposure, but not upon exposure to UV radiation in a hyperthermal asher. It was concluded that the glass darkening was likely due to the effects of ionizing radiation. Thus, both components of $\beta$-cloth, the PTFE and exposed glass fibers, darken in the space environment. Because there were no regions where the $\beta$-cloth was protected adjacent to regions that were eroded, it is difficult to quantitatively judge the actual depth of erosion.

Spectroscopic analysis indicated that the darkening of the PTFE was probably caused by radiation damage caused by bond unsaturation, rather than contamination. This is consistent with the degradation of mechanical properties observed on the outer FEP layer of the Hubble Space Telescope multilayer insulation after long-term exposure. The ratio of the $\alpha$ calculated for the front side relative to the back of the fabrics varied from about 1.0 (no change) to about 1.2, depending on the fraction of time the surface was shadowed. However, if the back side of the fabric that was under the black trim piece is taken as the initial $\alpha$ of the $\beta$-cloth then the $\alpha$ of the most heavily darkened areas increased by as much as 60 percent. The $\varepsilon$ of the samples was essentially unchanged, except for the heavily eroded regions of the black trim pieces.

Overall, the largest effect of 8.6 years of space exposure is the darkening (increase of $\alpha$ ) of the $\beta$-cloth, with no appreciable change in the emittance. The mean $\alpha$ was 21 percent higher than that measured on LDEF, and these samples were exposed 21 percent longer, implying a linear relationship with time, at least in the later stages of degradation. This should be factored into the thermal performance of spacesuit requirements. Although there was also erosion of the outer PTFE layer completely through to the glass fibers, and mechanical properties were not explicitly measured, no gross mechanical weakening or failures were noted. 


\section{Appendix A-Optical Photomicrographs}

Nomenclature for the photographs shown in this appendix uses the following convention. Samples taken from the five sides as defined in the text and Figures 4 and 5 are labeled A, B, C, D, and E. The number following the letter describes the sample number for that side. Within a sample, the center of the photograph corresponds to the map shown to the right. Last, the magnification of the photograph is recorded. For example the photo B2-1-25 was taken at a magnification of $25 \times$ of the center of the second sample taken from side B. The first two photomicrographs of each sample were photographed using the same white balance settings to show the color differences between the front (space exposed) and back sides of the sample.

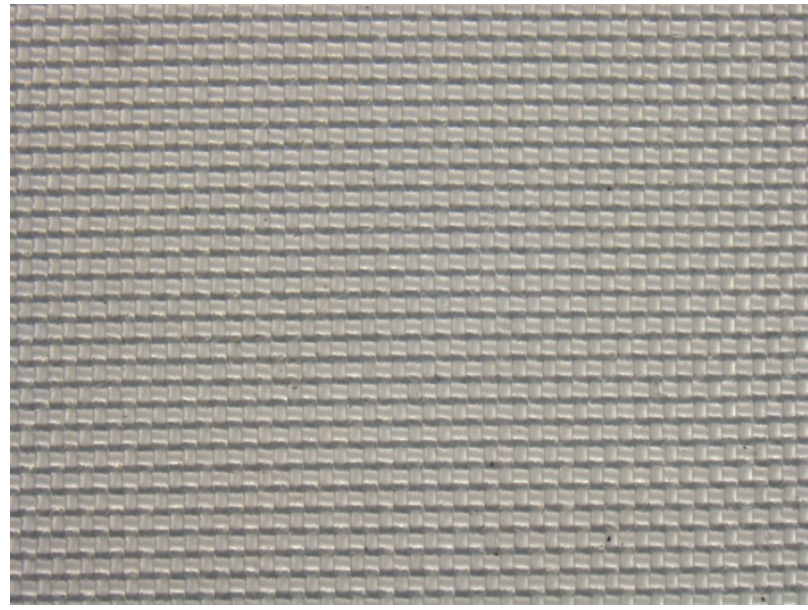

A1-1-7.1 back

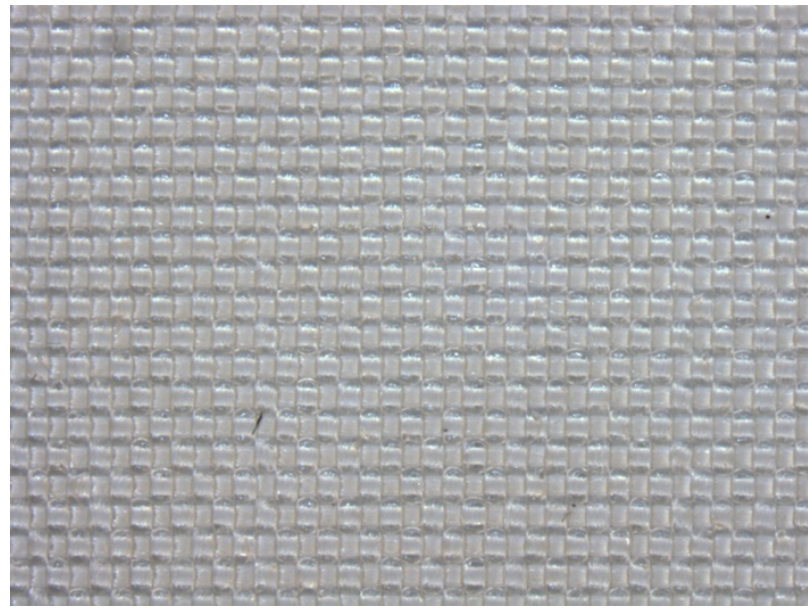

A1-1-10
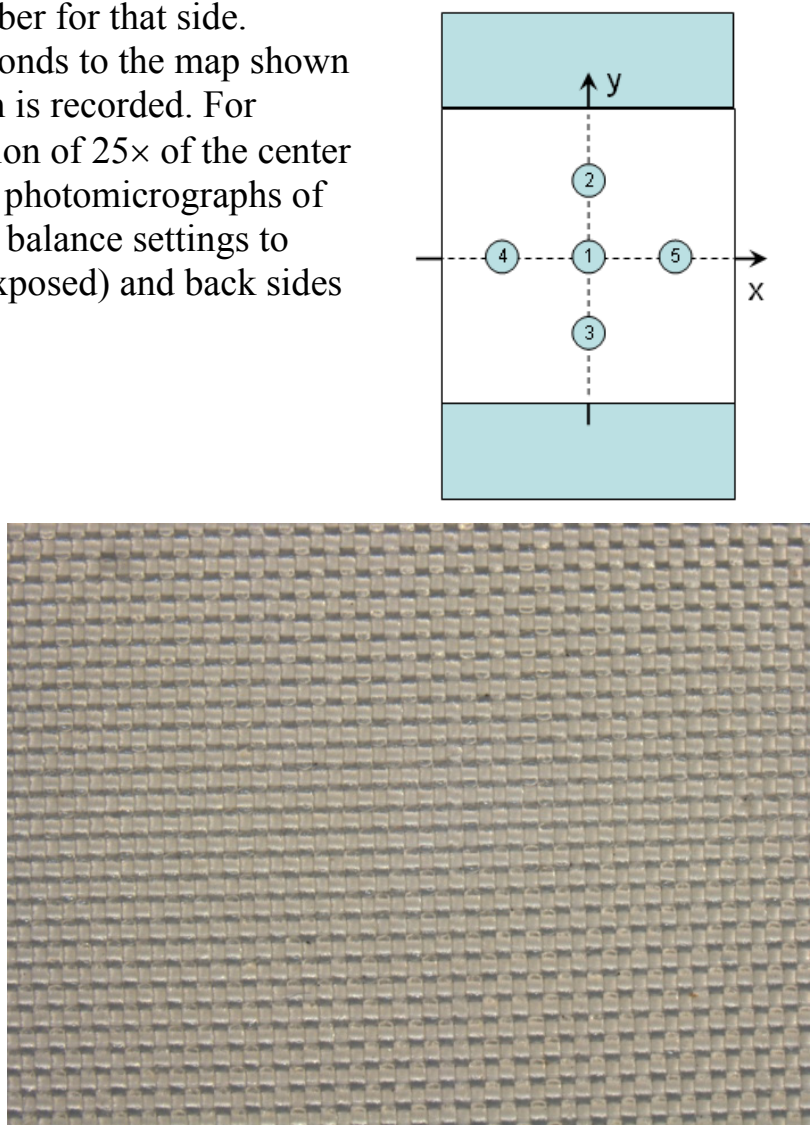

A1-1-7.1 front

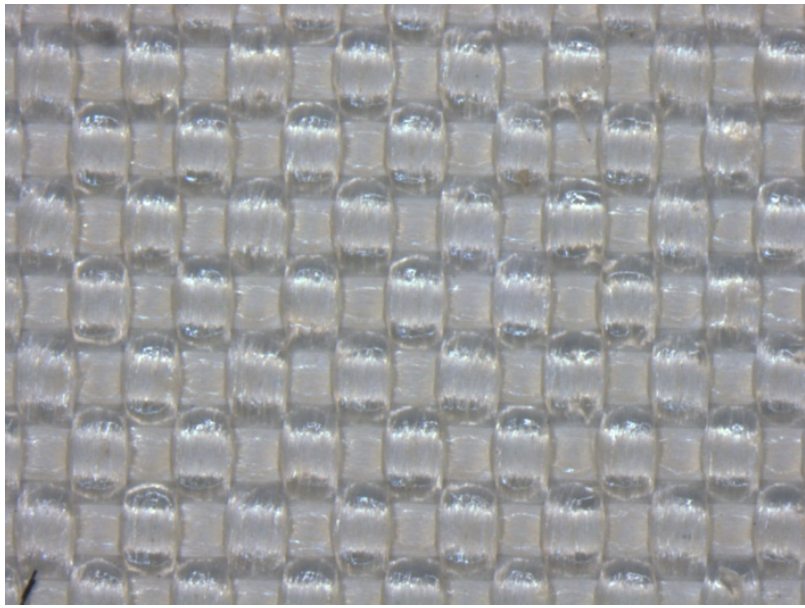

A1-1-25 


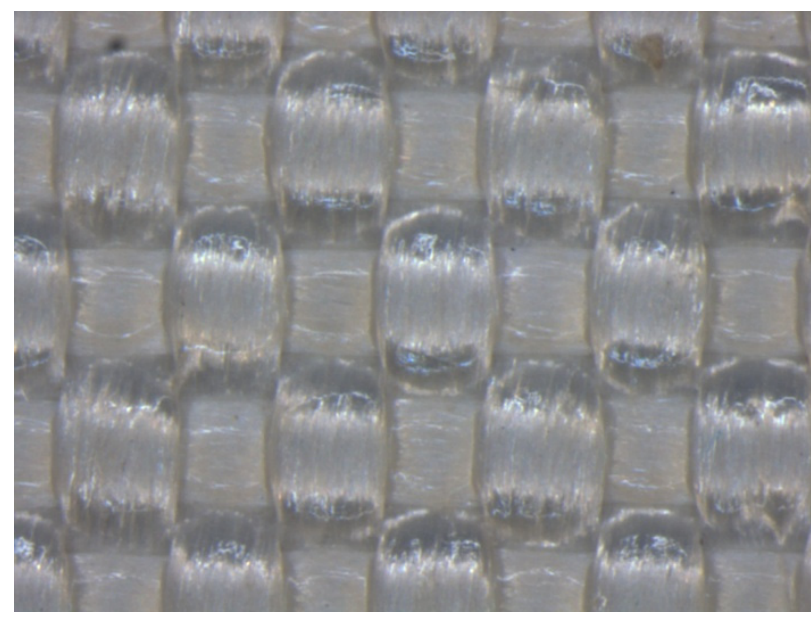

A1-1-50

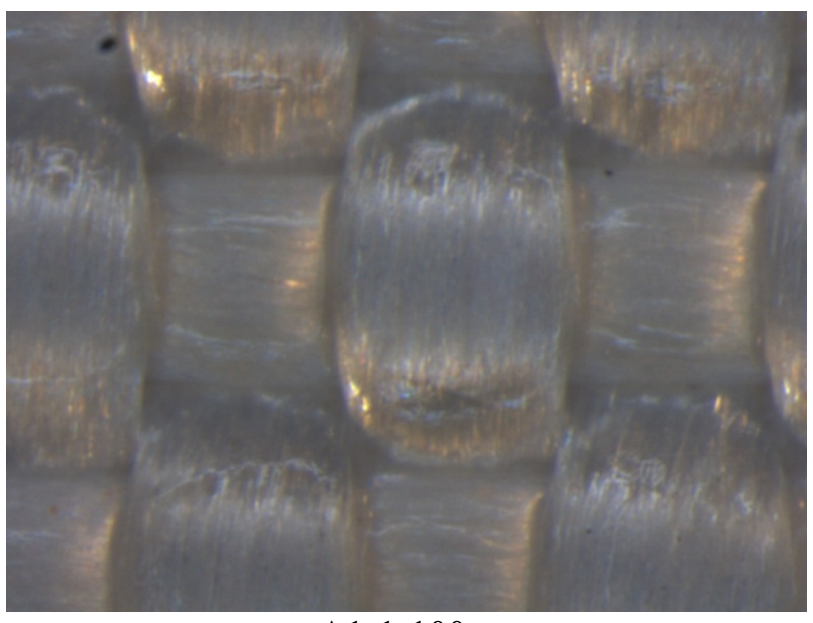

A1-1-100

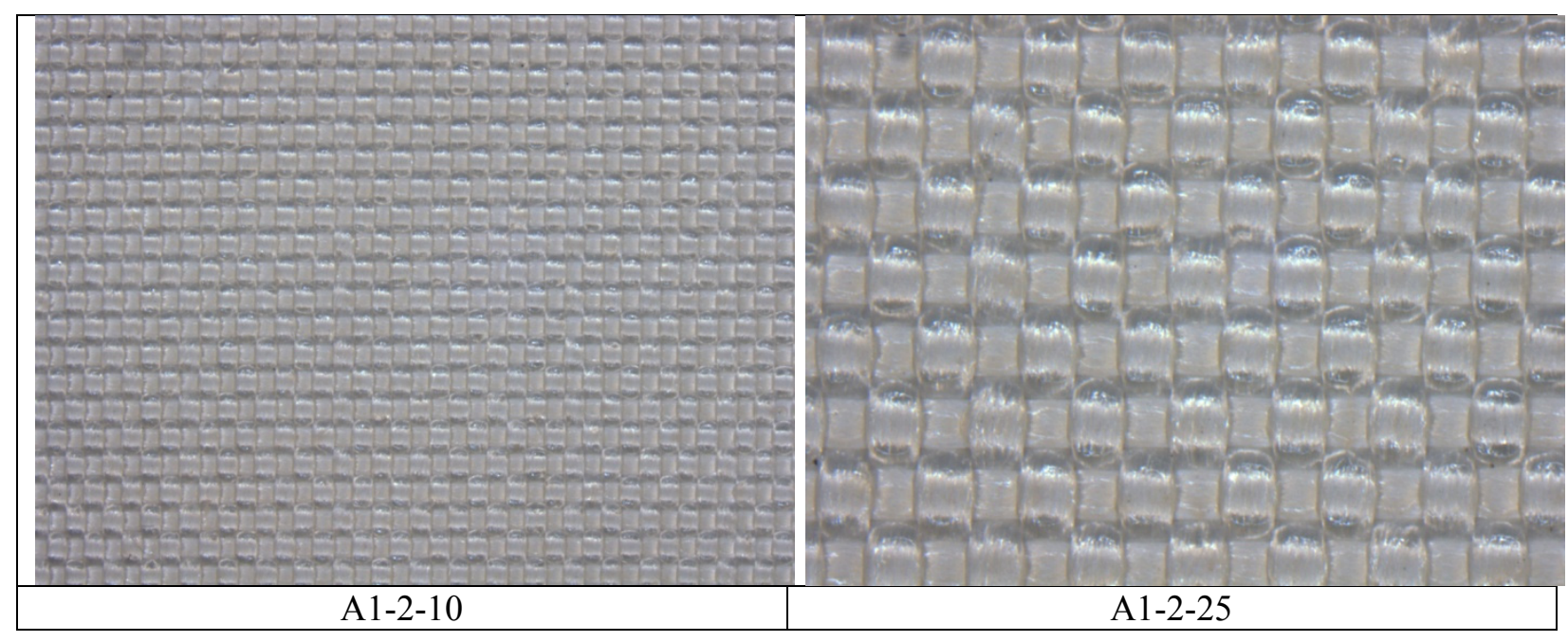

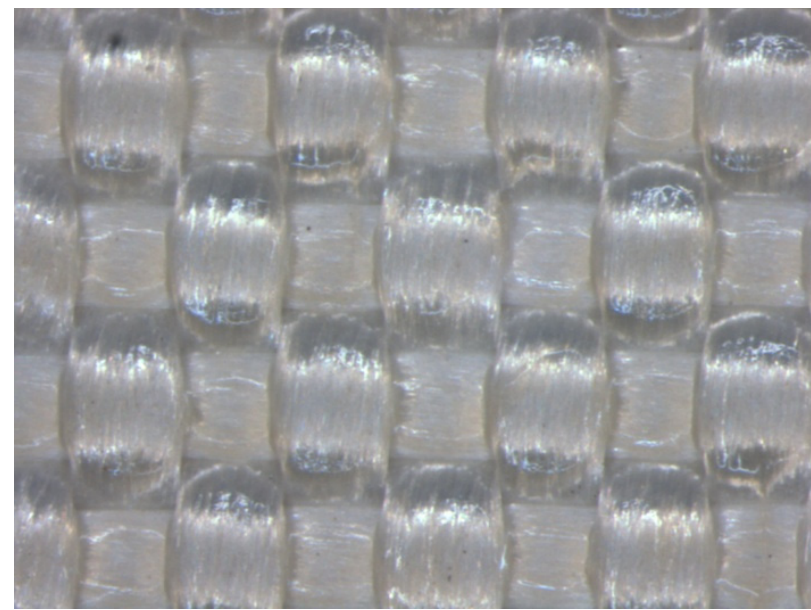

A $1-2-50$

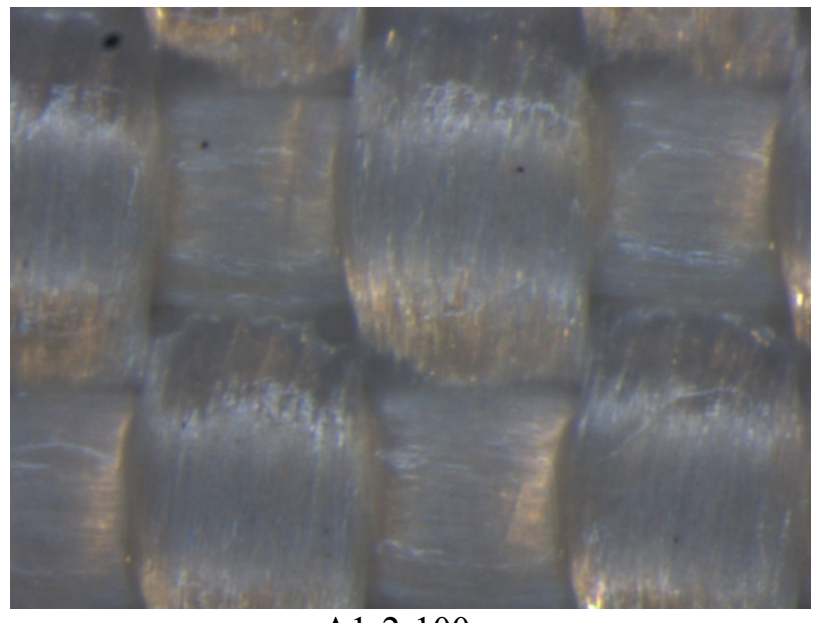

A1-2-100 


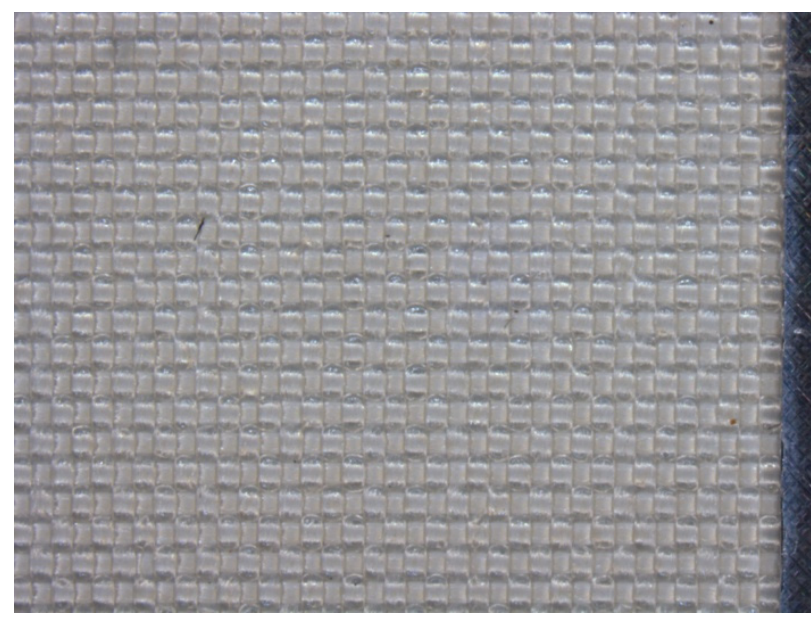

A1-3-10

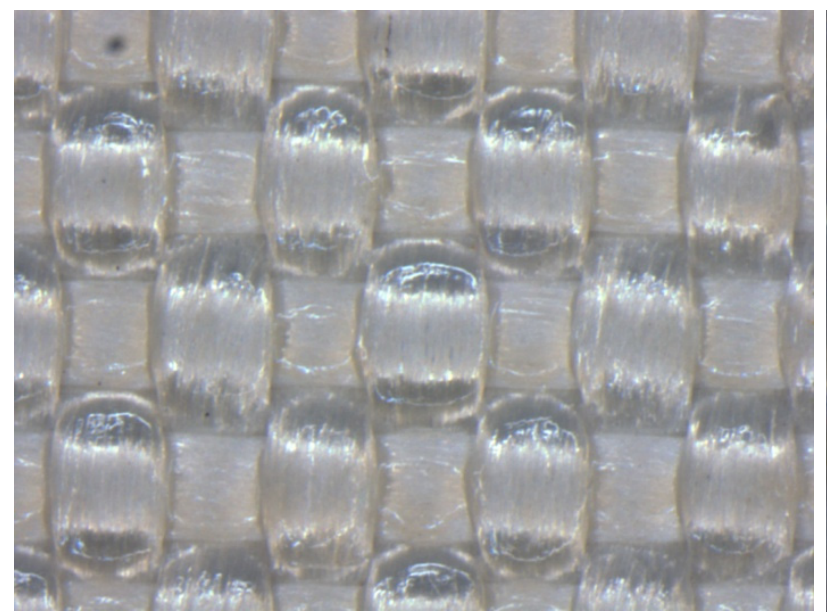

A $1-3-50$

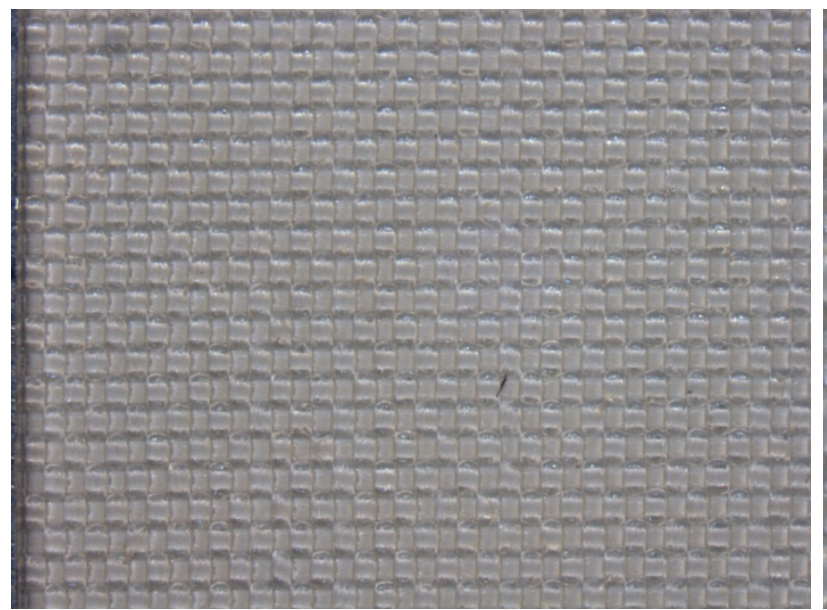

A1-4-10

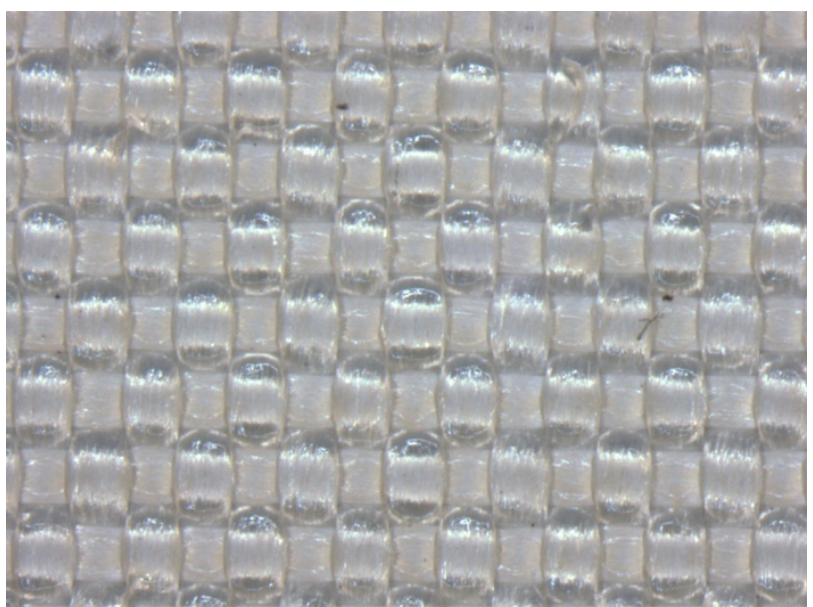

A1-3-25

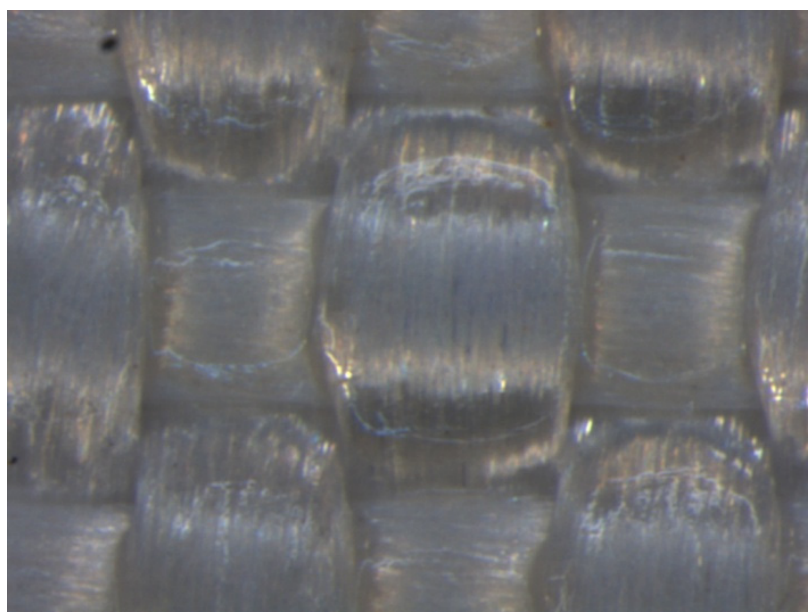

A1-3-100

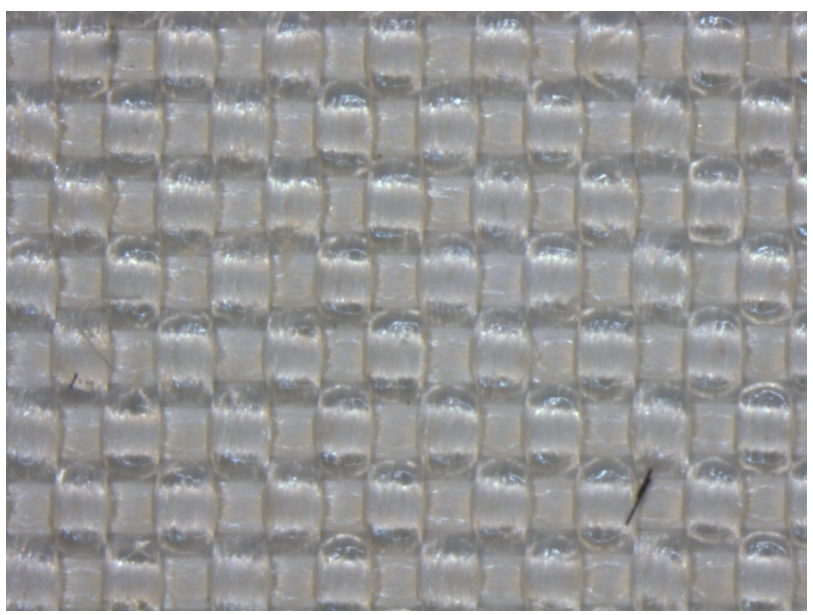

A1-4-25 


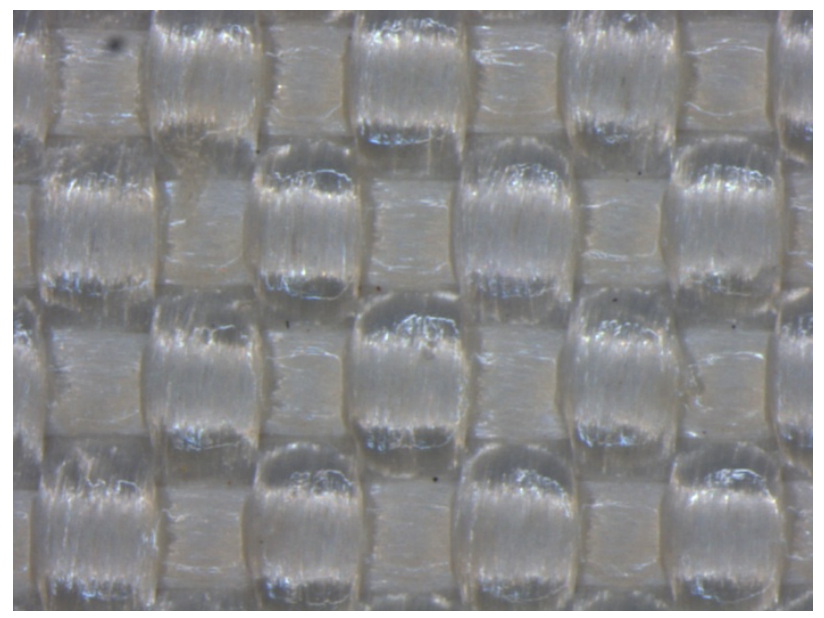

A1-4-50

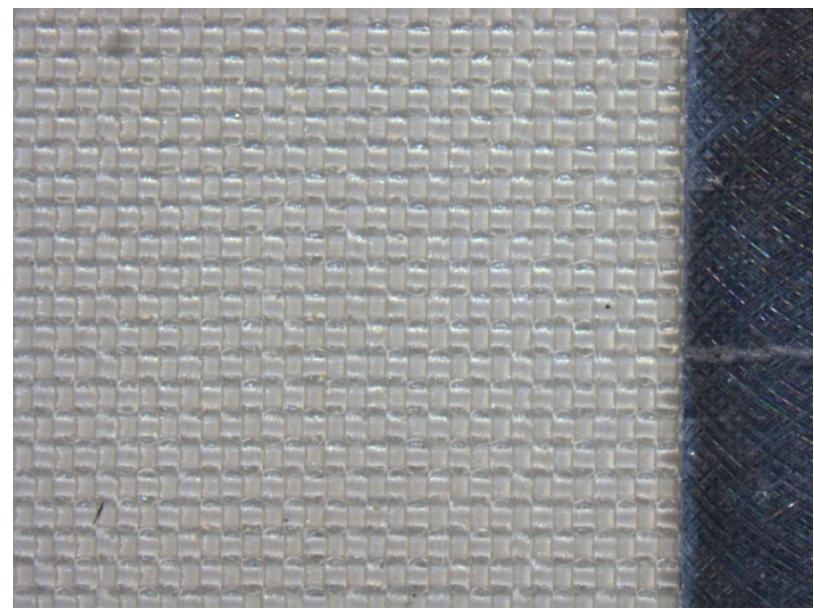

A1-5-10

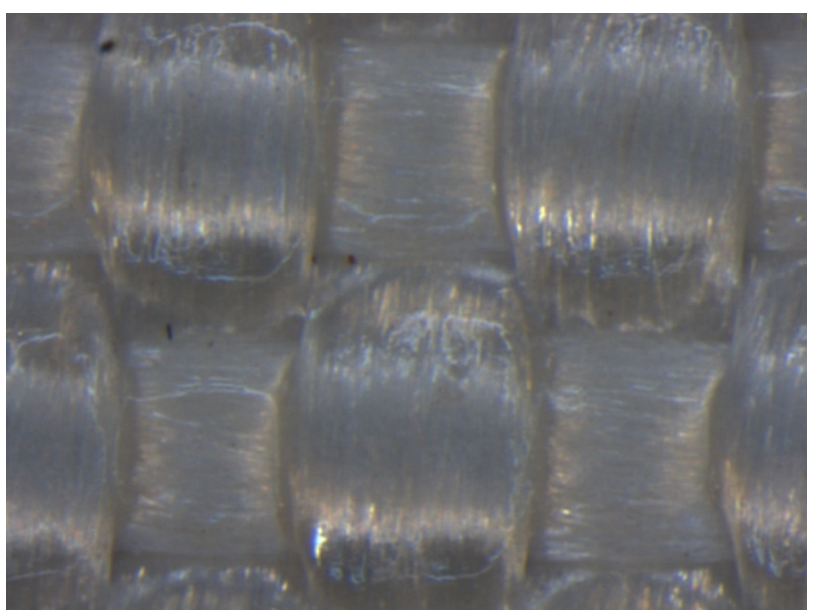

A1-4-100

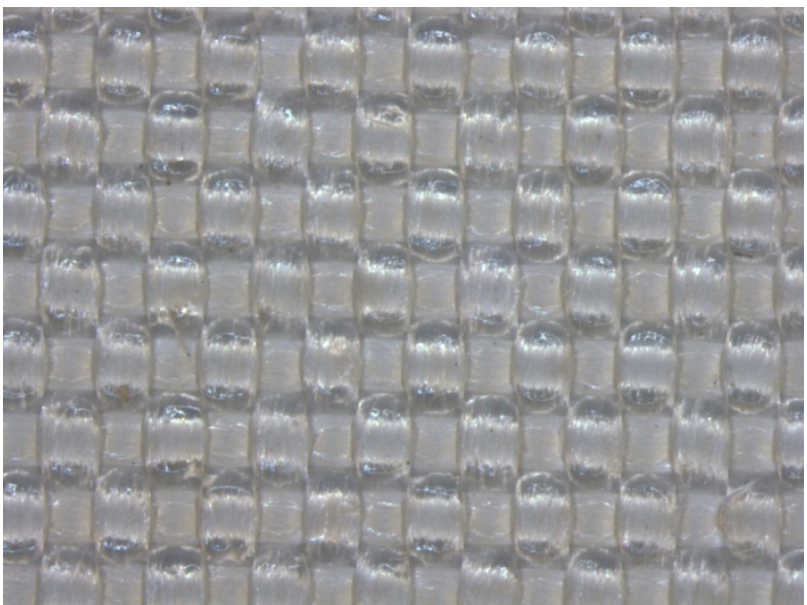

A1-5-25

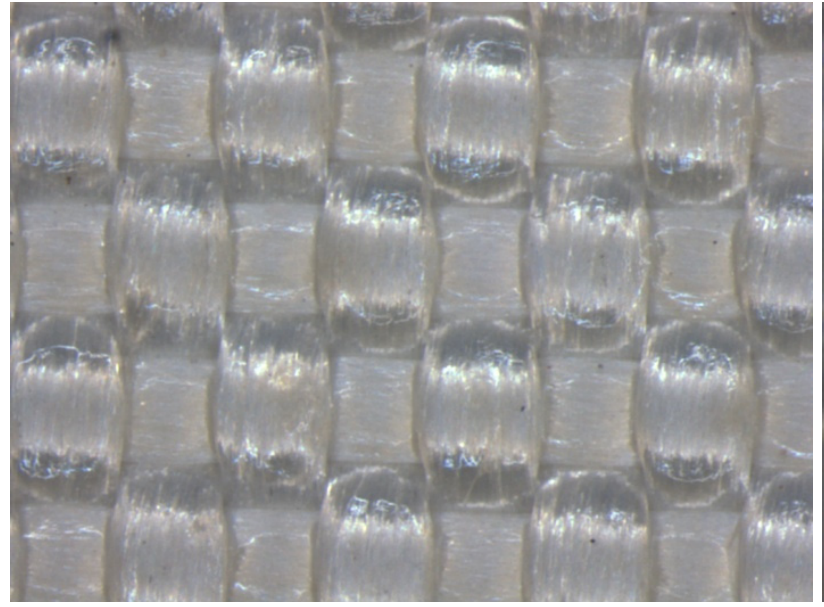

A1-5-50

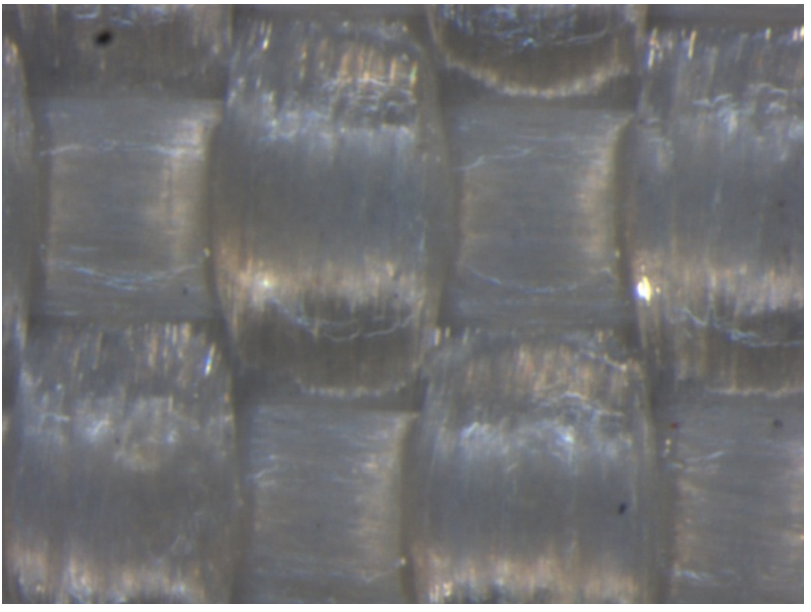

A1-5-100 


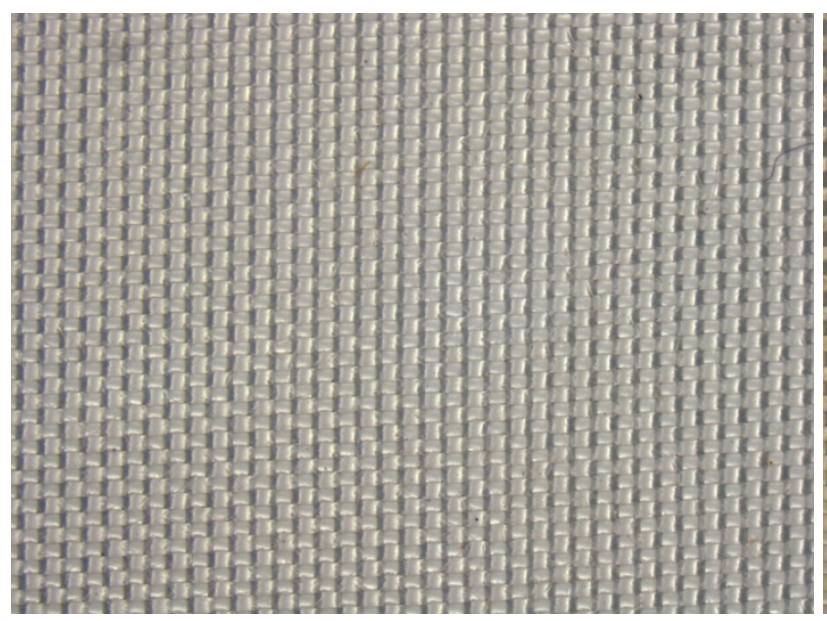

A2-1-7.1 back

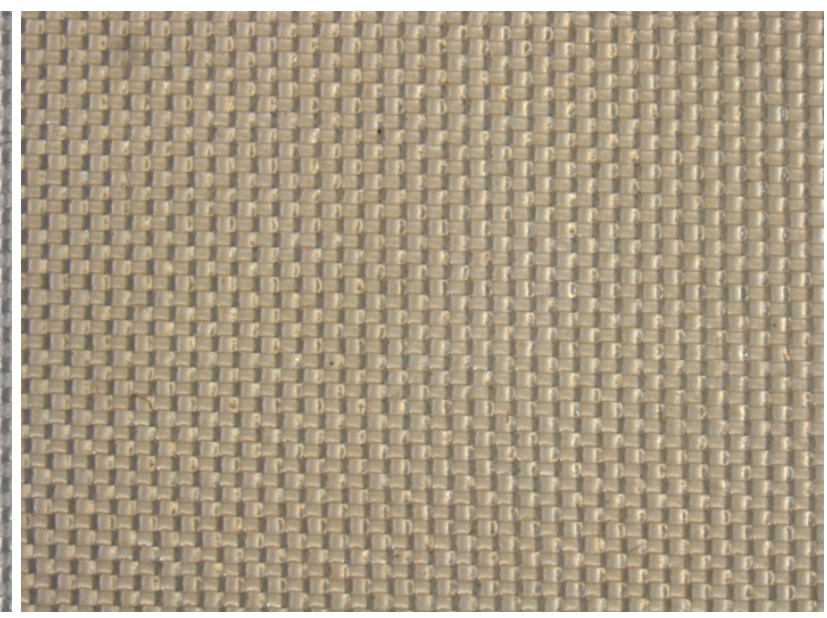

A2-1-7.1 front

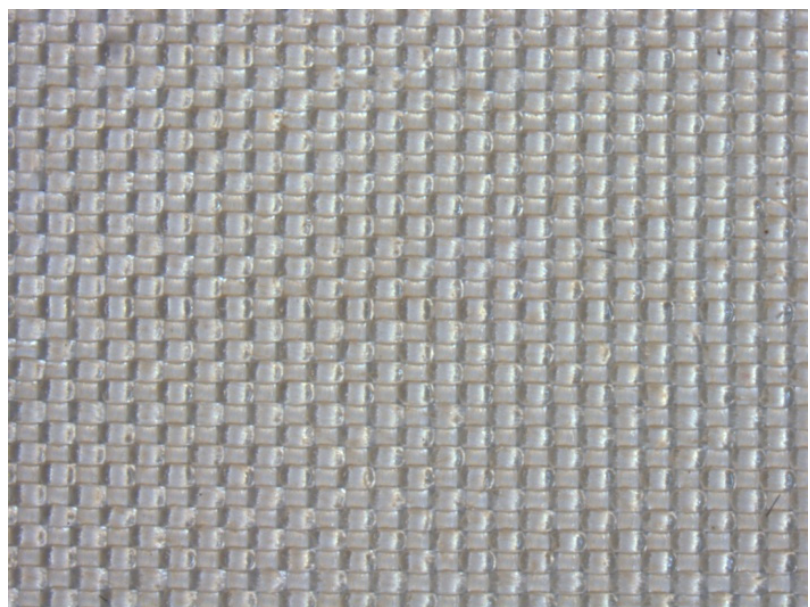

A2-1-10

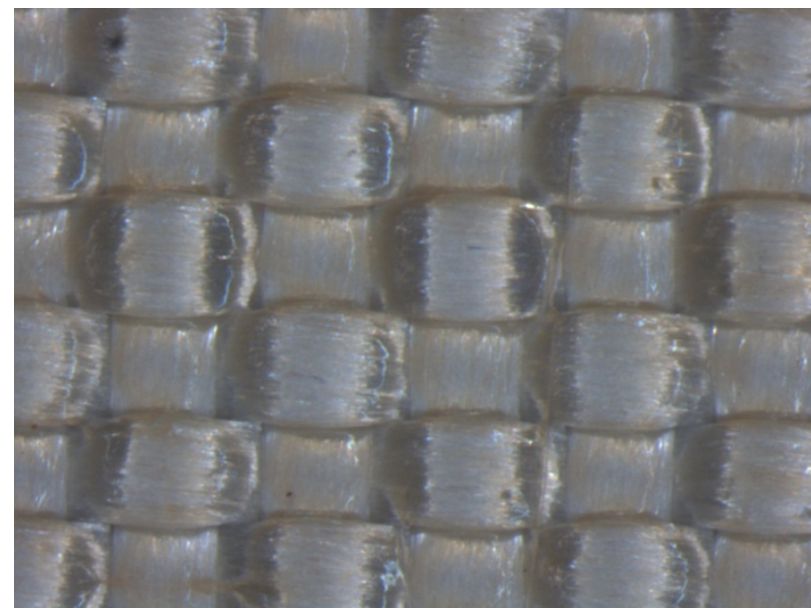

A2-1-50

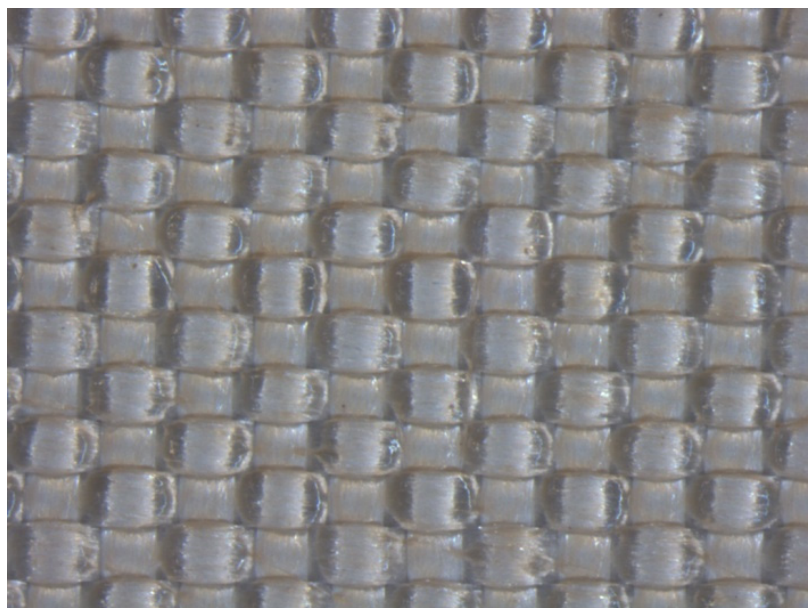

A2-1-25

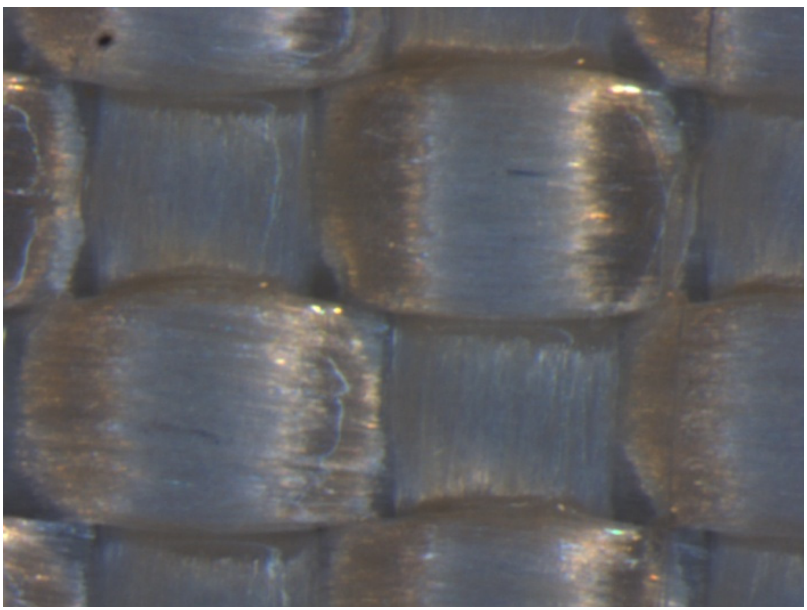

A2-1-100 


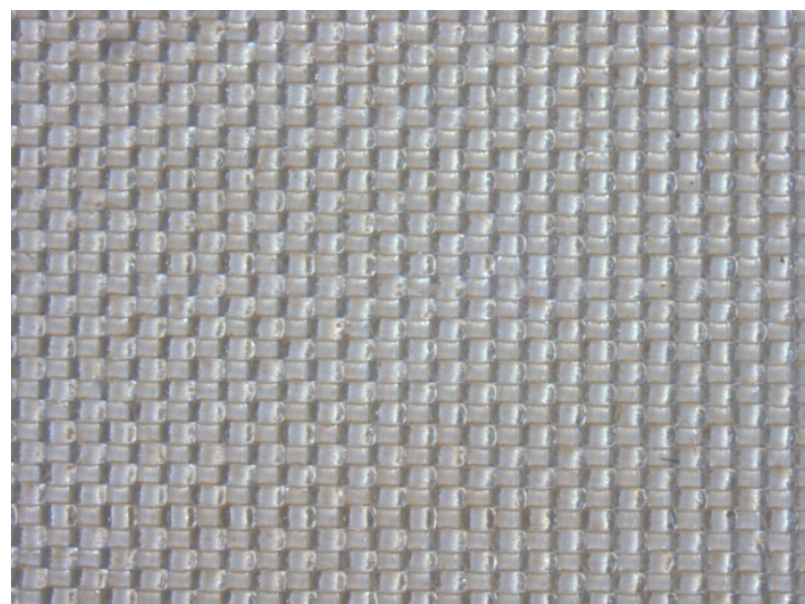

A2-2-10

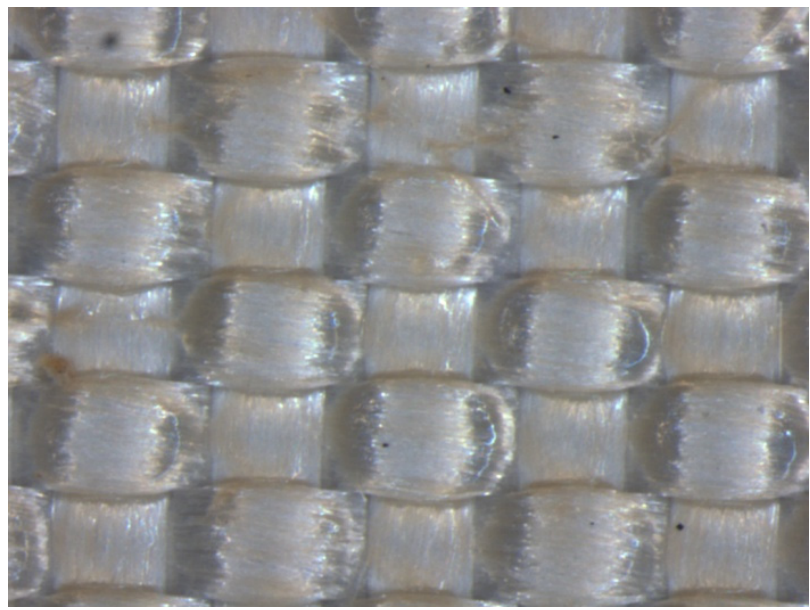

A2-2-50

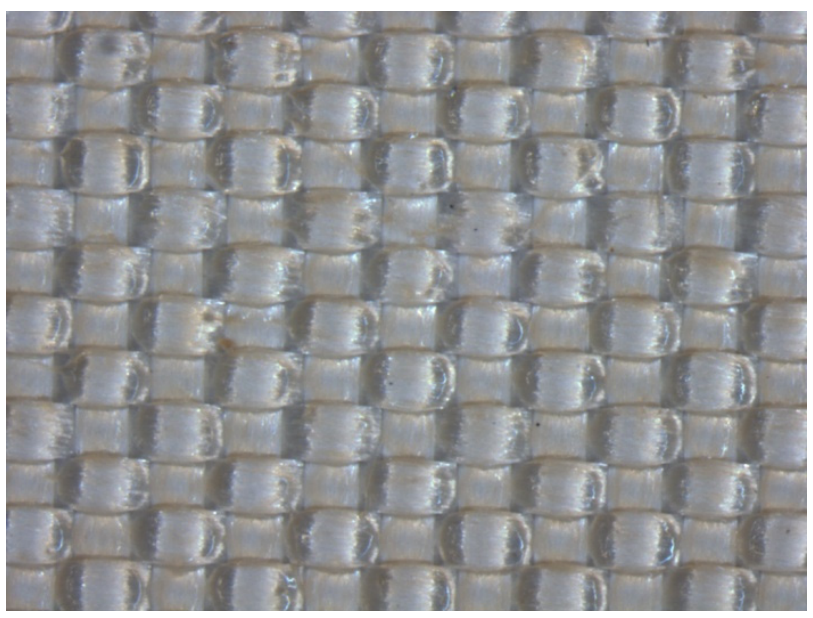

A2-2-25

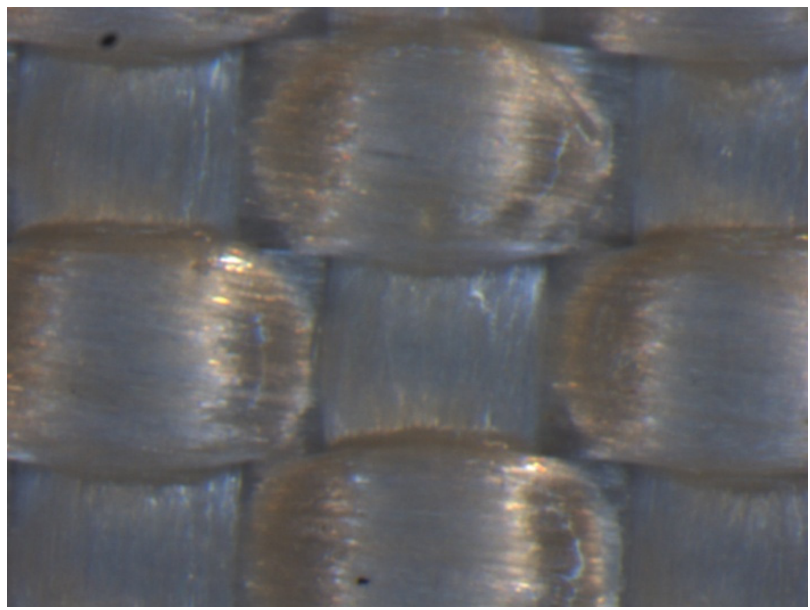

A2-2-100

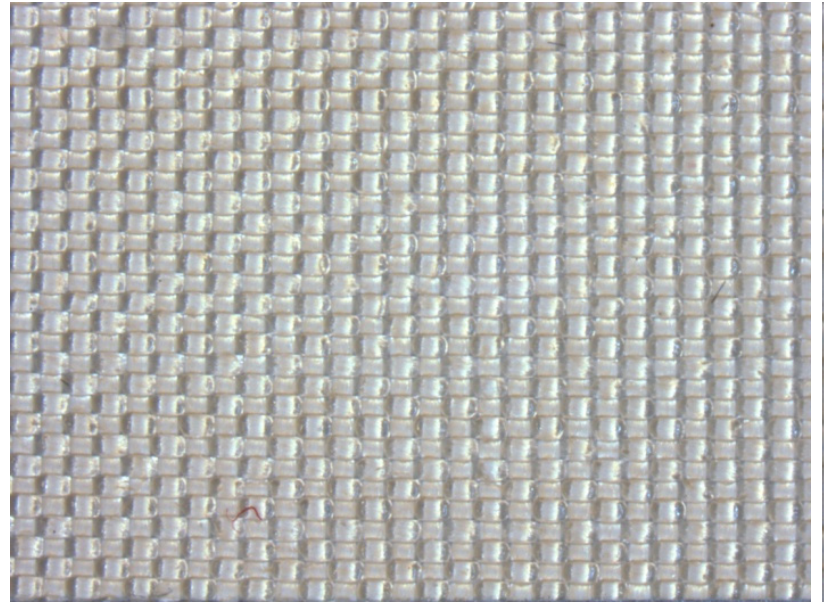

A2-3-10

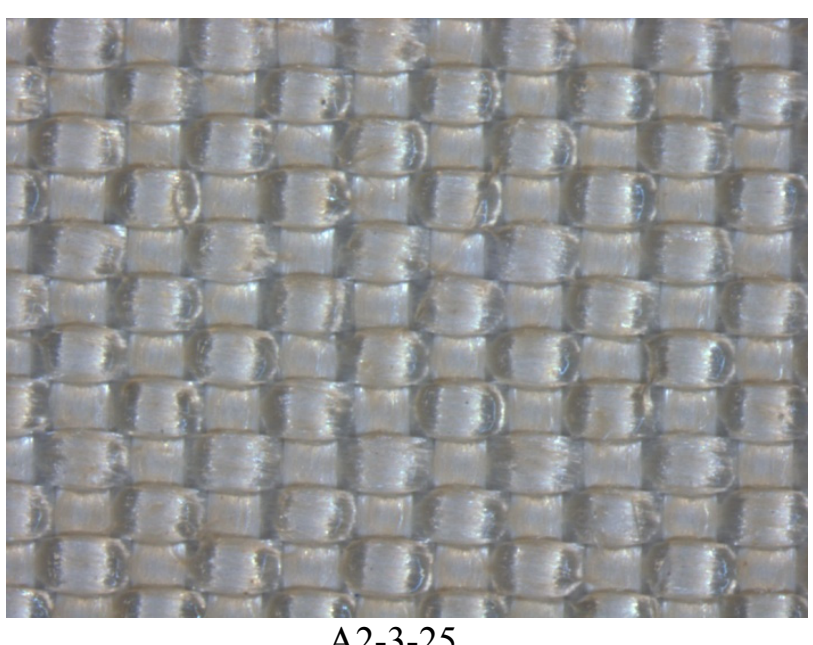

A2-3-25 


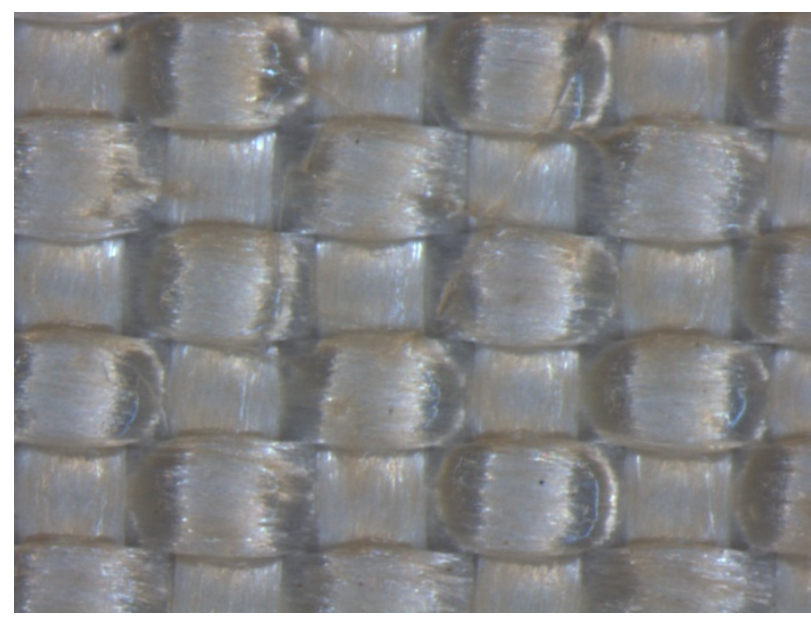

A2-3-50

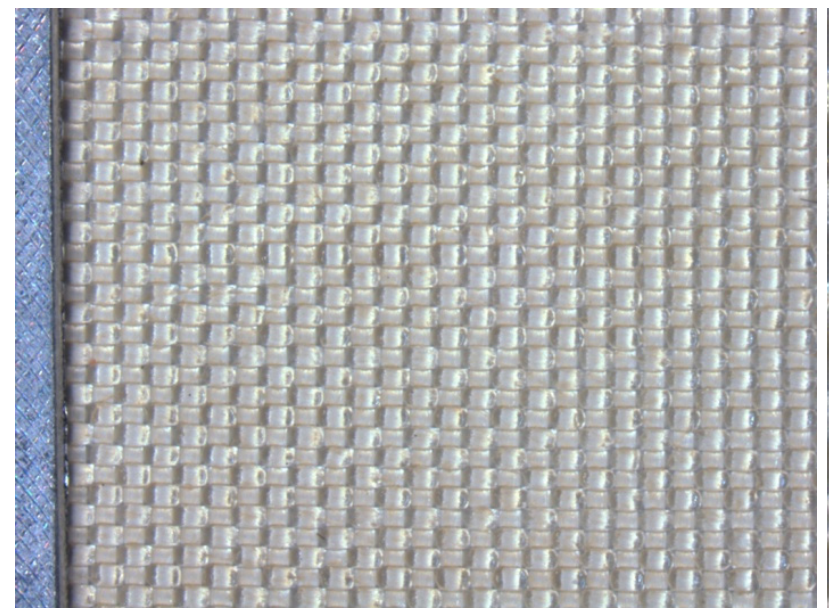

A2-4-10

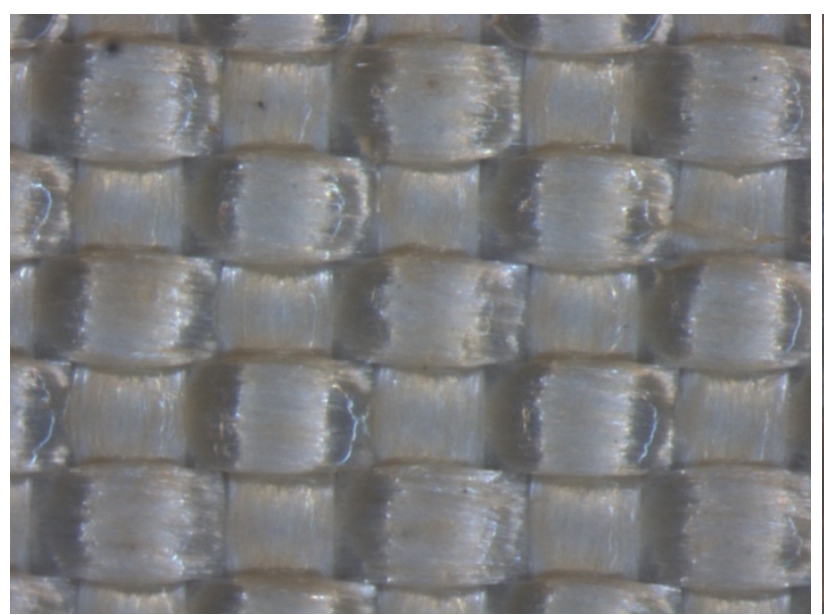

A2-4-50

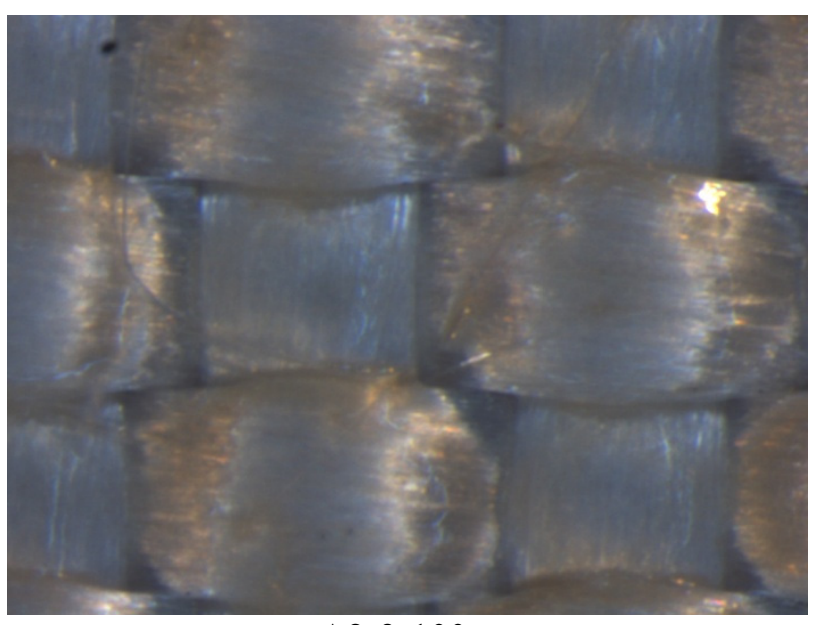

A2-3-100

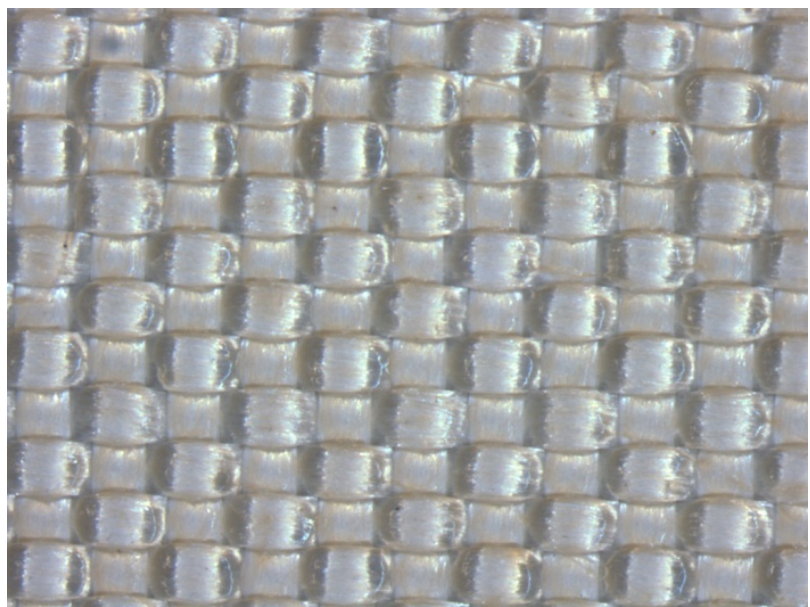

A2-4-25

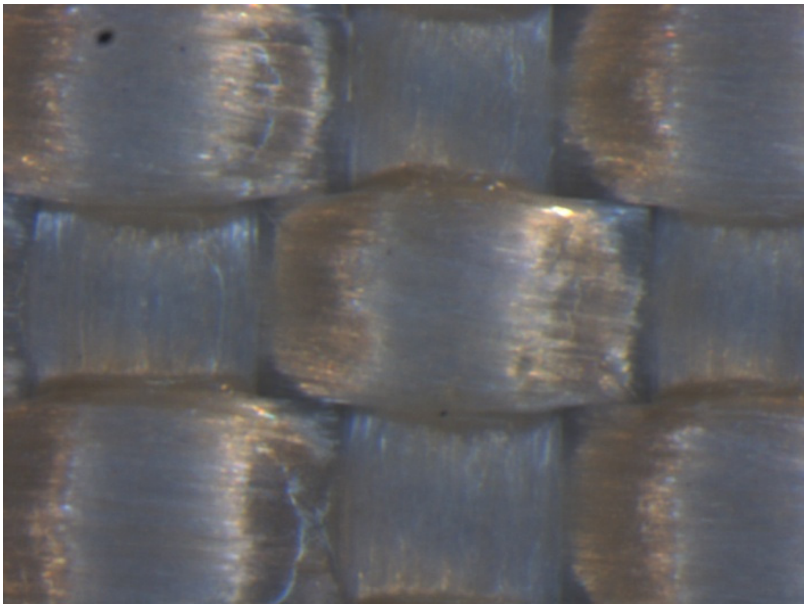

A2-4-100 


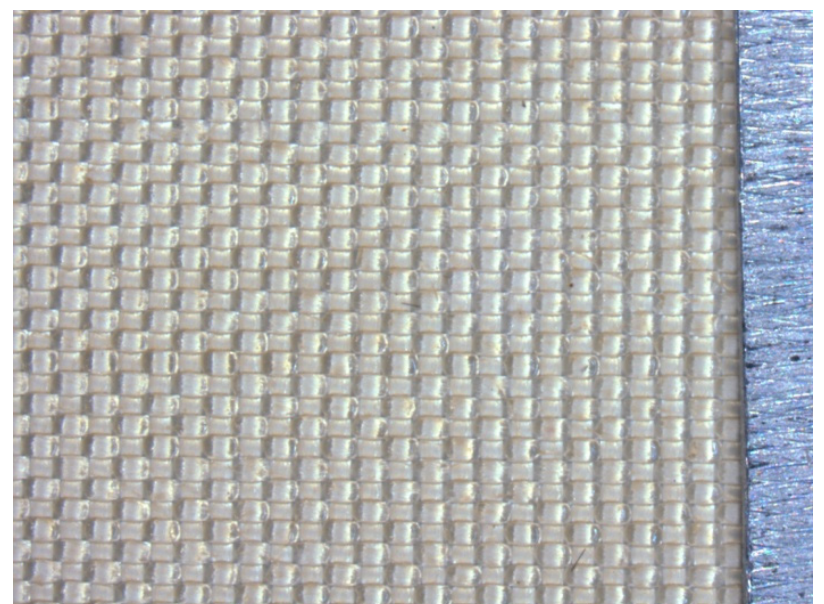

A2-5-10

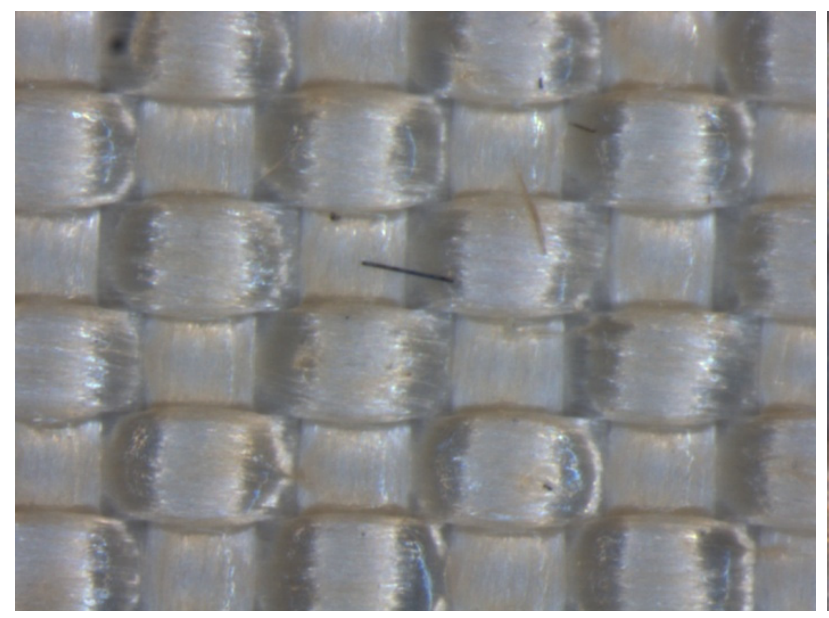

A2-5-50
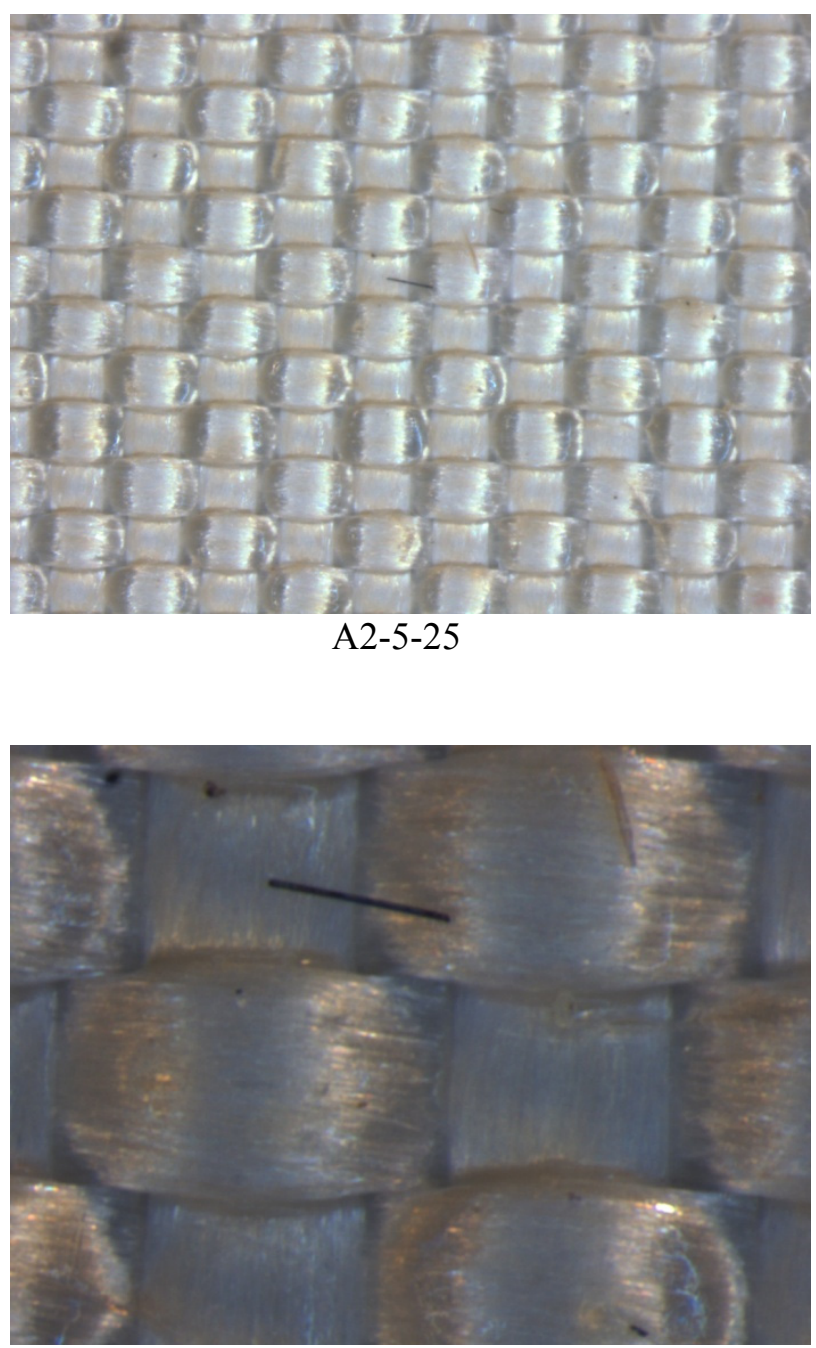

A2-5-100

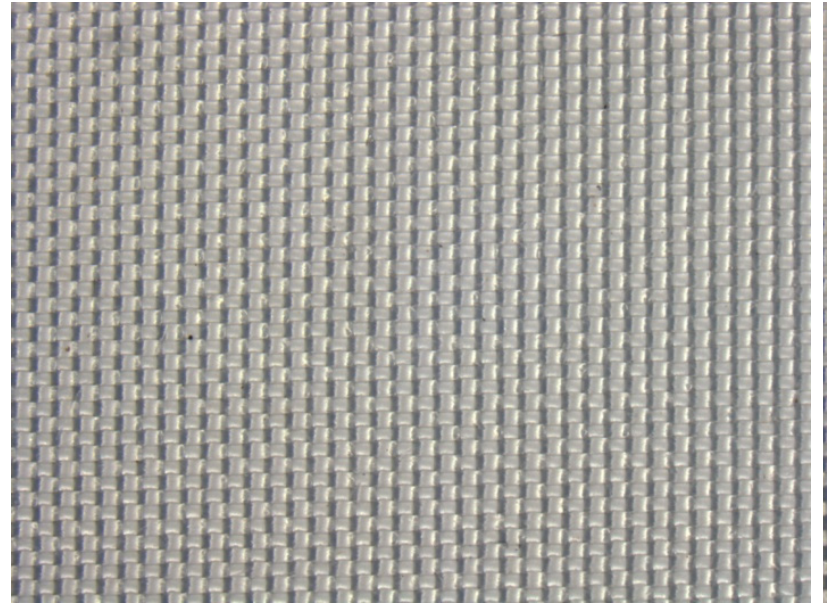

B1-1-7.1 back

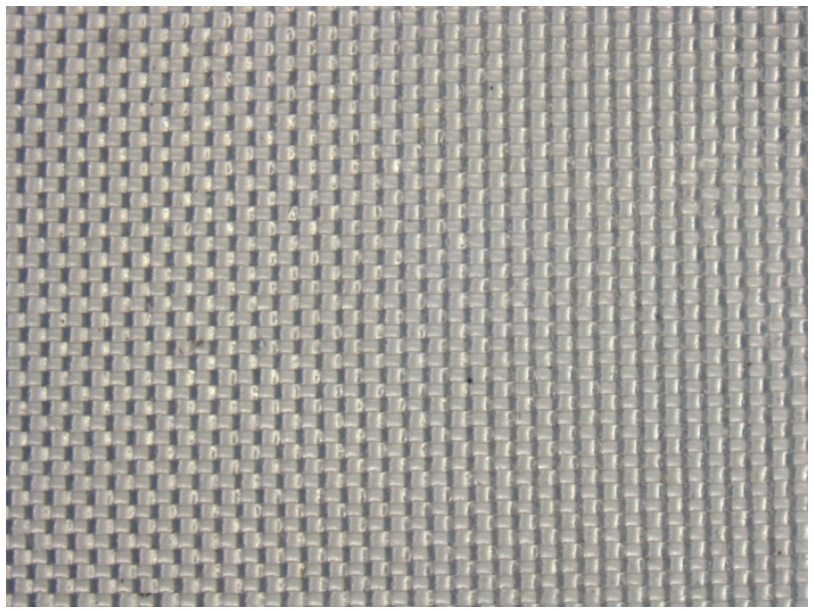

B1-1-7.1 front 


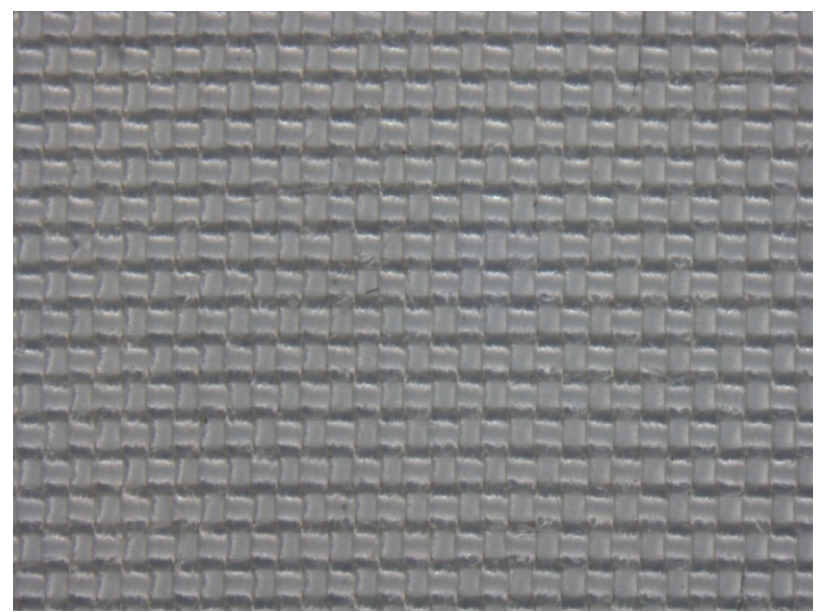

B1-1-10

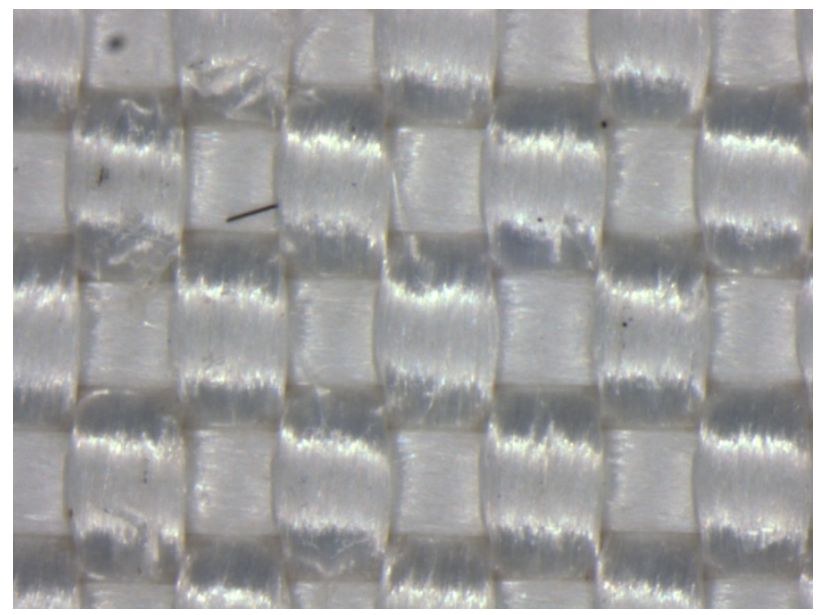

B1-1-50

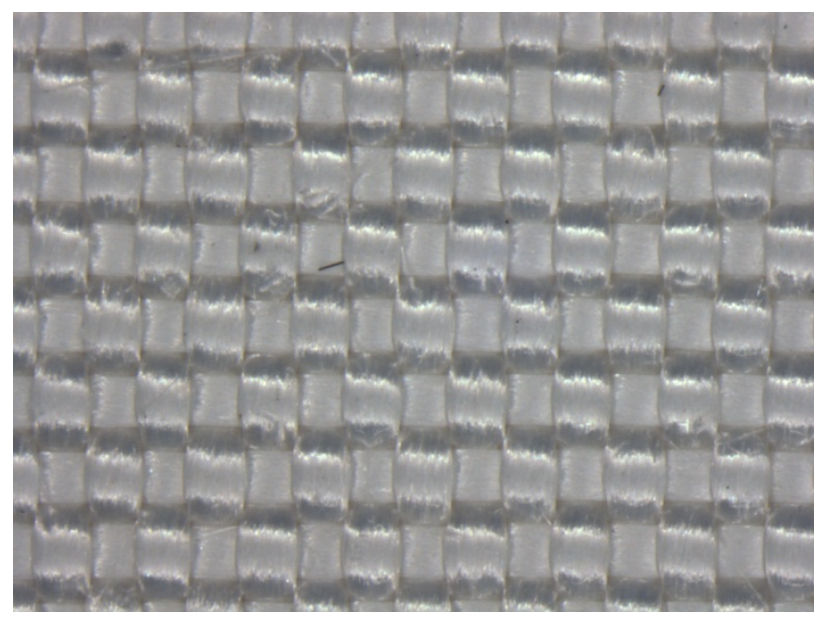

B1-1-25

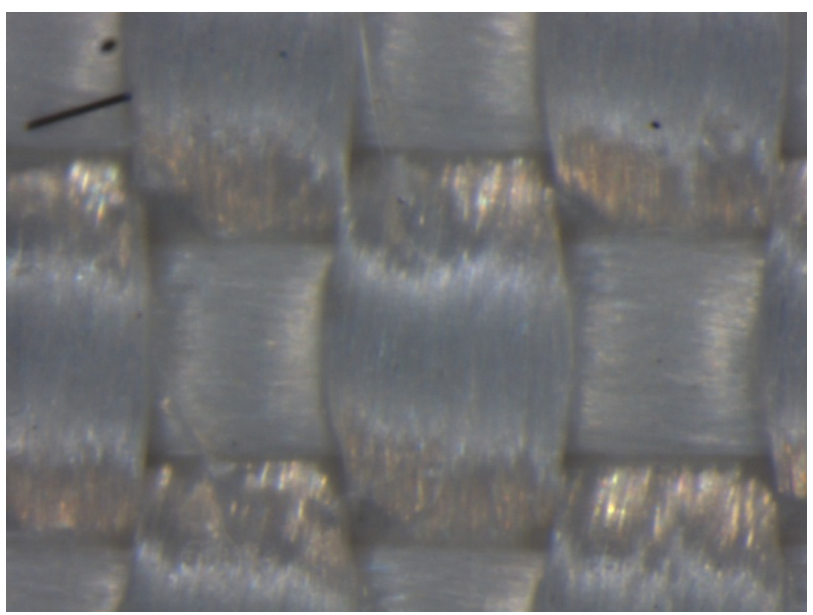

B1-1-100

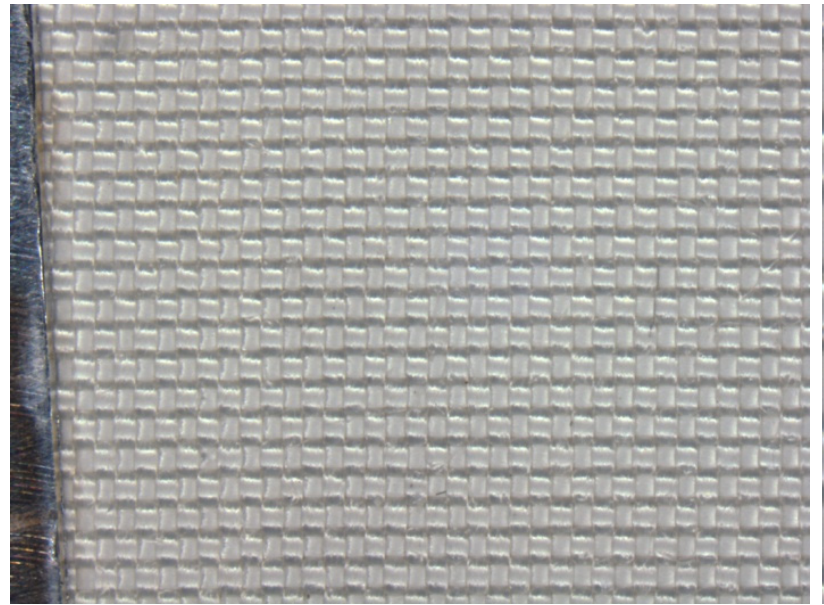

B1-2-10

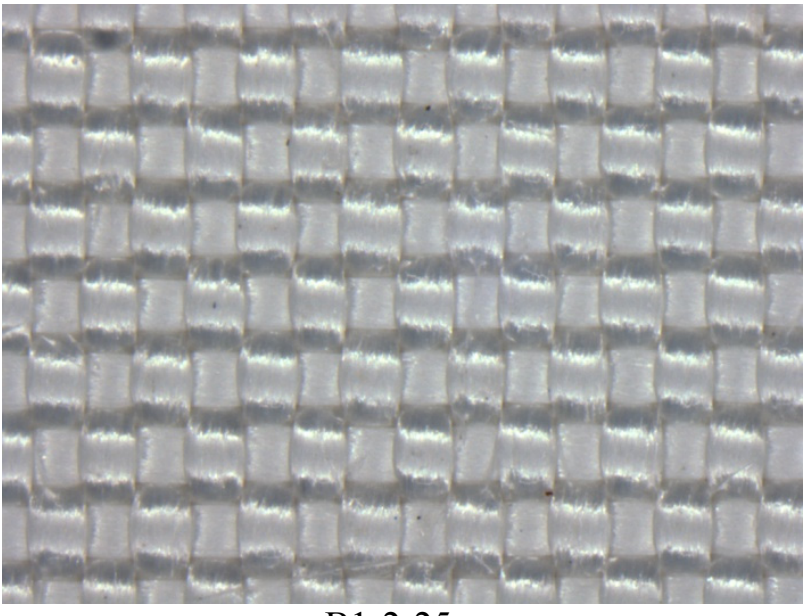

B1-2-25 


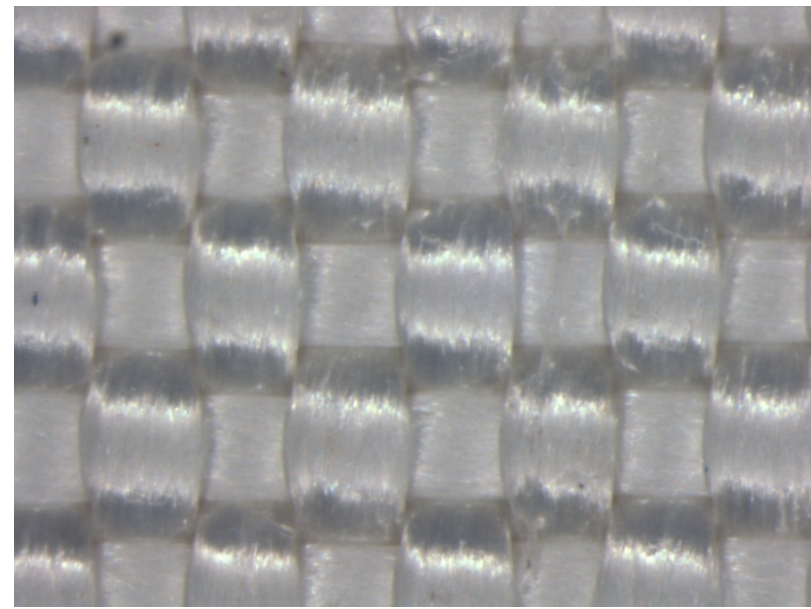

B1-2-50

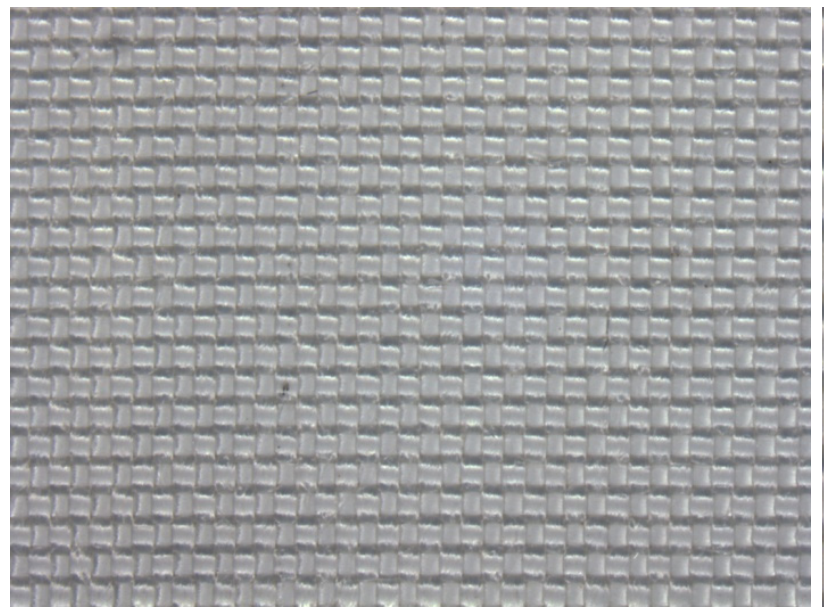

B1-3-10

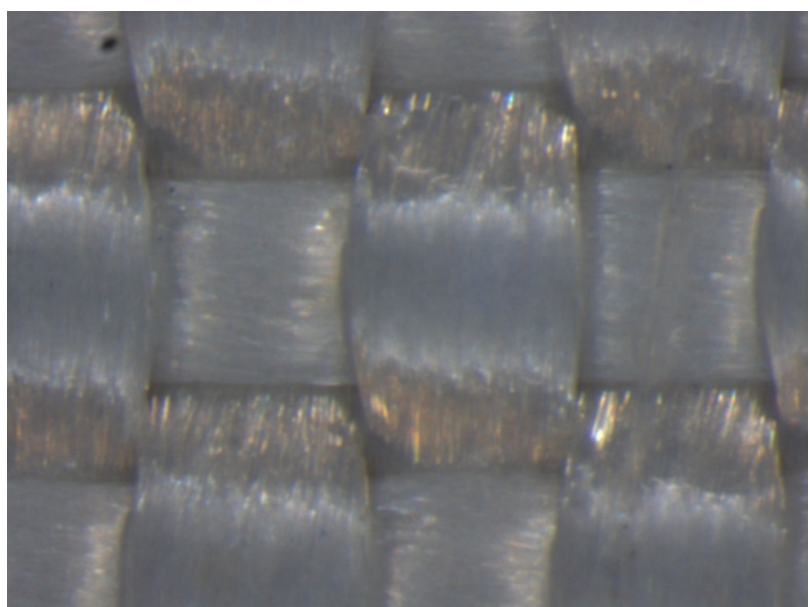

B1-2-100

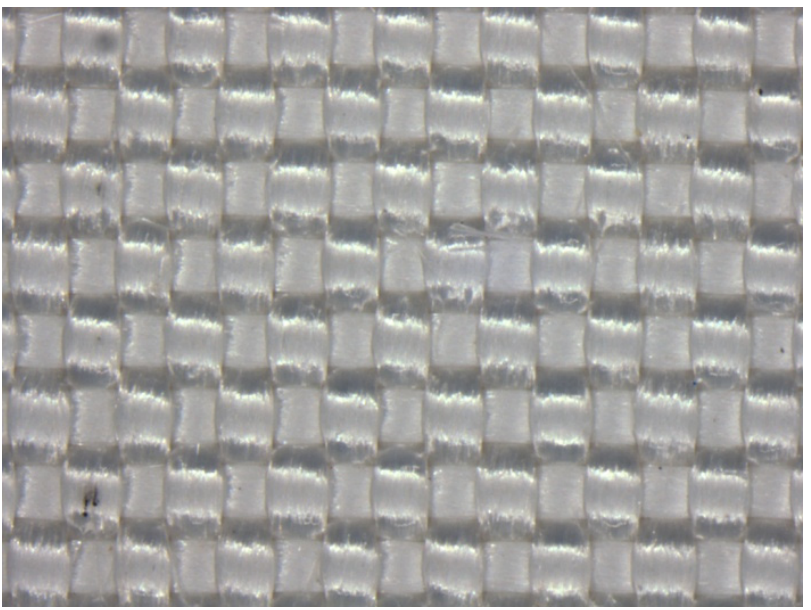

B1-3-25

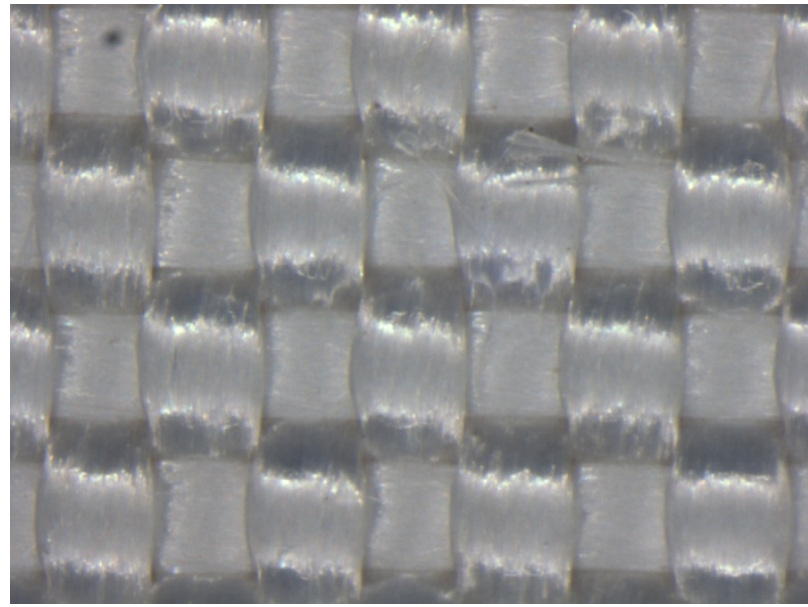

B1-3-50

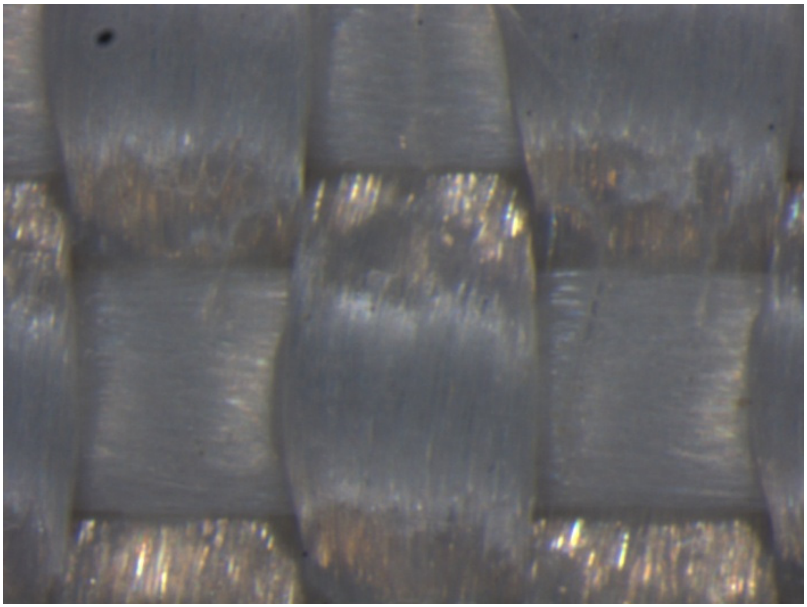

B1-3-100 


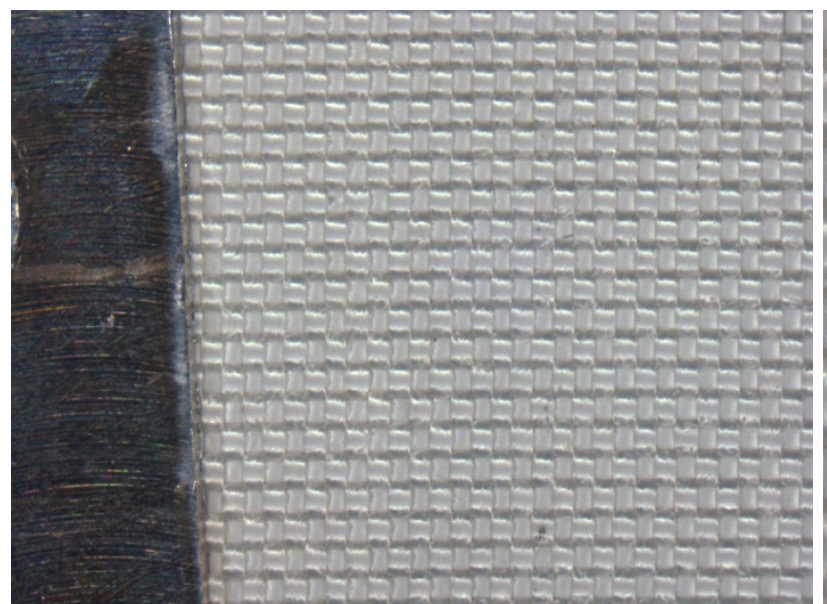

B1-4-10

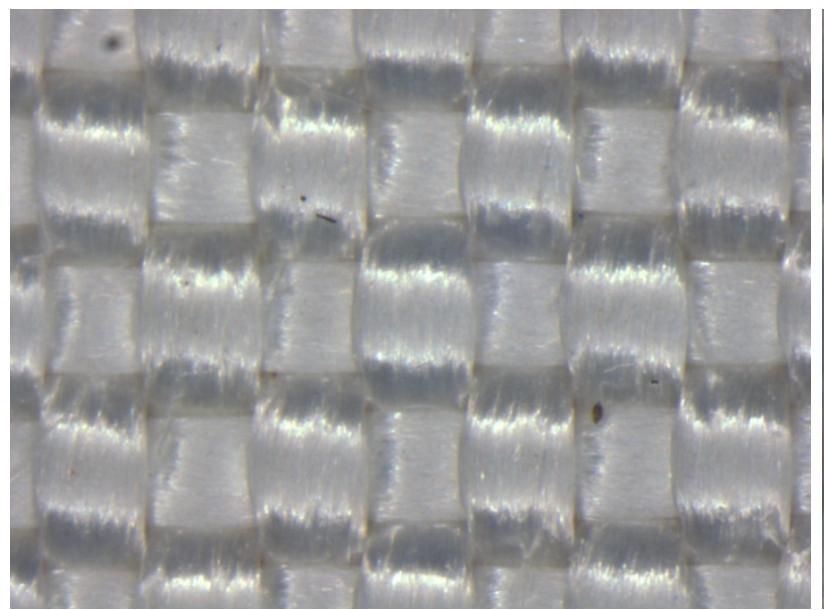

B1-4-50

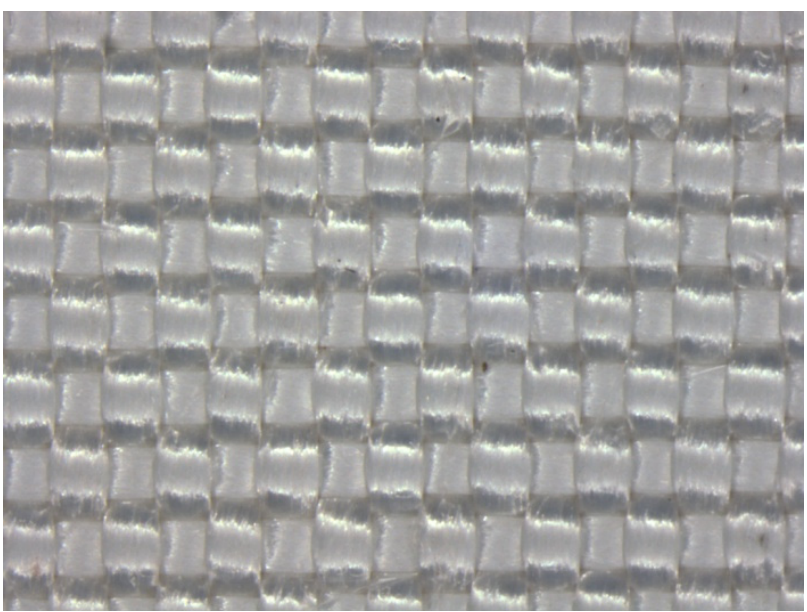

B1-4-25

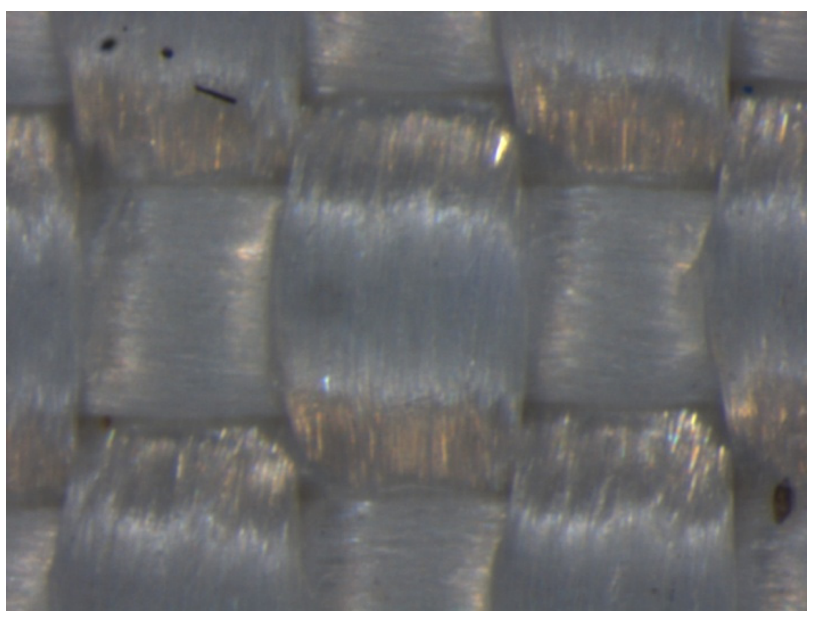

B1-4-100

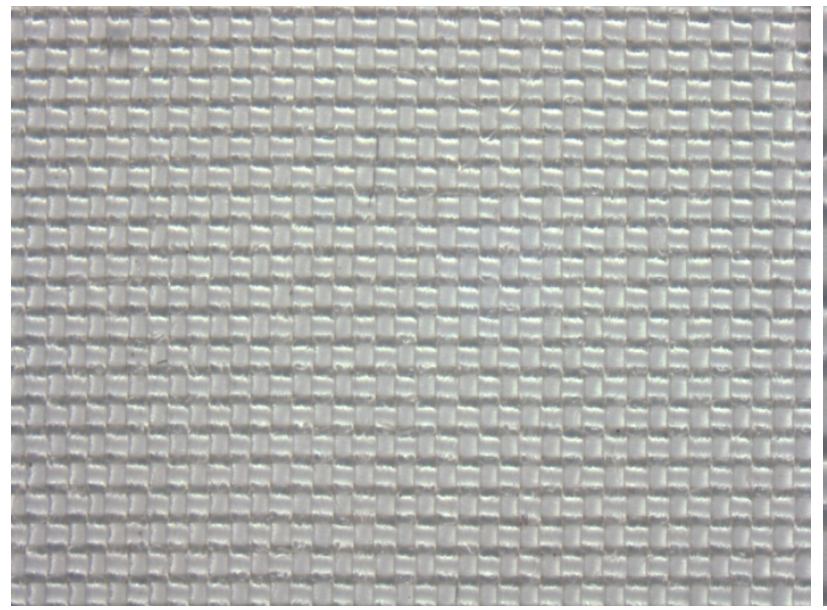

B1-5-10

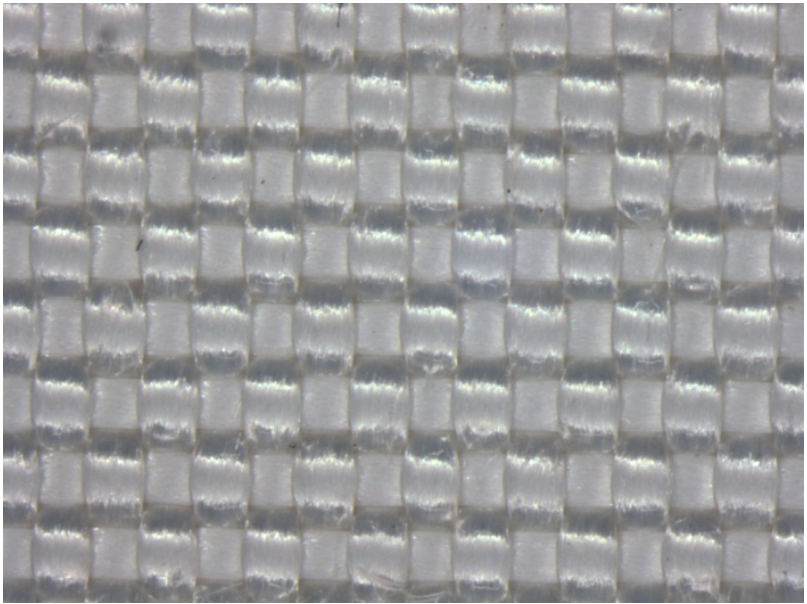

B1-5-25 


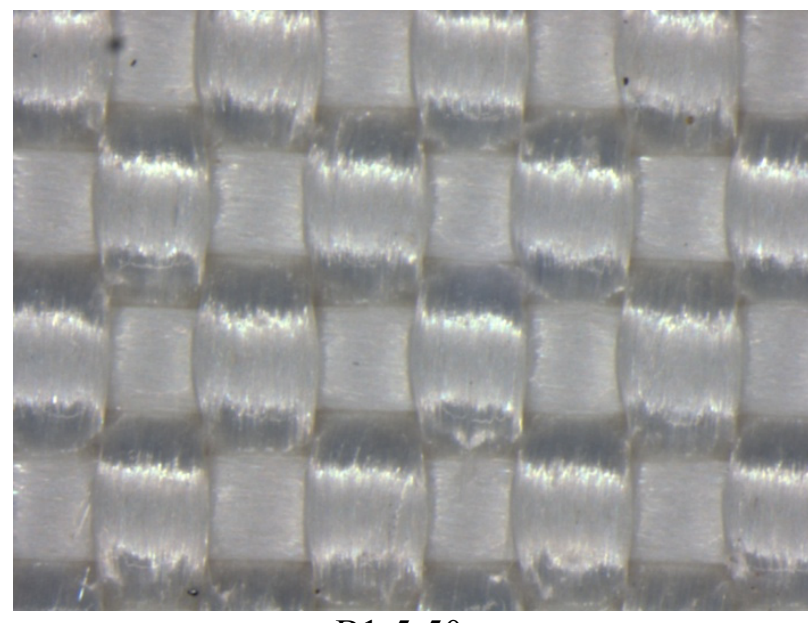

B1-5-50

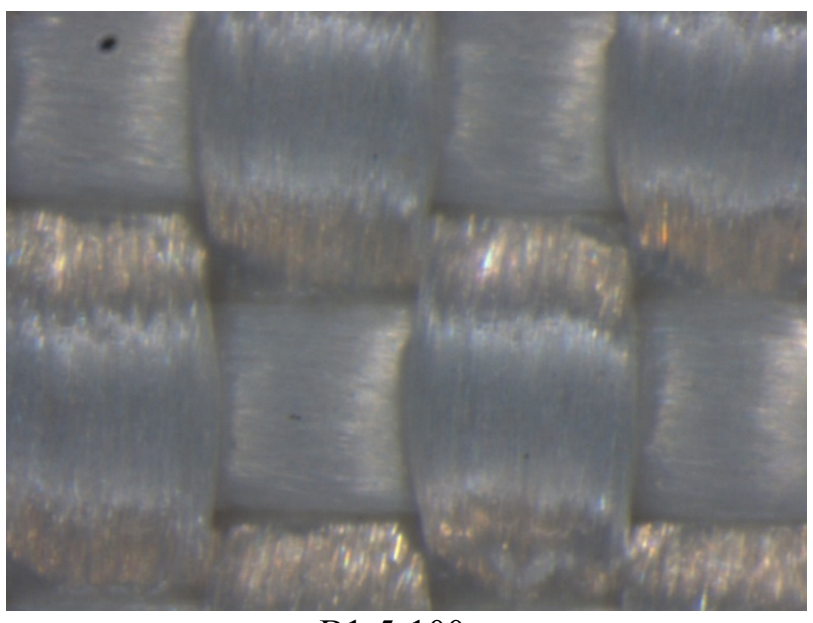

B1-5-100

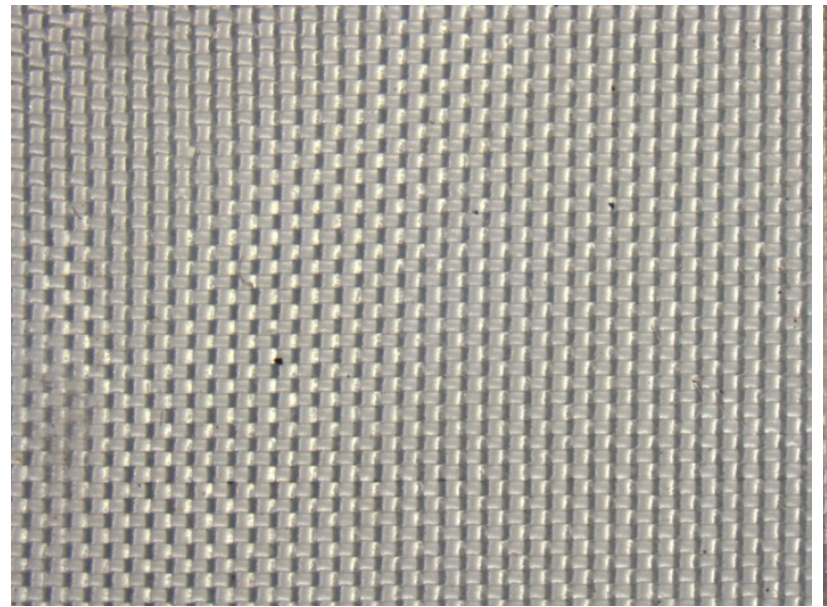

B2-1-7.1 back

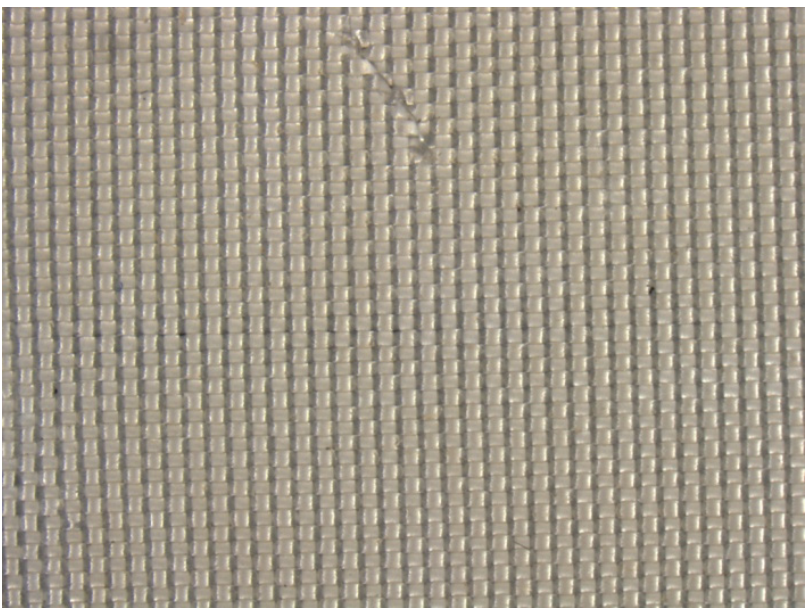

B2-1-7.1 front

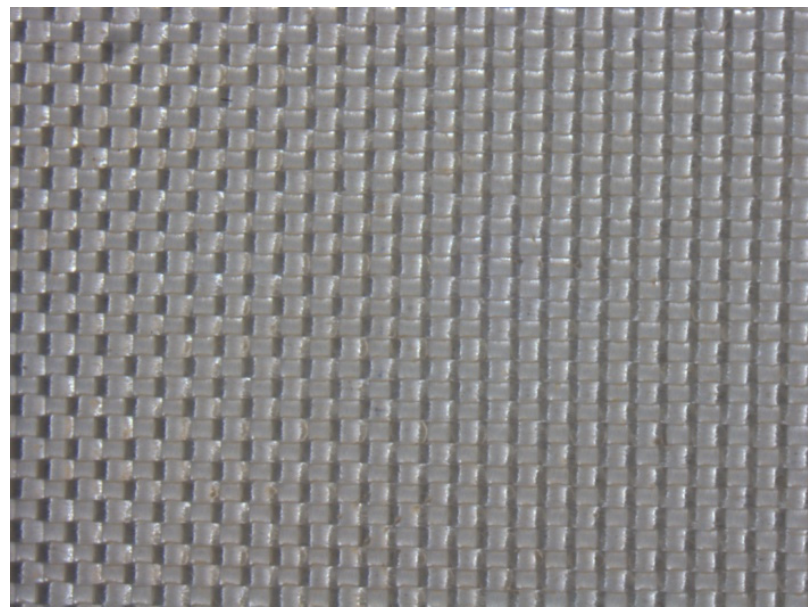

B2-1-10

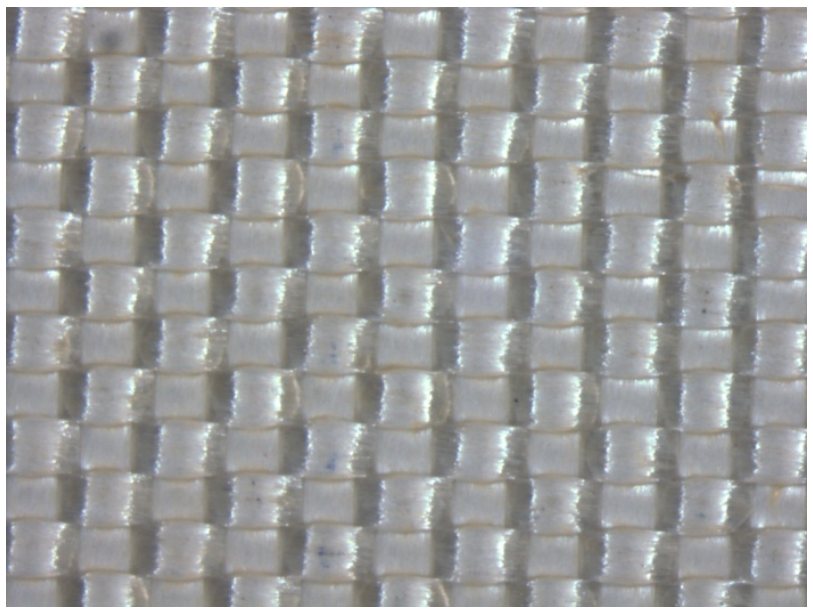

B2-1-25 


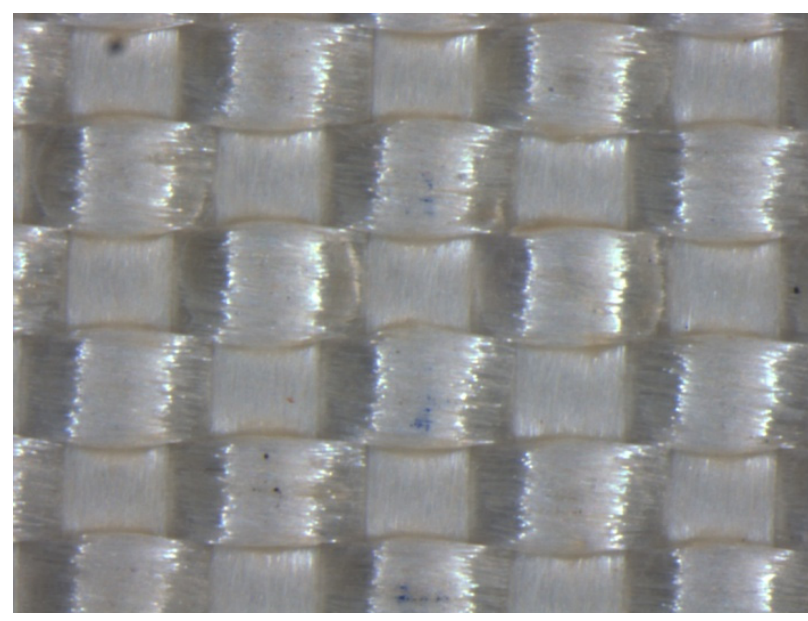

B2-1-50

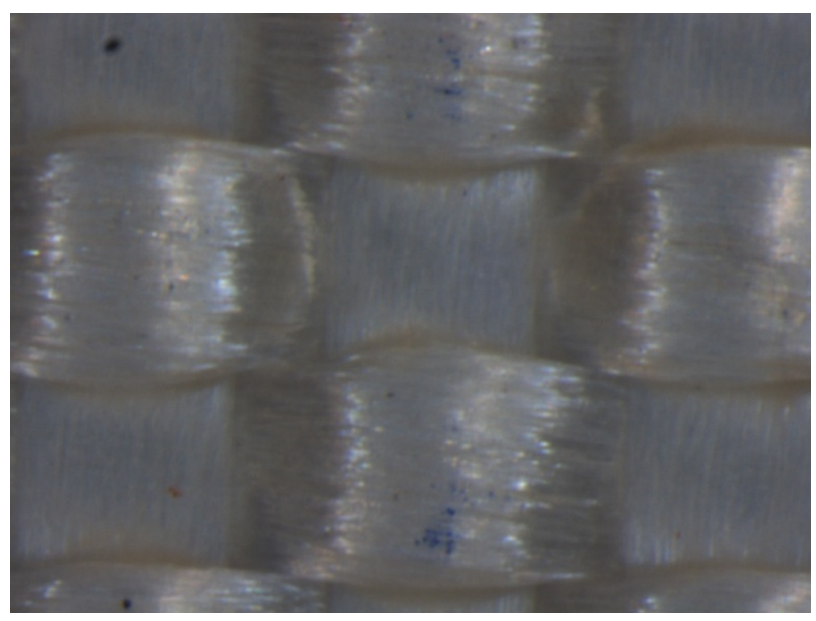

B2-1-100

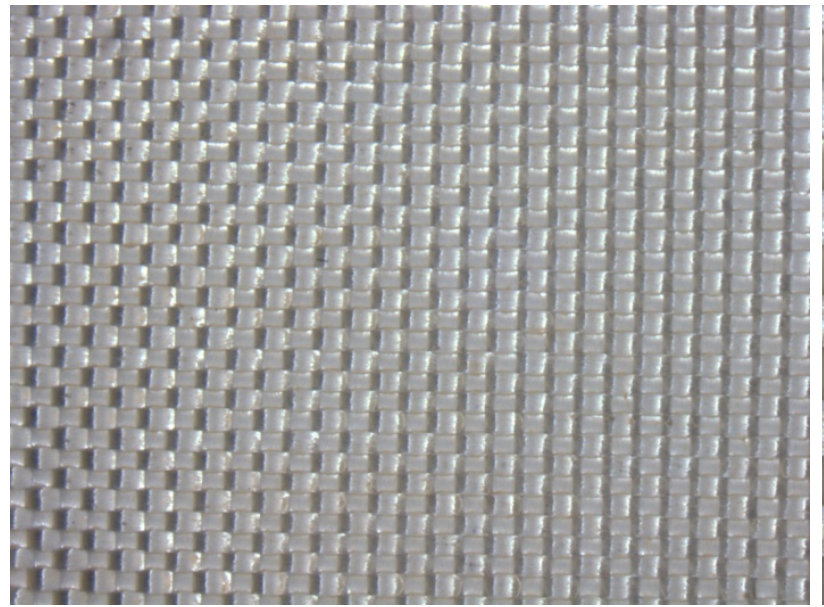

B2-2-10

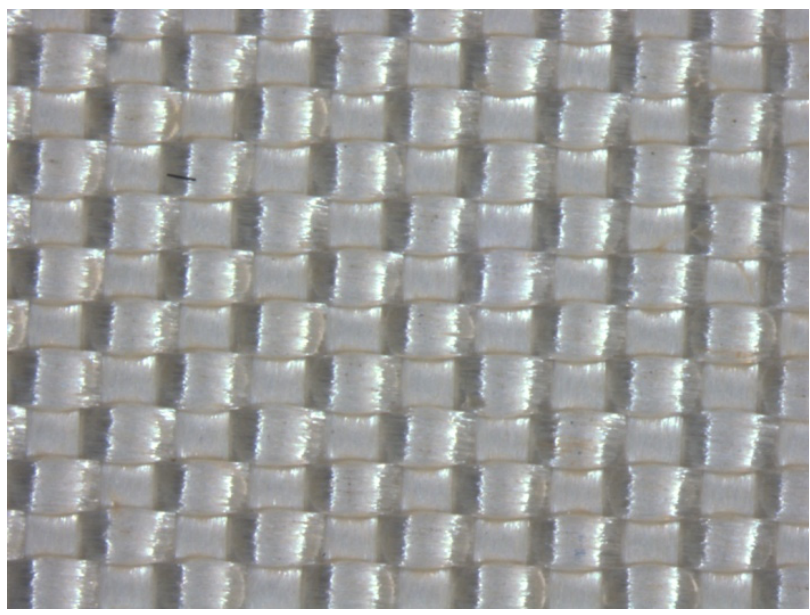

B2-2-25

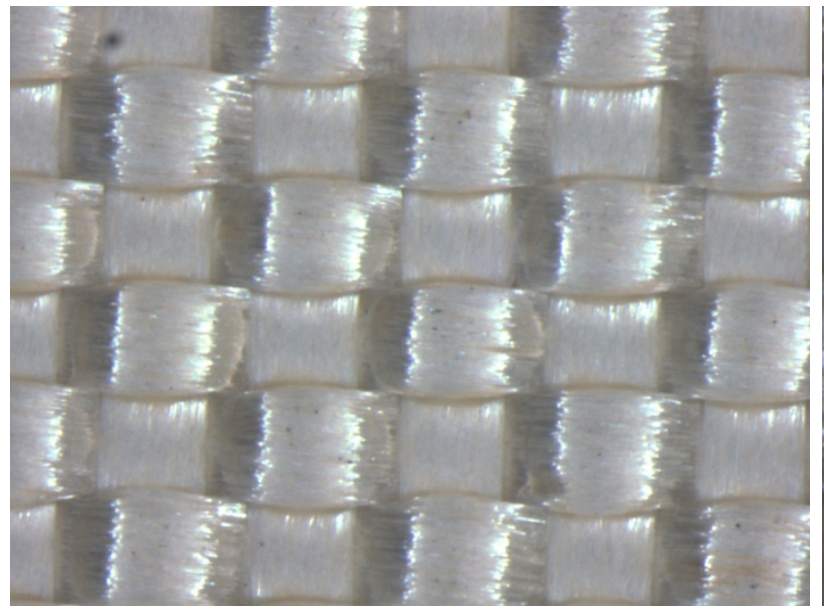

B2-2-50

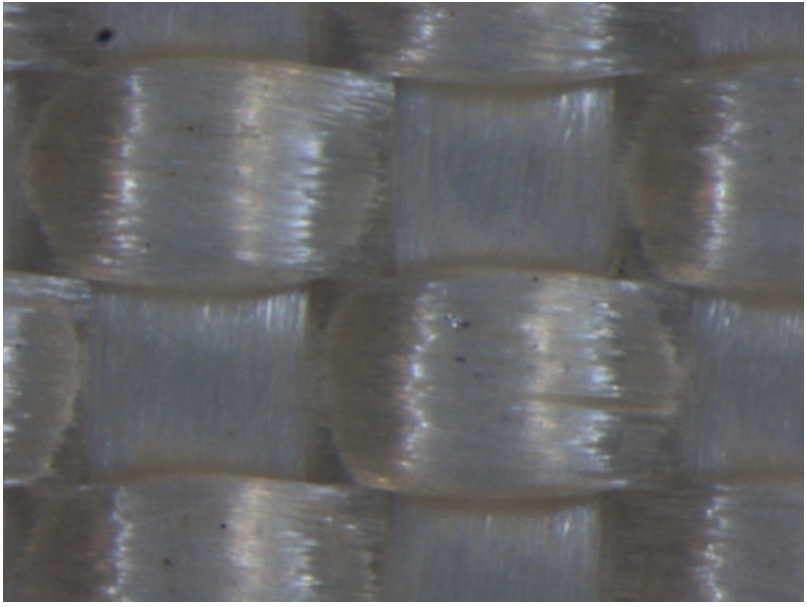

B2-2-100 


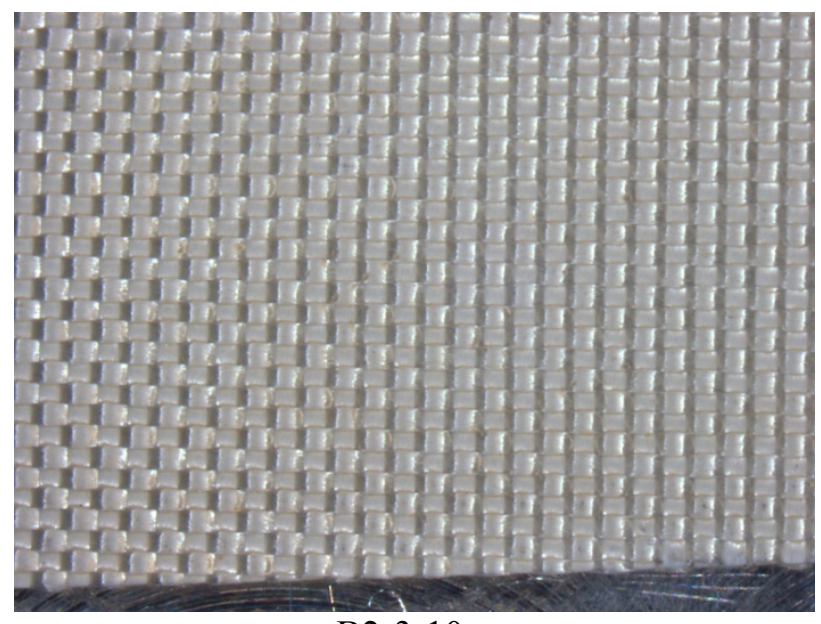

B2-3-10

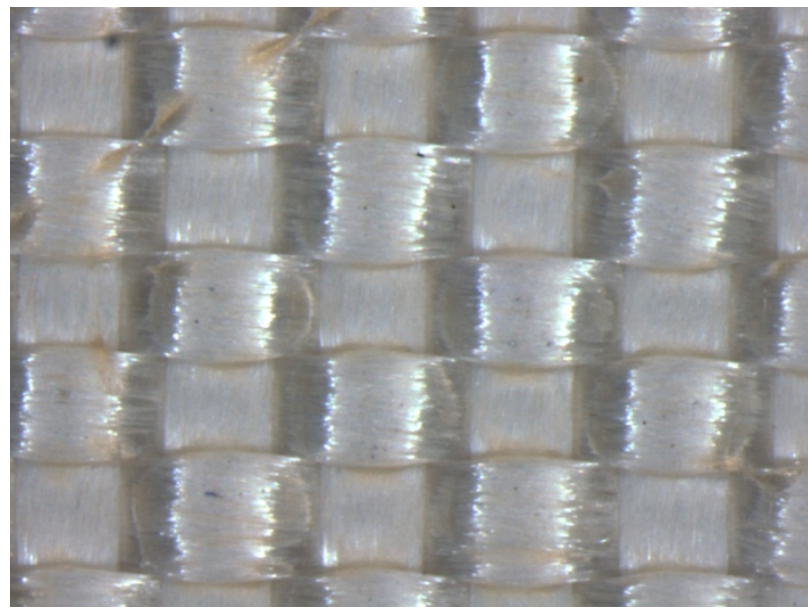

B2-3-50

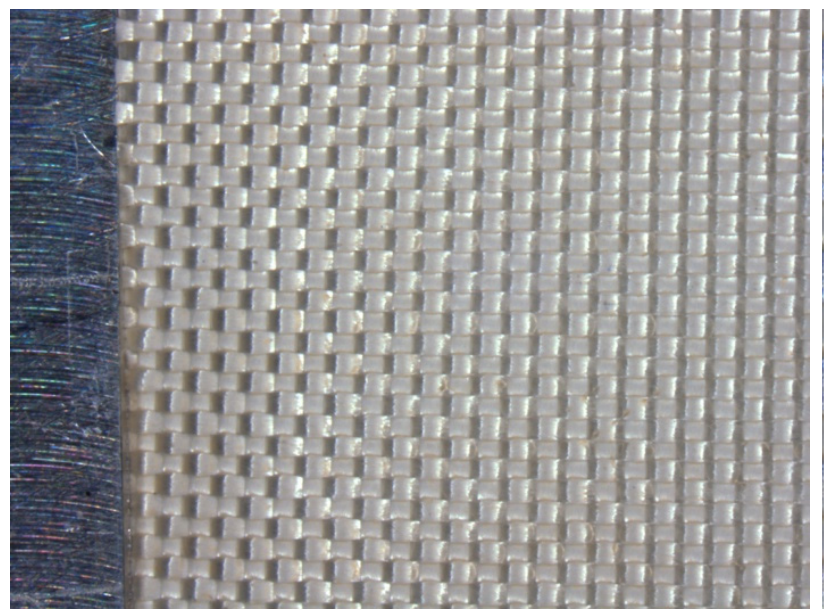

B2-4-10

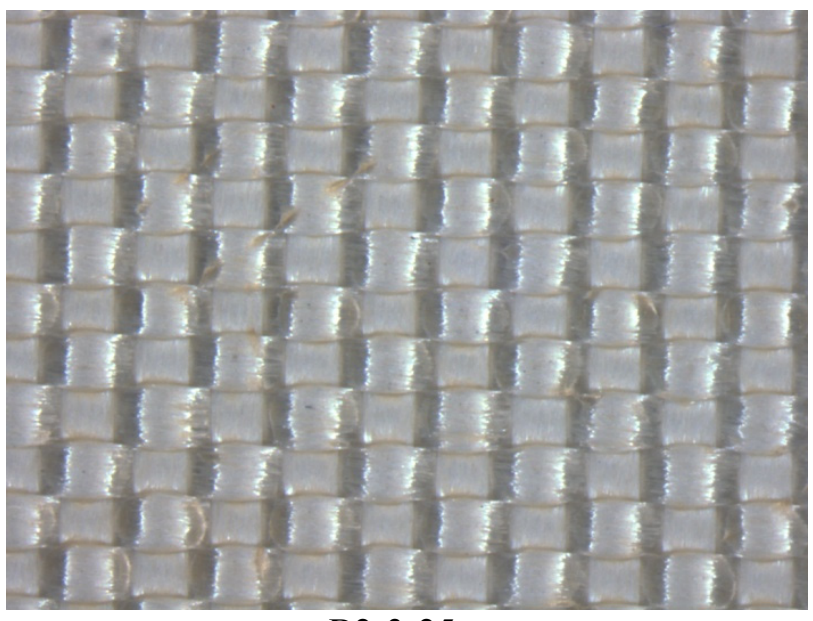

B2-3-25

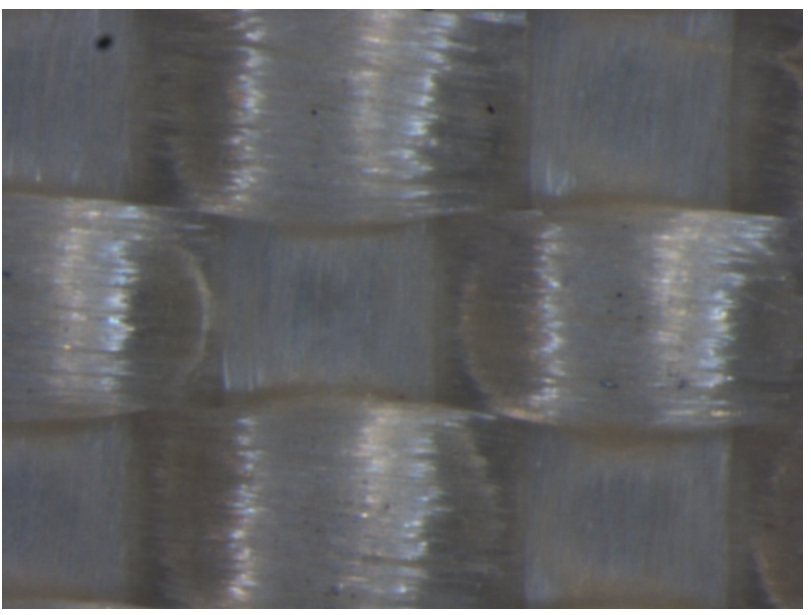

B2-3-100

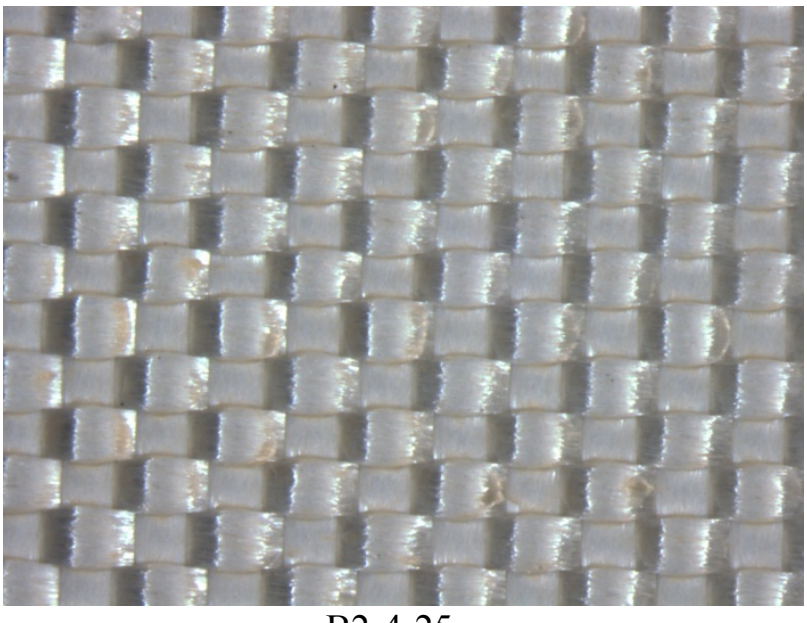

B2-4-25 


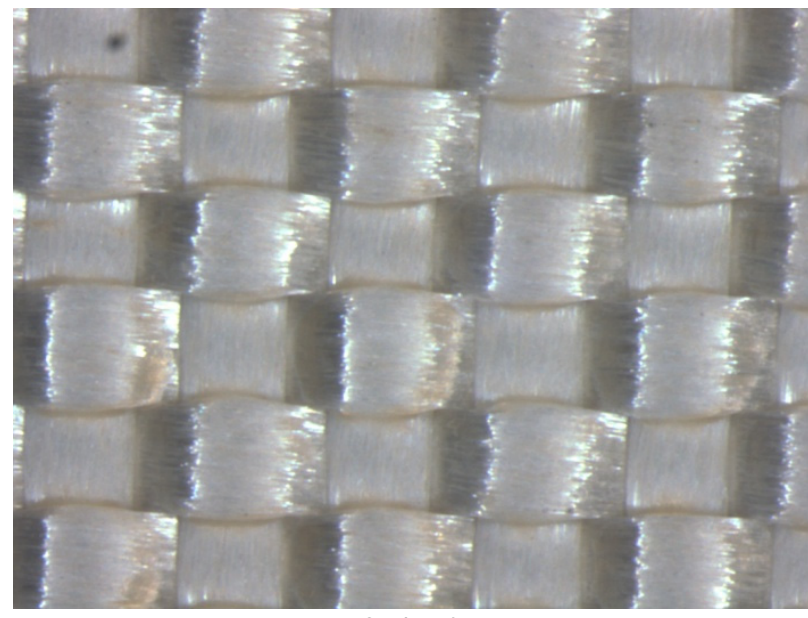

B2-4-50

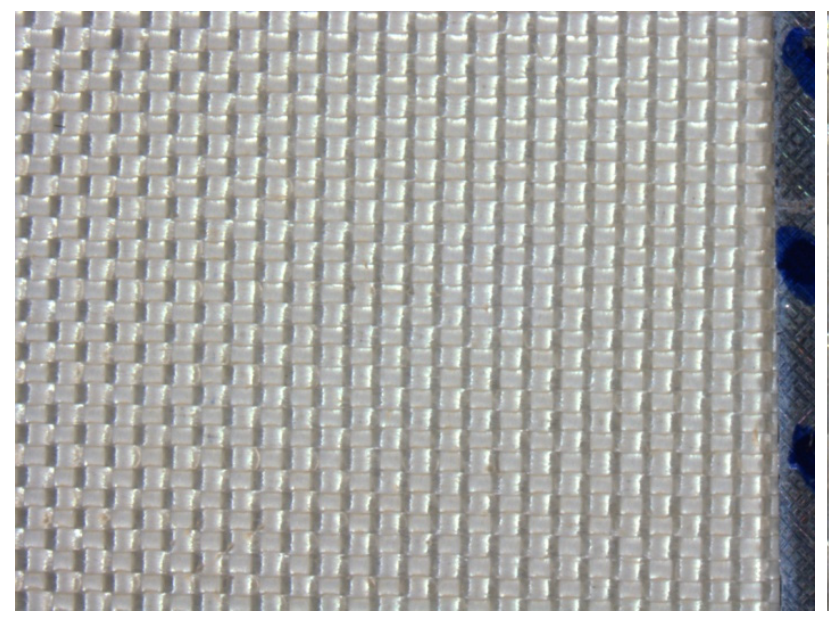

B2-5-10

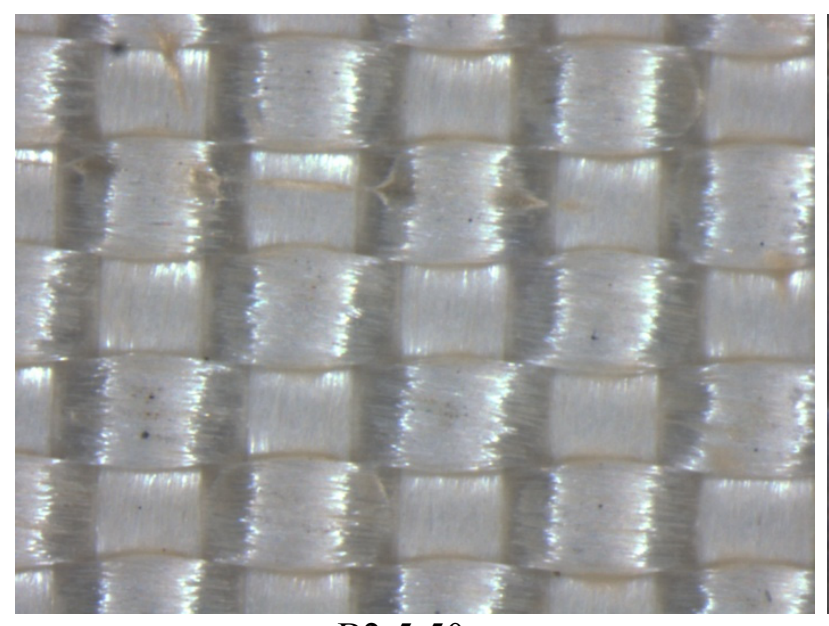

B2-5-50

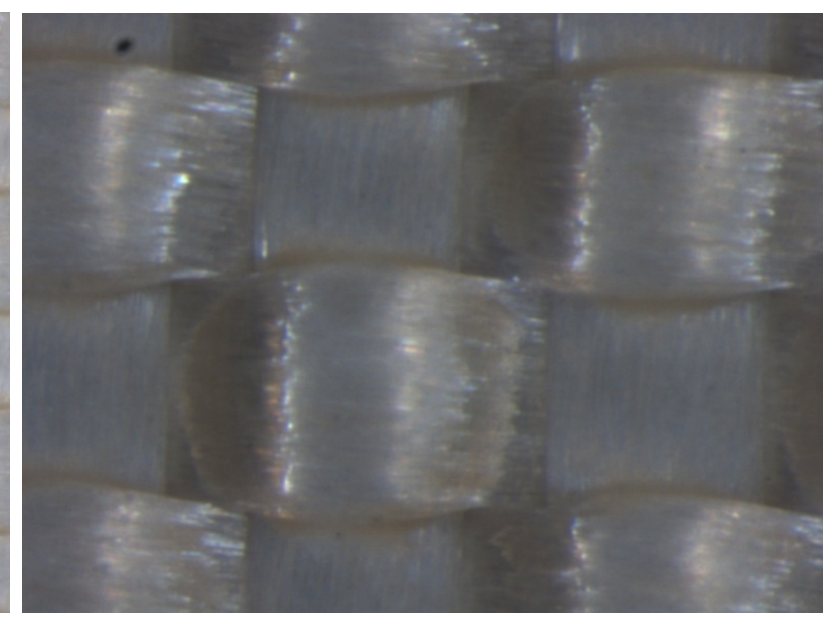

B2-4-100

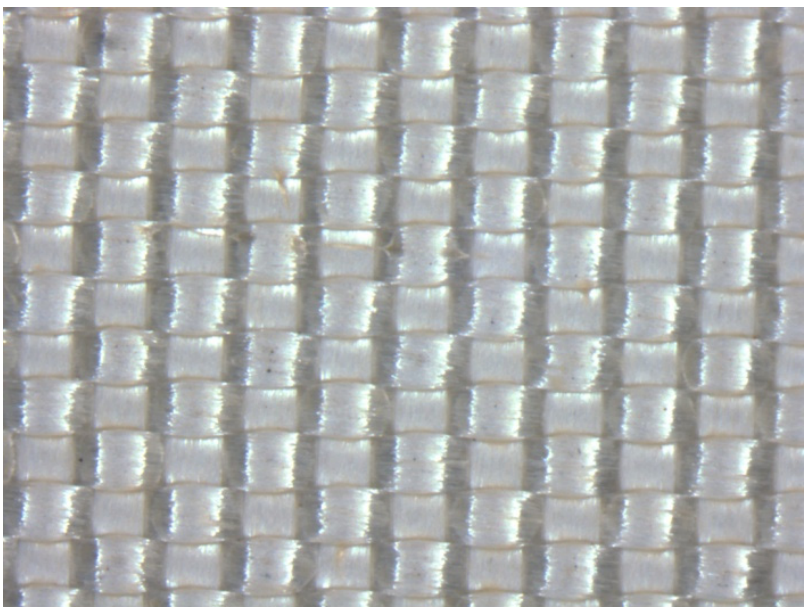

B2-5-25

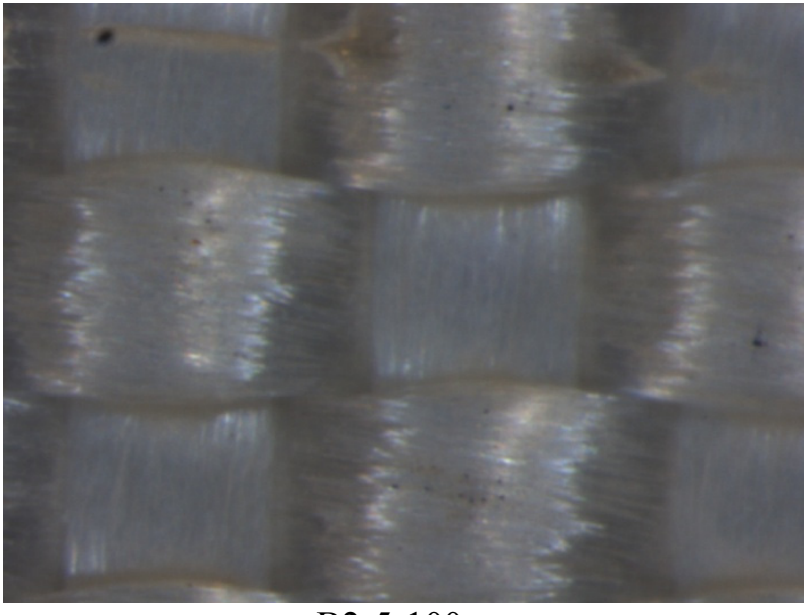

B2-5-100 


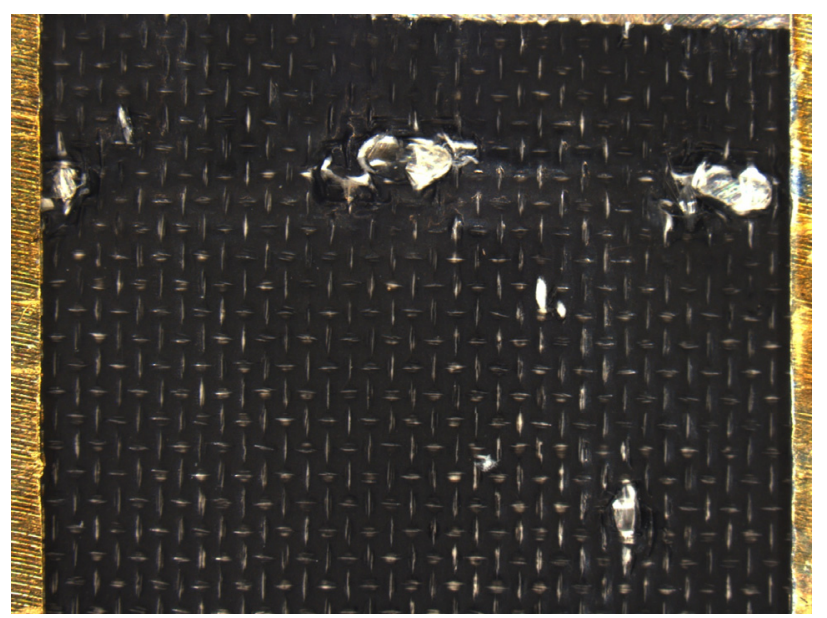

B3-1-7.1 black

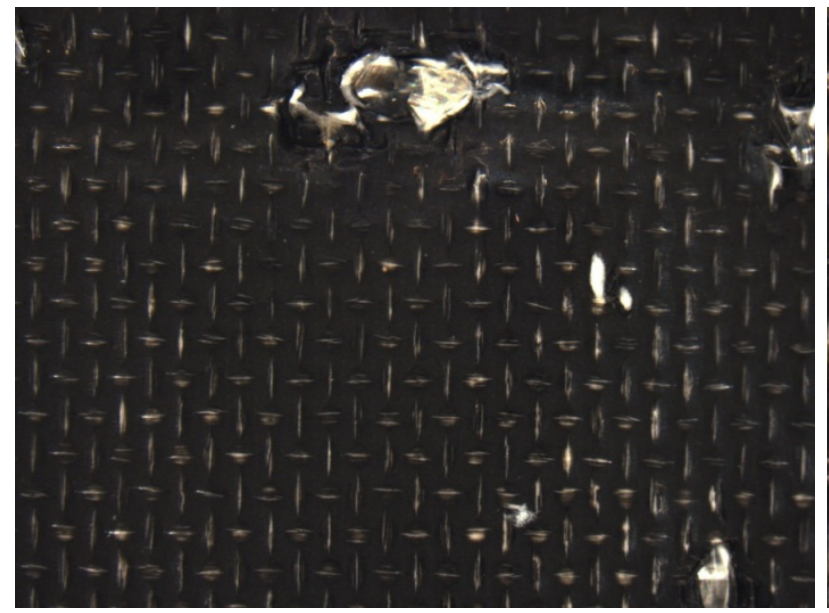

B3-1-10

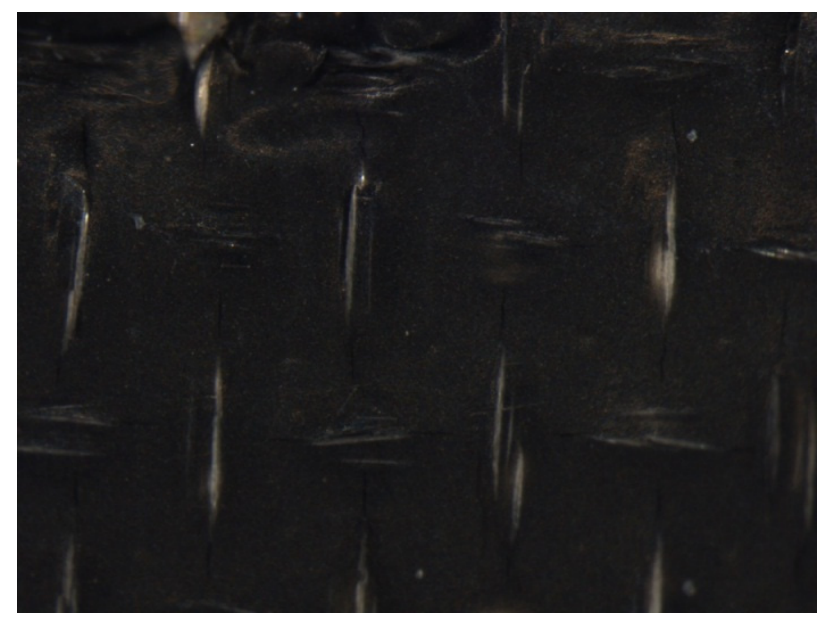

B3-1-50

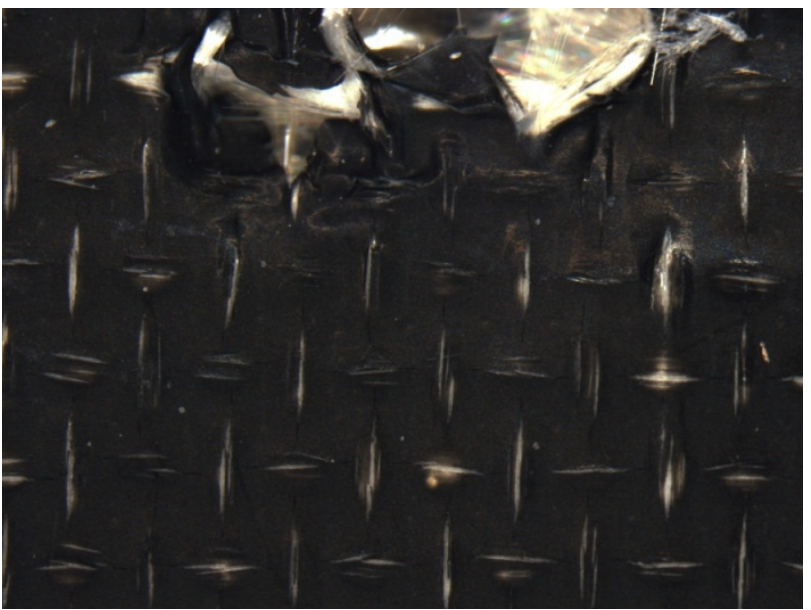

B3-1-25

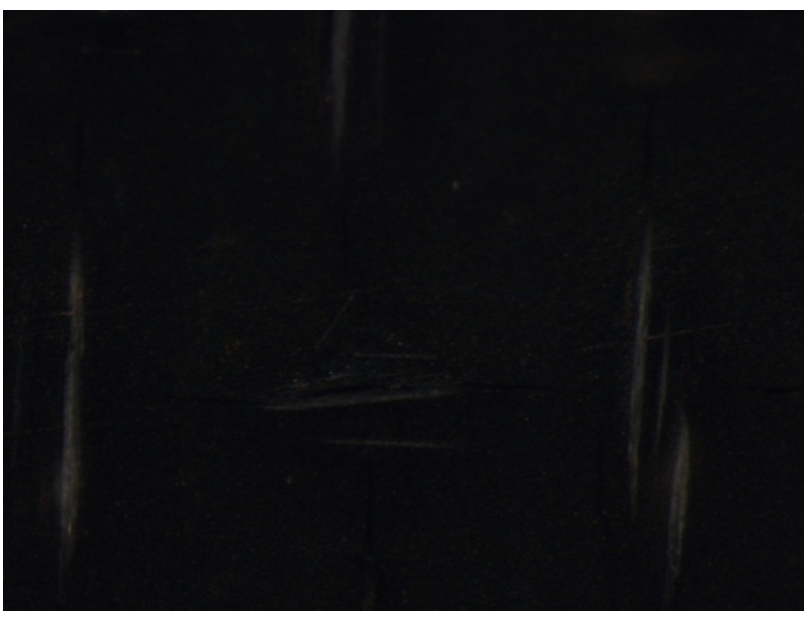

B3-1-10 


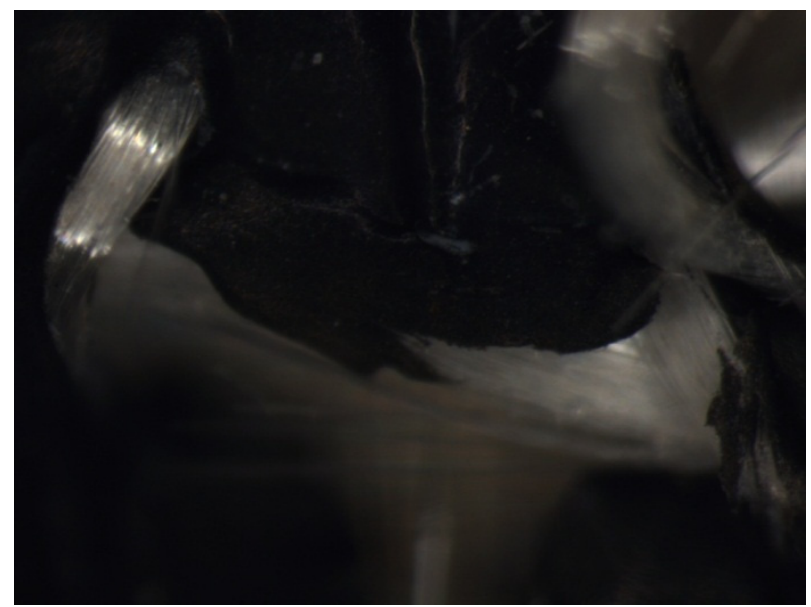

B3-2-100

Sample taken from under B3

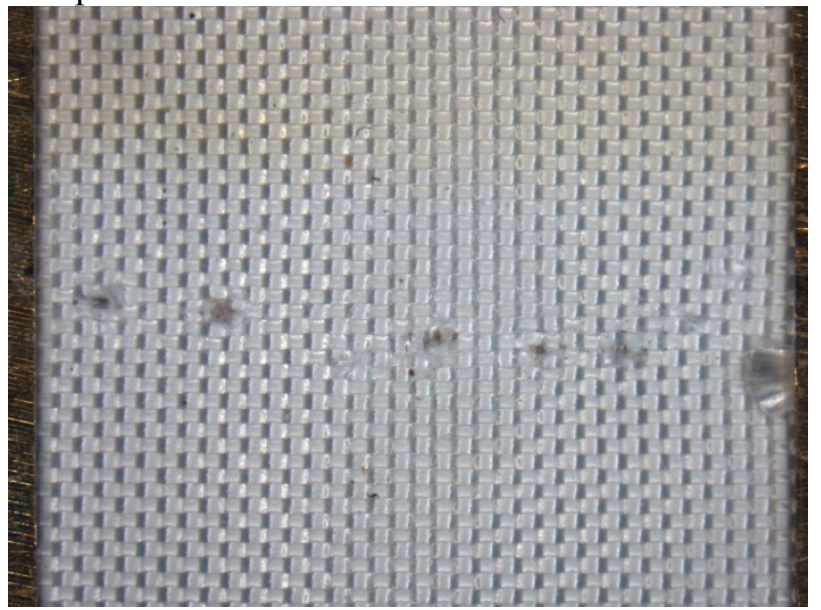

B4-1-7.1 under black

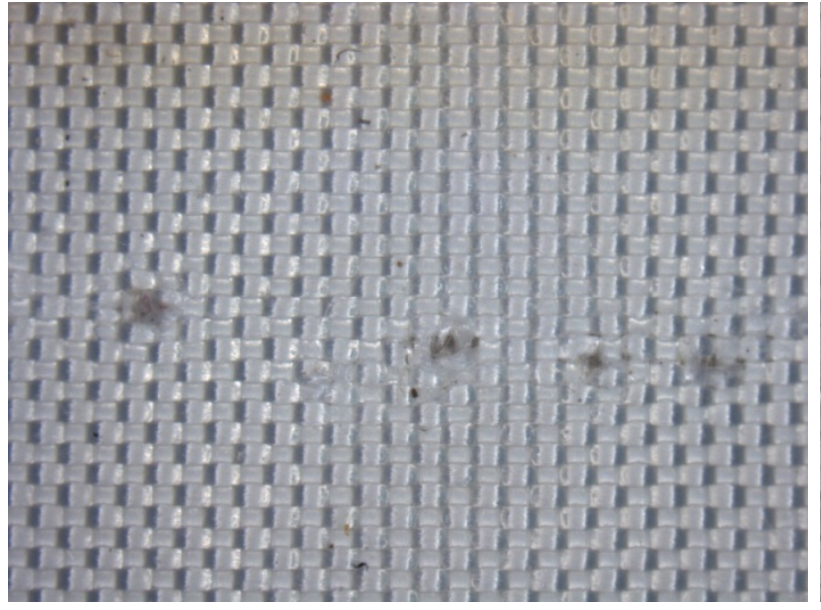

B4-1-10

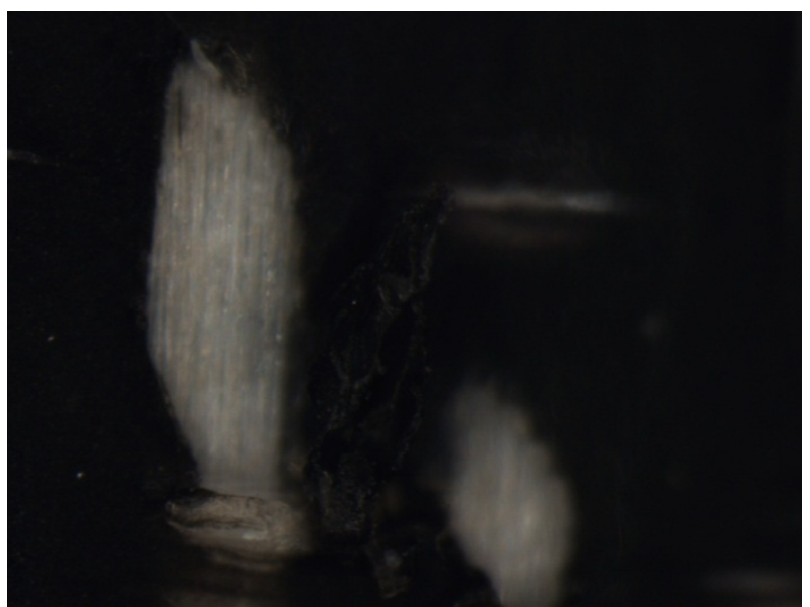

B3-3-100

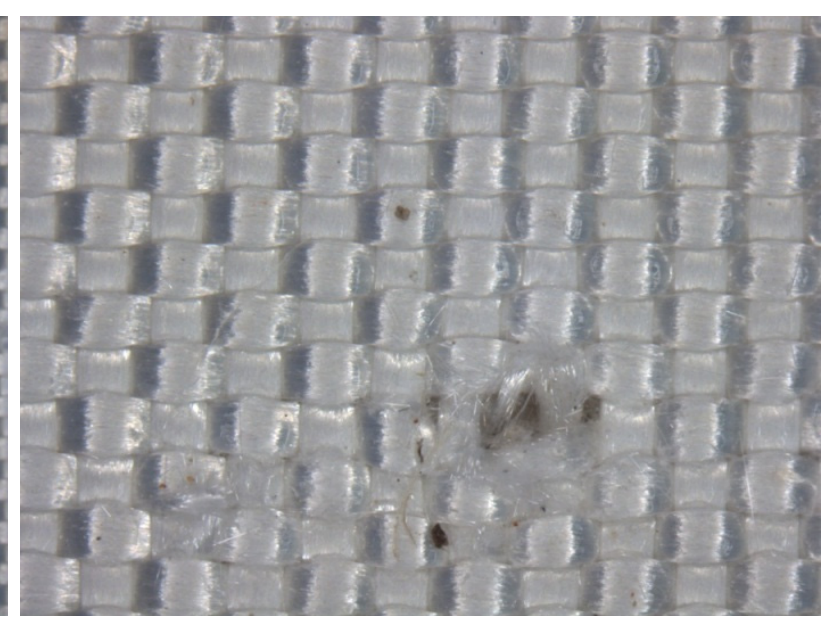

B4-1-25 


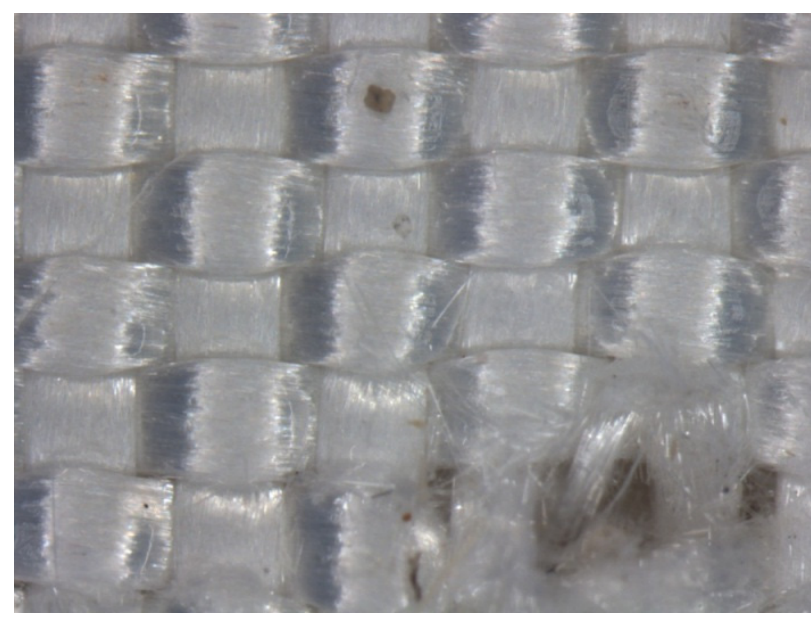

B4-1-50

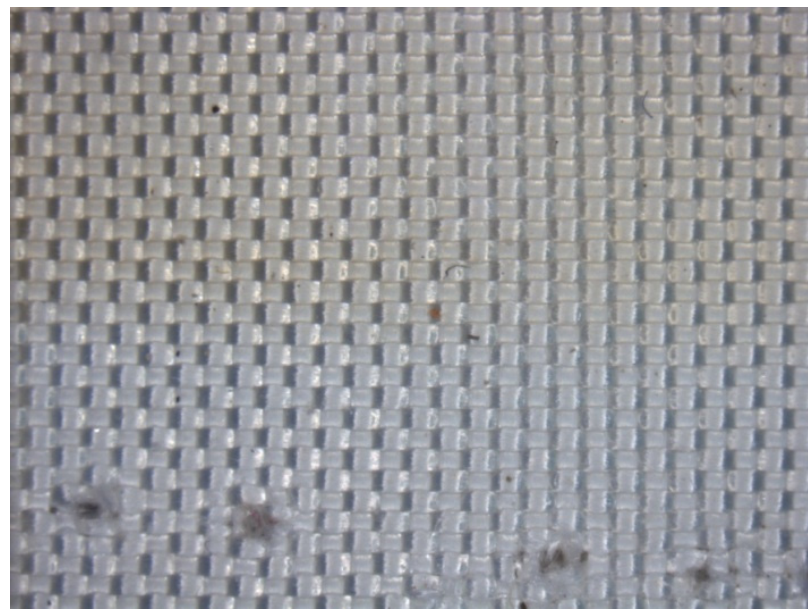

B4-2-10

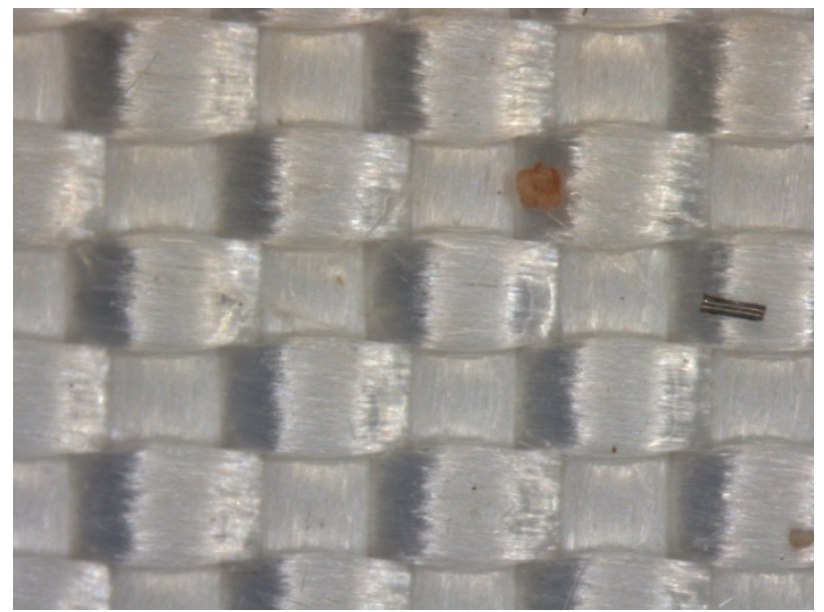

B4-2-50

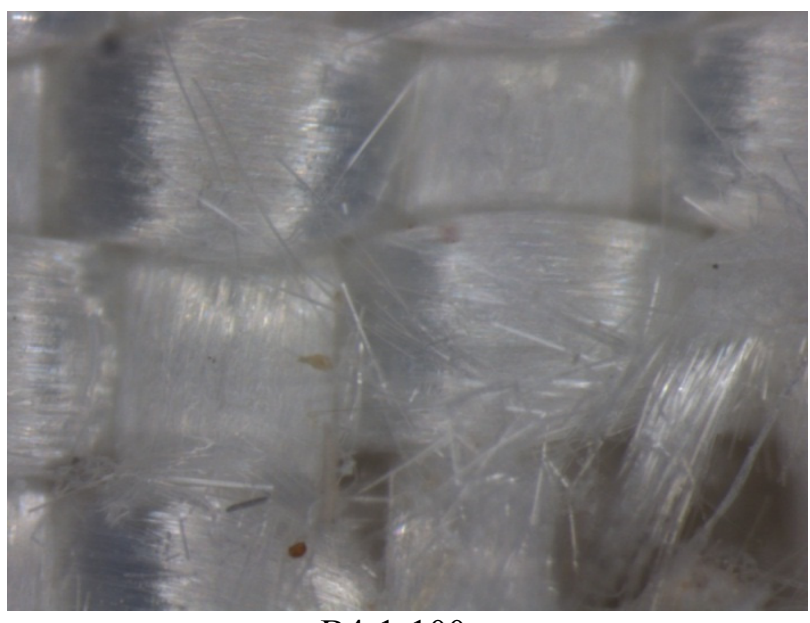

B4-1-100

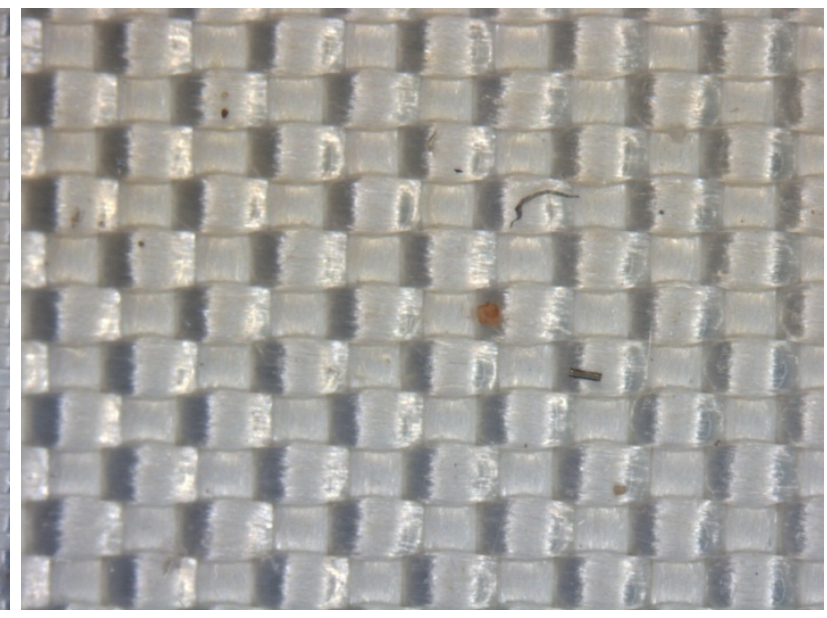

B4-2-25

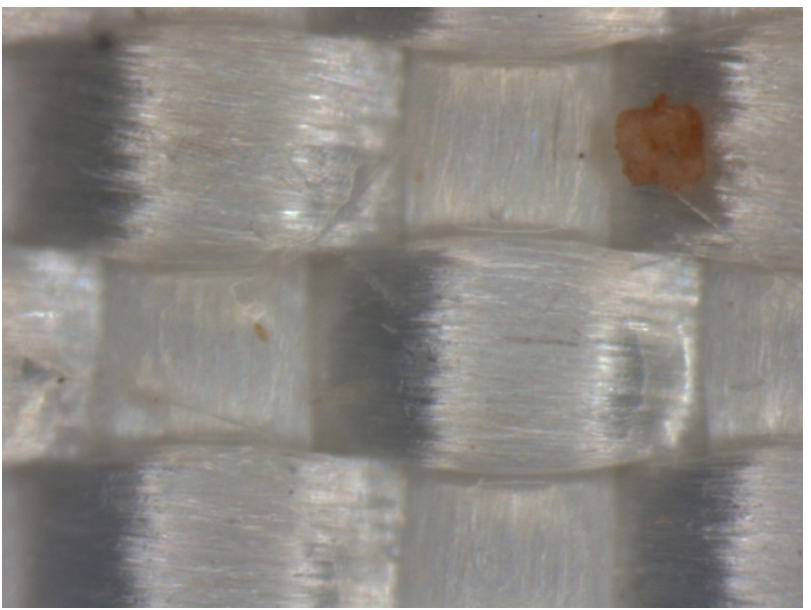

B4-2-100 
Sample taken from grey area

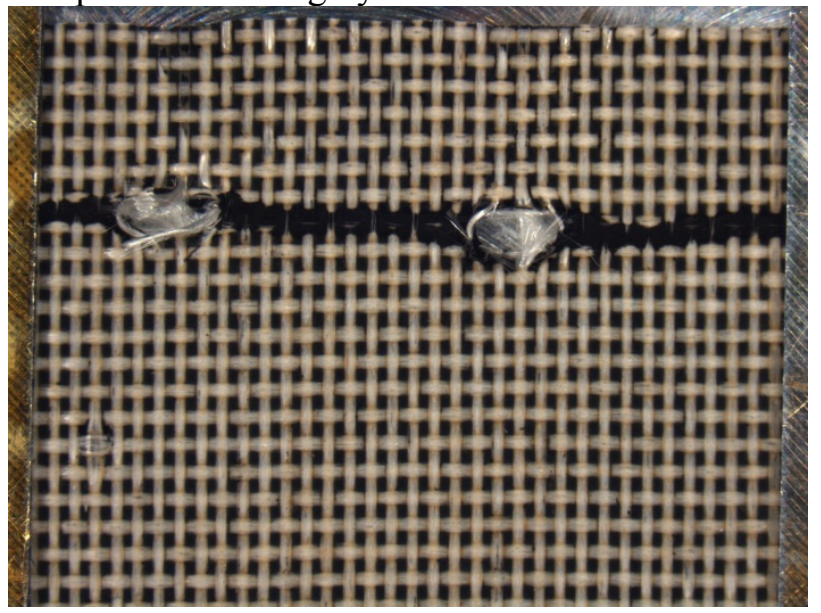

B5-1-7.1 grey

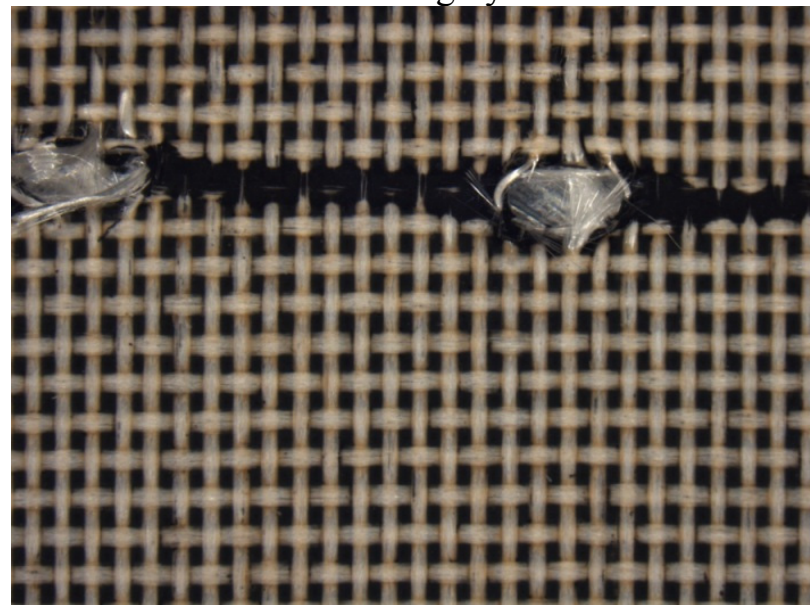

B5-1-10

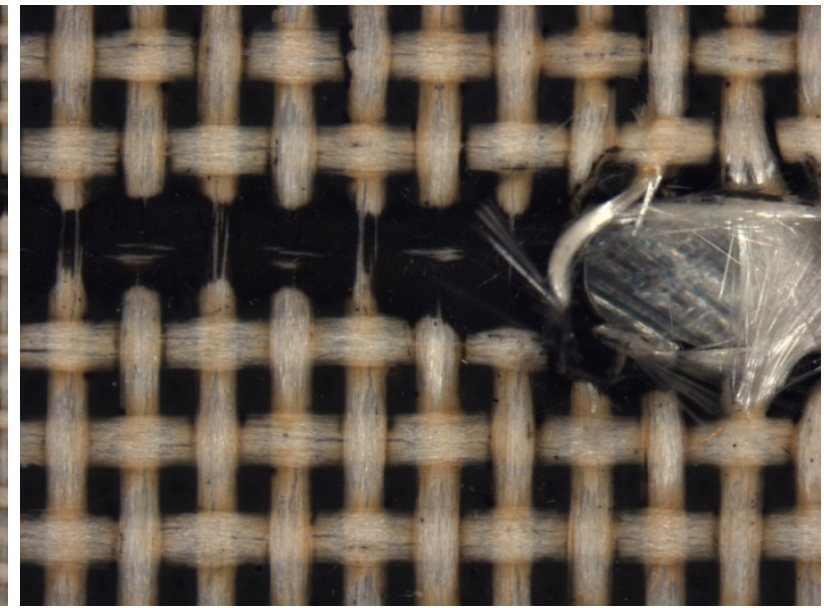

B5-1-25
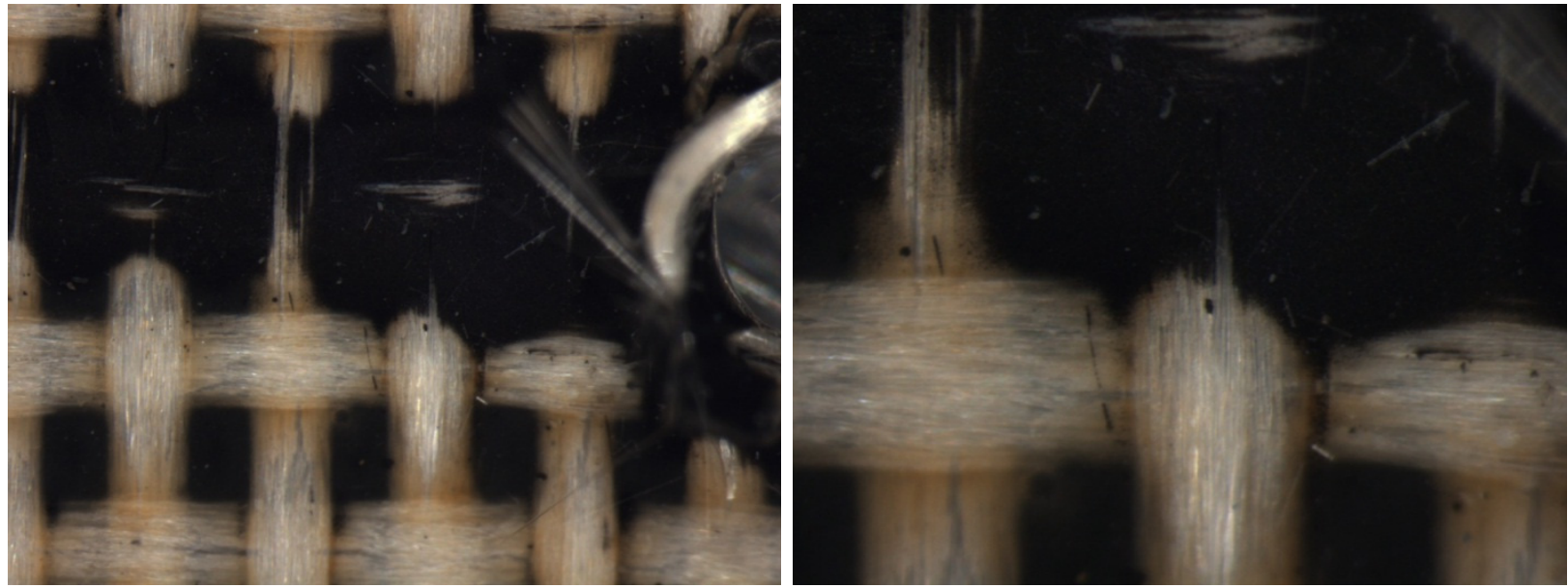

B5-1-50

B5-1-100 


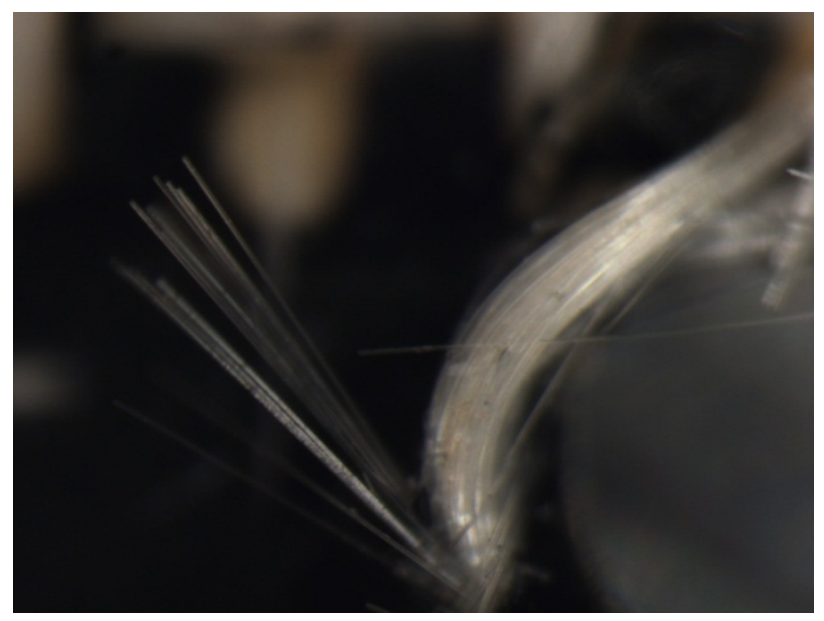

B5-2-100

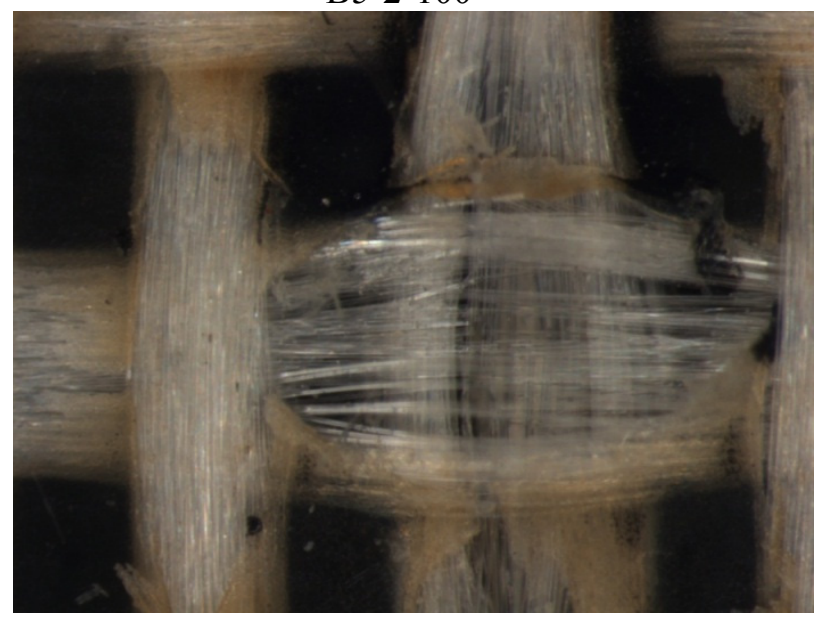

B5-4-100

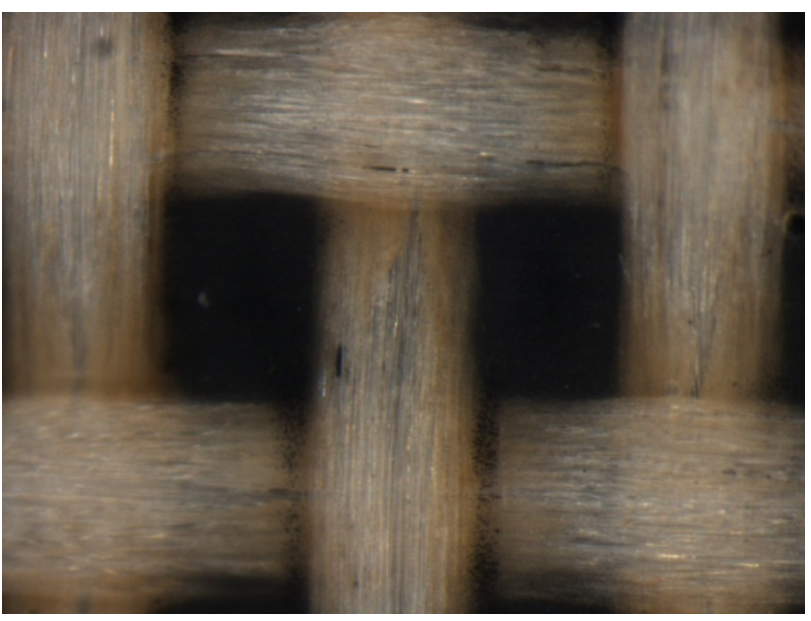

B5-3-100

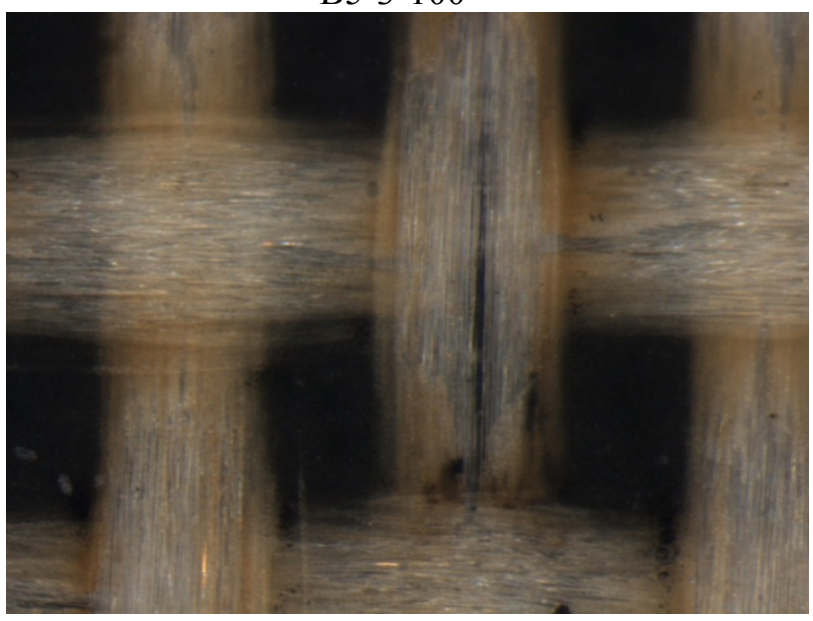

B5-5-100 
Sample taken from under B5
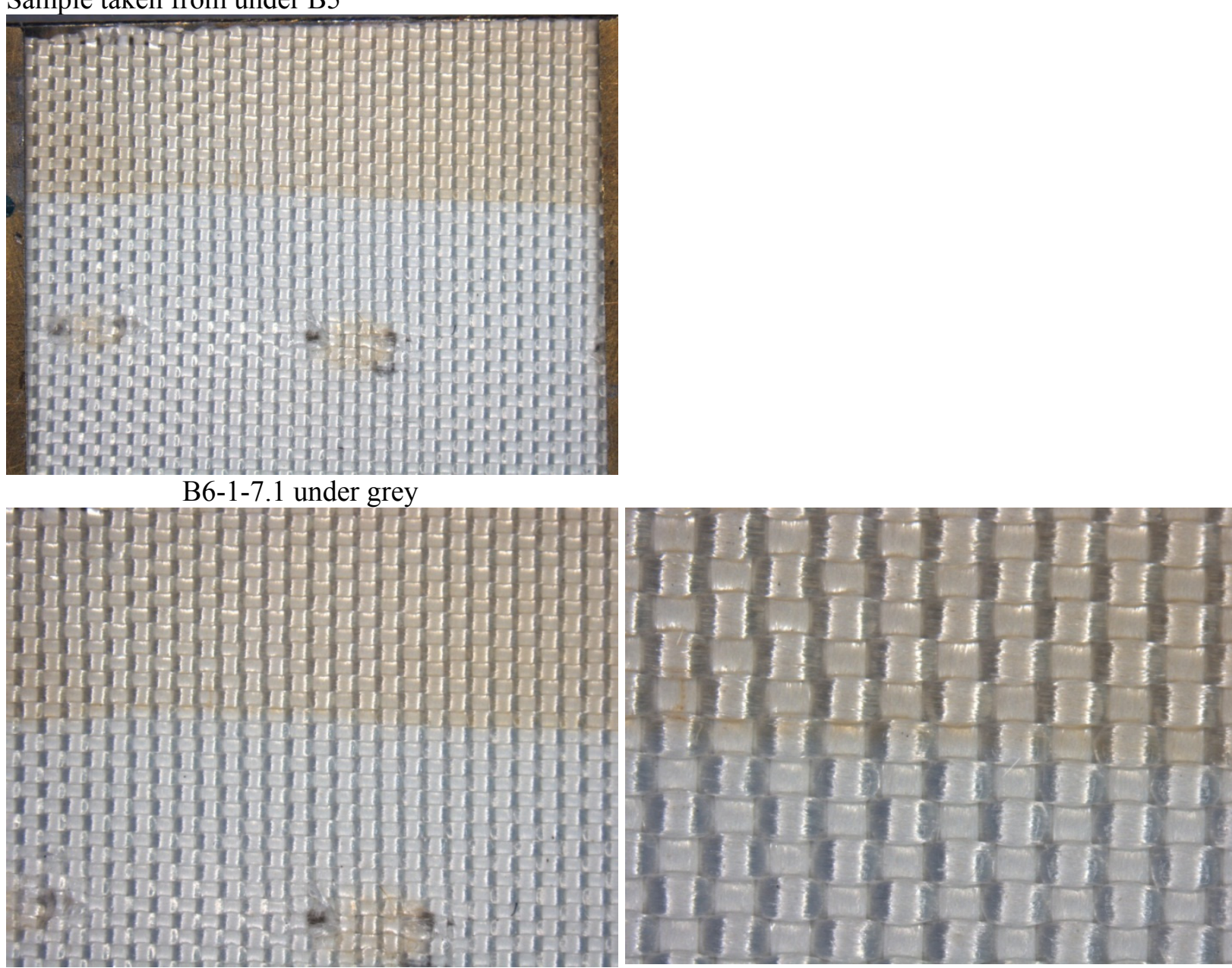

B6-1-10

B6-1-25

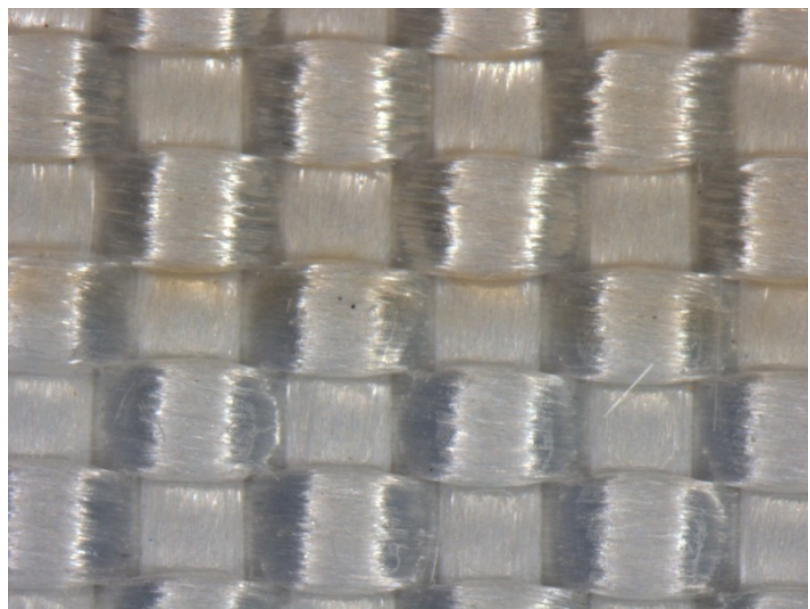

B6-1-50

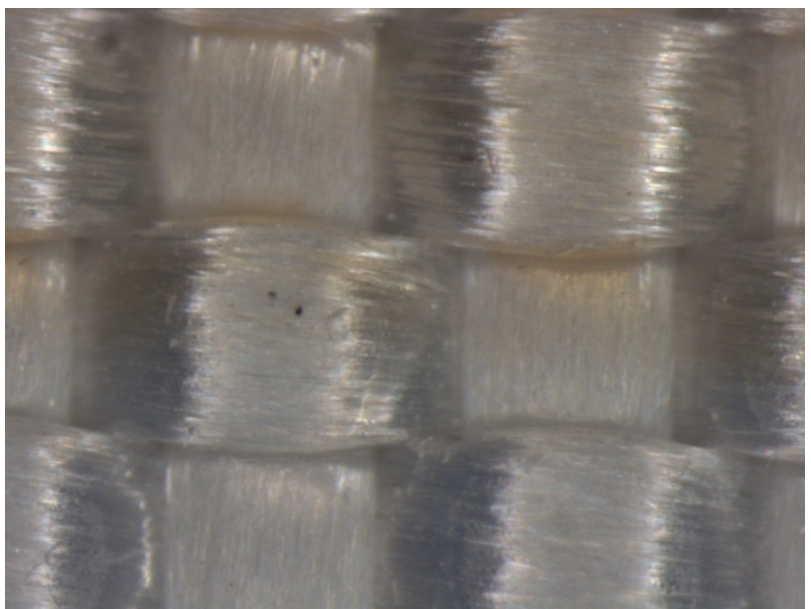

B6-1-100 


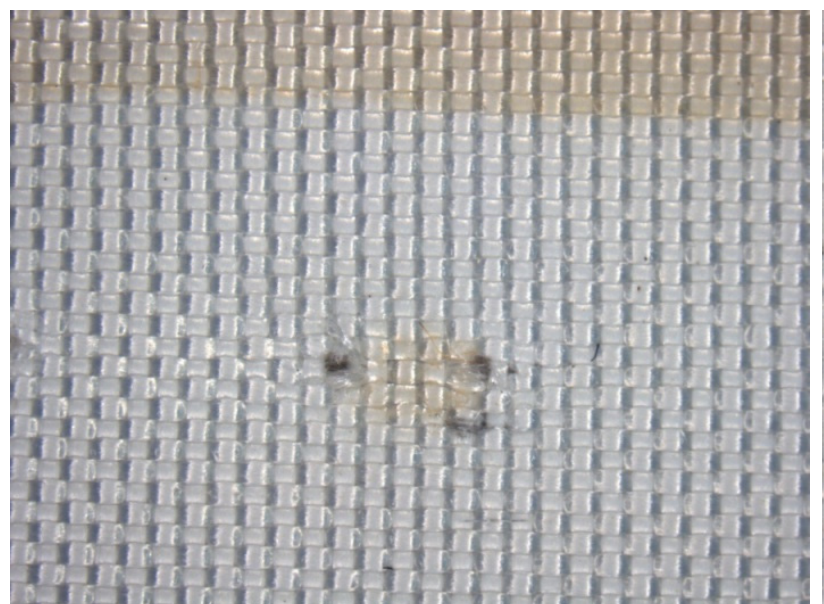

B6-2-10

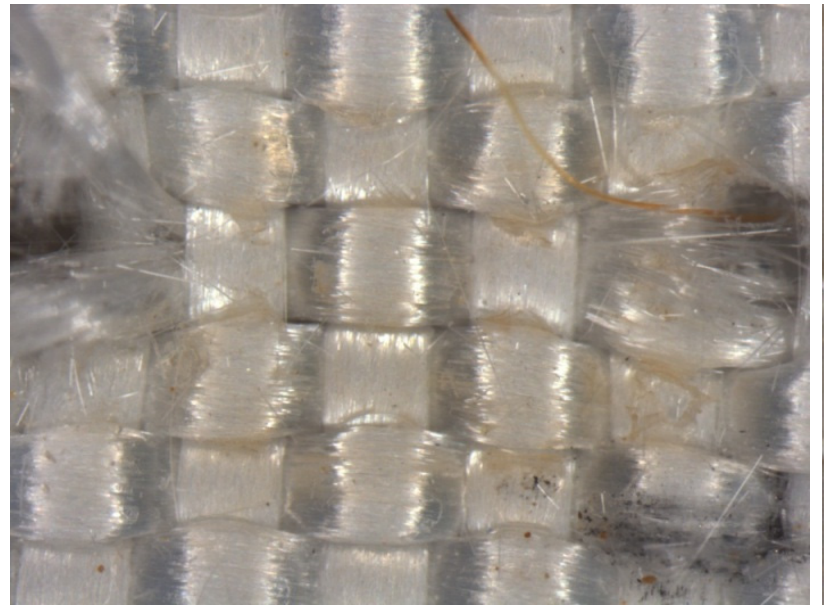

B6-2-50

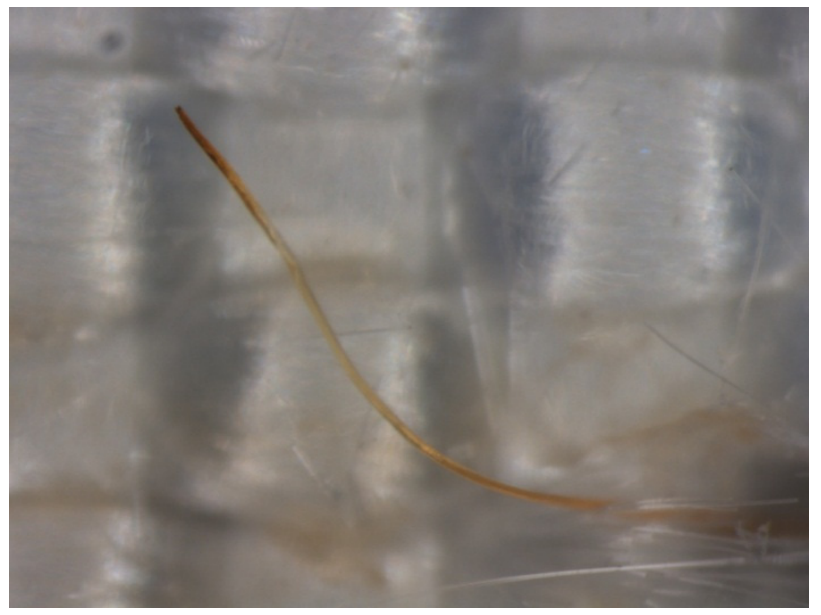

B6-3-100

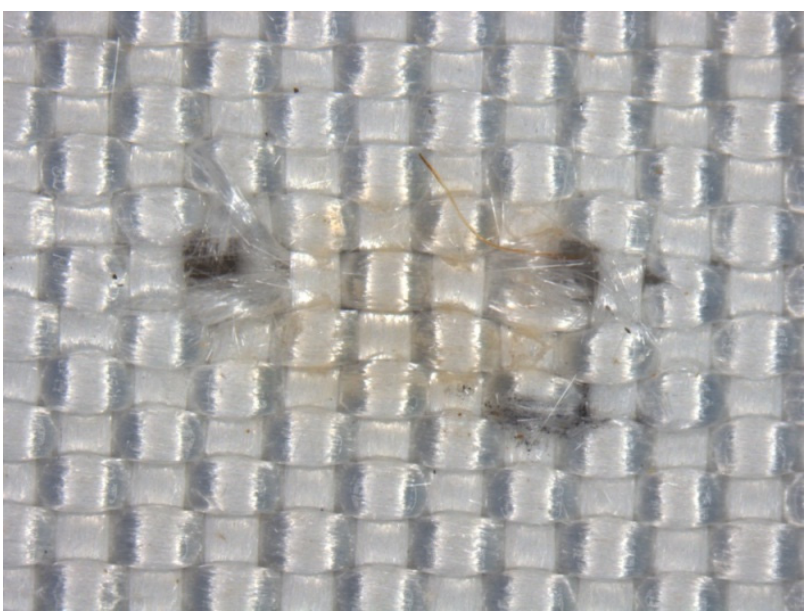

B6-2-25

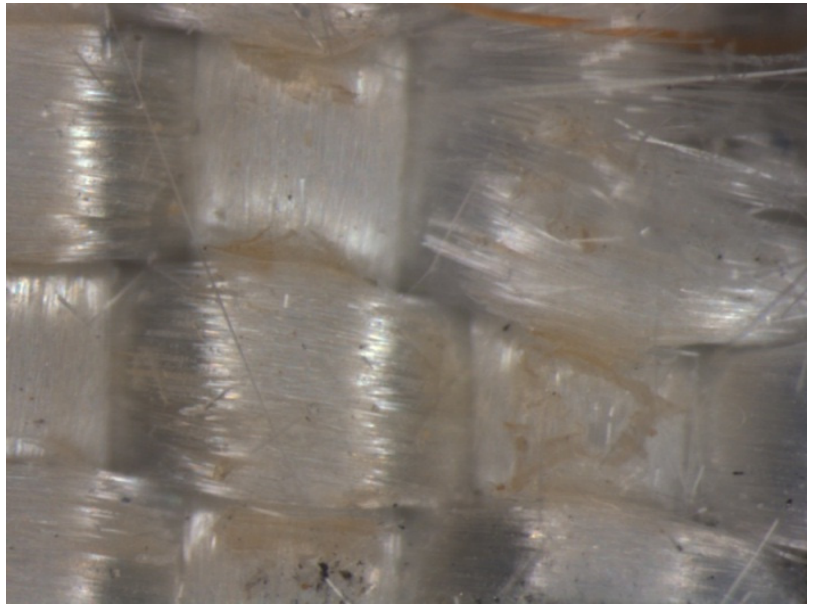

B6-2-100 


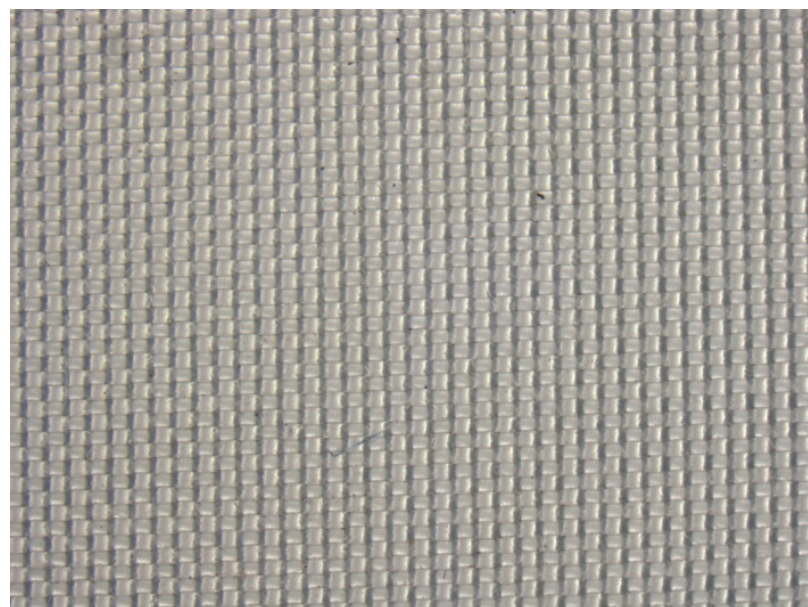

C1-1-7.1 back

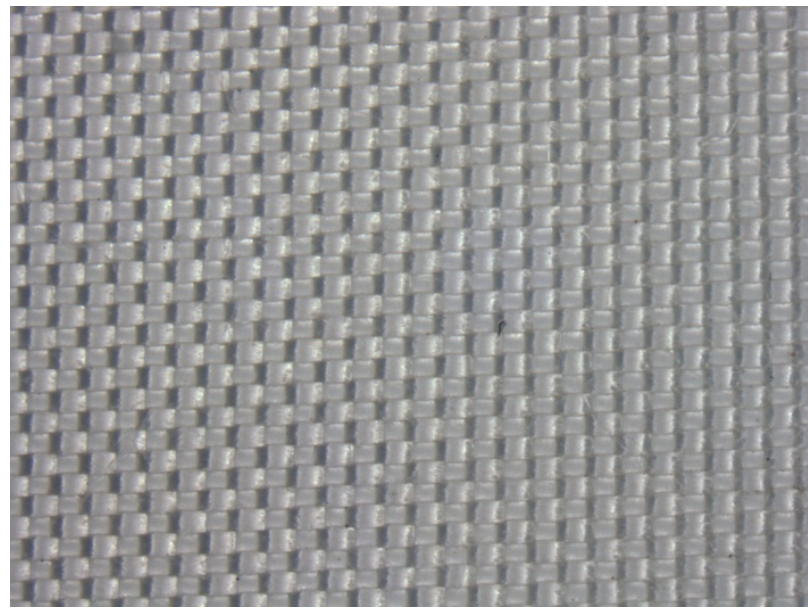

C1-1-10

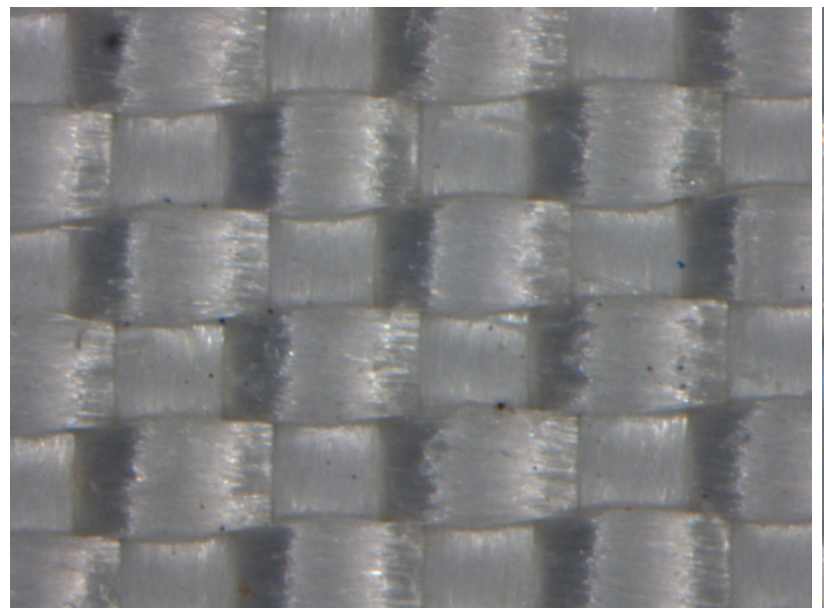

C1-1-50

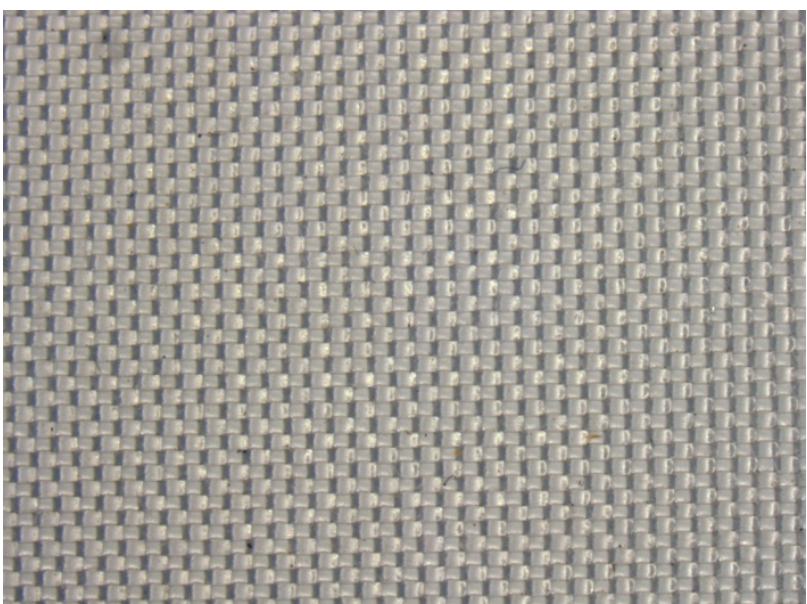

C1-1-7.1 front

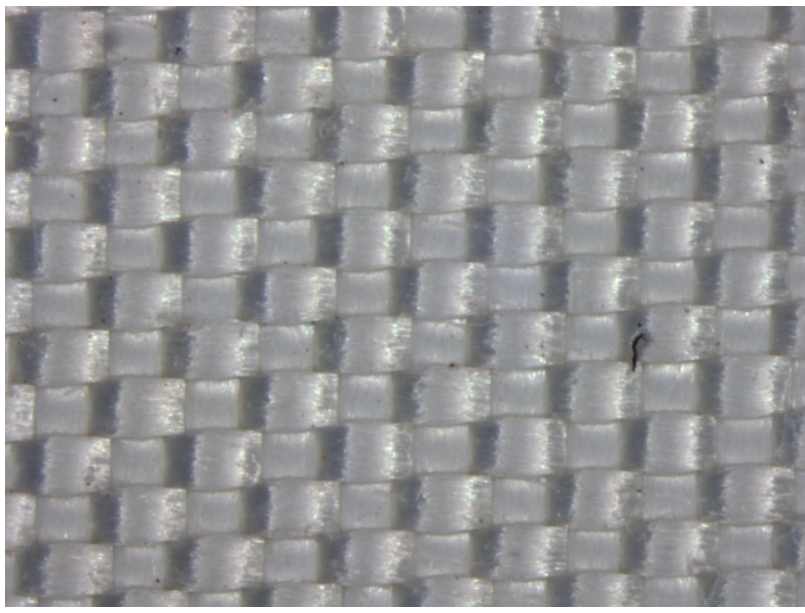

C1-1-25

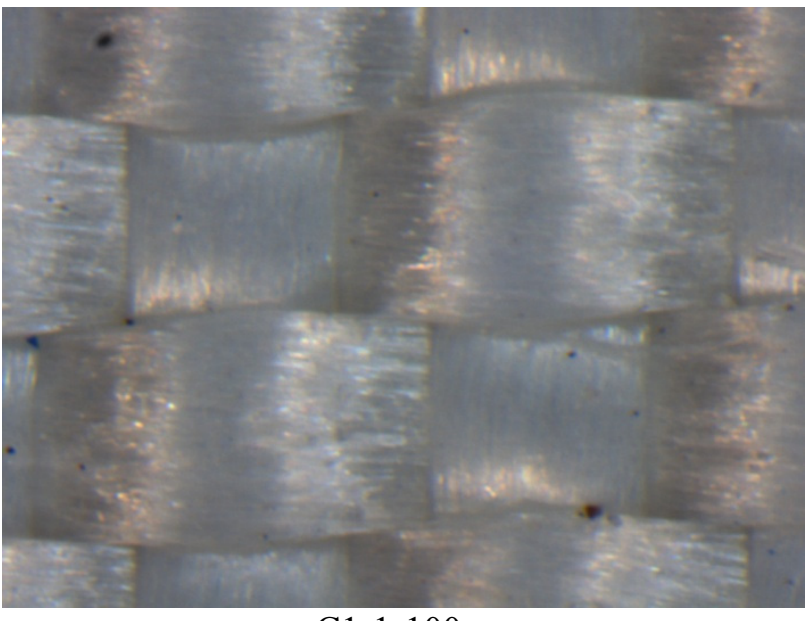

C1-1-100 

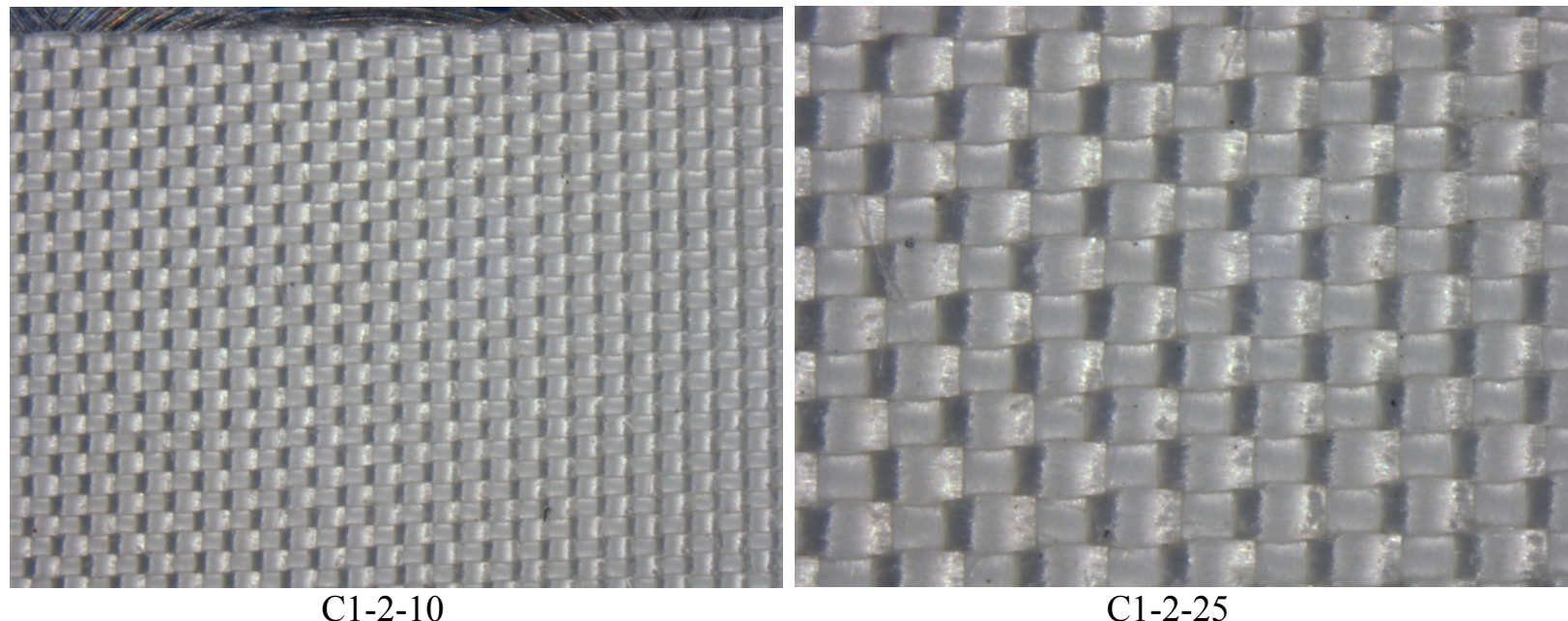

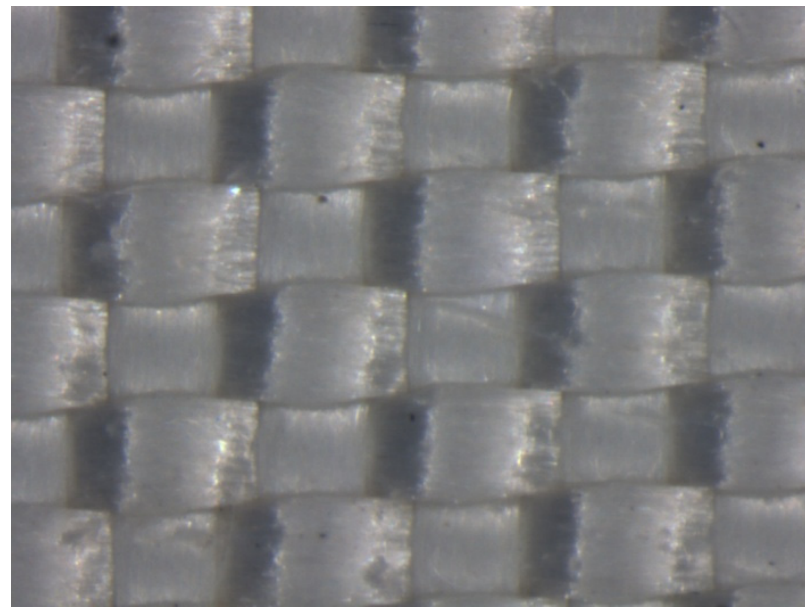

C1-2-50

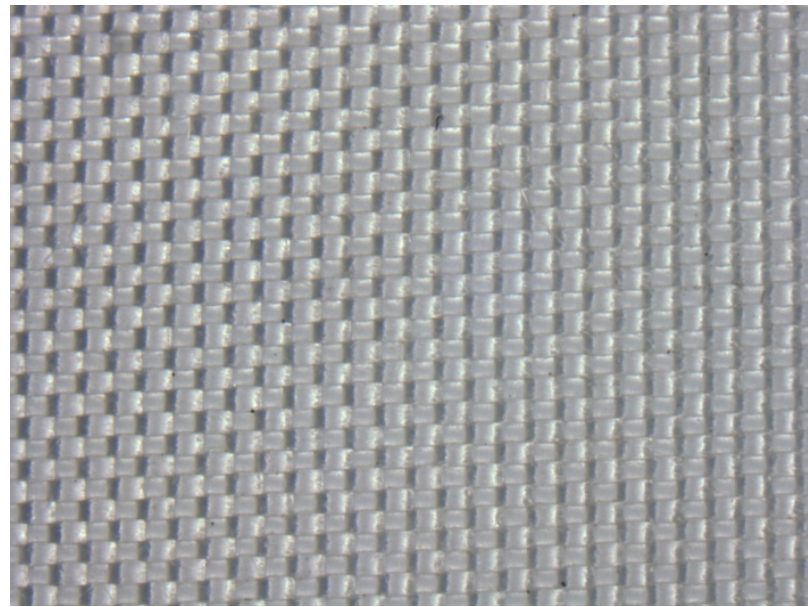

C1-3-10

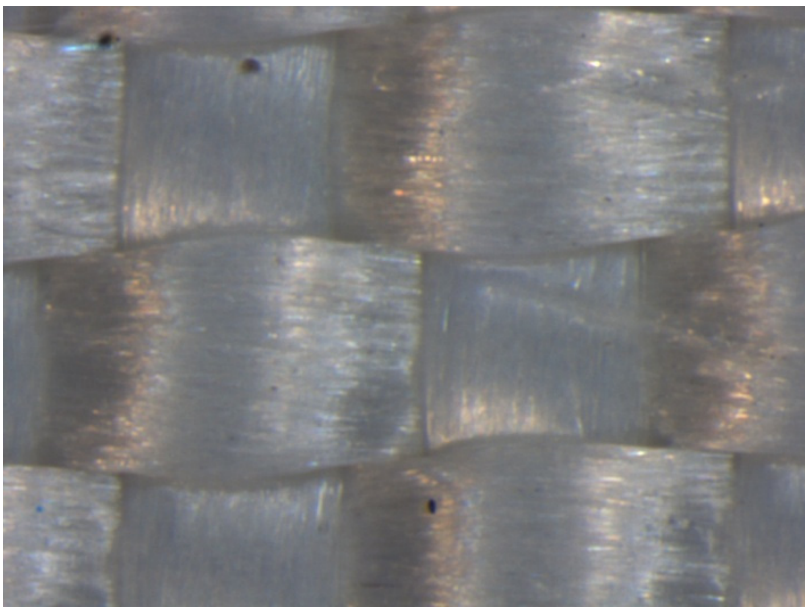

C1-2-100

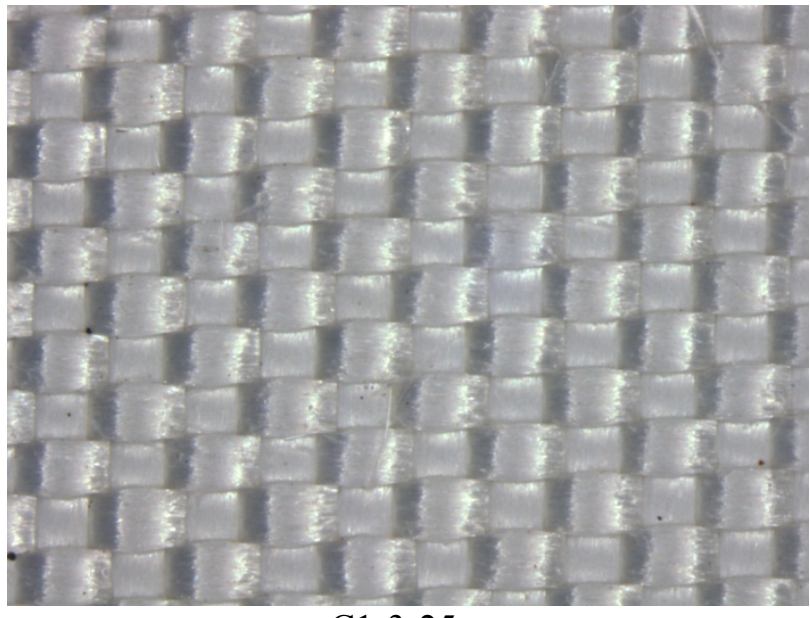

C1-3-25 


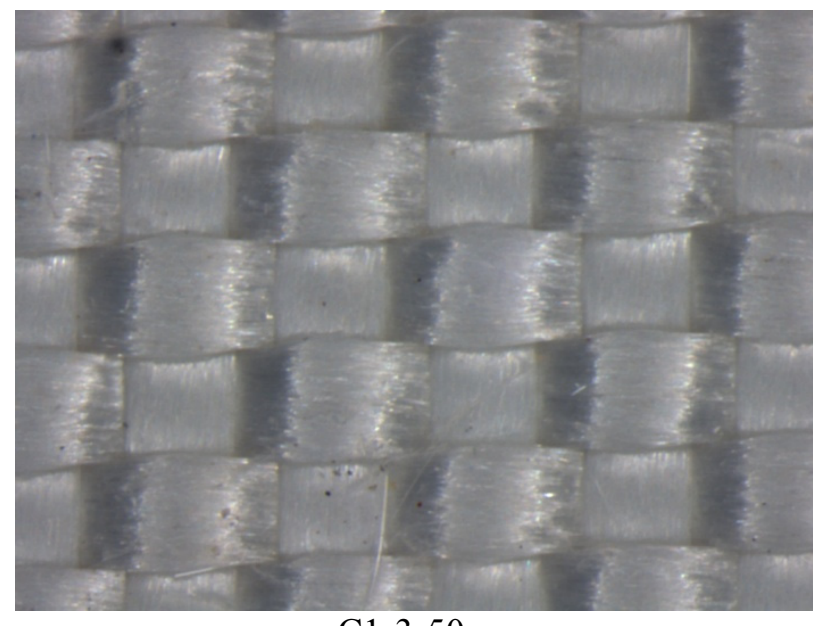

C1-3-50

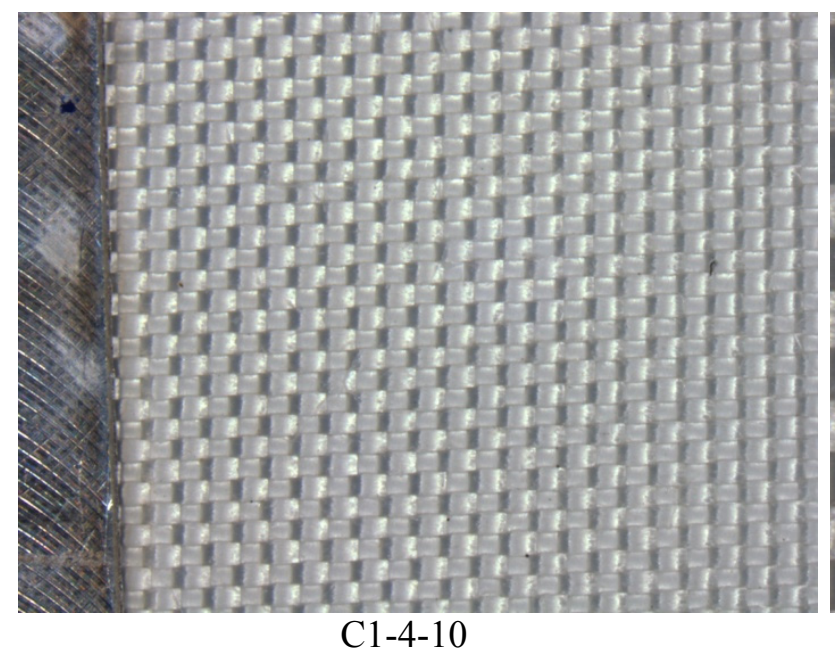

C1-4-10

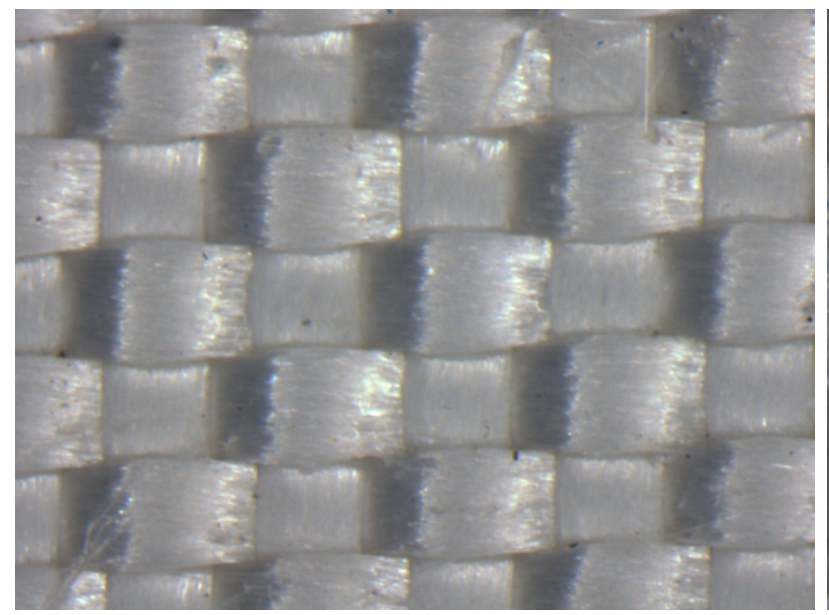

C1-4-50

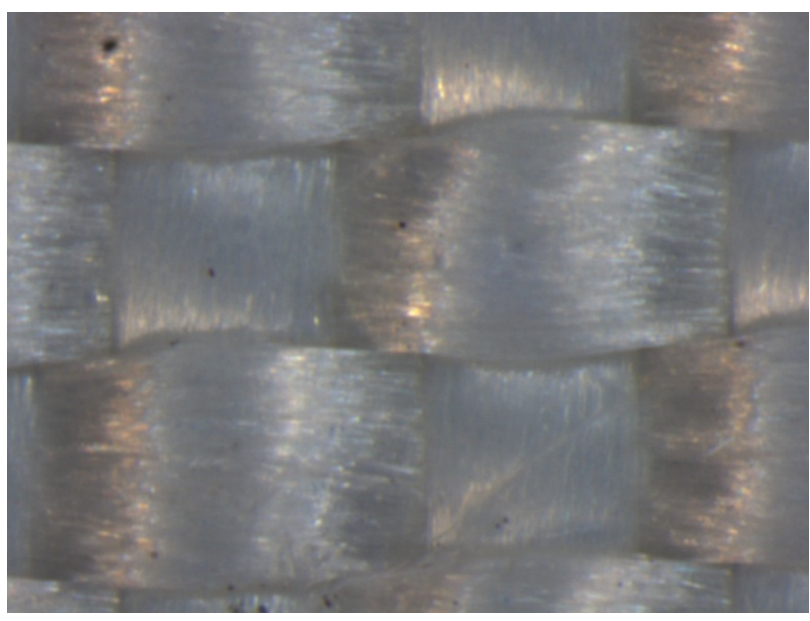

C1-3-100
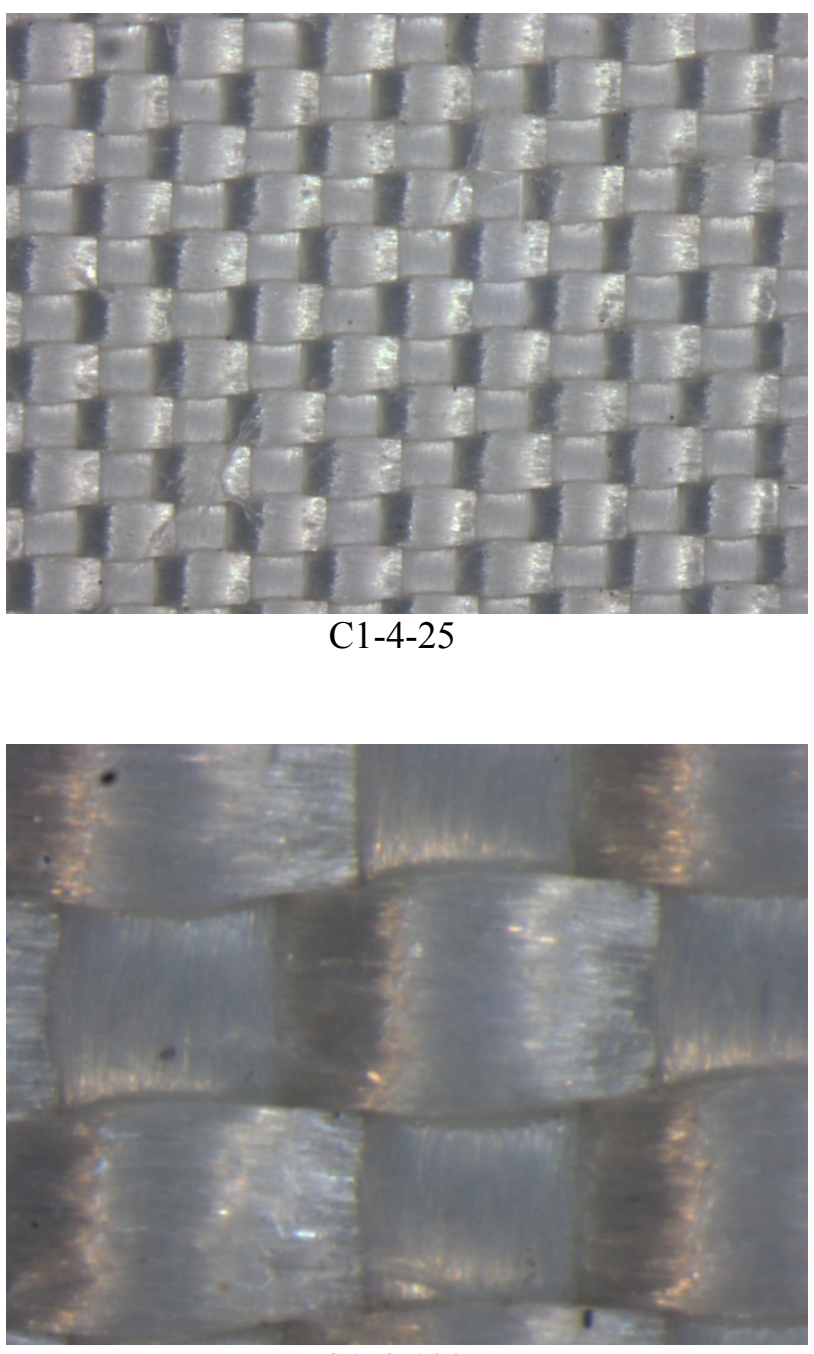

C1-4-100 


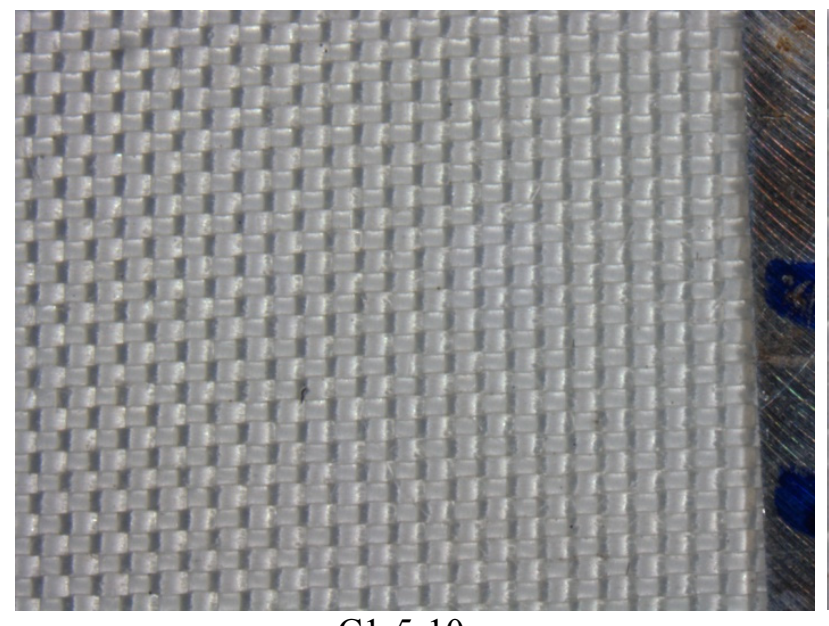

C1-5-10

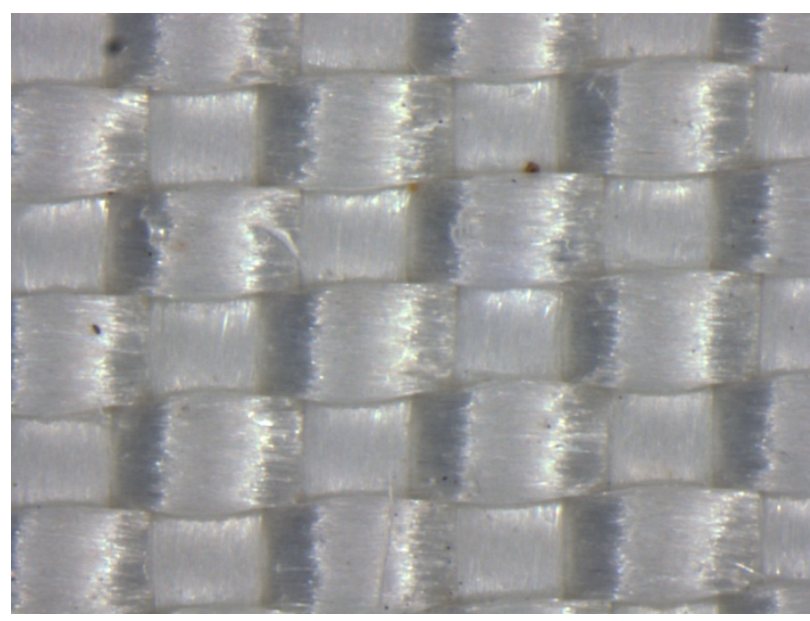

C1-5-50

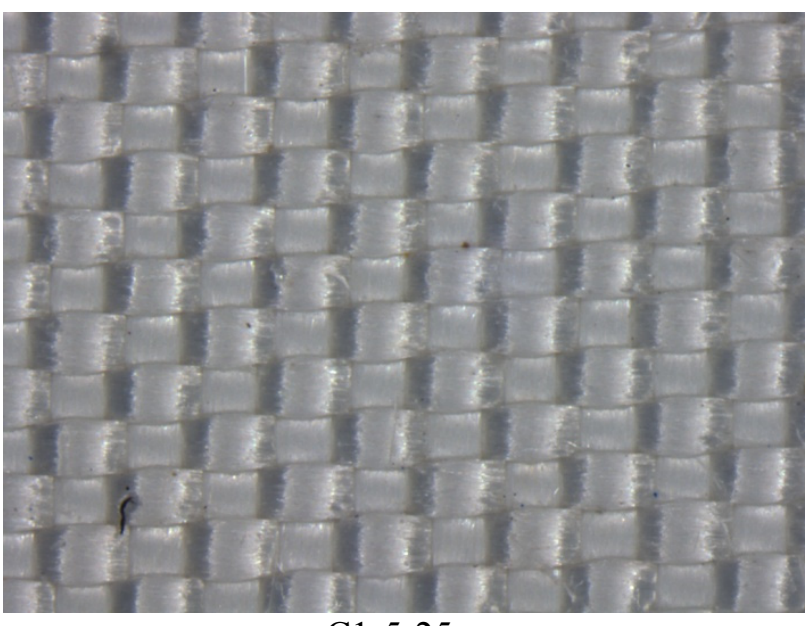

C1-5-25

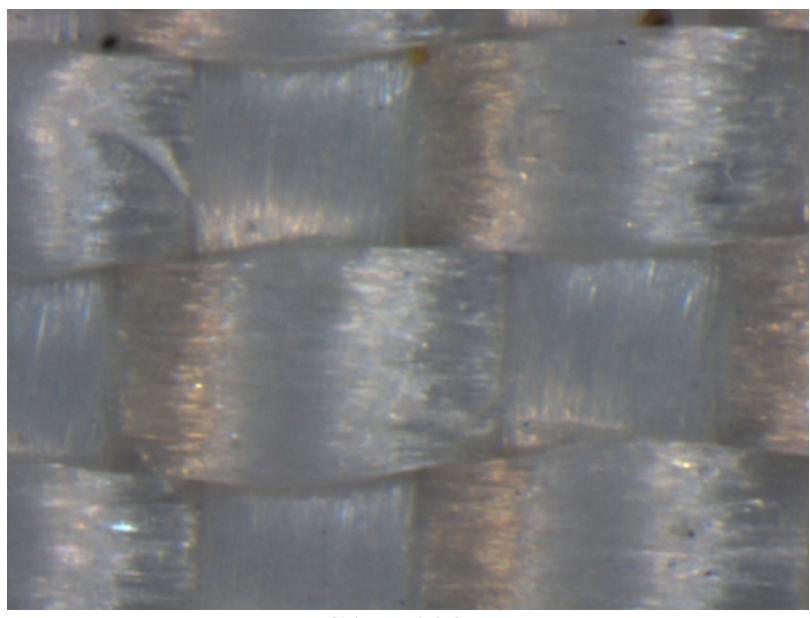

C1-5-100

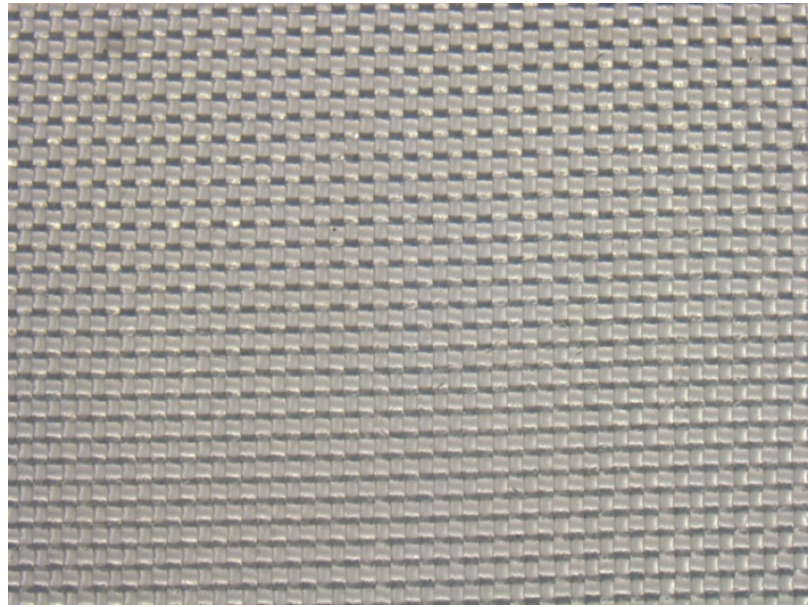

D1-1-7.1 back

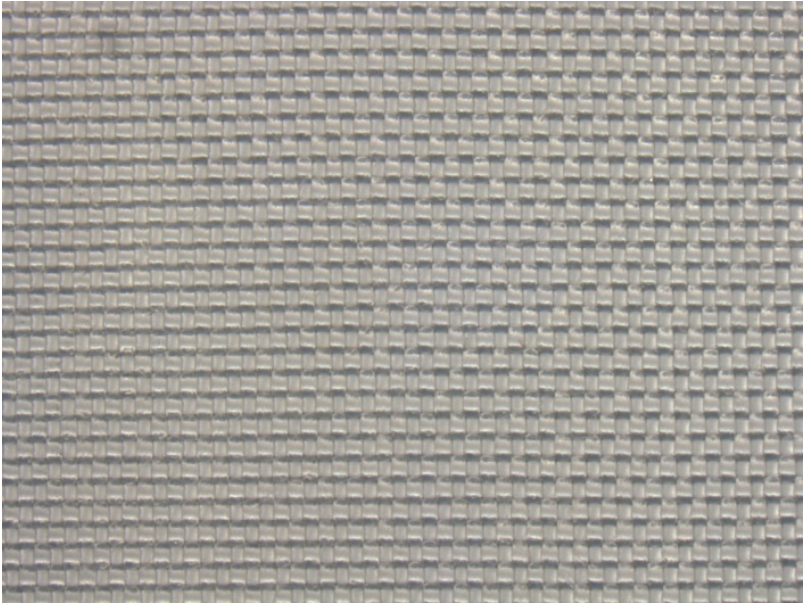

D1-1-7.1 front 


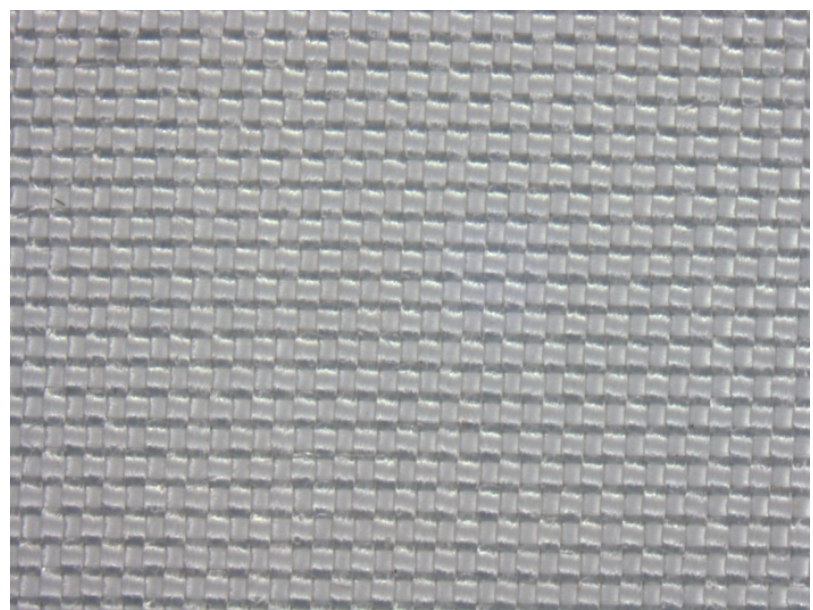

D1-1-10

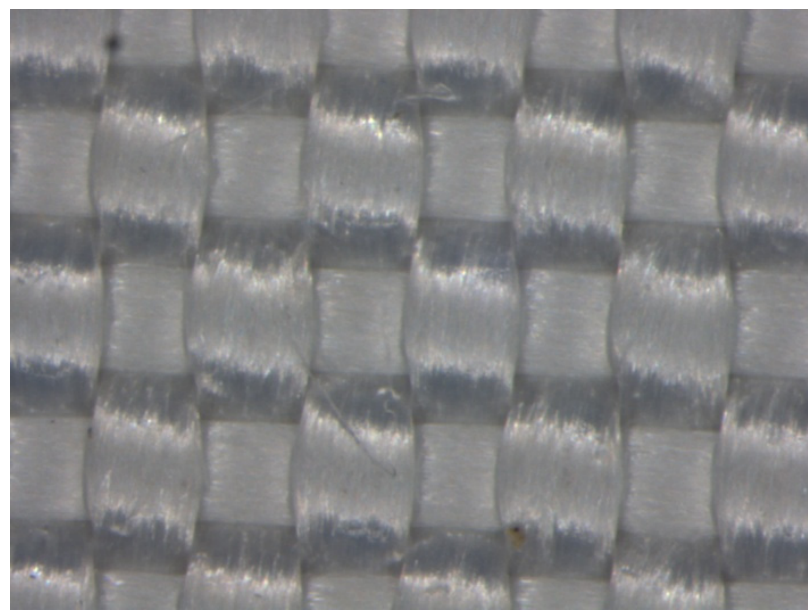

D1-1-50

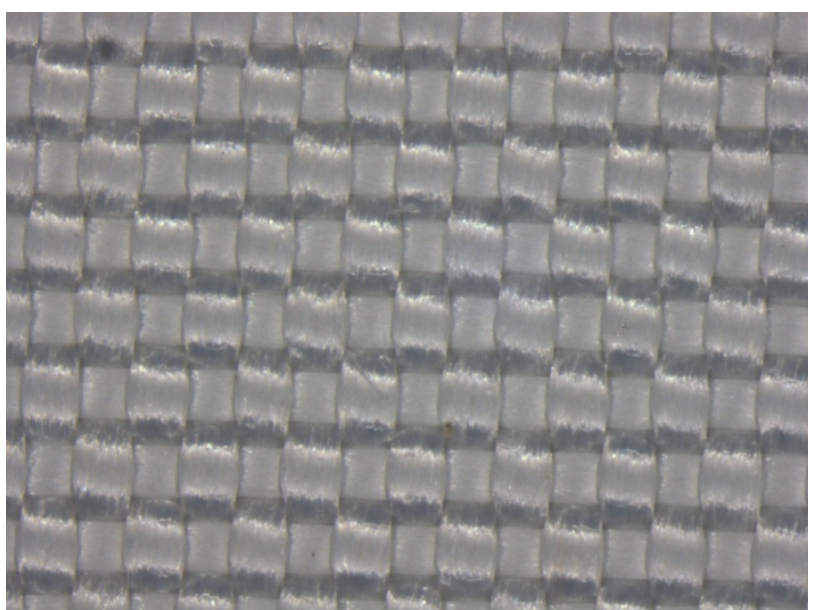

D1-1-25

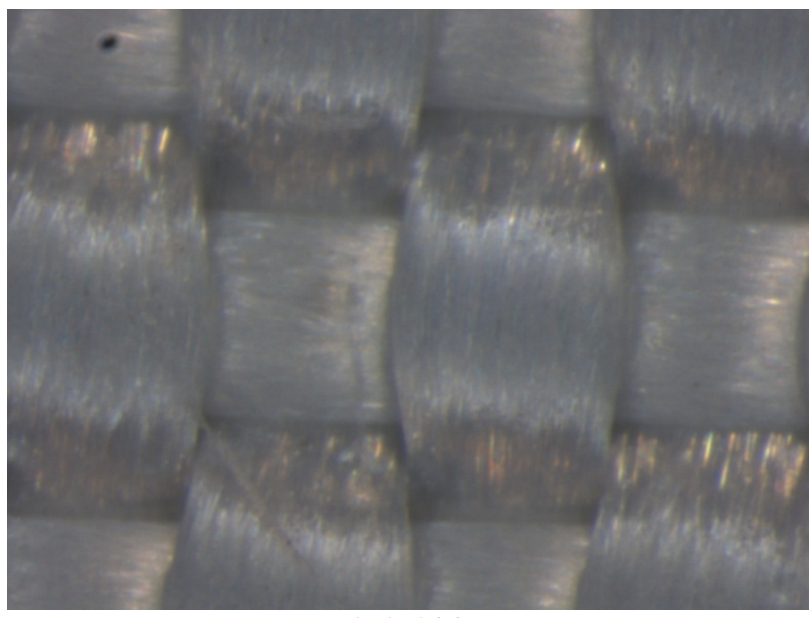

D1-1-100

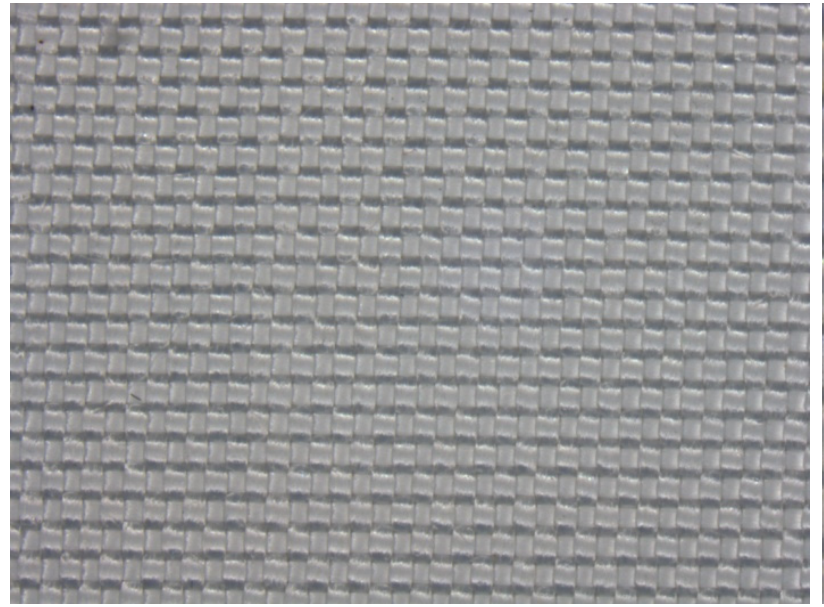

D1-2-10

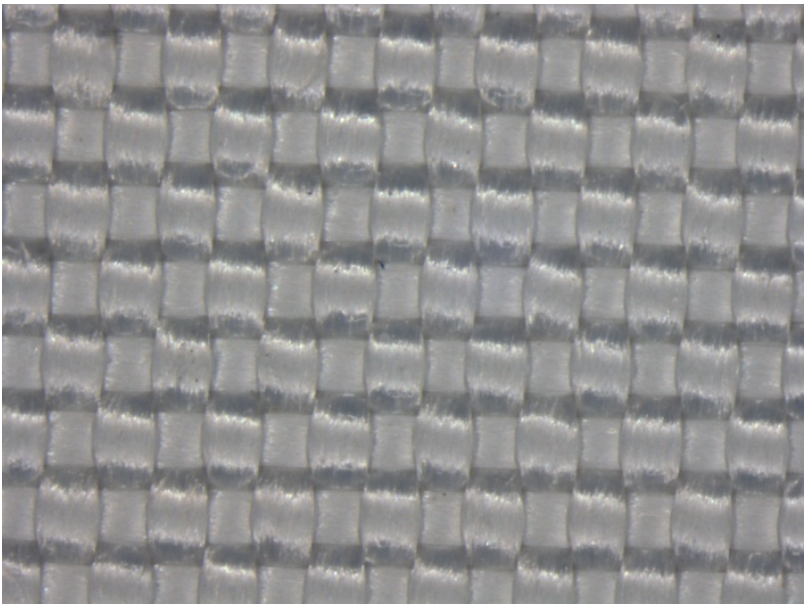

D1-2-25 


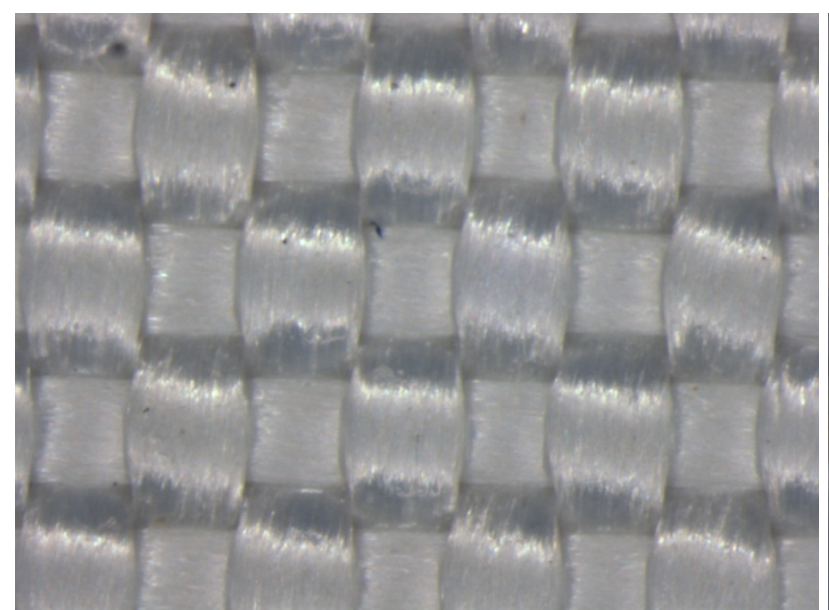

D1-2-50

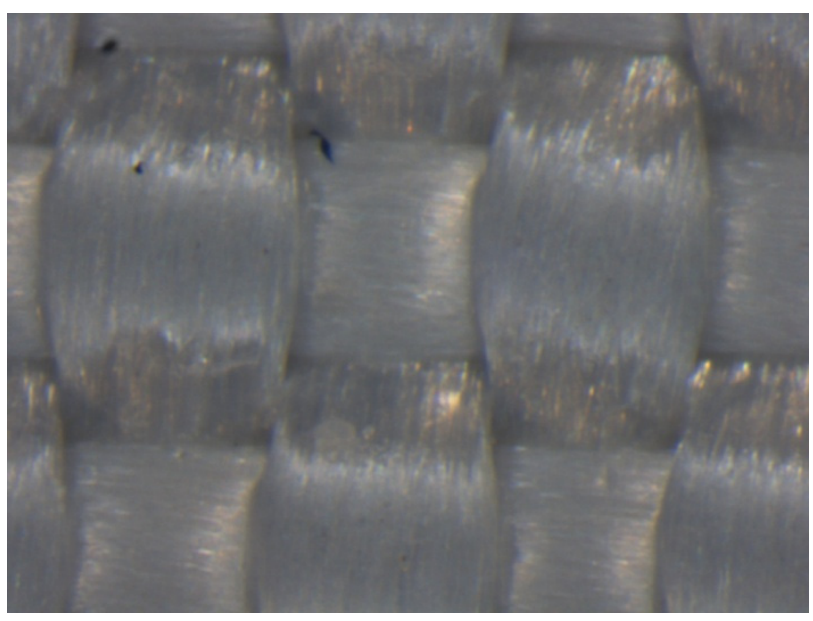

D1-2-100

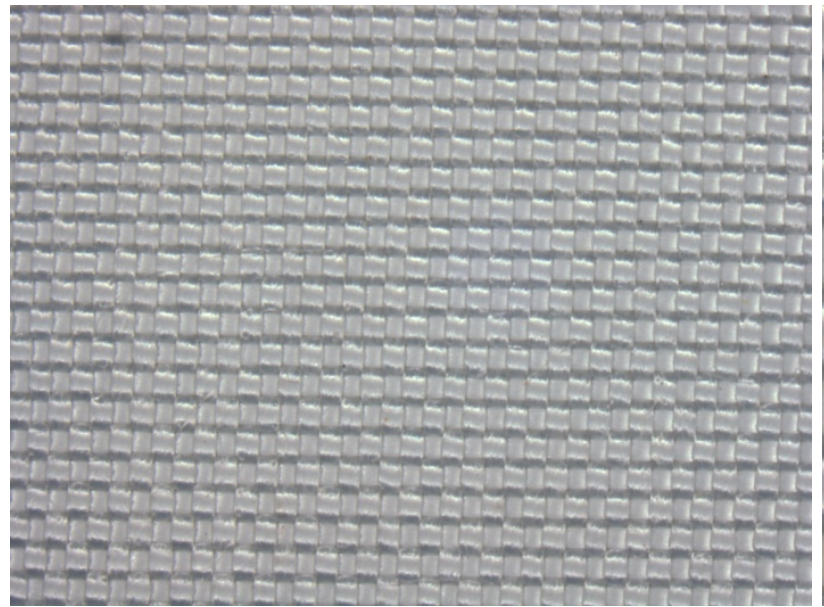

D1-3-10

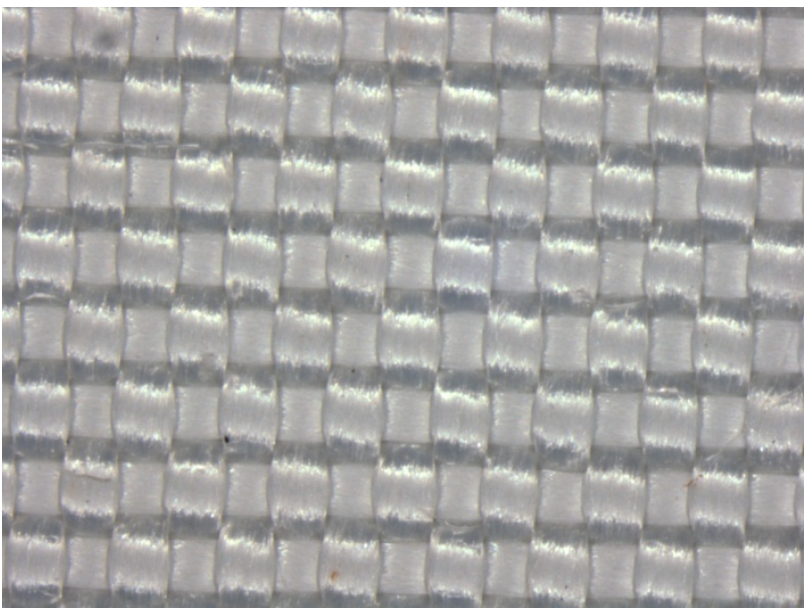

D1-3-25

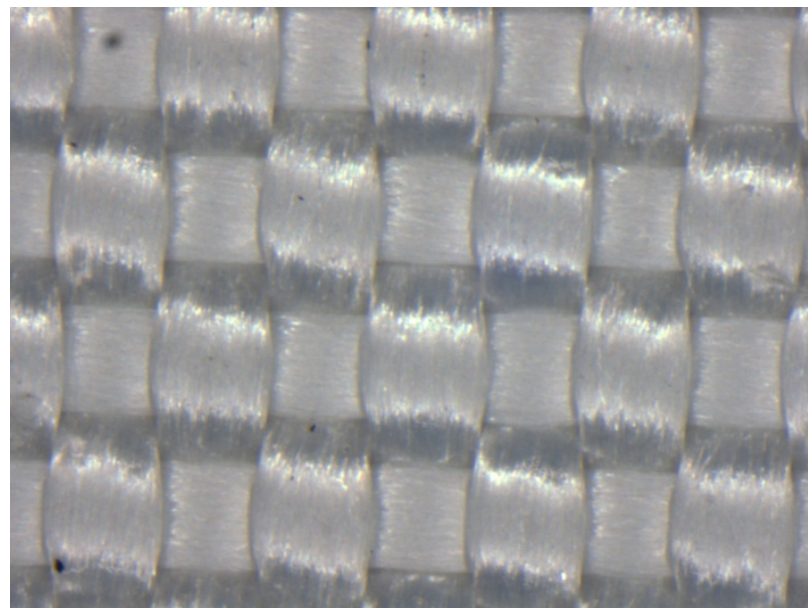

D1-3-50

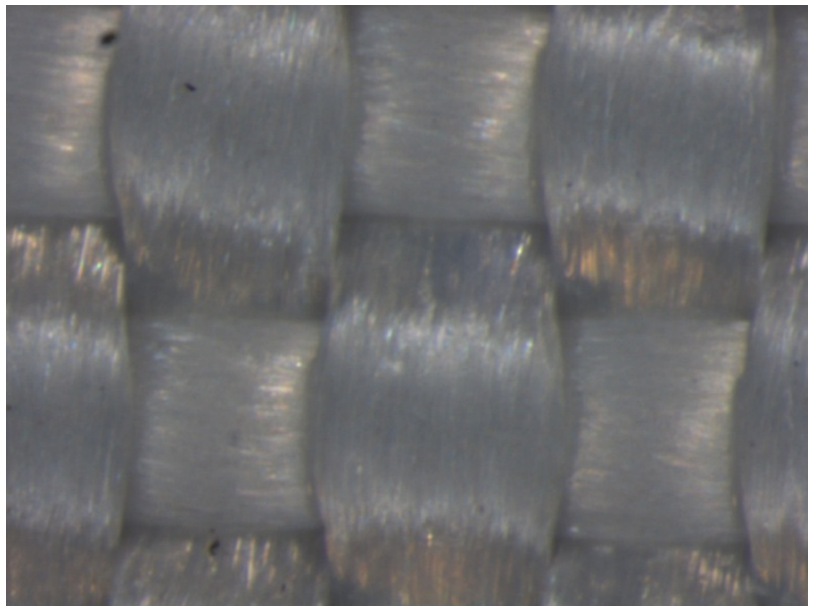

D1-3-100 


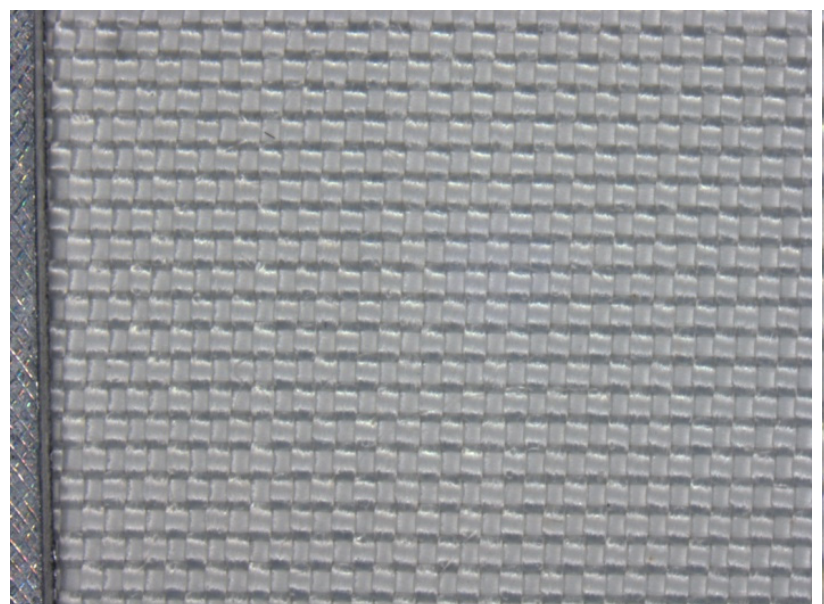

D1-4-10

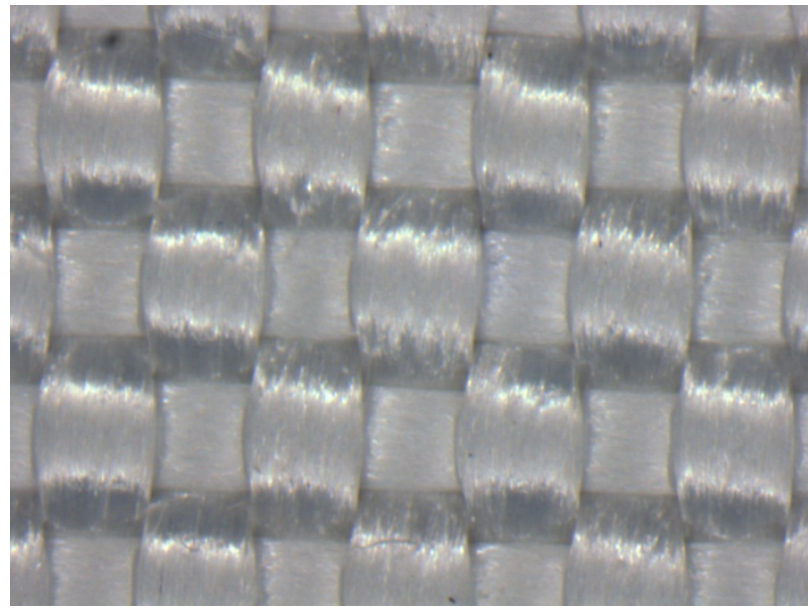

D1-4-50

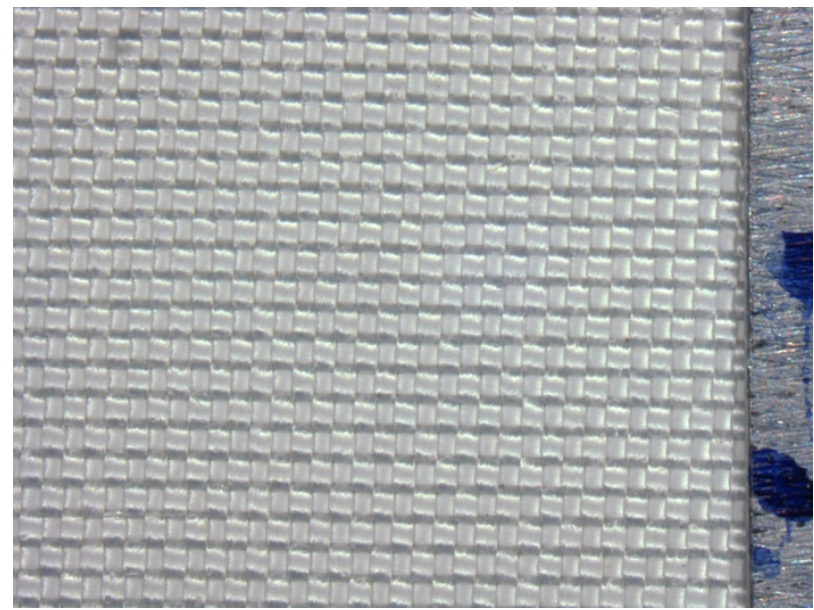

D1-5-10

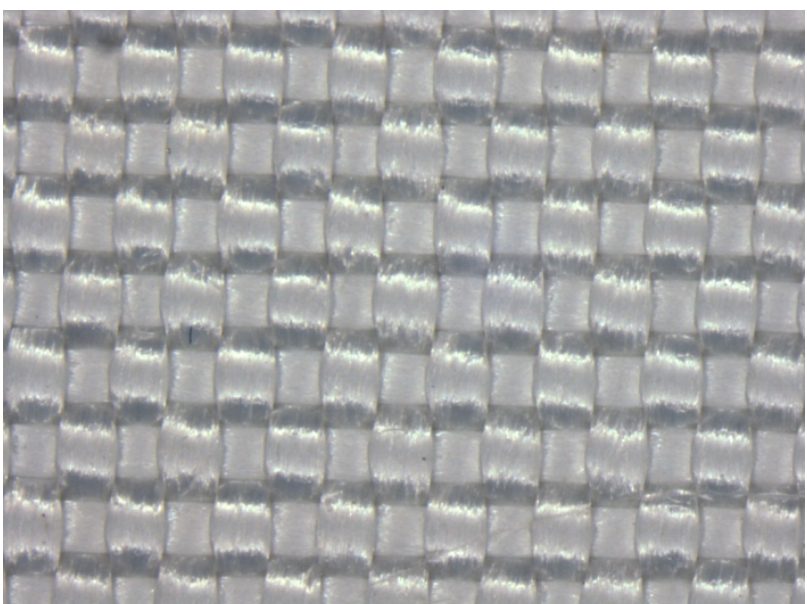

D1-4-25

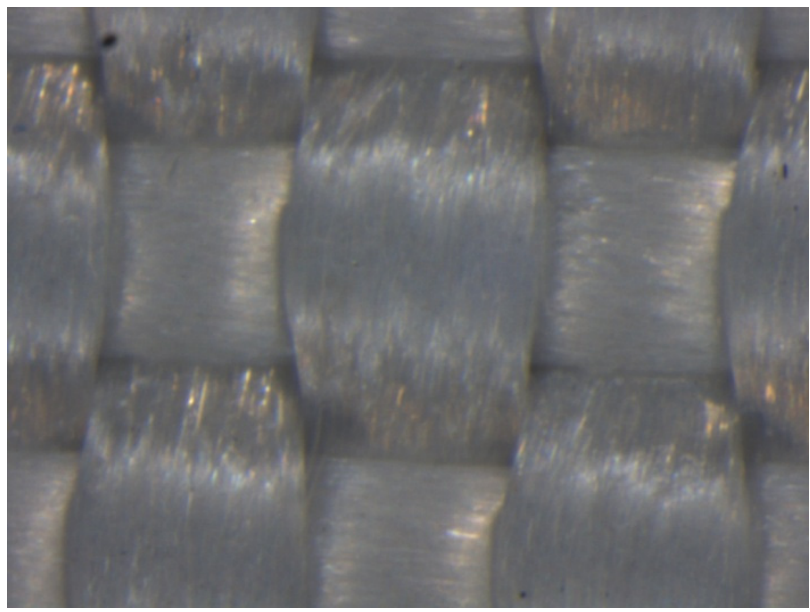

D1-4-100

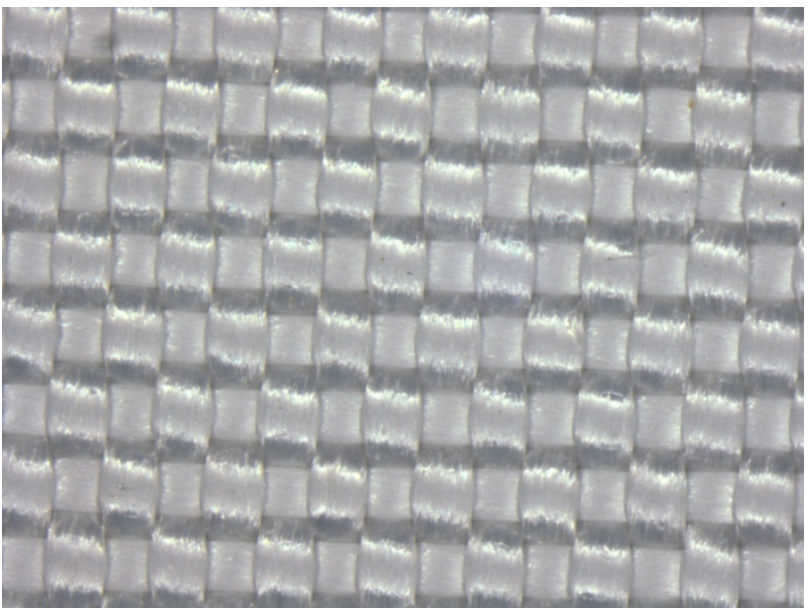

D1-5-25 


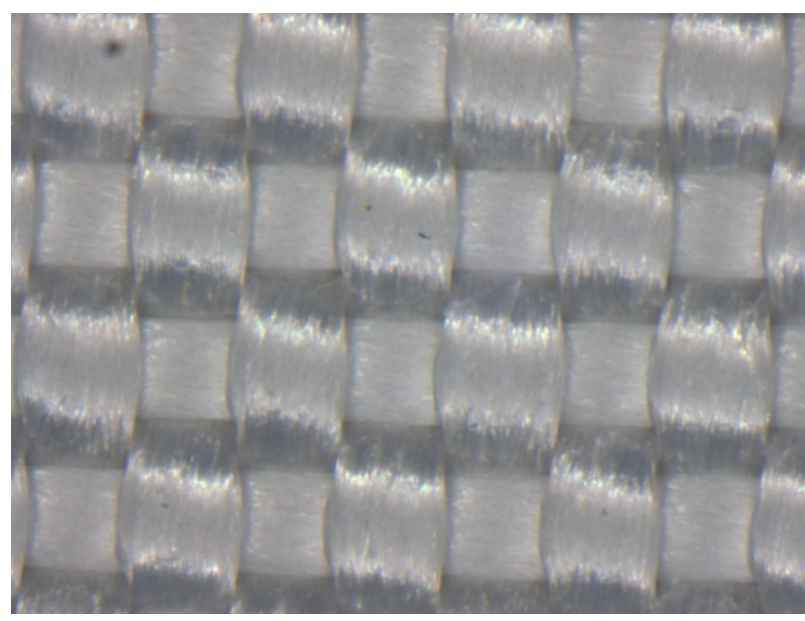

D1-5-50

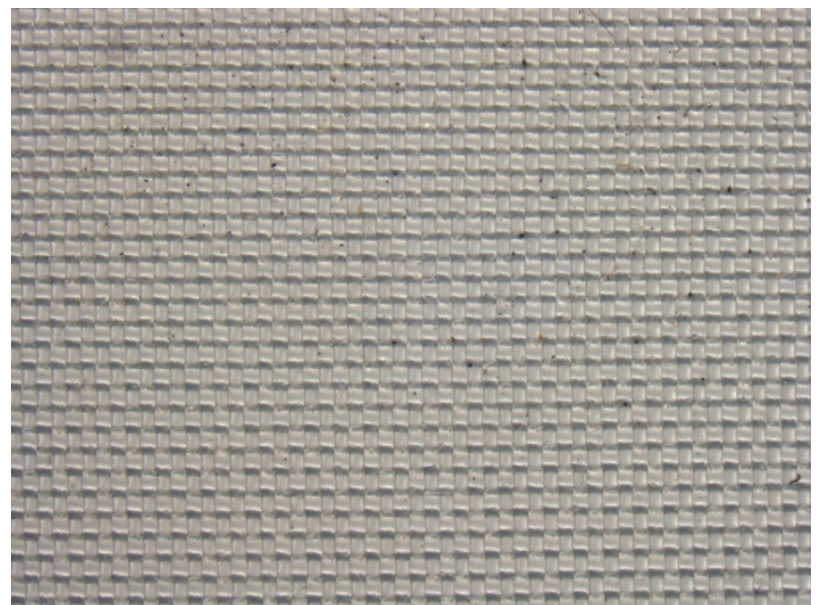

E1-1-7.1 back

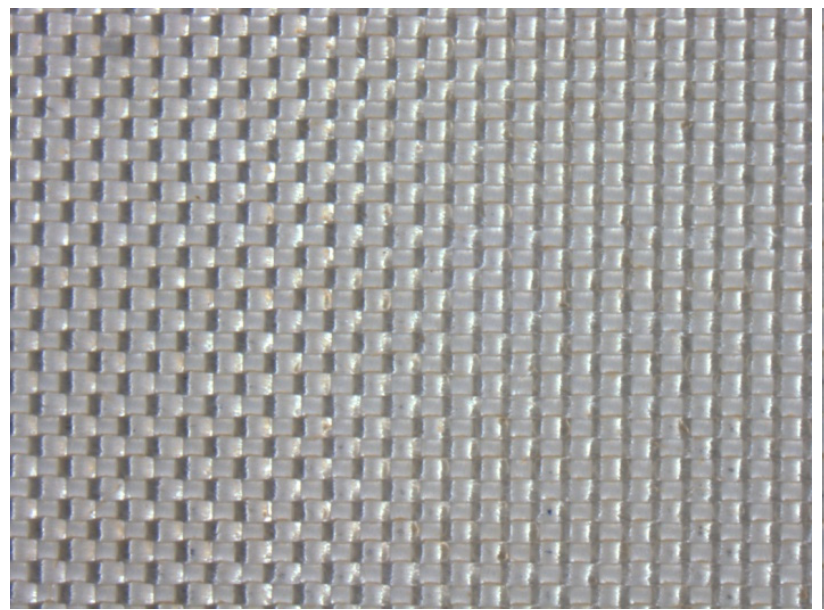

E1-1-10

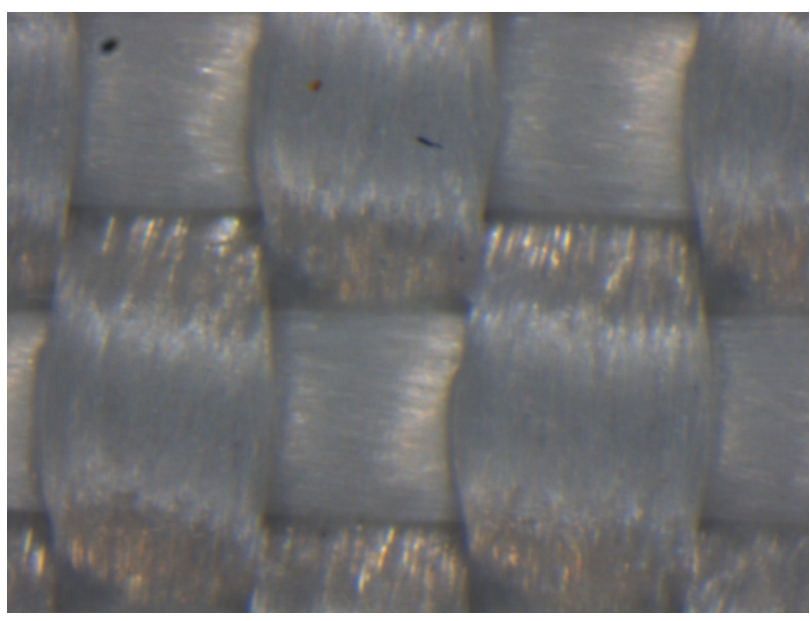

D1-5-100

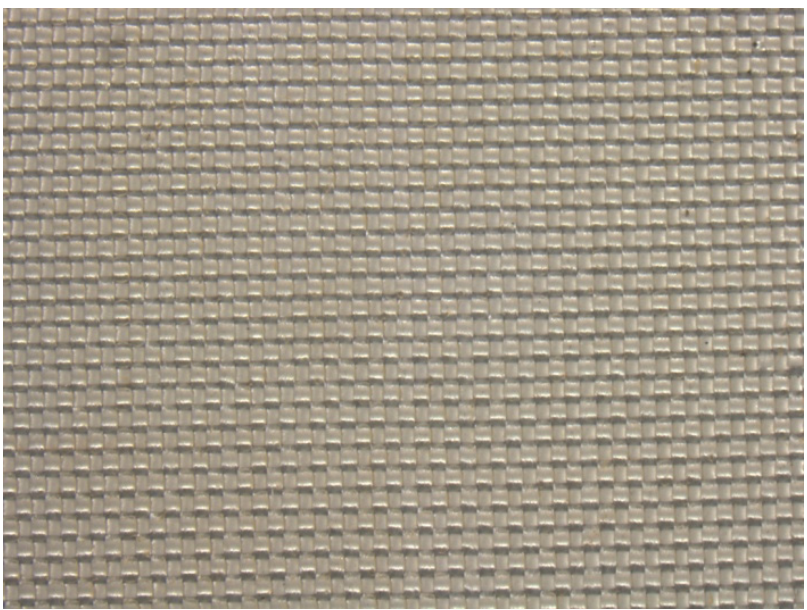

E1-1-7.1 front

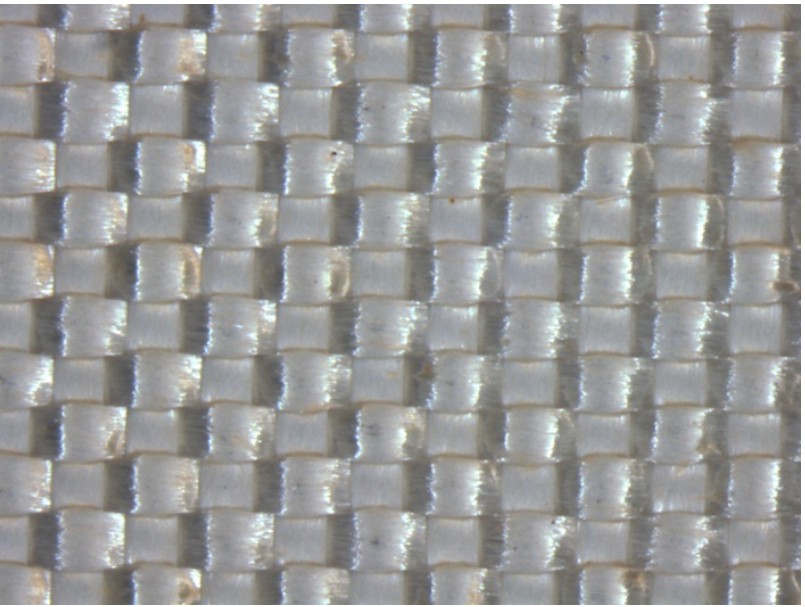

E1-1-25 


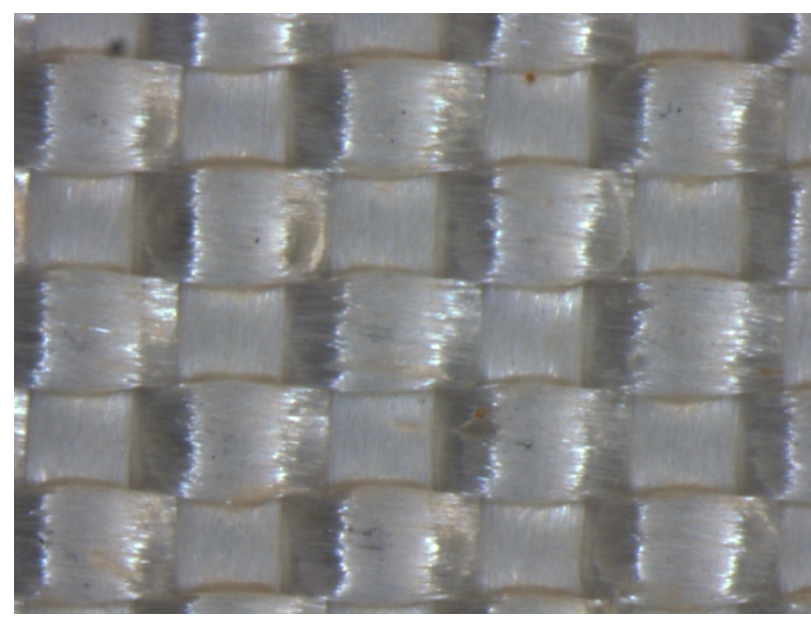

E1-1-50

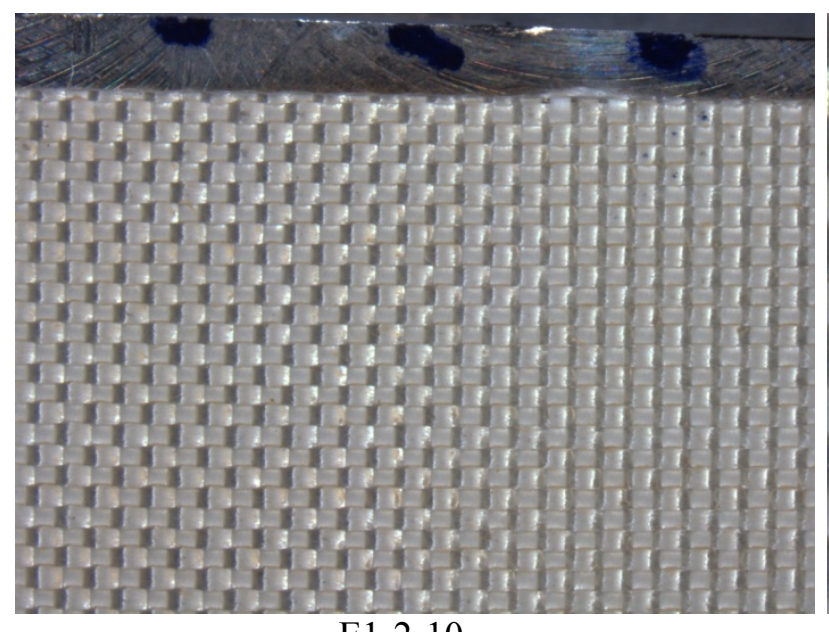

E1-2-10

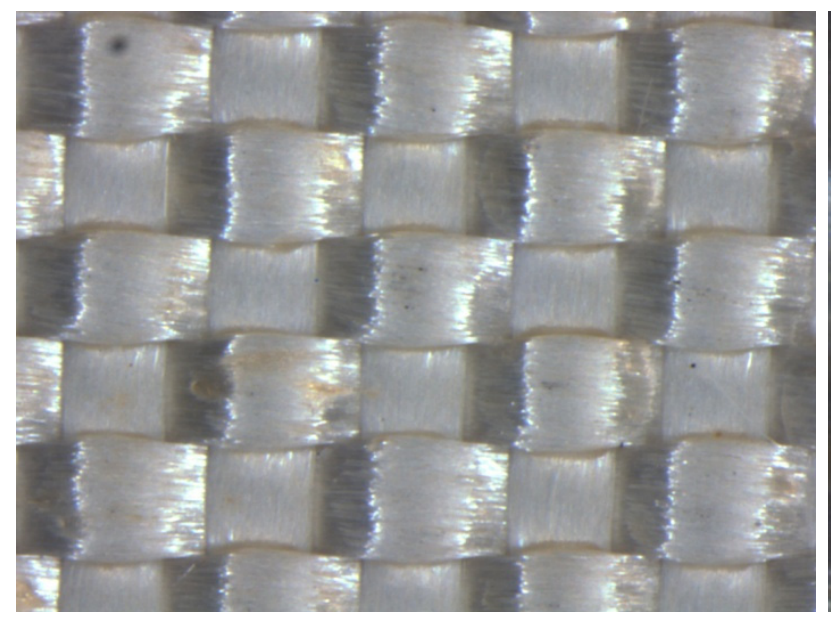

E1-2-50

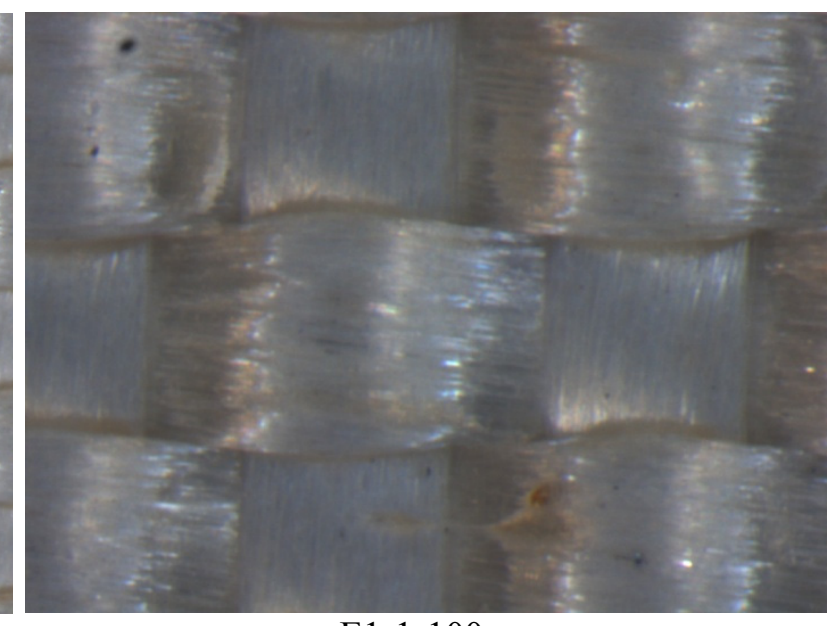

E1-1-100

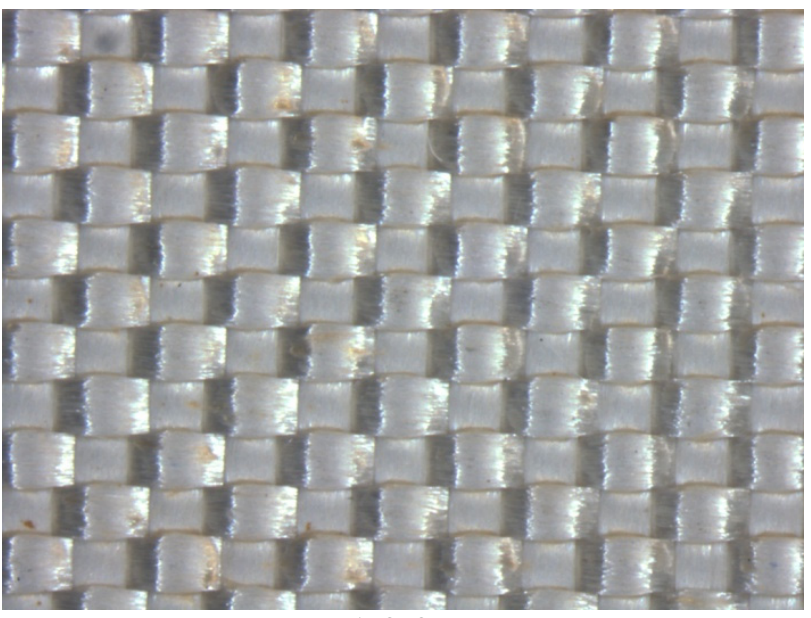

E1-2-25

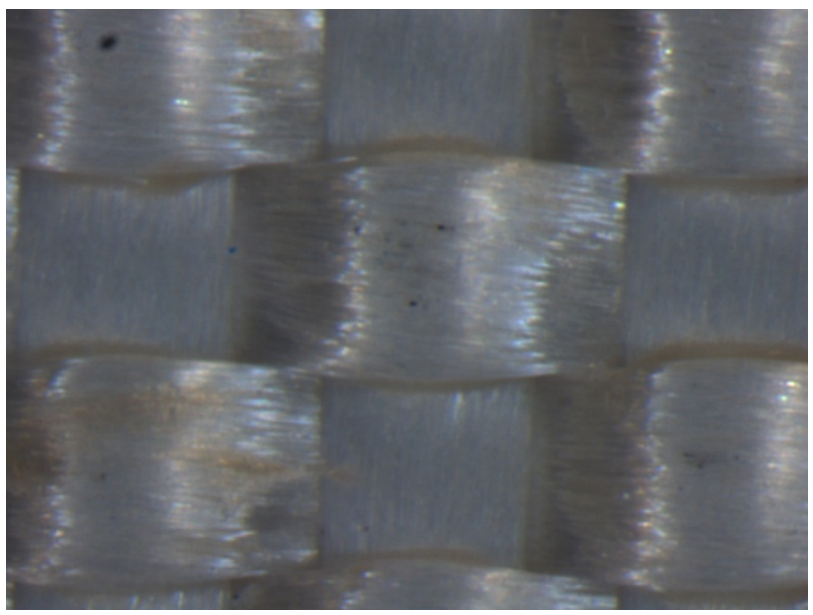

E1-2-100 


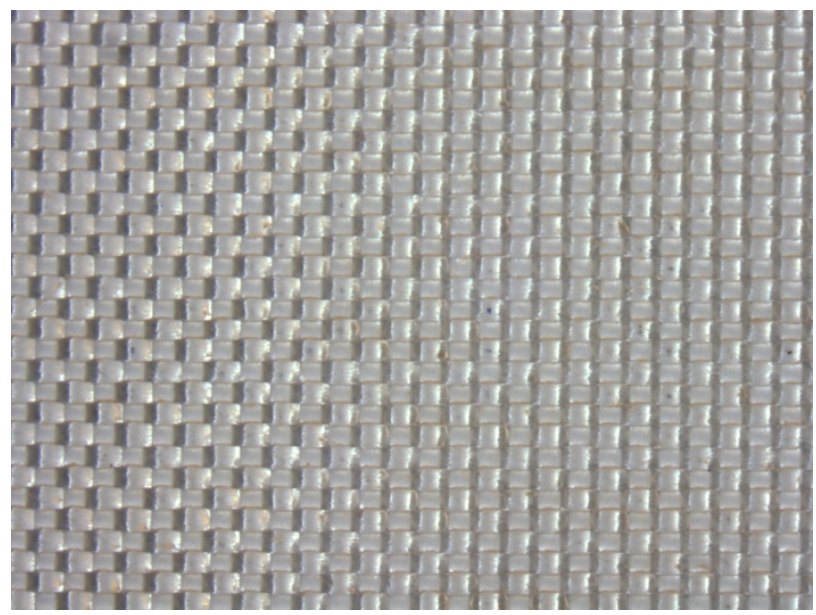

E1-3-10

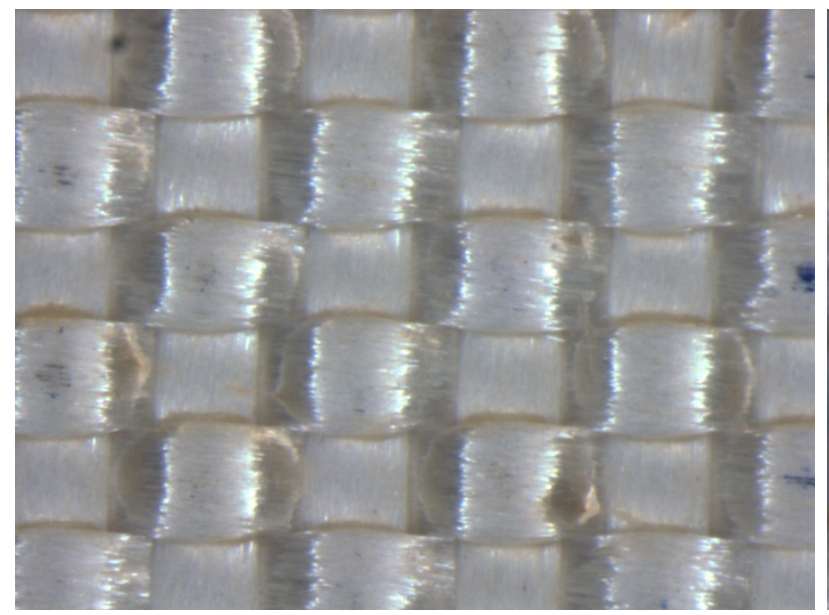

E1-3-50

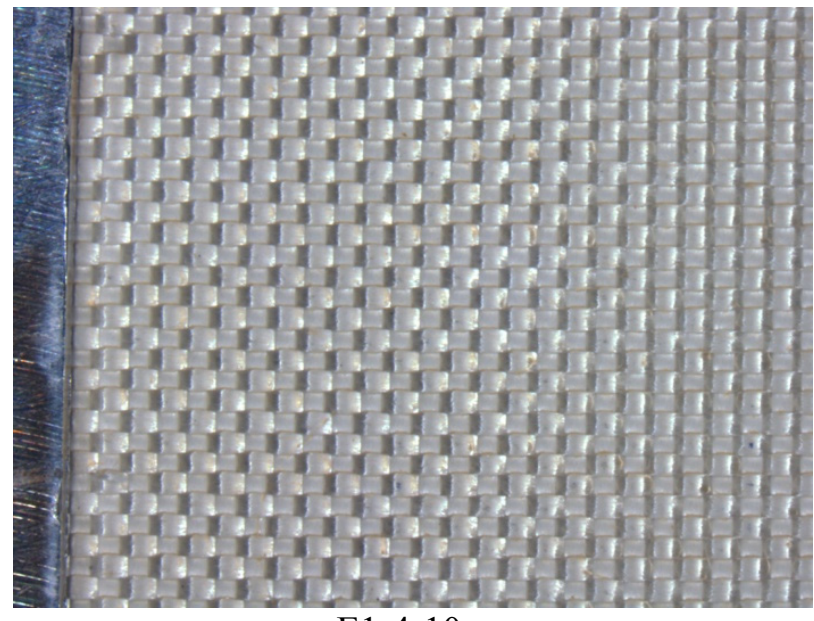

E1-4-10
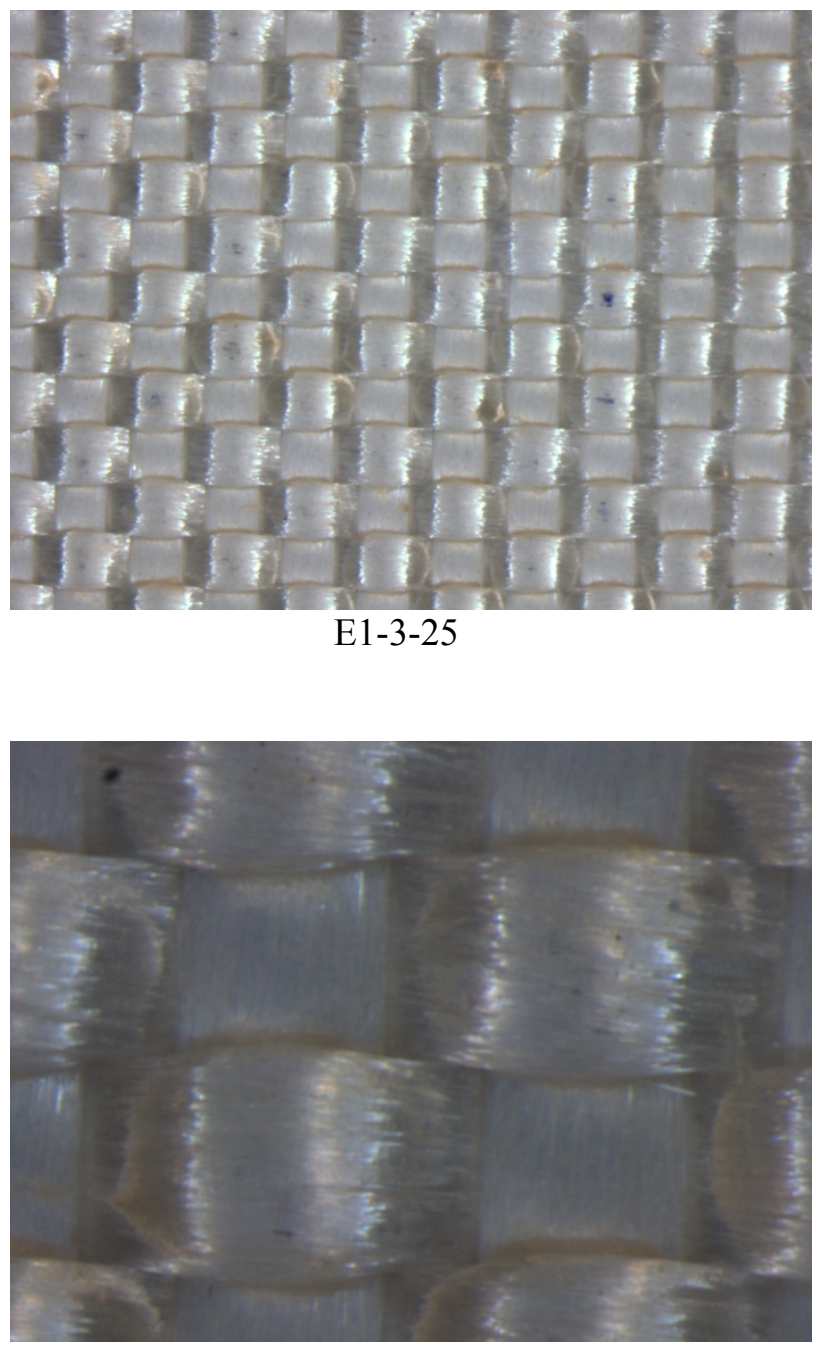

E1-3-100

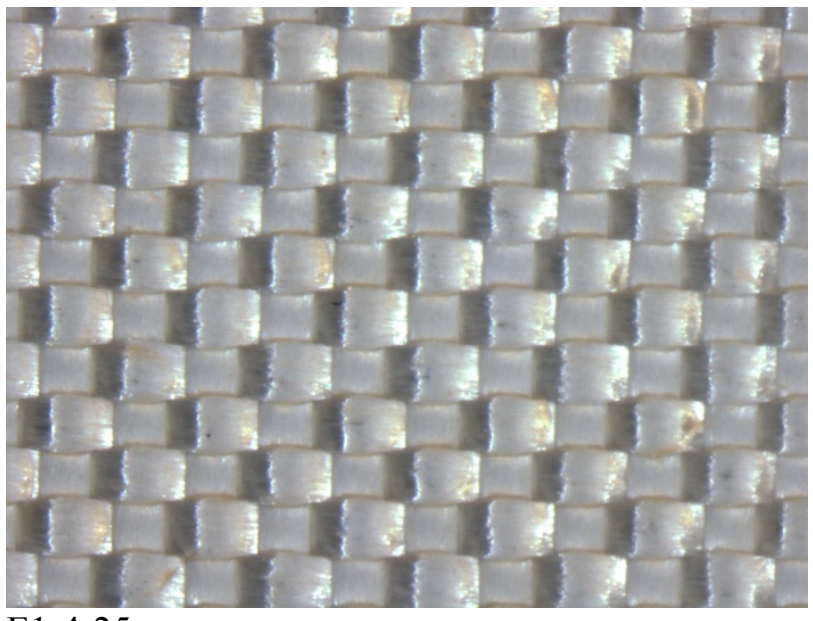

E1-4-25 


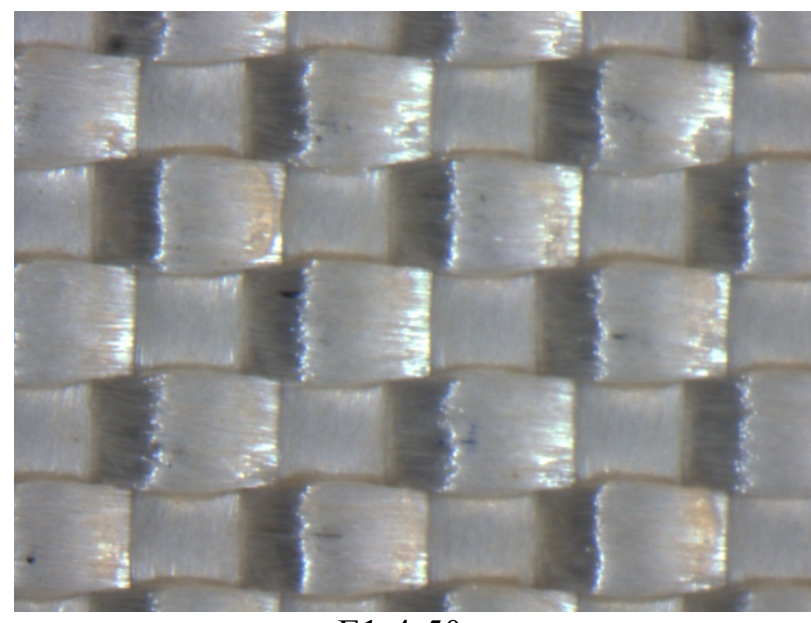

E1-4-50

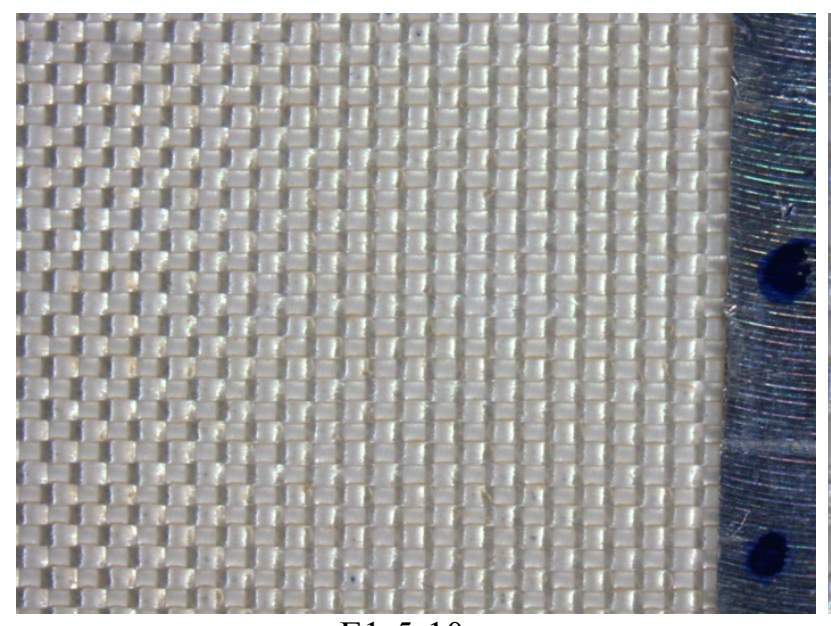

E1-5-10

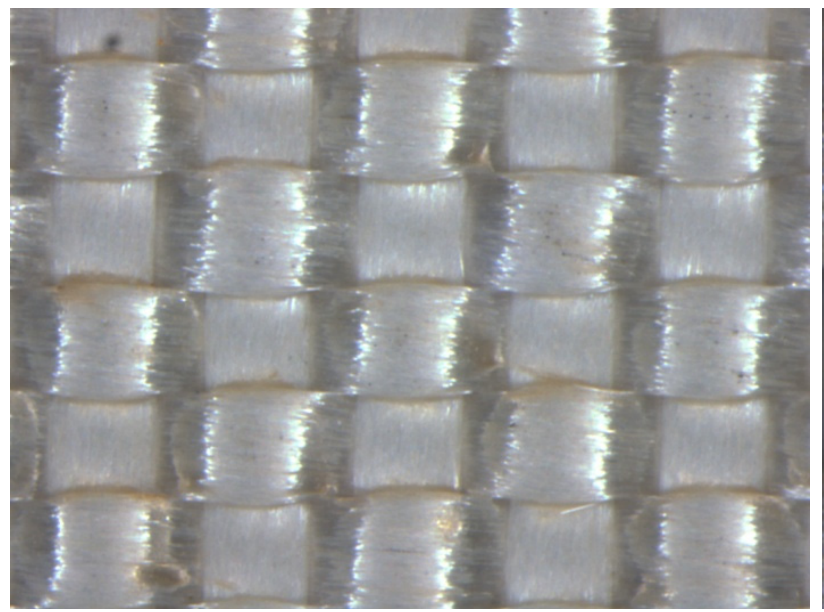

E1-5-50

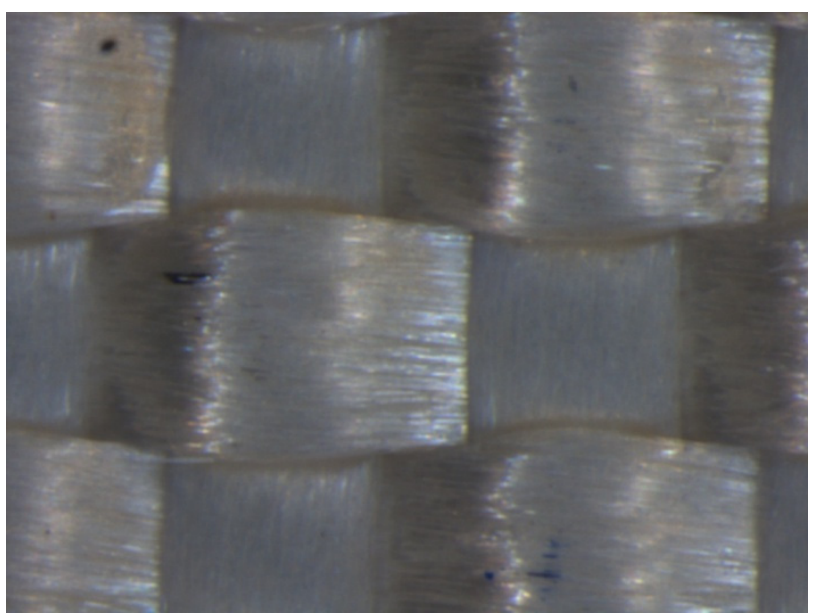

E1-4-100

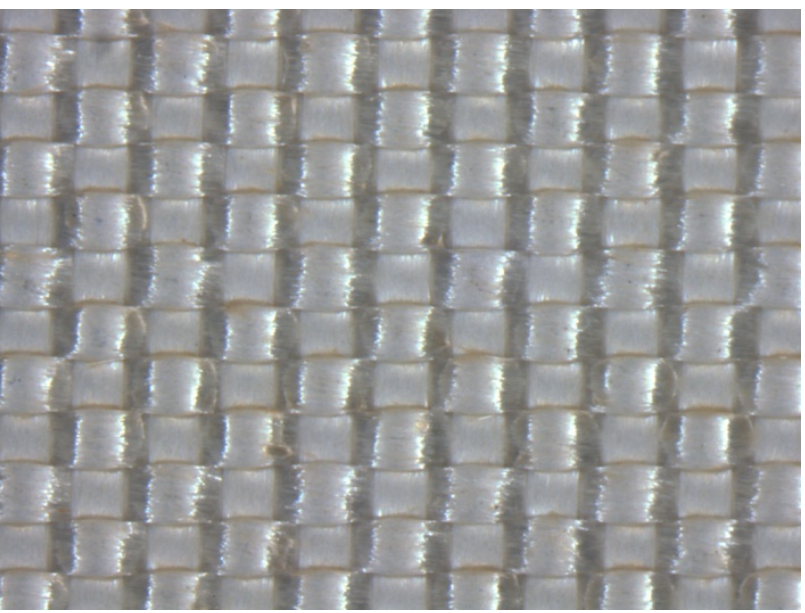

E1-5-25

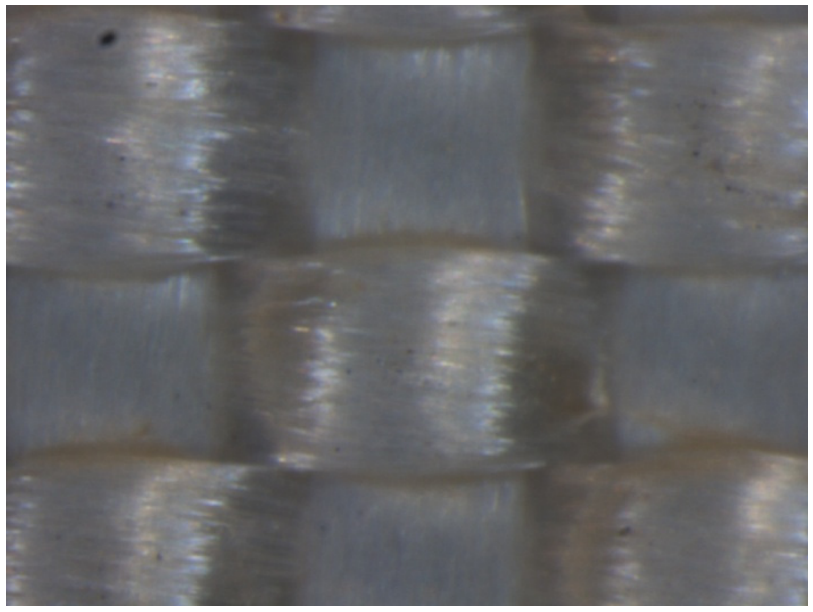

E1-5-100 



\section{Appendix B-Field Emission Scanning Electron Photomicrographs}

Nomenclature for the photographs shown in this appendix uses the following convention. Samples taken from the five sides as defined in the text and Figures 4 and 5 are labeled A, B, C, D, and E. The number following the letter describes the sample number for that side. If the sample was gold coated, the number is followed by a G. Within a sample, the center of the photograph corresponds to the map shown to the right. Last, the magnification of the photograph is recorded. For example the photo A1G-1-500 was taken at a magnification of $500 \times$ of the center of the gold coated first sample taken from side A.

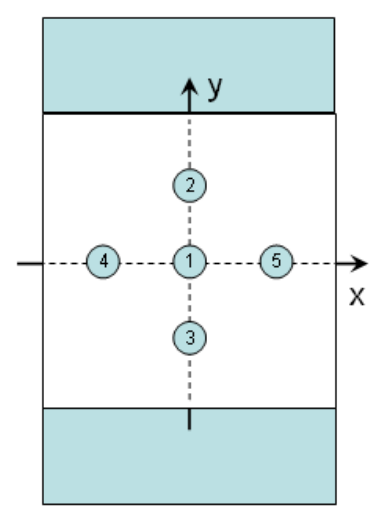

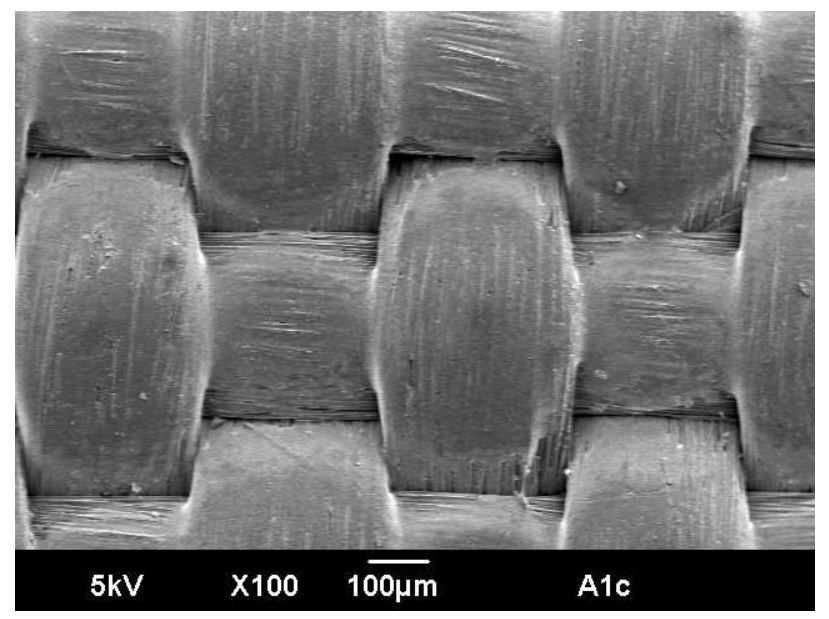

A1G-1-100

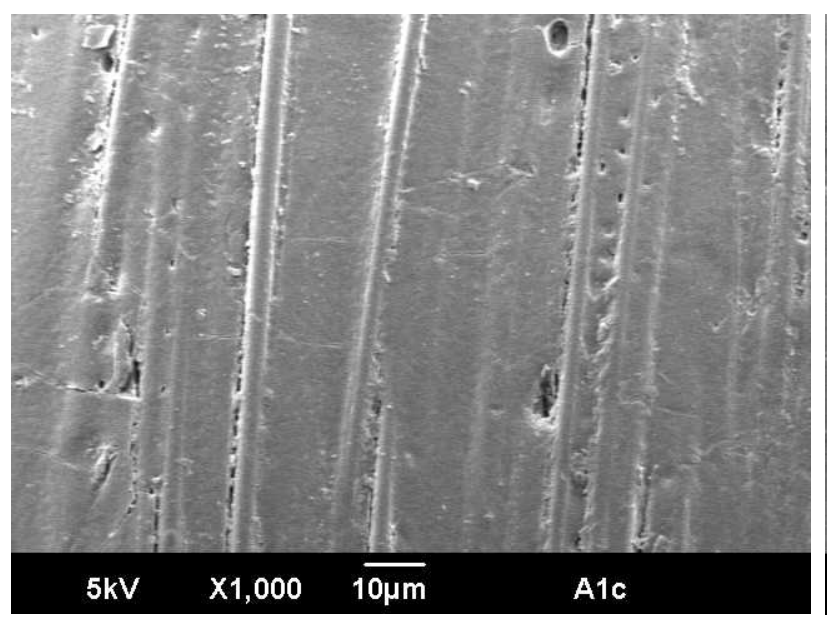

A1G-1-1000

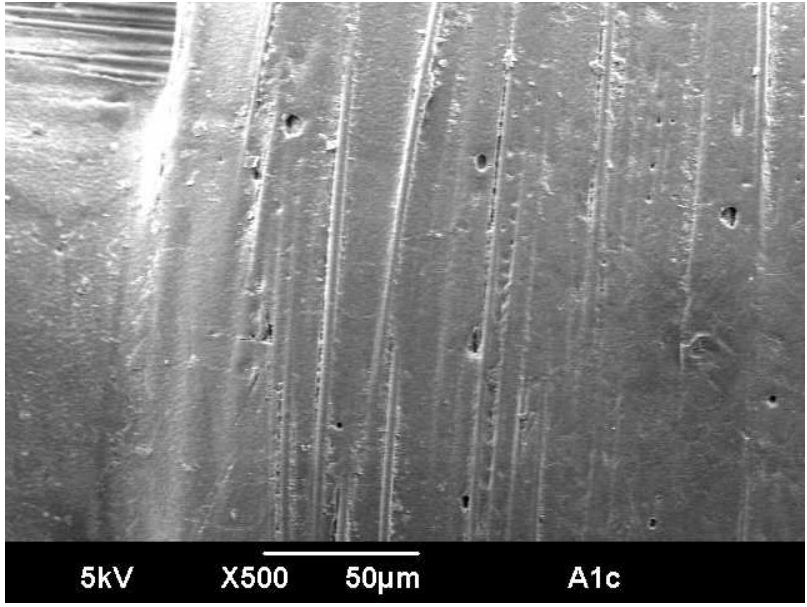

A1G-1-500

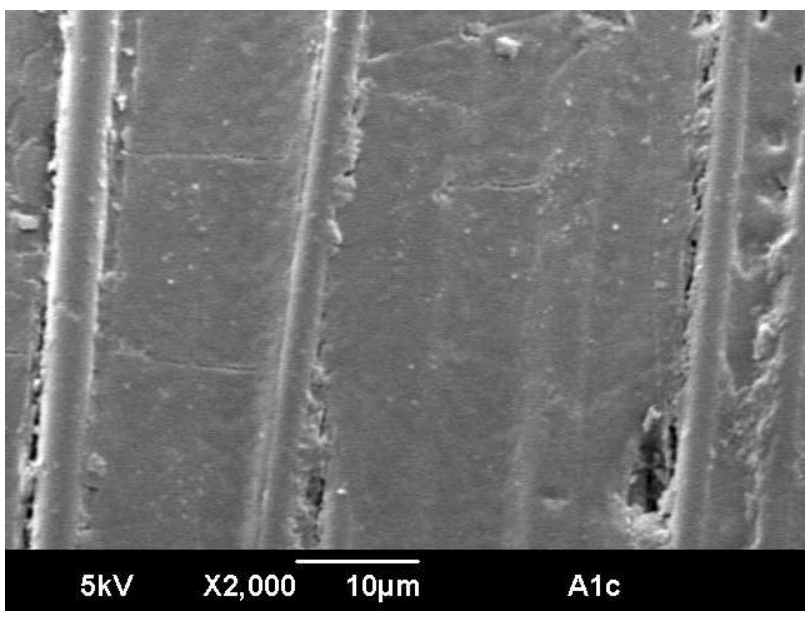

A1G-1-2000 

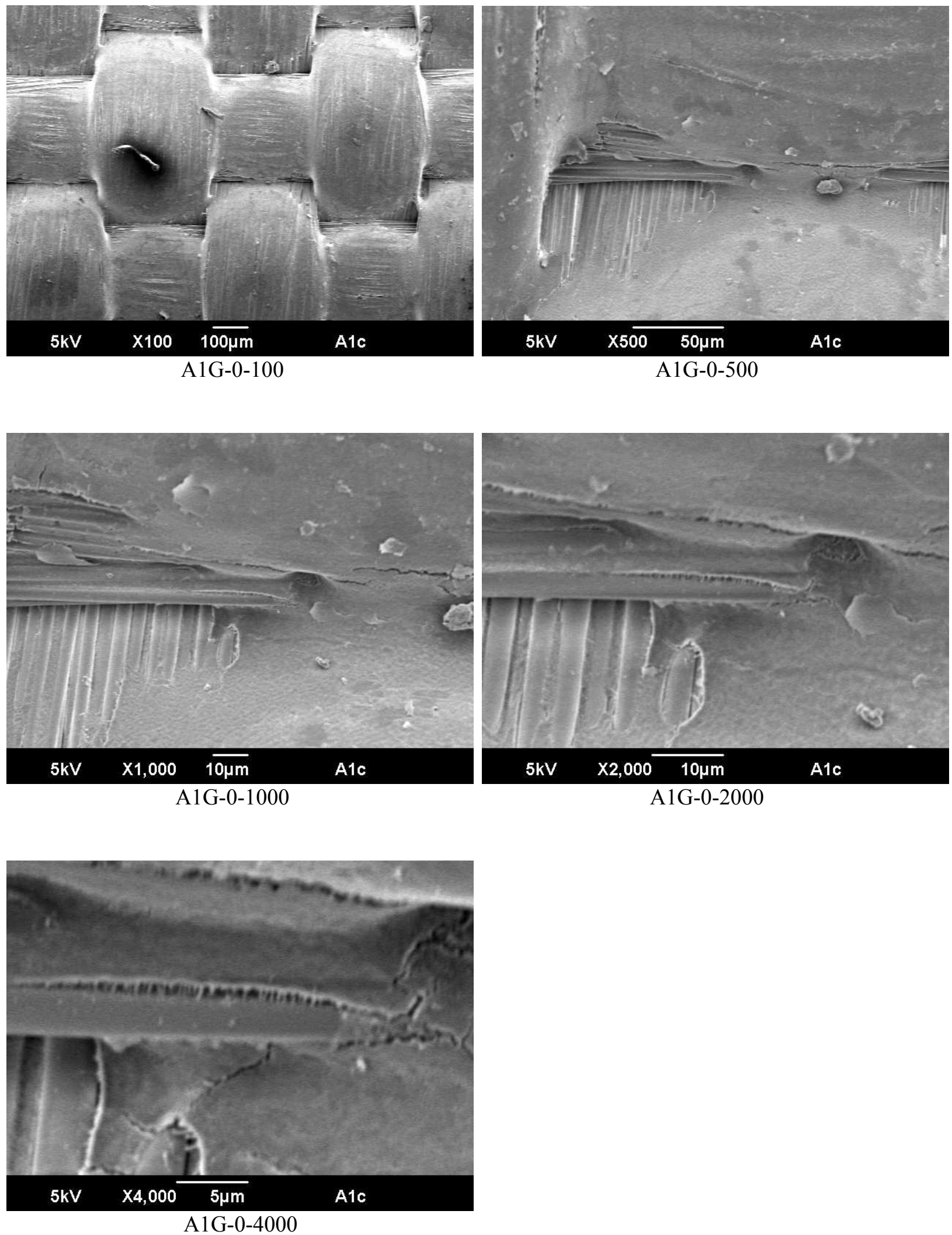

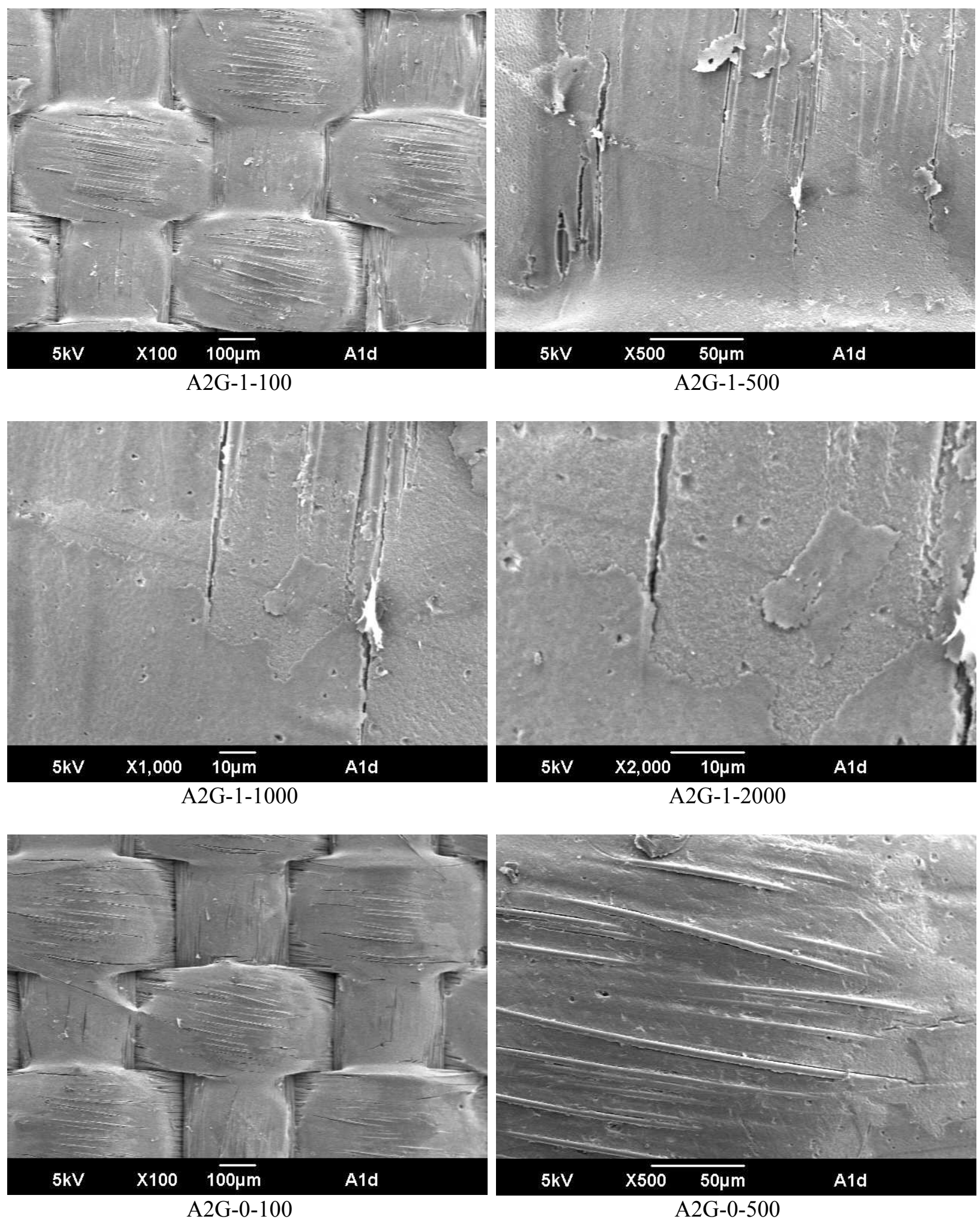


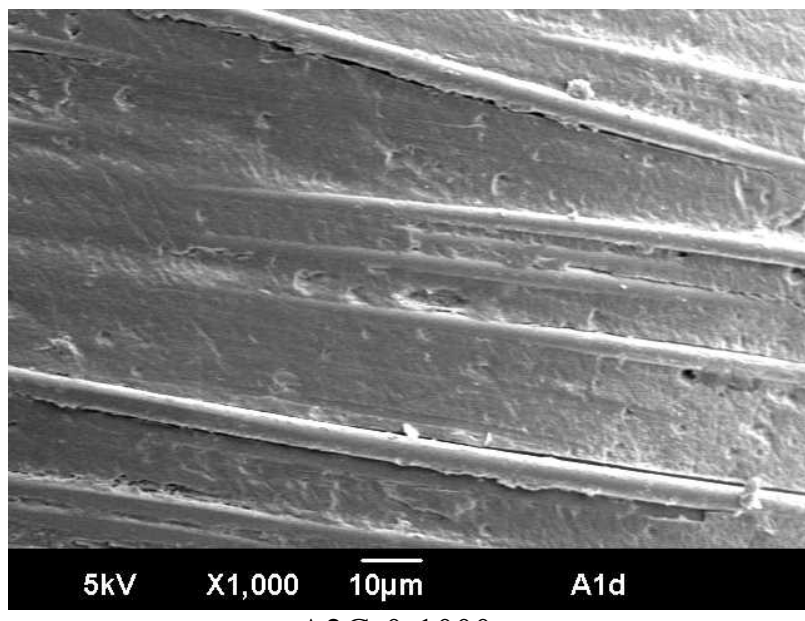

A2G-0-1000

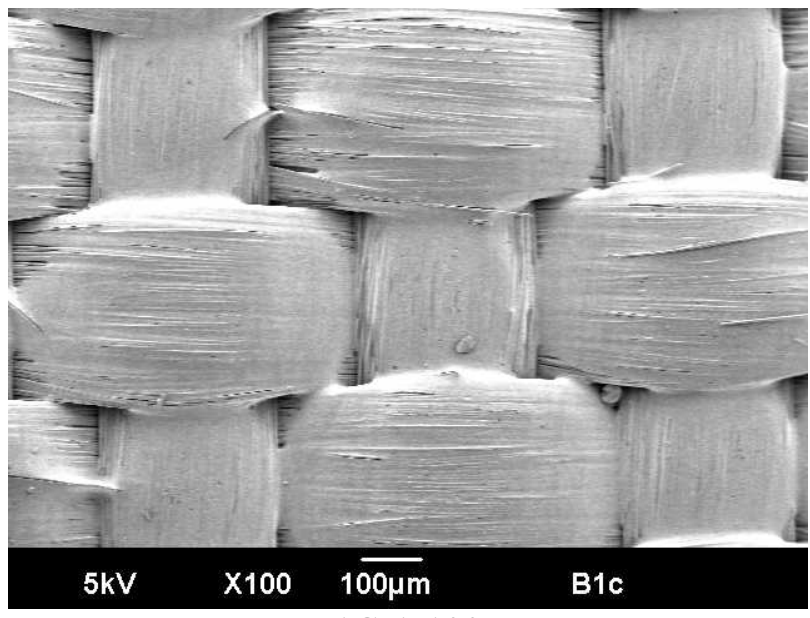

B1G-1-100

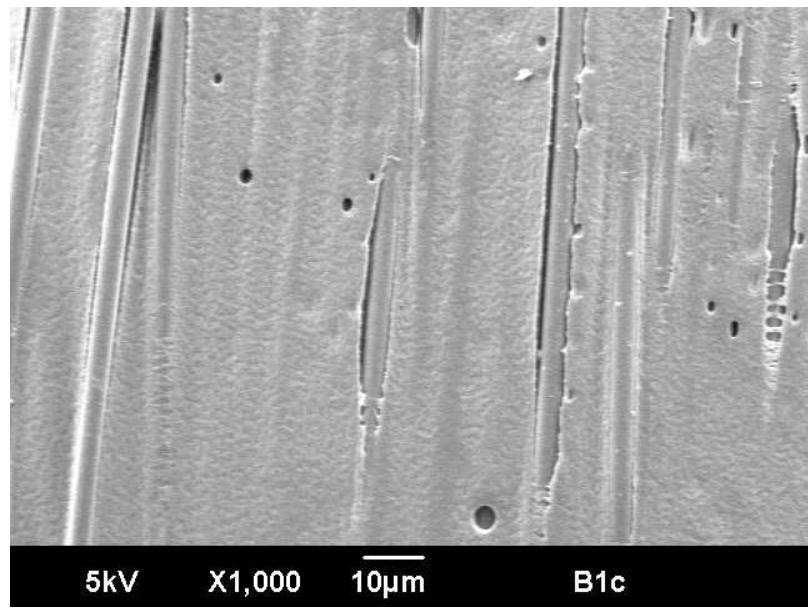

B1G-1-1000
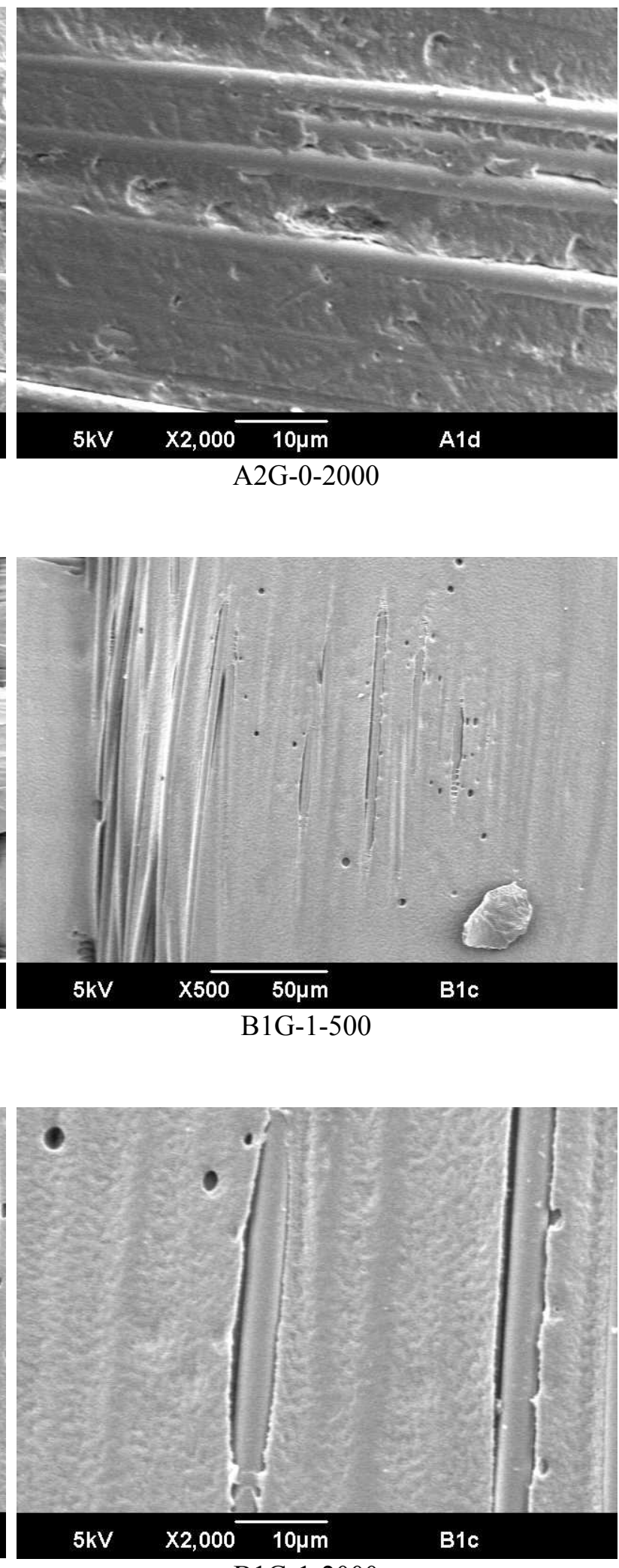

B1G-1-2000 

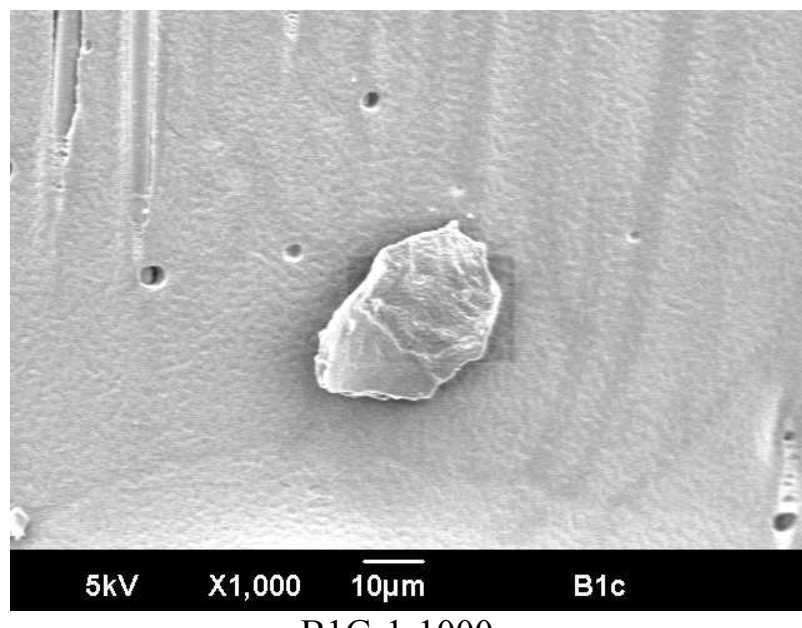
B1G-1-1000
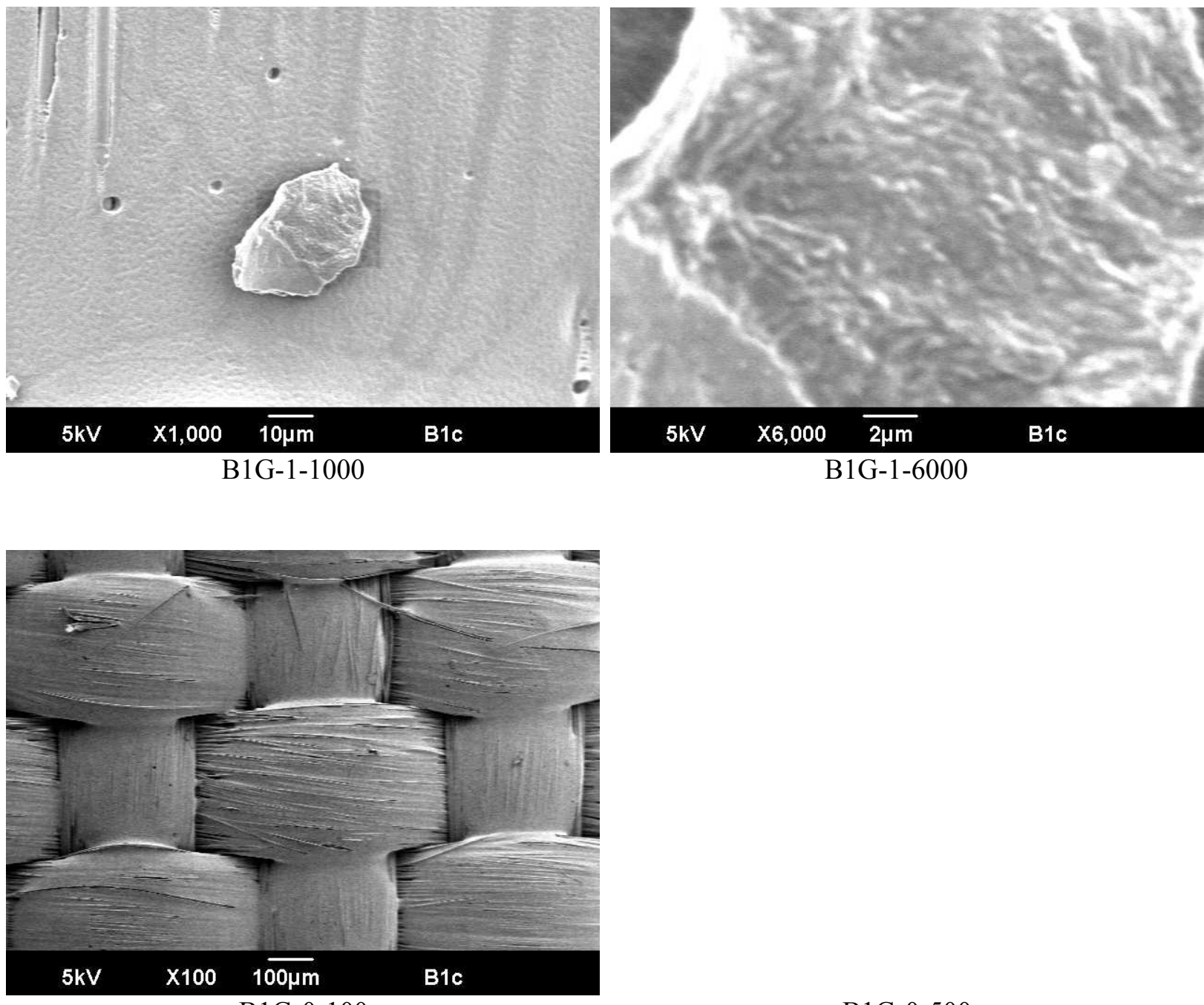
B1G-0-100

B1G-0-500

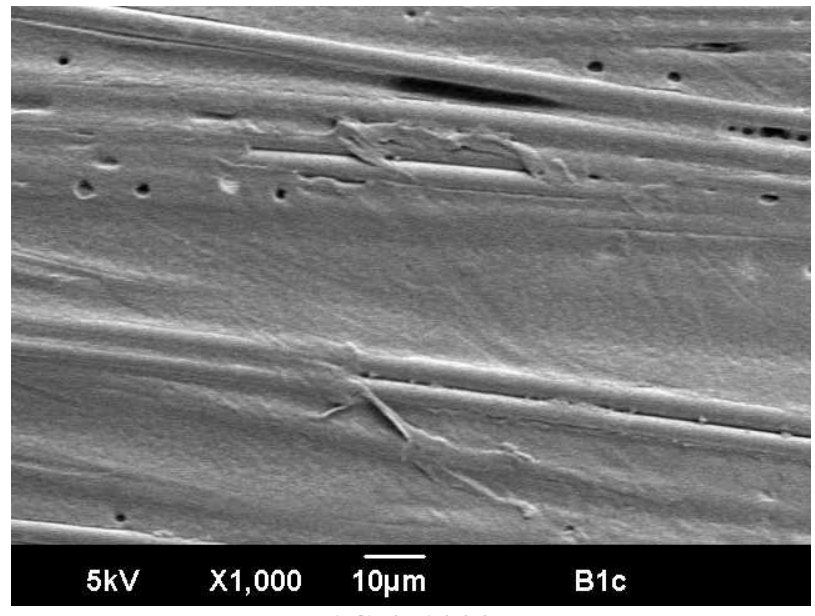

B1G-0-1000

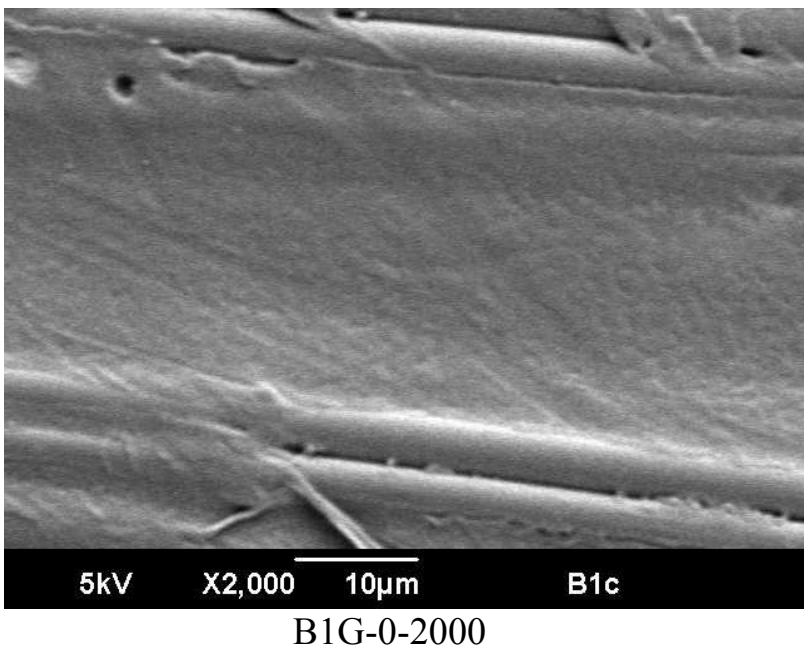



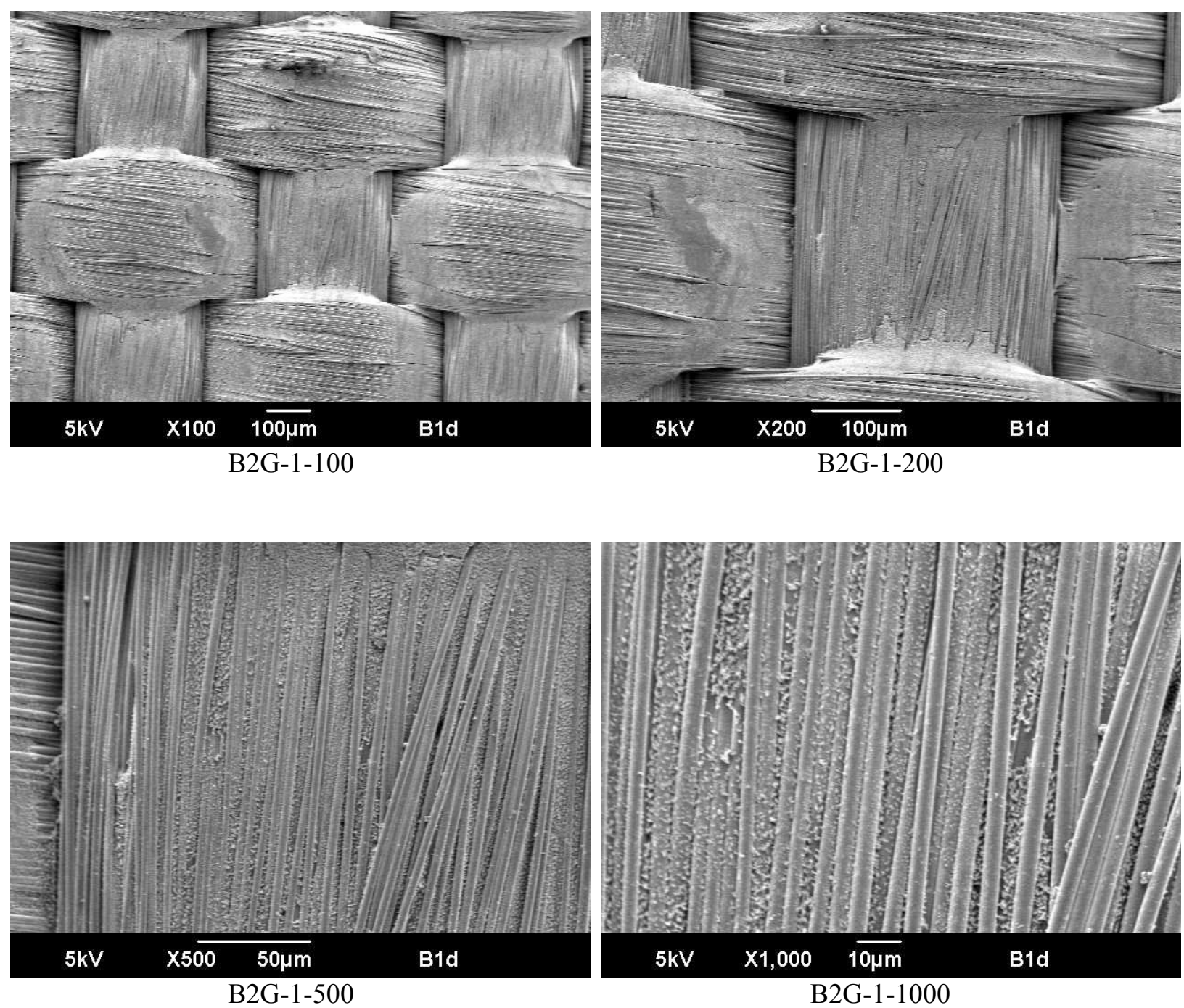

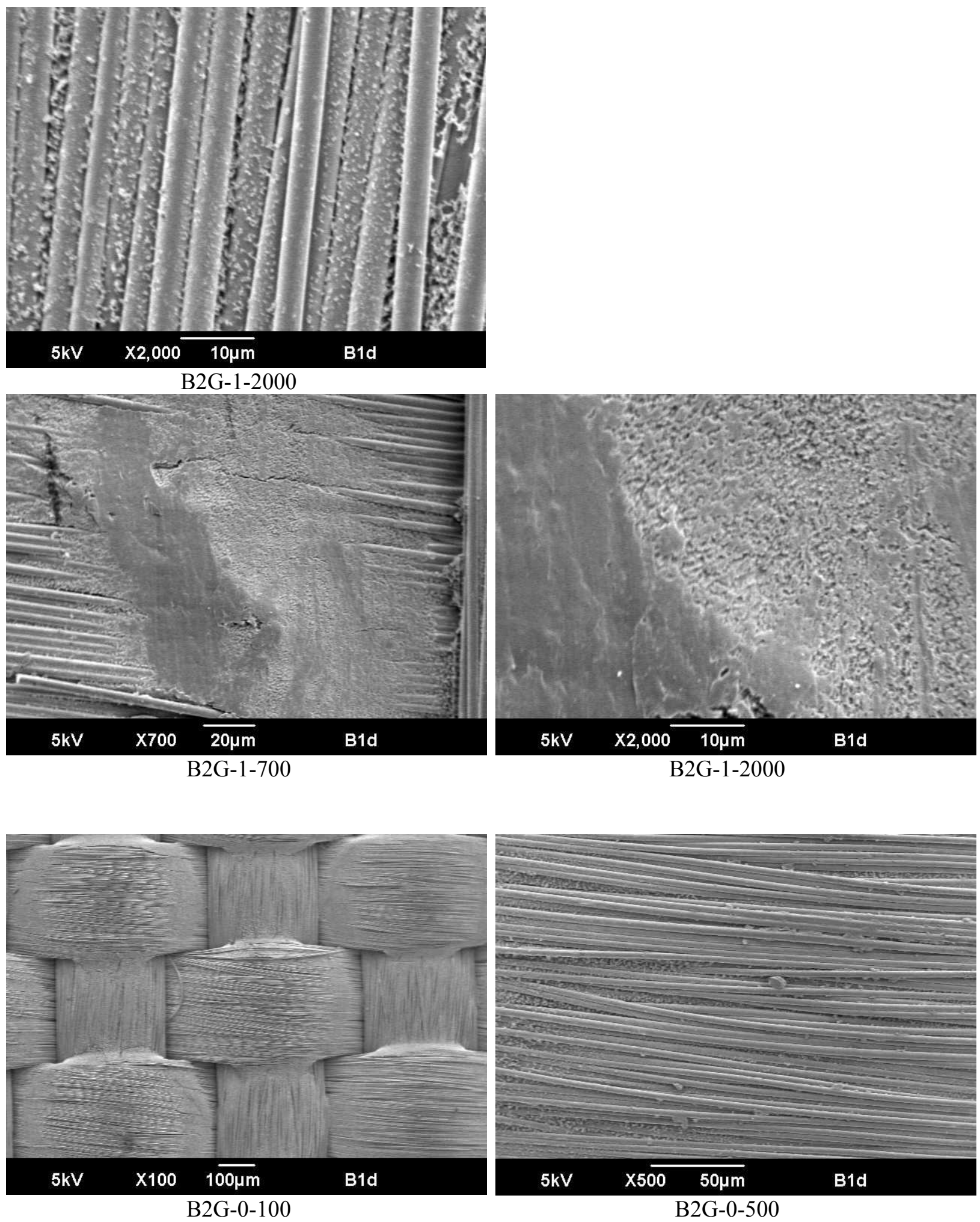


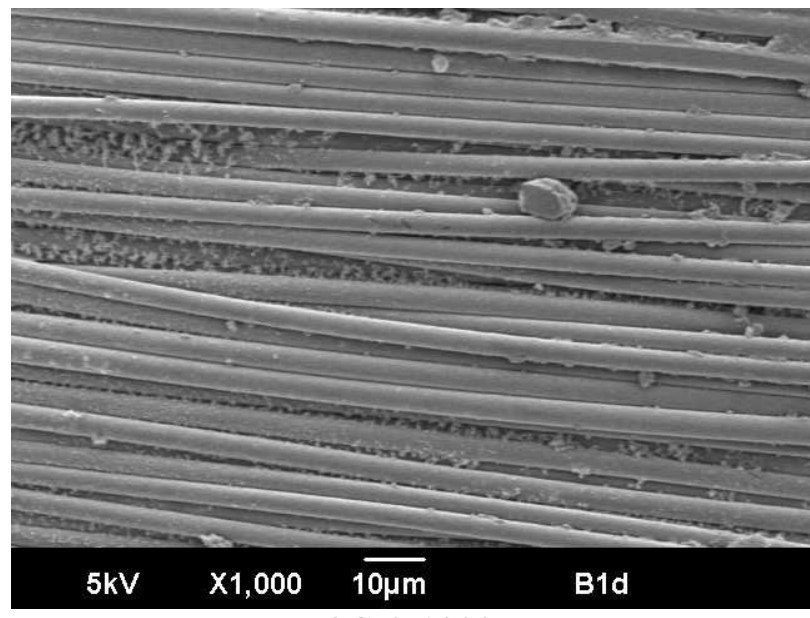

B2G-0-1000

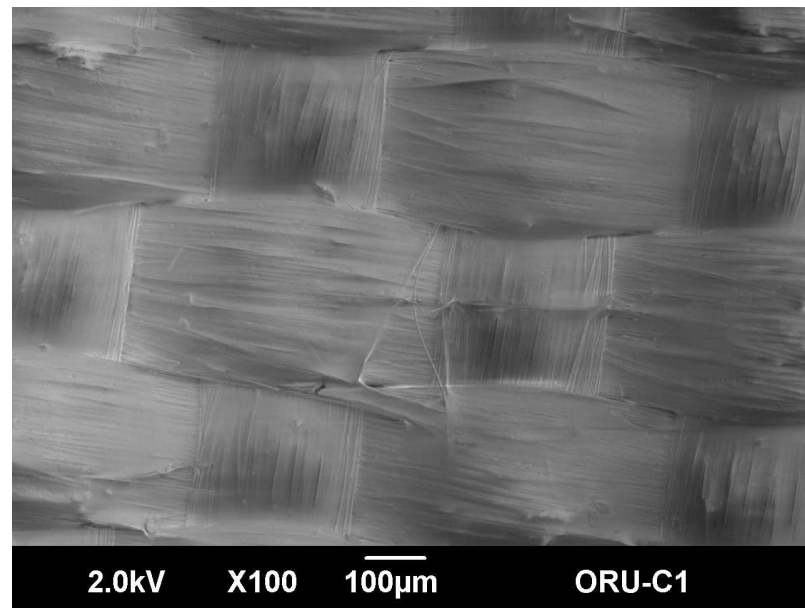

C1-1-100

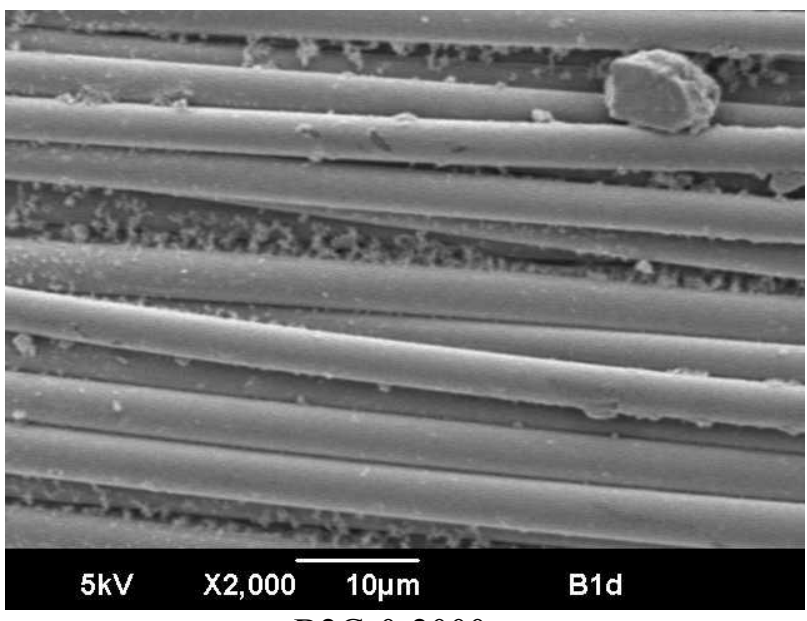

B2G-0-2000

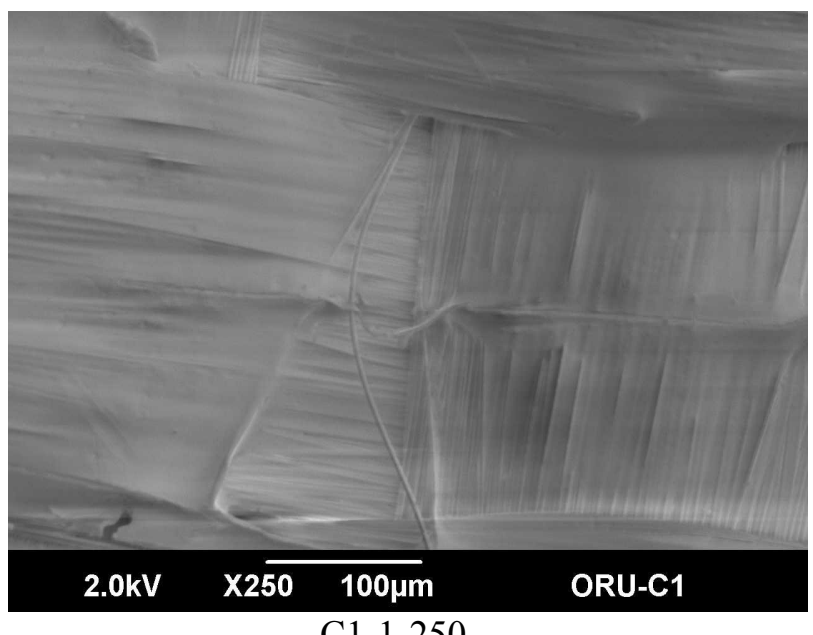

C1-1-250

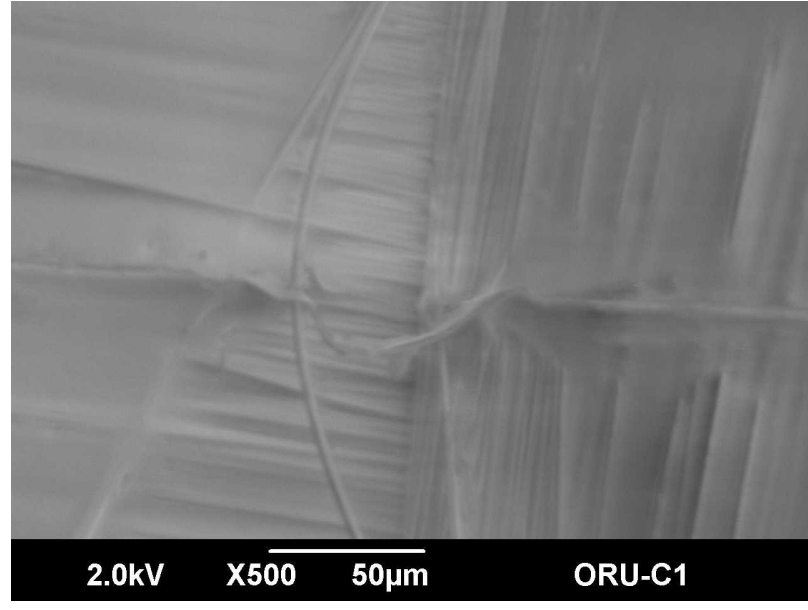

C1-1-500

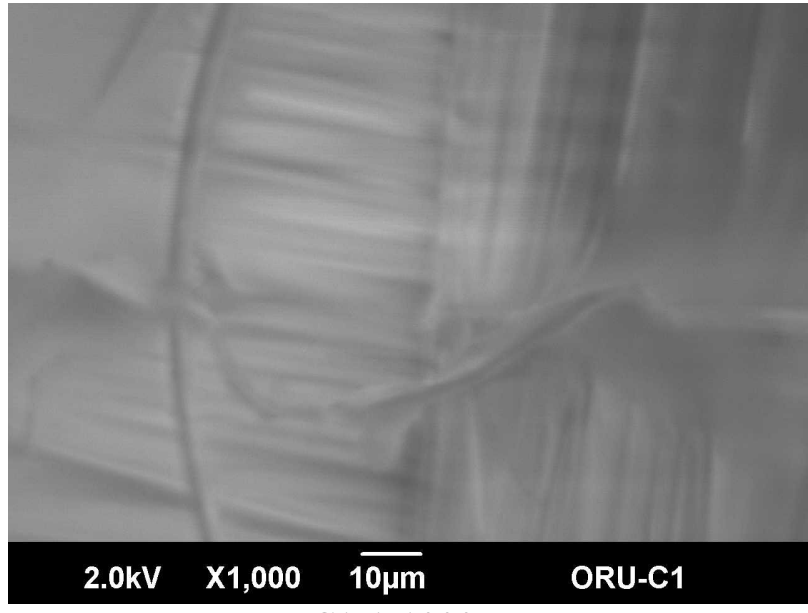

C1-1-1000 

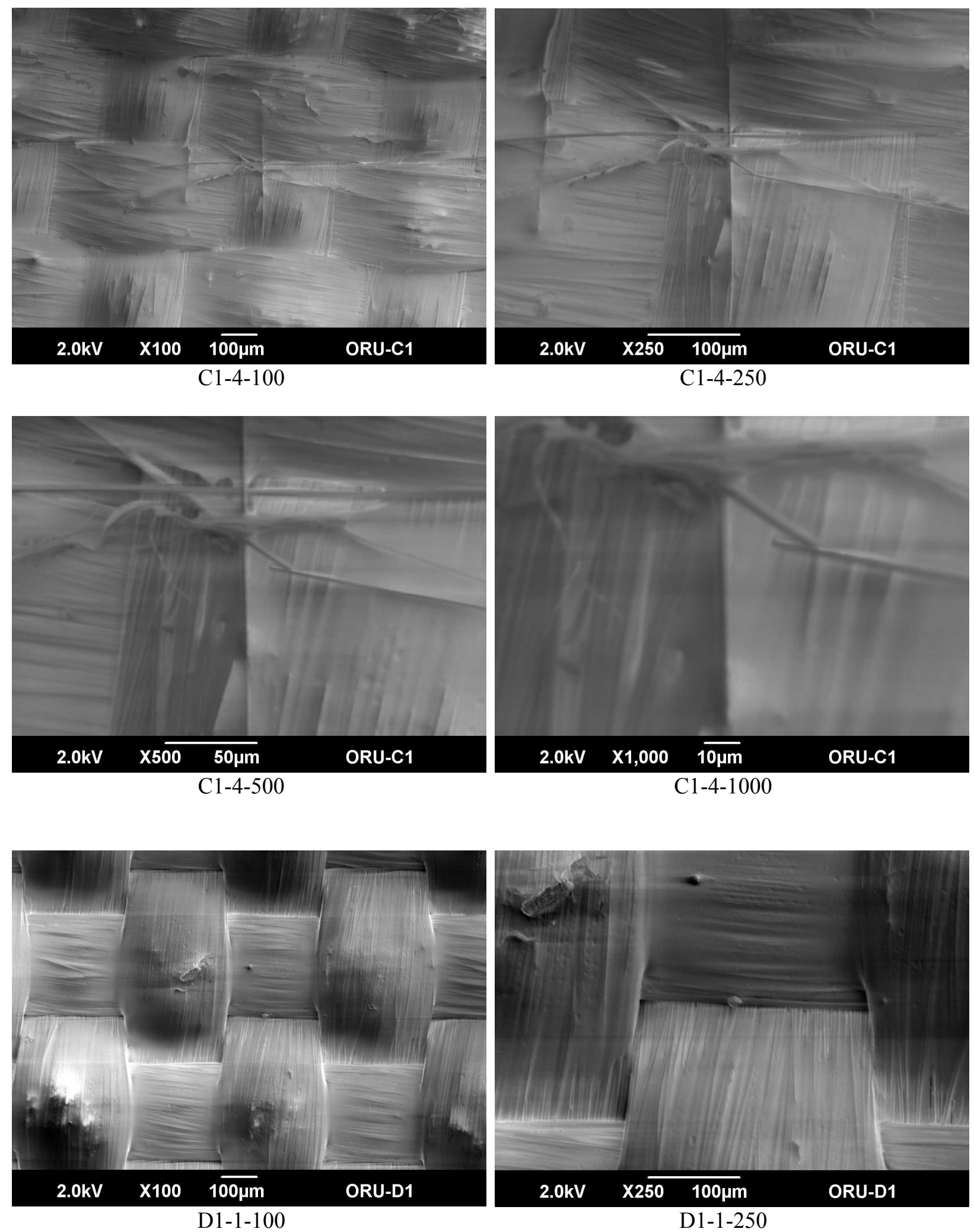

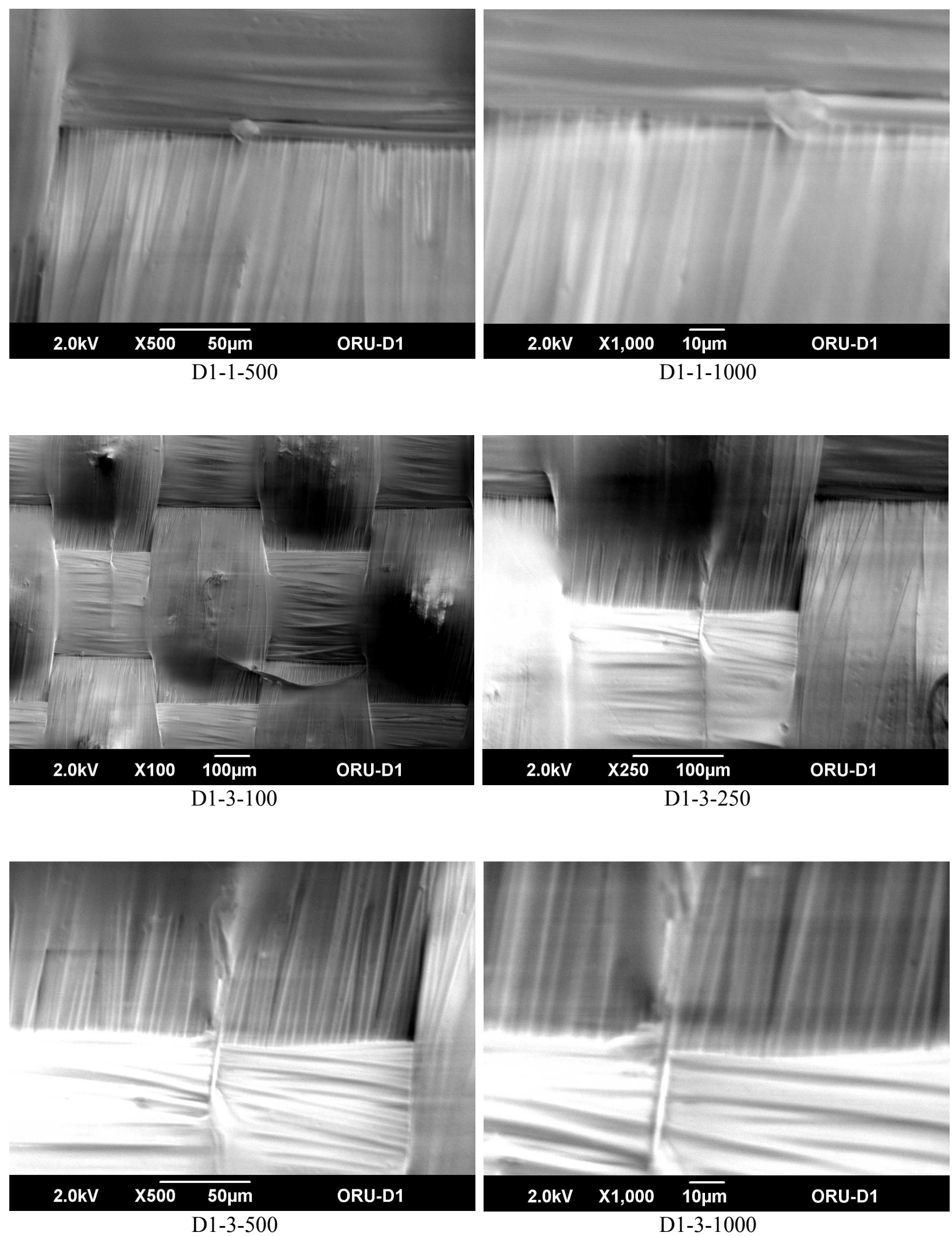

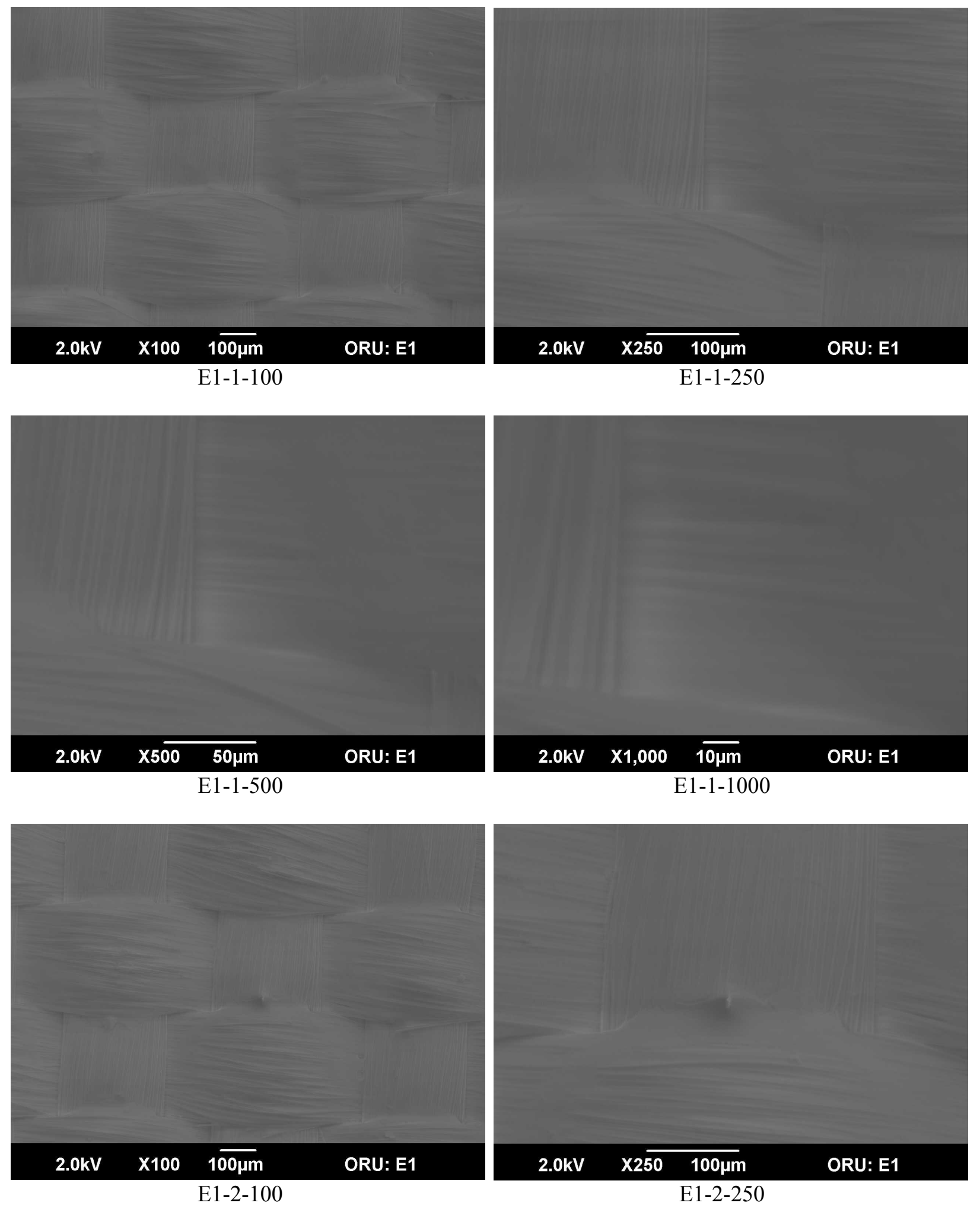


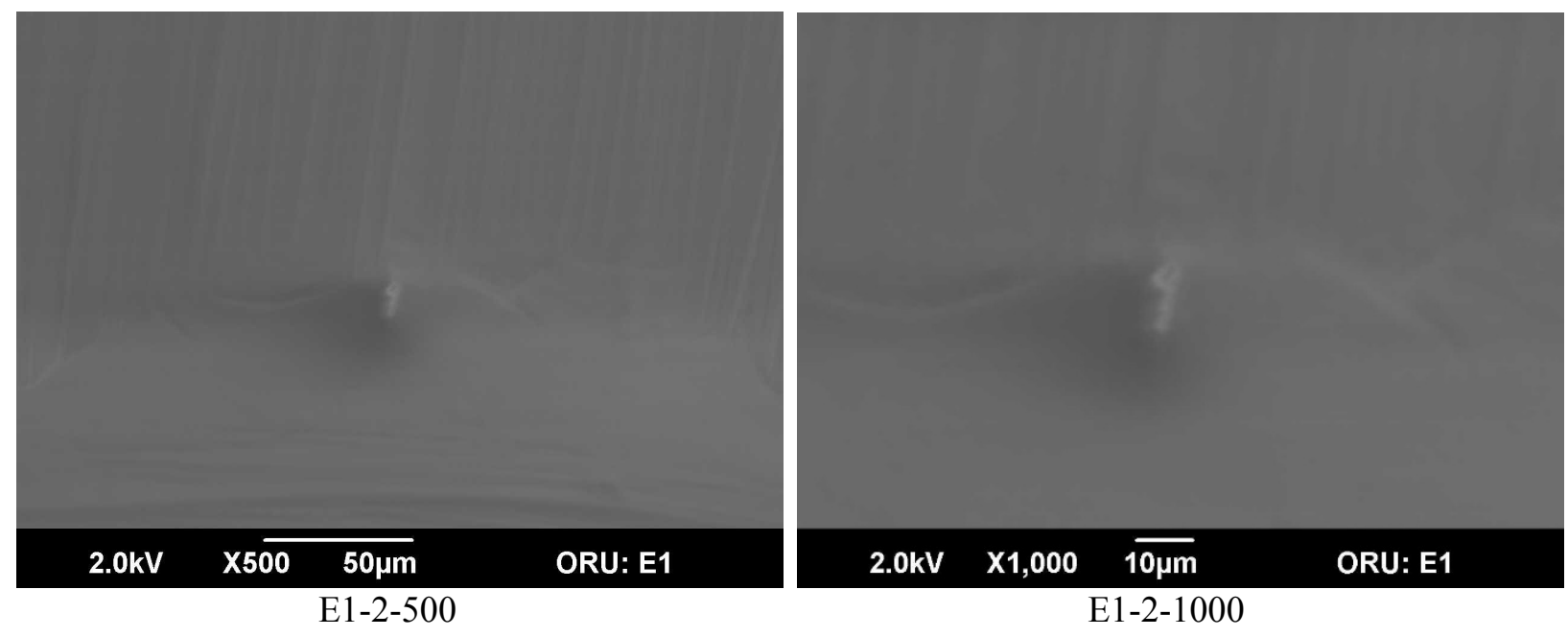




\section{Appendix C-Total Reflectivity of Battery Orbital Replacement Unit Samples}

Nomenclature for the spectra shown in this appendix uses the following convention. Samples taken from the five sides as defined in the text and Figure 4 and 5 are labeled A1, A2, B1, B2, C1, D1, and E1. The two samples taken from sides A and B are taken from a lighter area (A1-1 and B1-1) and a darker area (A1-2 and B1-2). The total integrated reflectance as a function of wavelength (250 to $2500 \mathrm{~nm}$ ) of the front and back of each sample was measured using a Varian Cary 5000 UV-vis-NIR Spectrophotometer equipped with an integrating sphere. These data were used to determine the total integrated solar absorptance of the fabrics as well. It was assumed that the color of the backs of the samples was the same as the original color, since it is unlikely that radiation penetrated to the back of the fabric. 


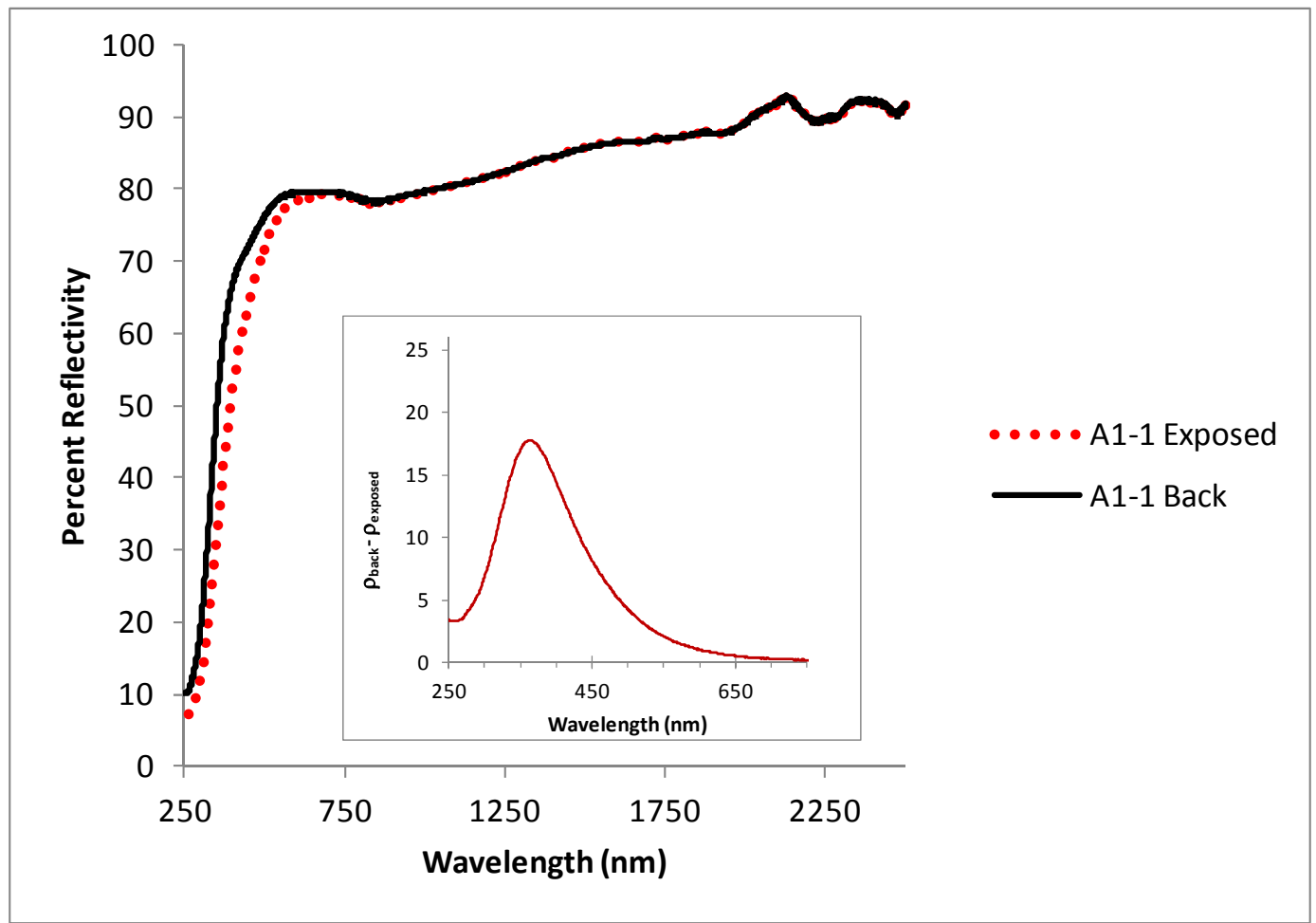

Total reflectivity, $\rho(\lambda)$, of the back surface, exposed surface, and difference for sample A1-1.

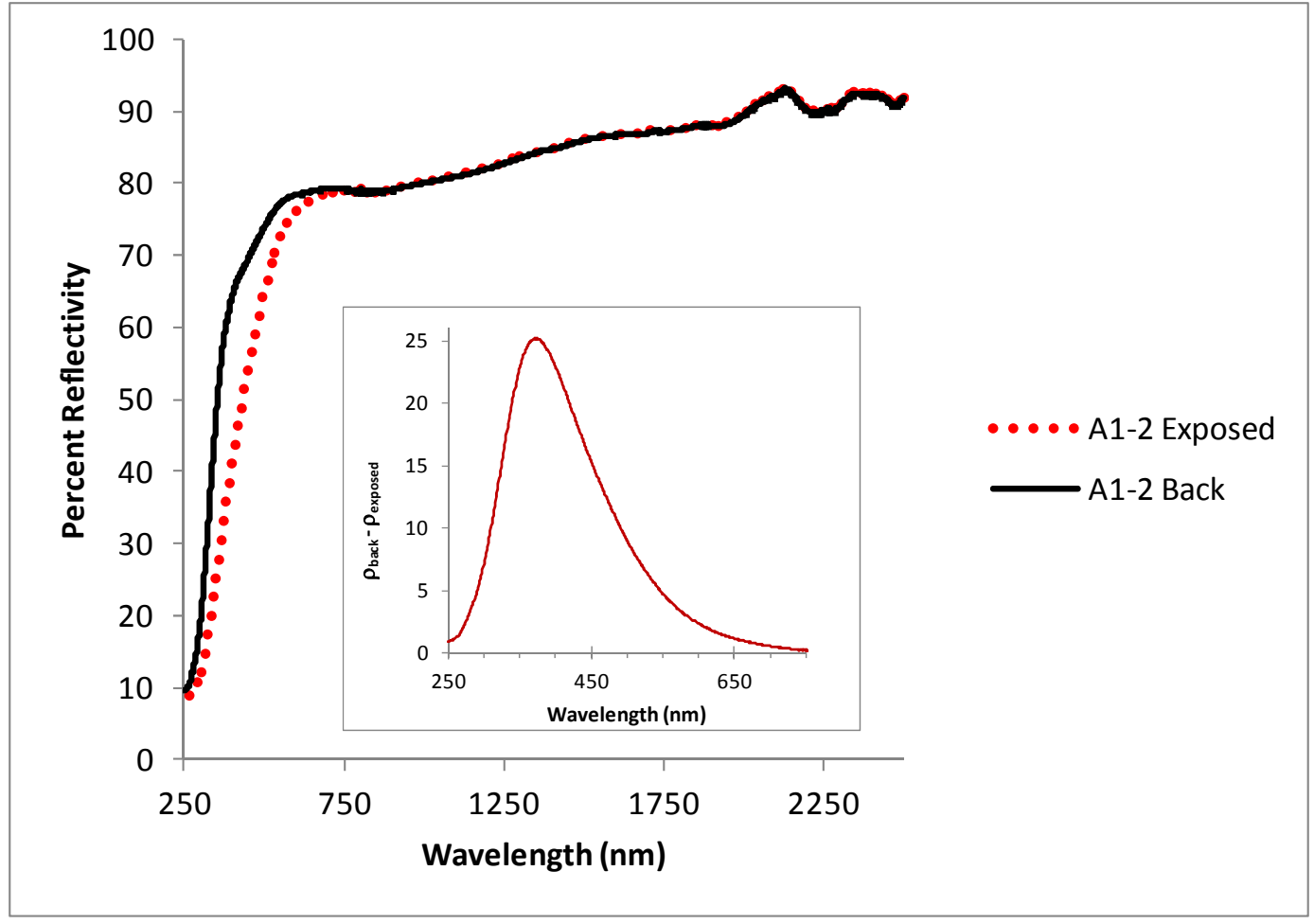

Total reflectivity, $\rho(\lambda)$, of the back surface, exposed surface, and difference for sample A1-2. 


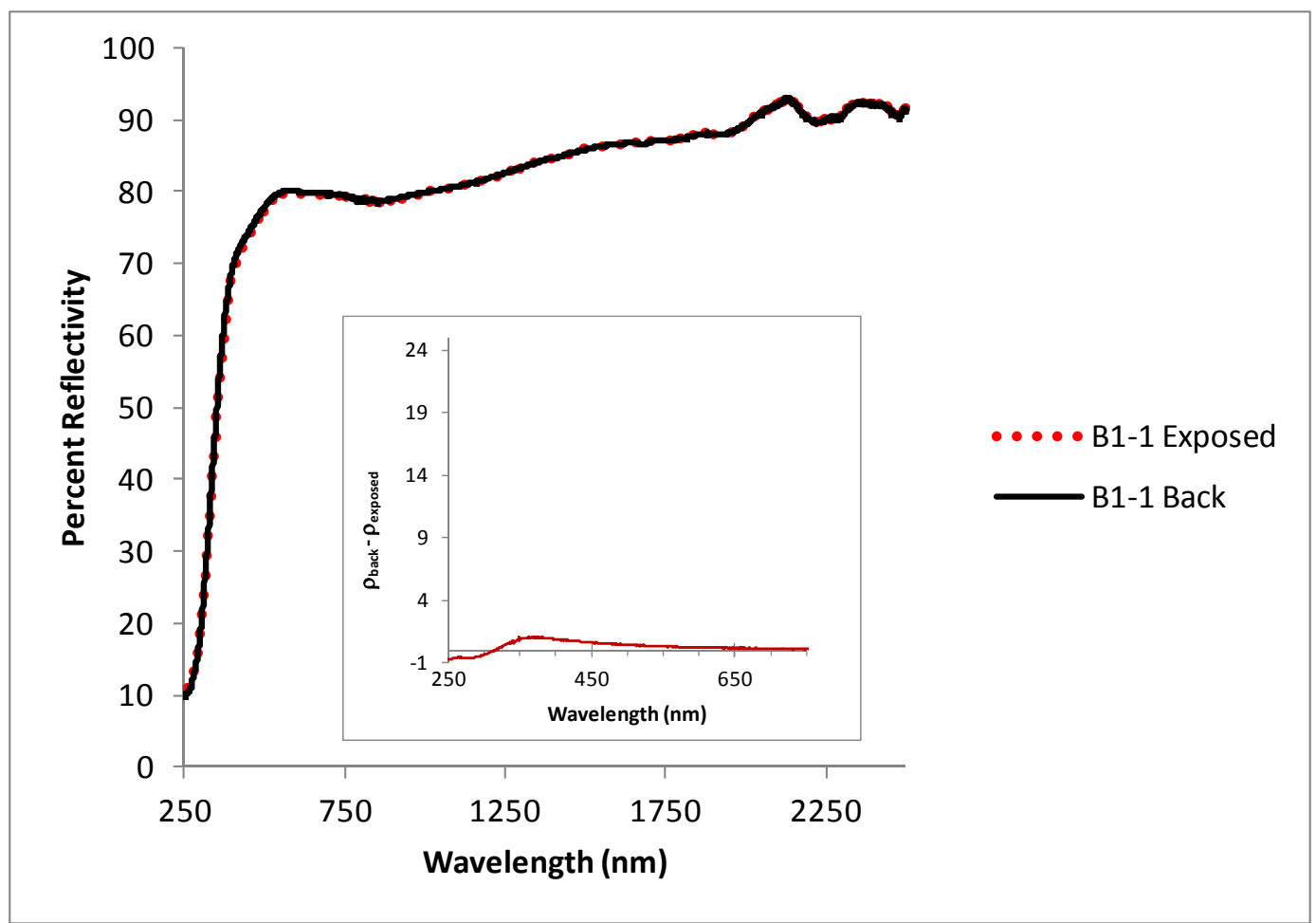

Total reflectivity, $\rho(\lambda)$, of the back surface, exposed surface, and difference for sample B1-1.

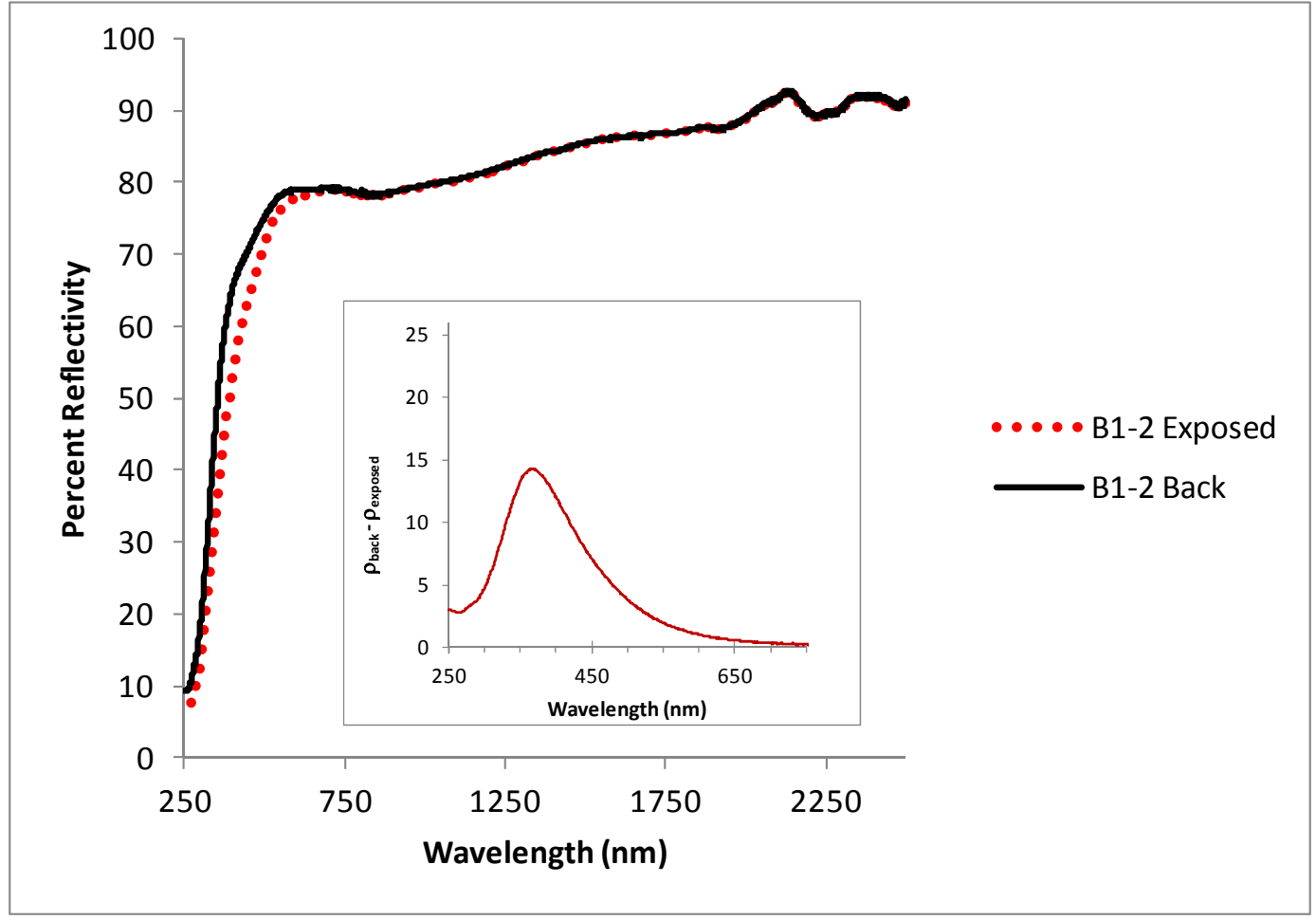

Total reflectivity, $\rho(\lambda)$, of the back surface, exposed surface, and difference for sample B1-2. 


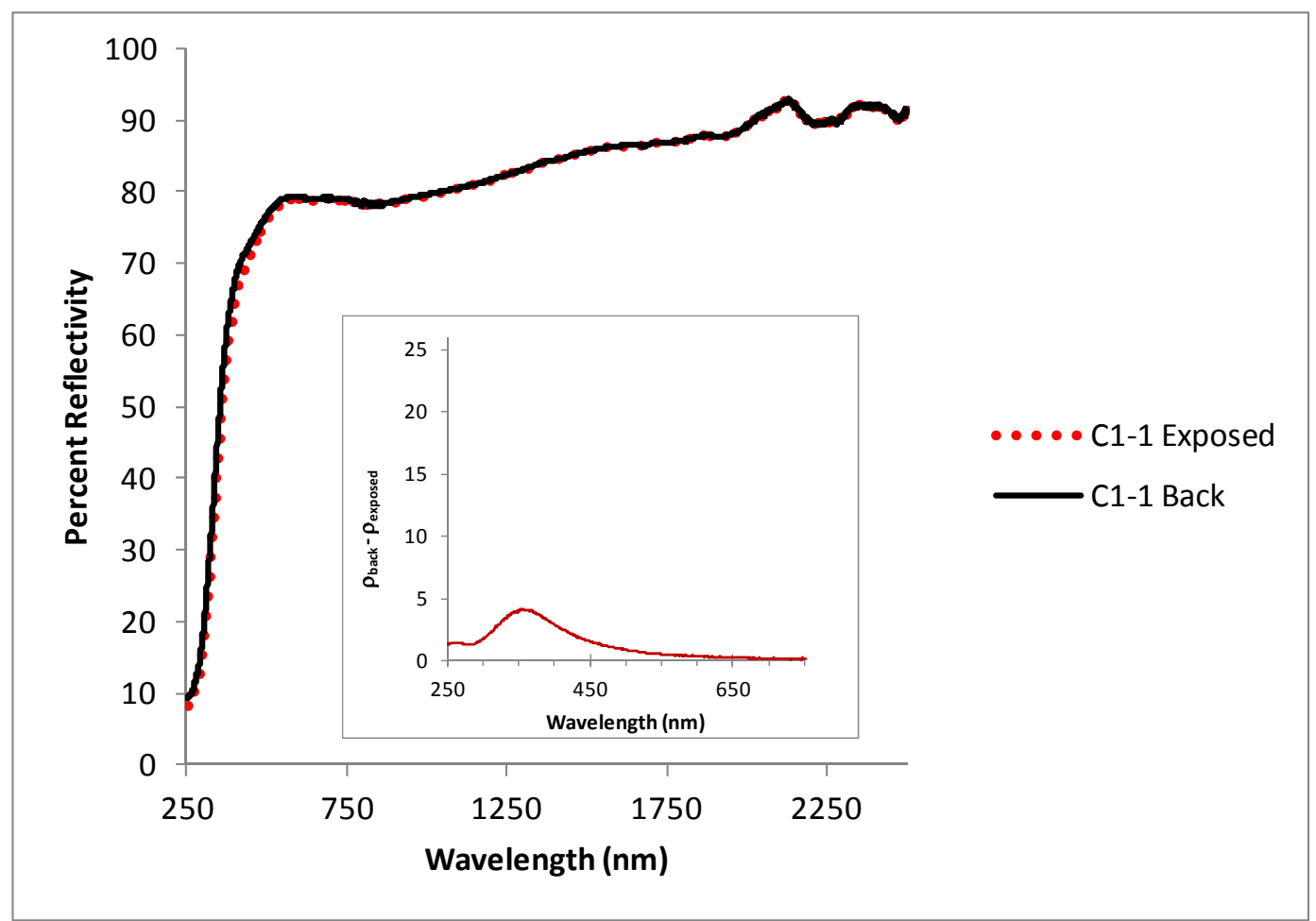

Total reflectivity, $\rho(\lambda)$, of the back surface, exposed surface, and difference for sample C1-1.

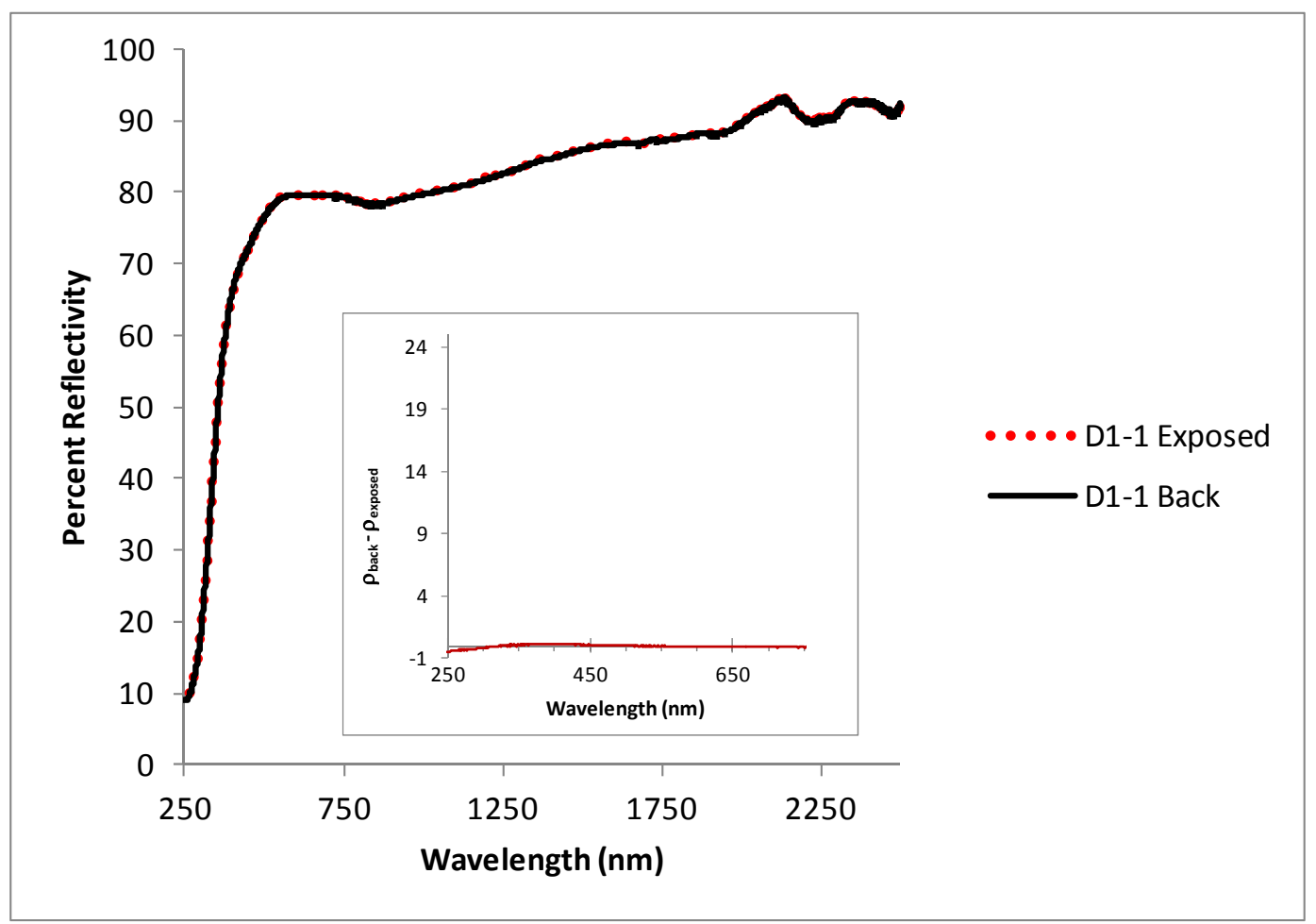

Total reflectivity, $\rho(\lambda)$, of the back surface, exposed surface, and difference for sample D1-1. 


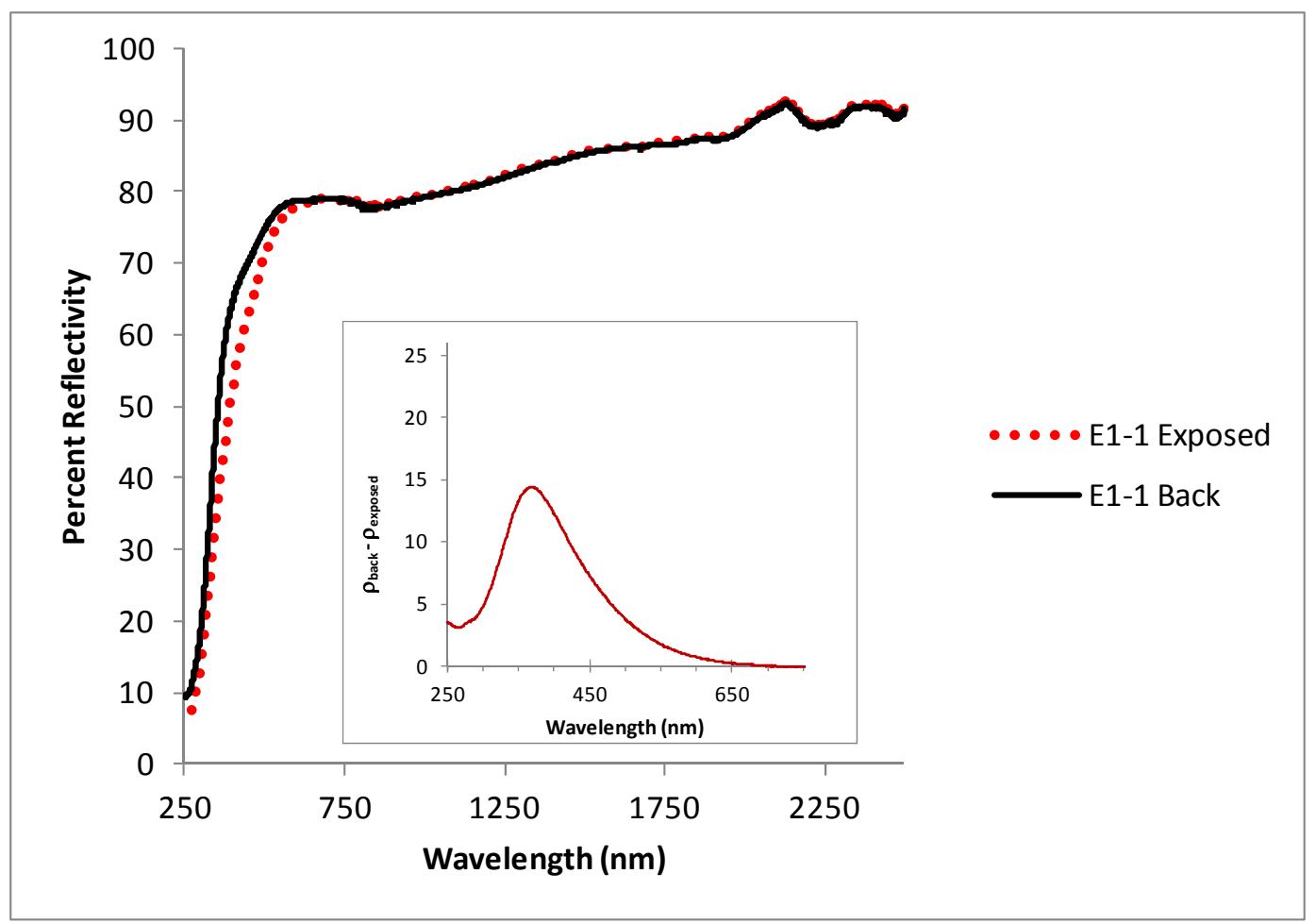

Total reflectivity, $\rho(\lambda)$, of the back surface, exposed surface, and difference for sample E1-1.

Integrated solar absorptance, $\alpha$, for each sample and peak of difference spectrum.

\begin{tabular}{|c|c|c|c|c|}
\hline & $\alpha_{\text {Back }}$ & $\alpha_{\text {Exposed }}$ & $\alpha_{\text {Exposed }} / \alpha_{\text {Back }}$ & Diff Peak, $\mathrm{nm}$ \\
\hline A1-1 & 0.246 & 0.274 & 1.12 & $363 \pm 3$ \\
\hline A1-2 & 0.253 & 0.299 & 1.18 & $372 \pm 2$ \\
\hline B1-1 & 0.240 & 0.242 & 1.01 & \\
\hline B1-2 & 0.251 & 0.275 & 1.10 & $368 \pm 3$ \\
\hline C1-1 & 0.246 & 0.253 & 1.03 & \\
\hline D1-1 & 0.247 & 0.246 & 1.00 & \\
\hline E1-1 & 0.255 & 0.277 & 1.09 & $369 \pm 2$ \\
\hline Mean & 0.248 & 0.267 & & \\
\hline St Dev & 0.005 & 0.020 & & \\
\hline
\end{tabular}




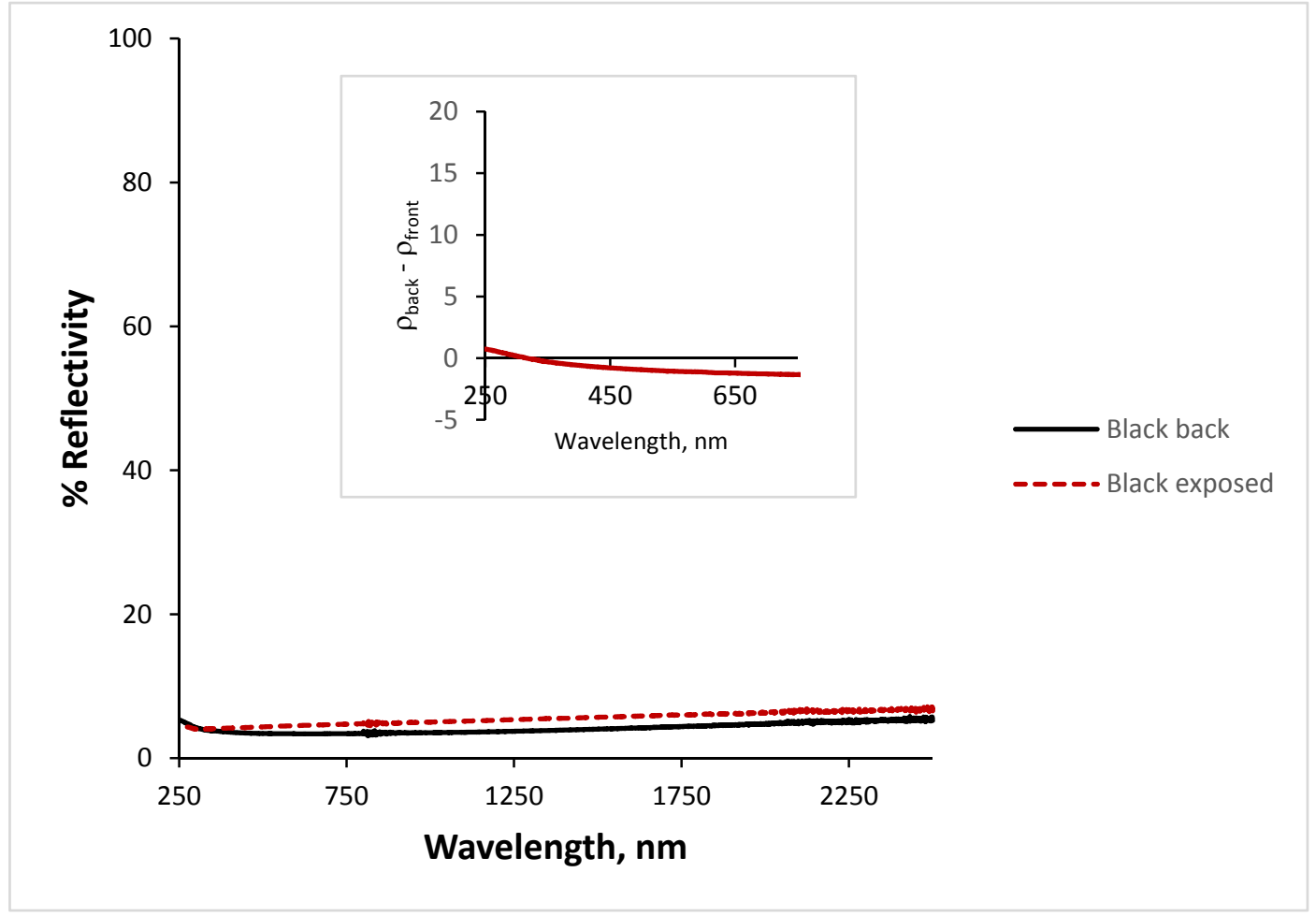

Total reflectivity, $\rho(\lambda)$, of the back surface, exposed surface, and difference for the black trim sample on B1-1.

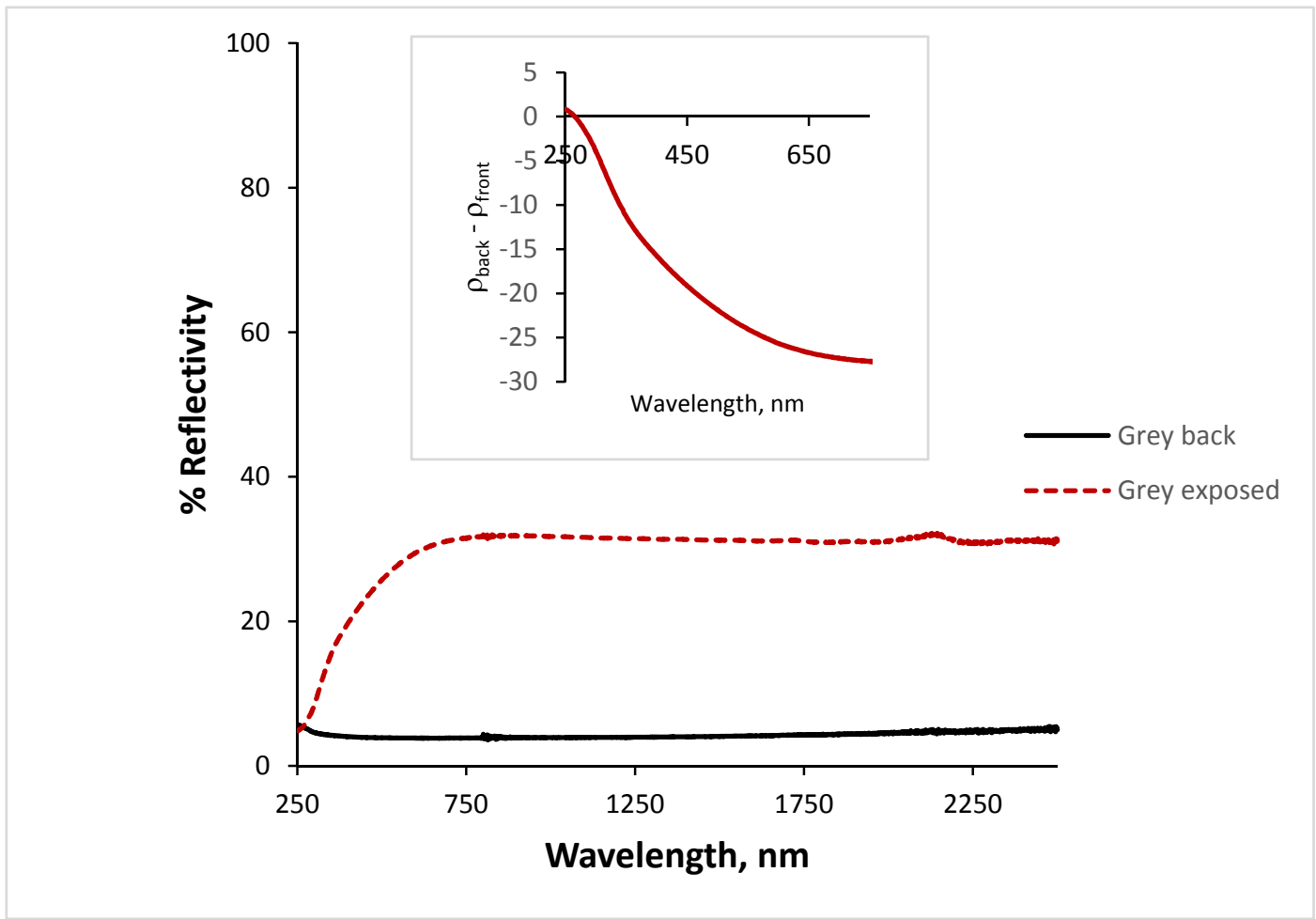

Total reflectivity, $\rho(\lambda)$, of the back surface, exposed surface, and difference for the exposed black trim sample (grey) on B1-1. 


\section{Appendix D-Energy Dispersive X-Ray Spectroscopy}

Nomenclature for the photographs shown in this appendix uses the following convention. Samples taken from the five sides as defined in the text and Figures 4 and 5 are labeled A and B. The number following the letter describes the sample number for that side. All samples were gold coated.

Data taken for samples of the black trim (and associated "grey" areas) were collected with a newer detector. Those data lead to the semiquantitative values listed in the table below.

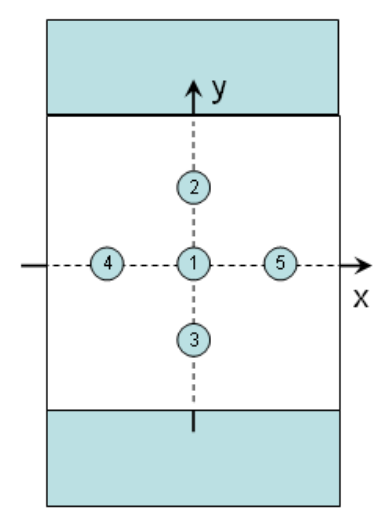

\begin{tabular}{|lllll|l|l|l|l|l|l|}
\multicolumn{1}{c}{} & \multicolumn{1}{c}{ C } & \multicolumn{1}{c}{ F } & O & \multicolumn{1}{c}{ Si } & Al & Ca & Na & Mg & Au \\
\hline Black 1 & 43 & 55 & 2 & & & & & & \\
\hline Black 2 & 43 & 55 & & & & & & & 1 \\
\hline Black 2 under & 50 & 50 & & & & & & & 0.3 \\
\hline Black line Au & 41 & 57 & & & & & & & 1 \\
\hline Grey 1 & 26 & 45 & 17 & 6 & 2 & 2 & 2 & 1 & \\
\hline Grey 2 & 27 & 44 & 16 & 6 & 2 & 2 & 2 & & 1 \\
\hline Q Contam & 24 & 40 & 20 & 8 & 3 & 4 & & & 1 \\
\hline W ORU & 35 & 56 & & 5 & 2 & 2 & & & 1 \\
\hline & & & & & & & & & \\
\hline Error, \% & 9 & 6 & 8 & 5 & 6 & 7 & 9 & 10 & 10 \\
\hline
\end{tabular}




\section{A1c-1}

c:łedax32\}genesisigenspc.spc

Label A:

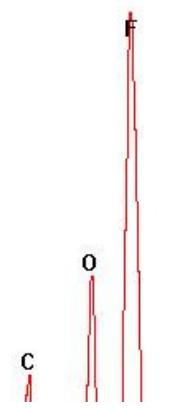

Label A:

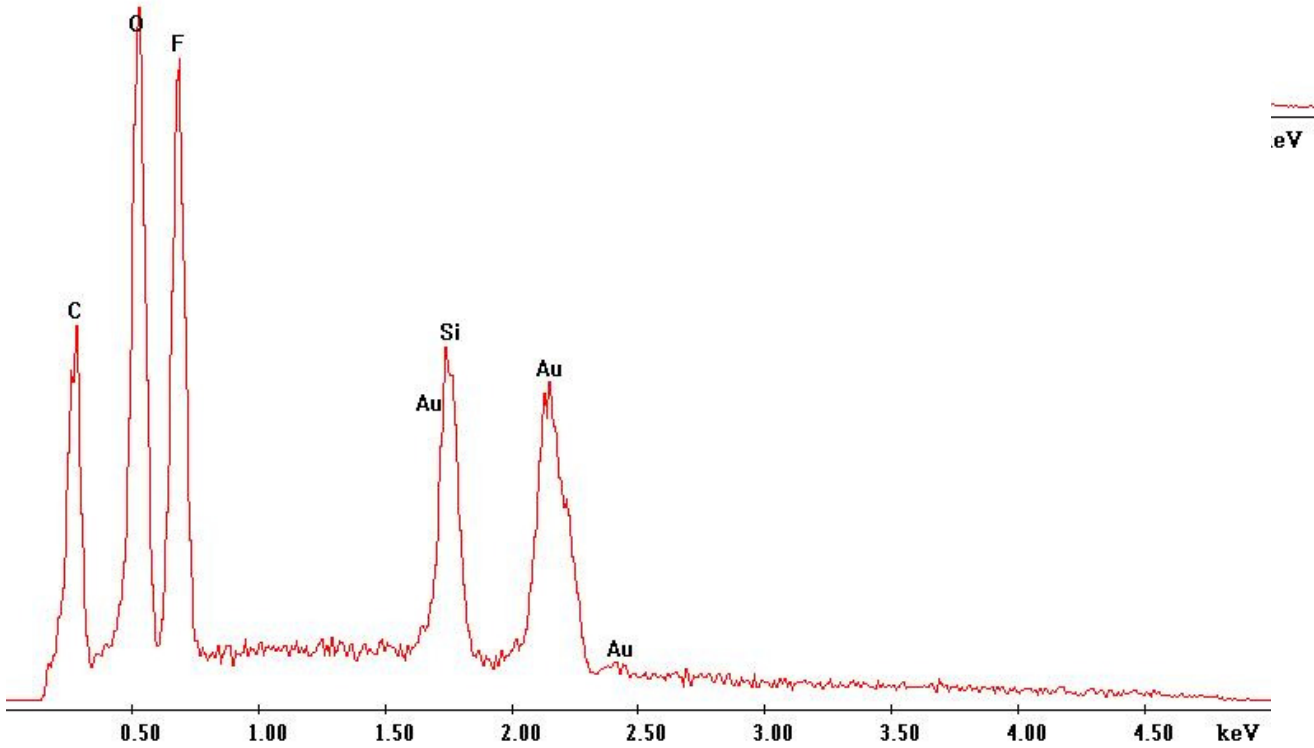




\section{A1d-1}

c:łedax32\}genesisigenspc.spc

Label A:

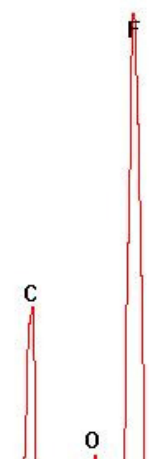

\section{A1d-2}

c:\{eda×32\}genesisigenspc.spc

Label A:

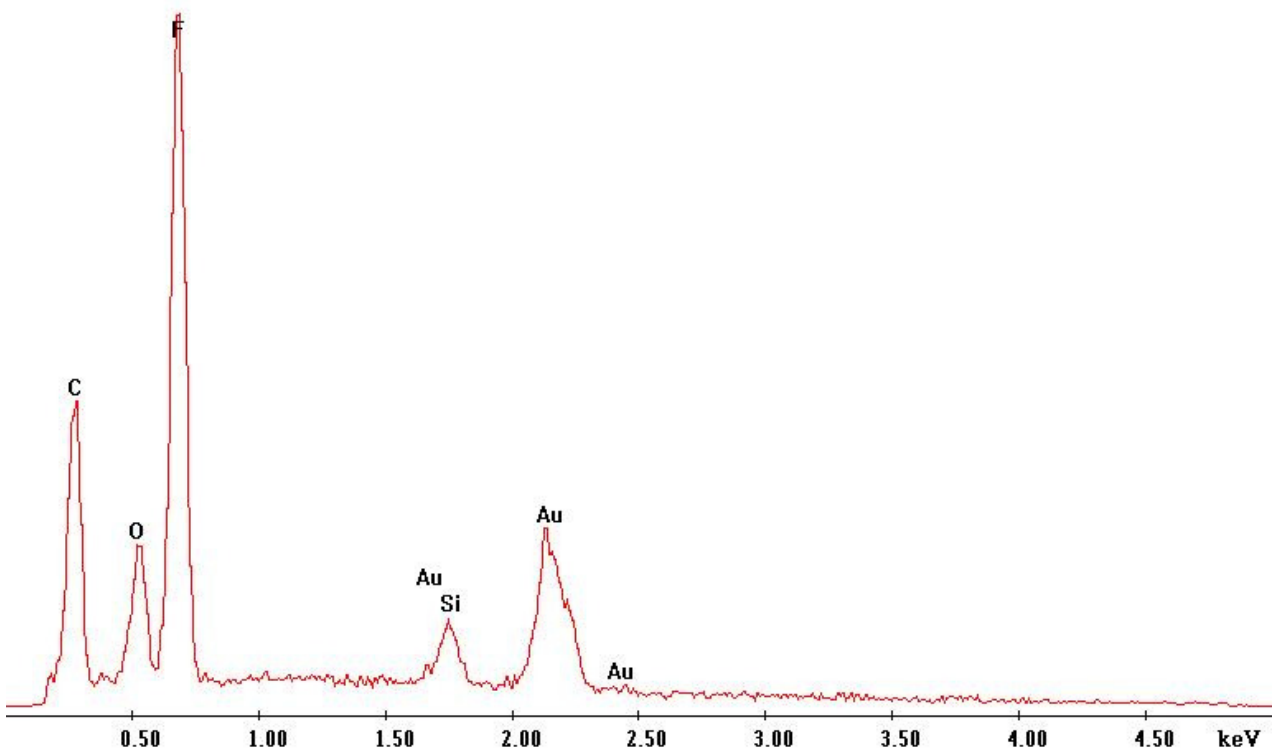




\section{B1c-1}

c:\{edax32\}genesisigenspc.spc

Label A:

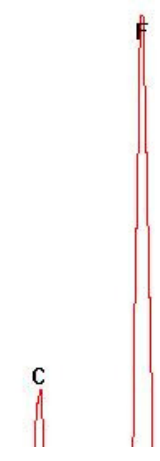

\section{B1c-2}

c:łedax32\}genesisigenspc.spc

Label A:

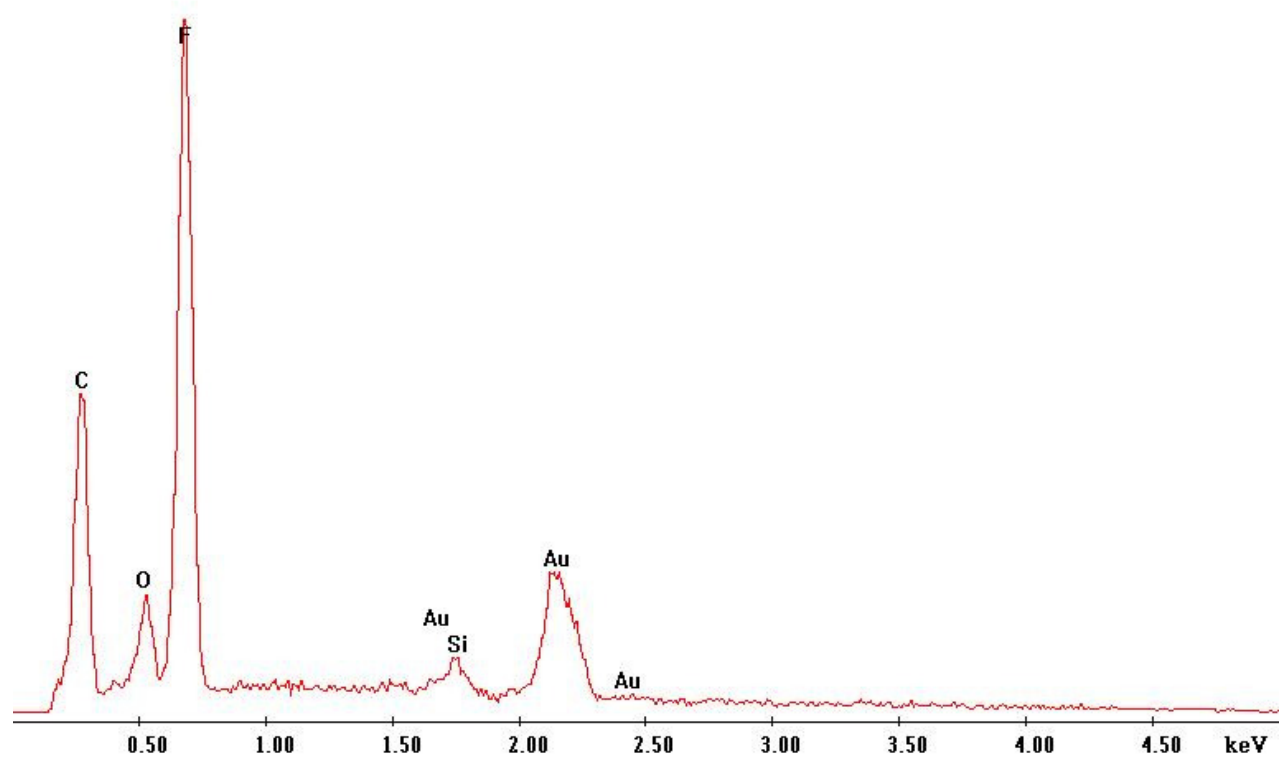




\section{B1c-2b}

c:\{eda×32\}genesisigenspc.spc

Label A:

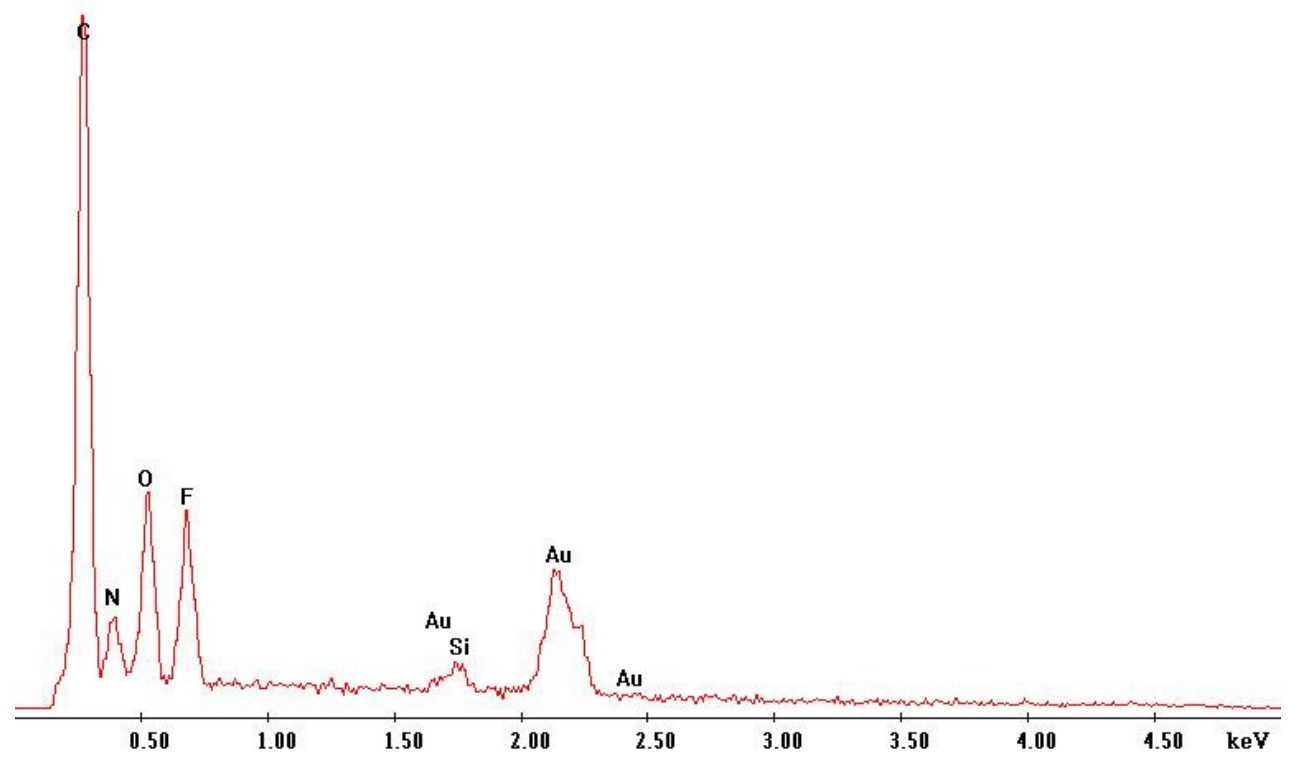




\section{B1d-1}

c:|edax32\}genesisigenspc.spc

Label A:

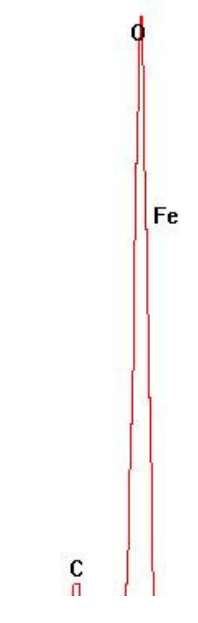

Label A:

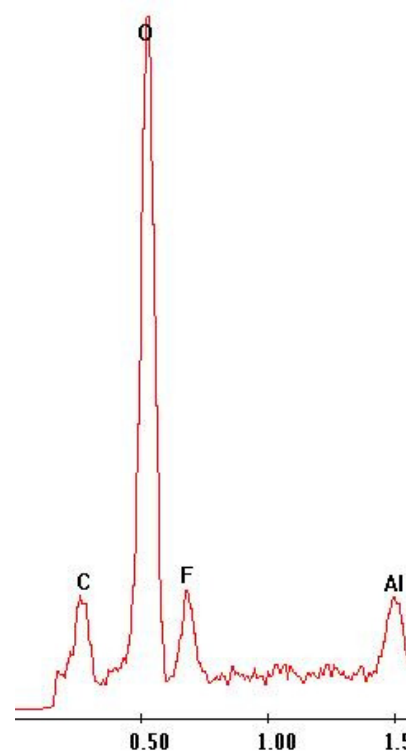

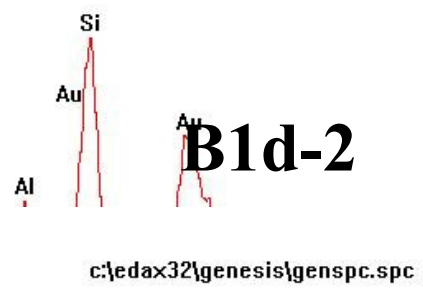

c:łedax32\}genesisigenspc.spc 


\section{B1d-2b}

c:\{edax32\}genesisłgenspc.spc

Label A:

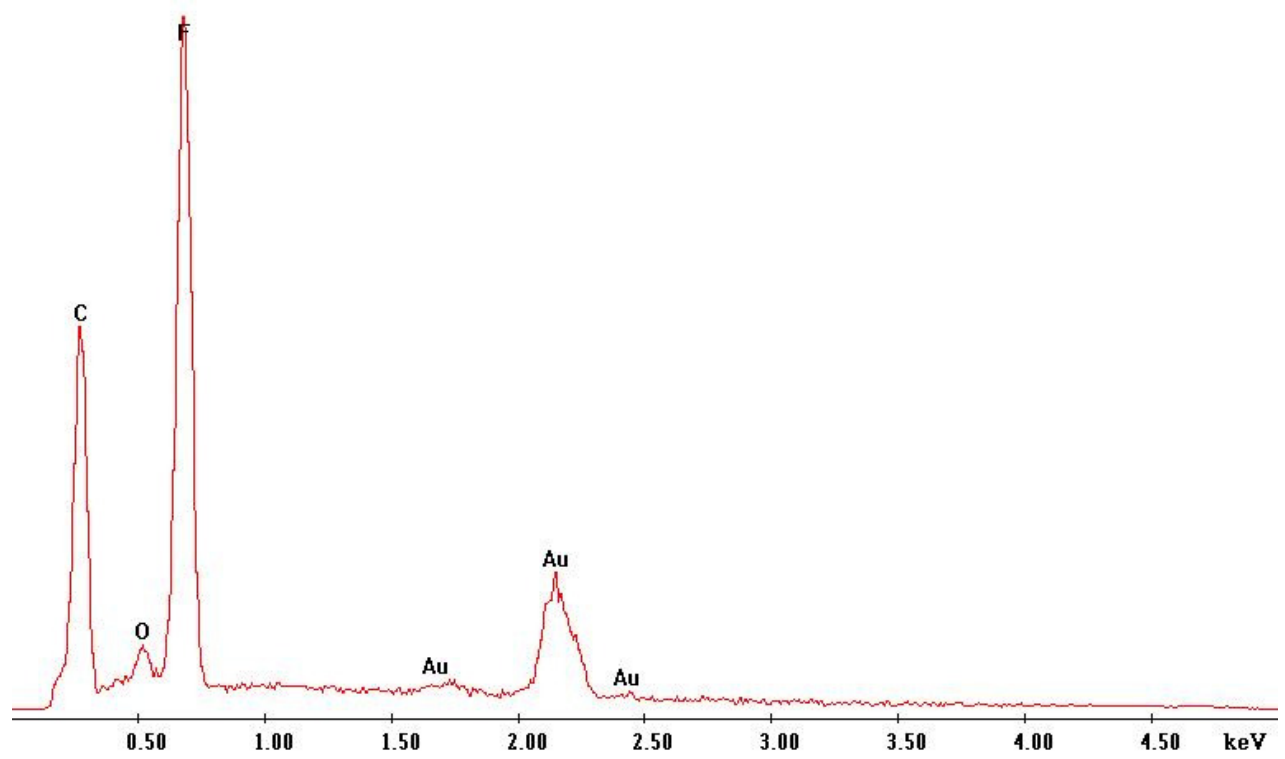




\section{Black trim}
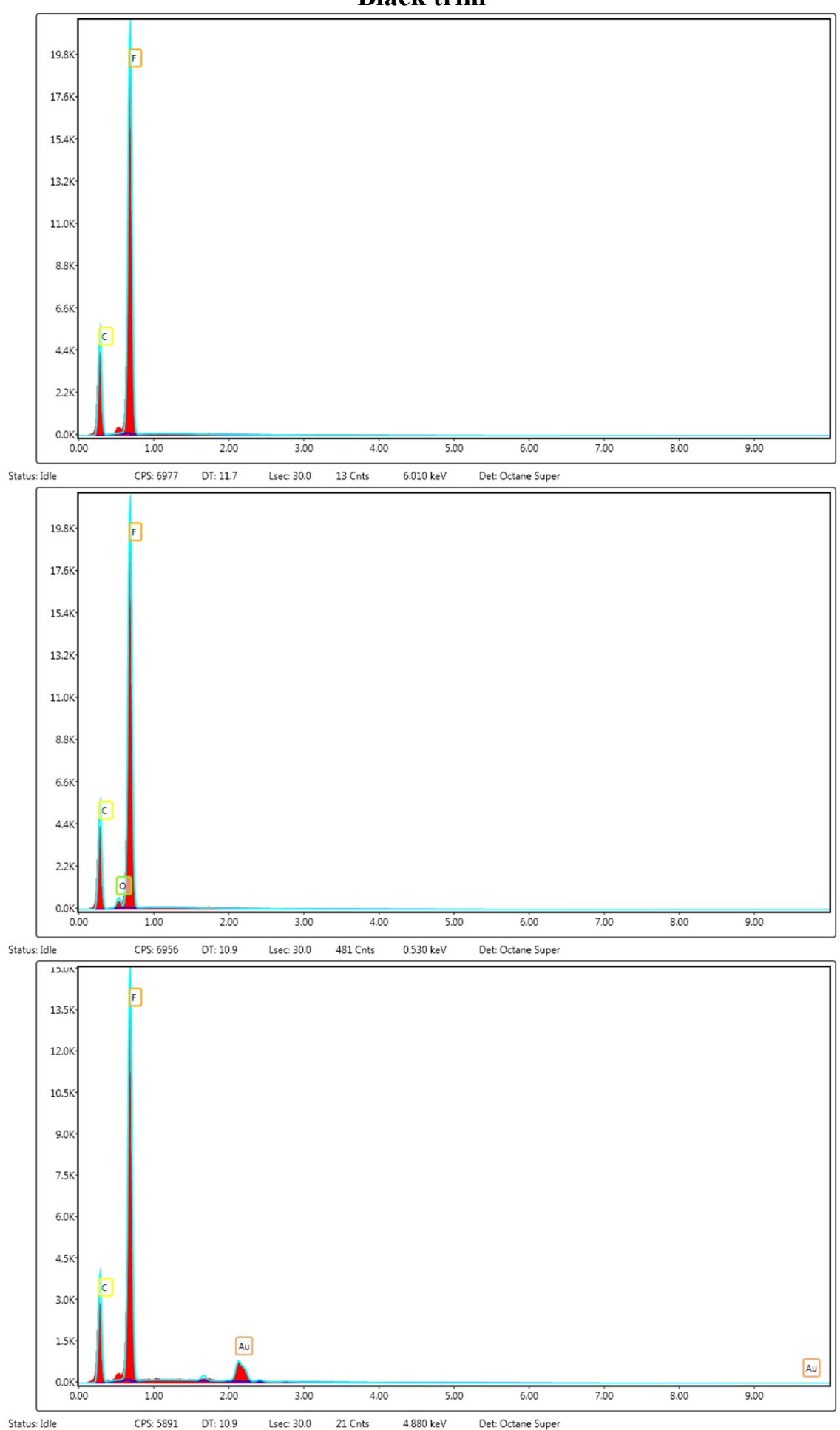


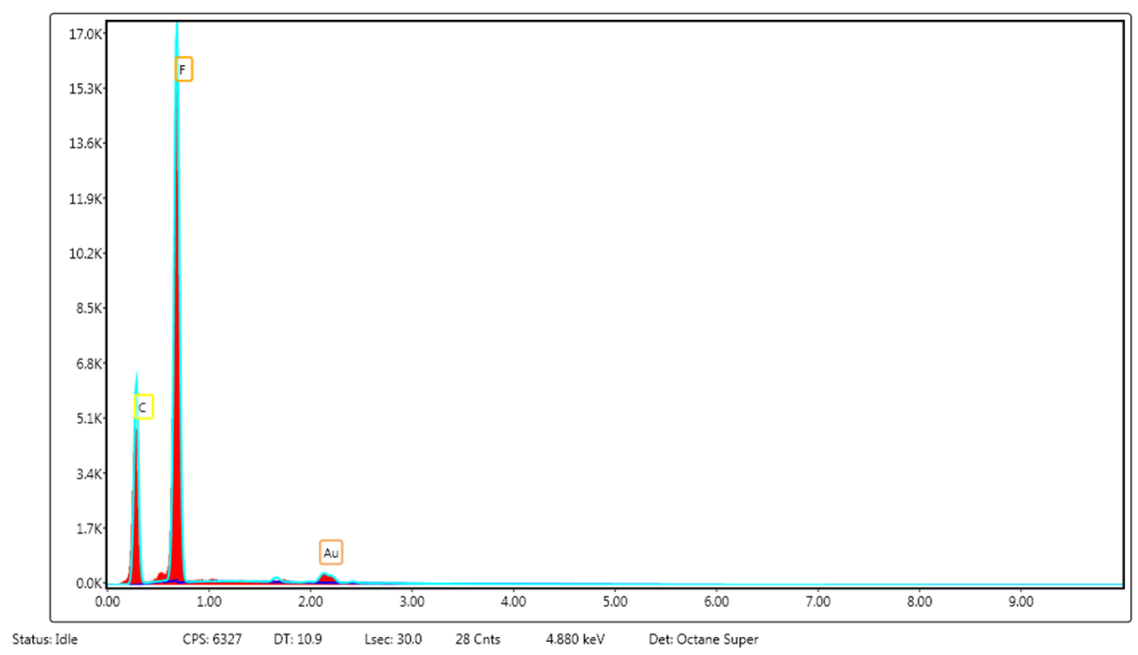

"Grey" trim
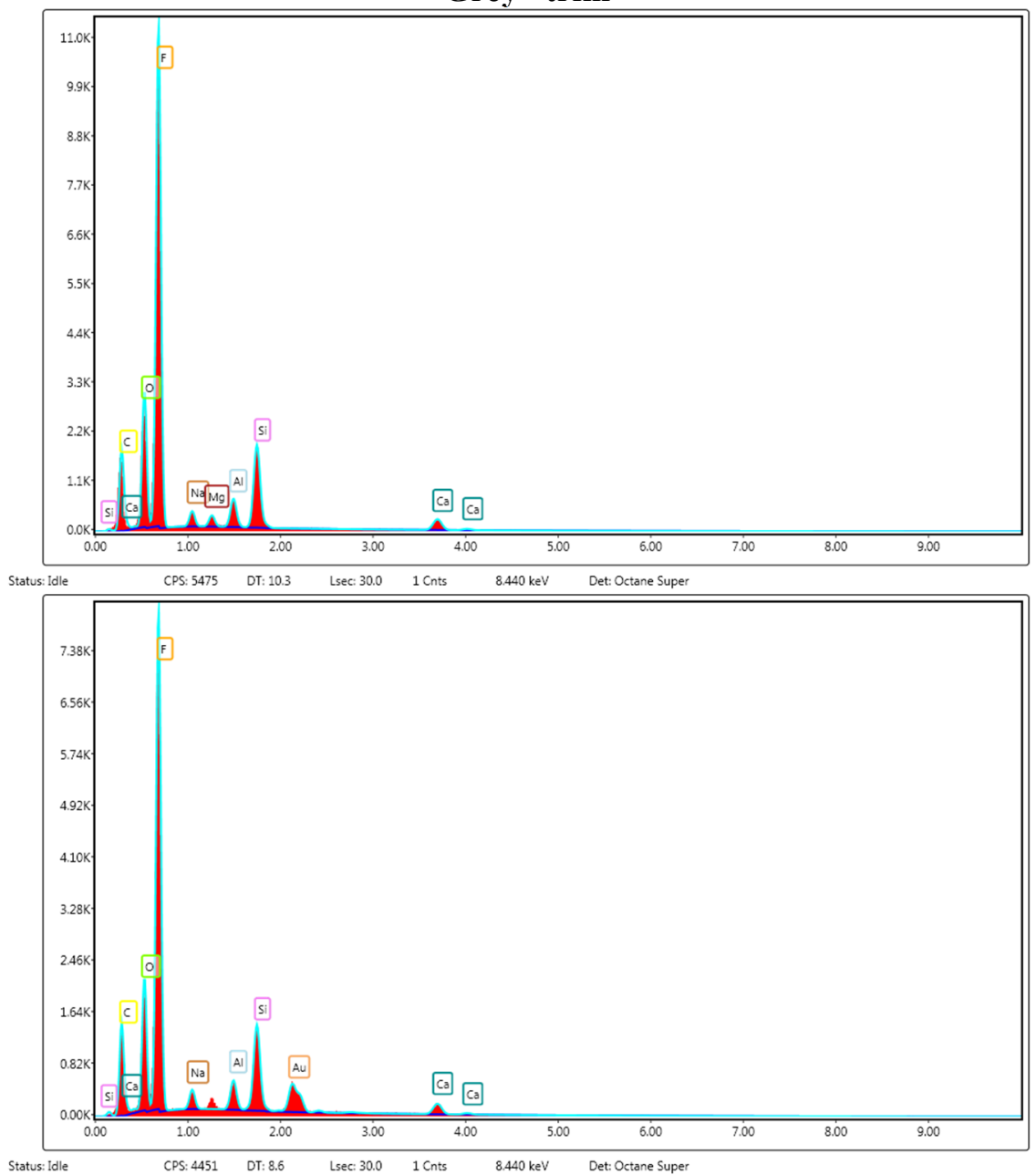

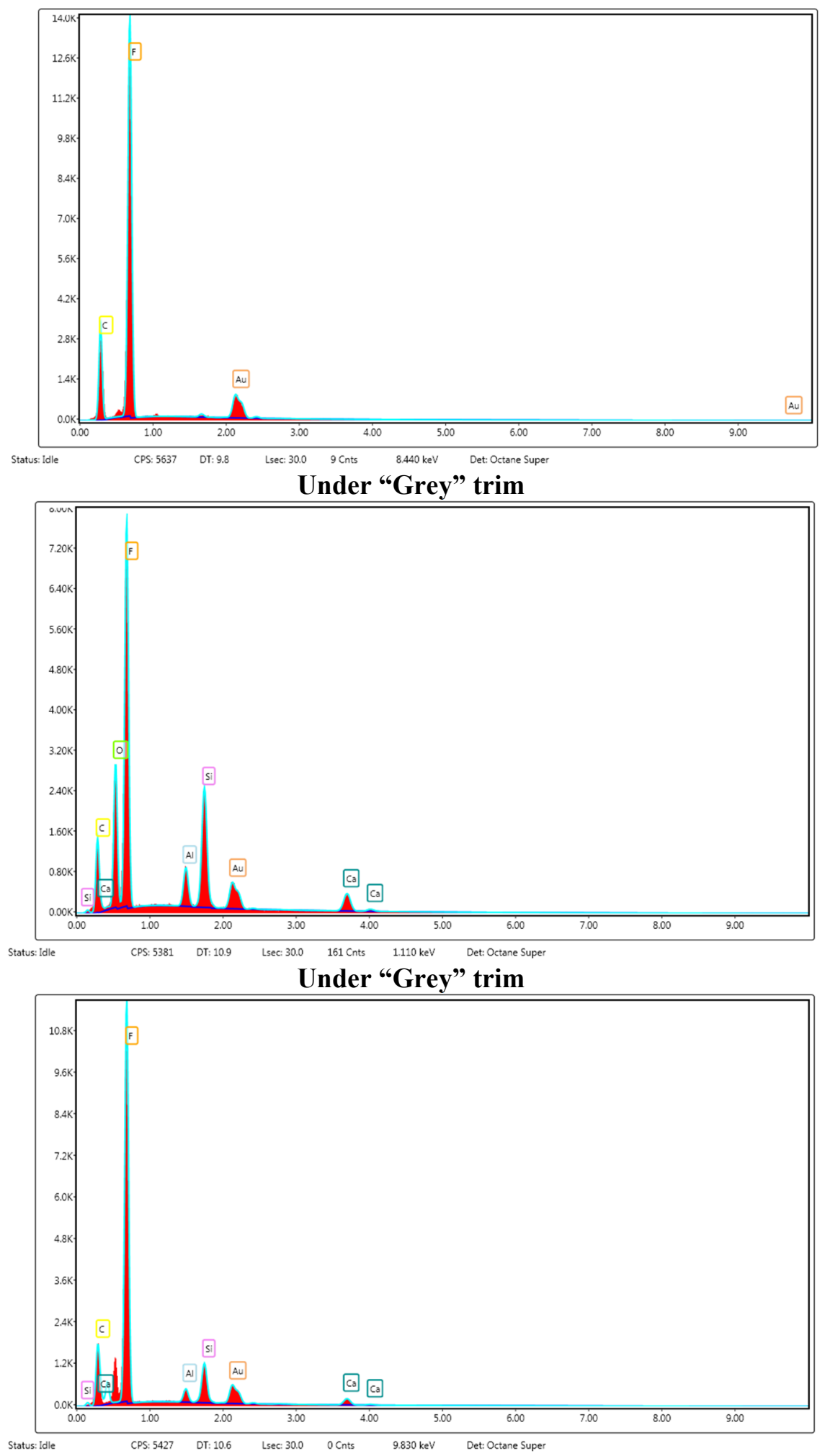


\section{Appendix E-Infrared Spectra}

Nomenclature for the spectra shown in this appendix uses the following convention. Samples taken from the five sides as defined in the text and Figure 4 and 5 are labeled A1, A2, B1, B2, C1, D1, and E1. The two samples taken from sides A and B are taken from a lighter area (A1 and B1) and a darker area (A2 and B2). The total reflectivity $(\rho(\lambda))$ in the mid-infrared region (wavelength 2.5 to $25 \mu \mathrm{m}$ ) was measured using an iS50 Nicolet Spectrophotometer (ThermoFisher) equipped with a Pike integrating sphere measured on a deuterated triglycine sulfate (DTGS) detector. Data were collected using OMNIC software. Each spectrum shows the back side and the front side of each sample. For the most part the curves lie on top of each other, but in the darker samples (A2, B2, E1) there are some differences in the 8 to $9 \mu \mathrm{m}$ range, and so a blow up of the 5 to $10 \mu \mathrm{m}$ region is also shown for each sample. 
A1

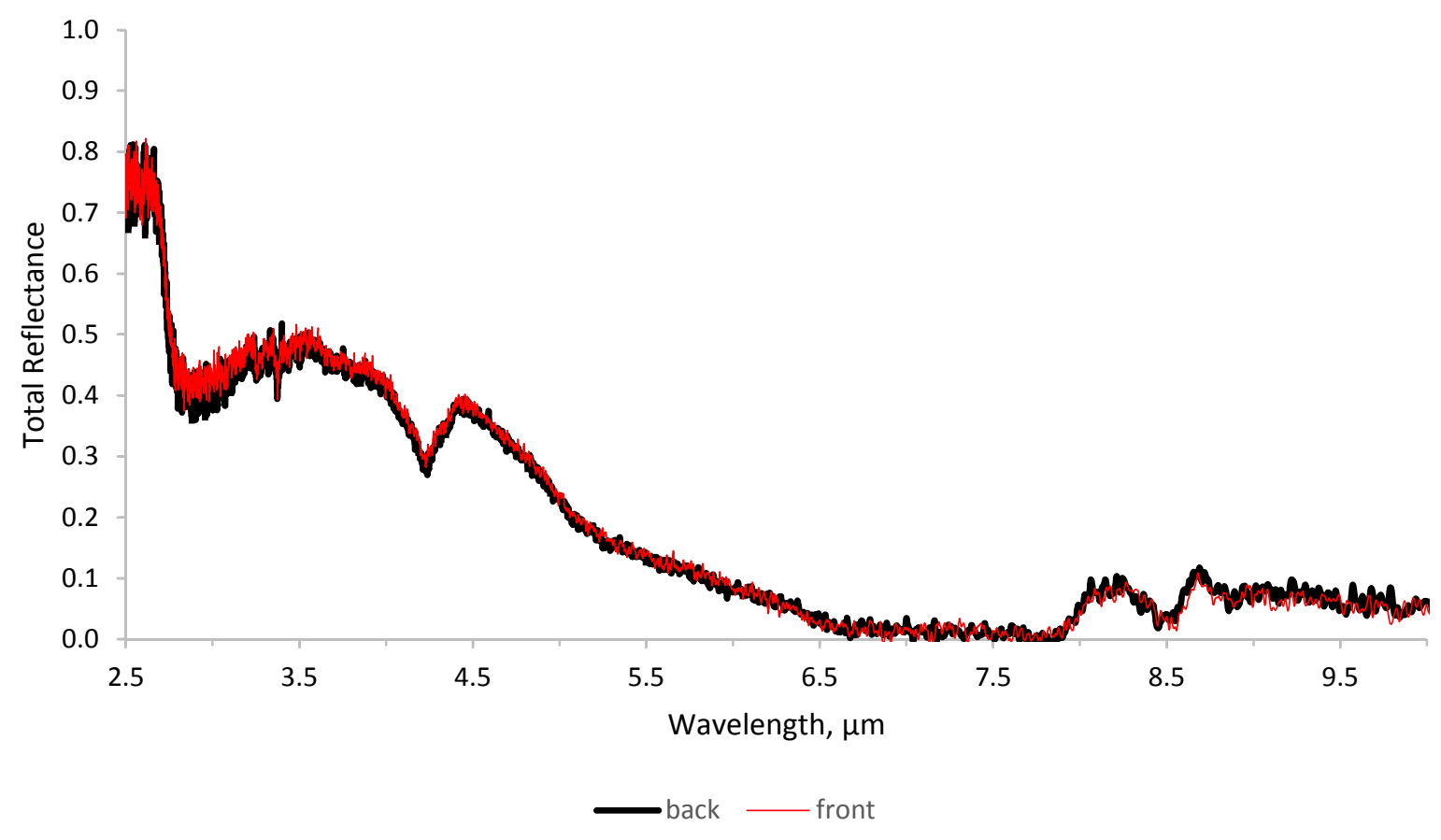

A1

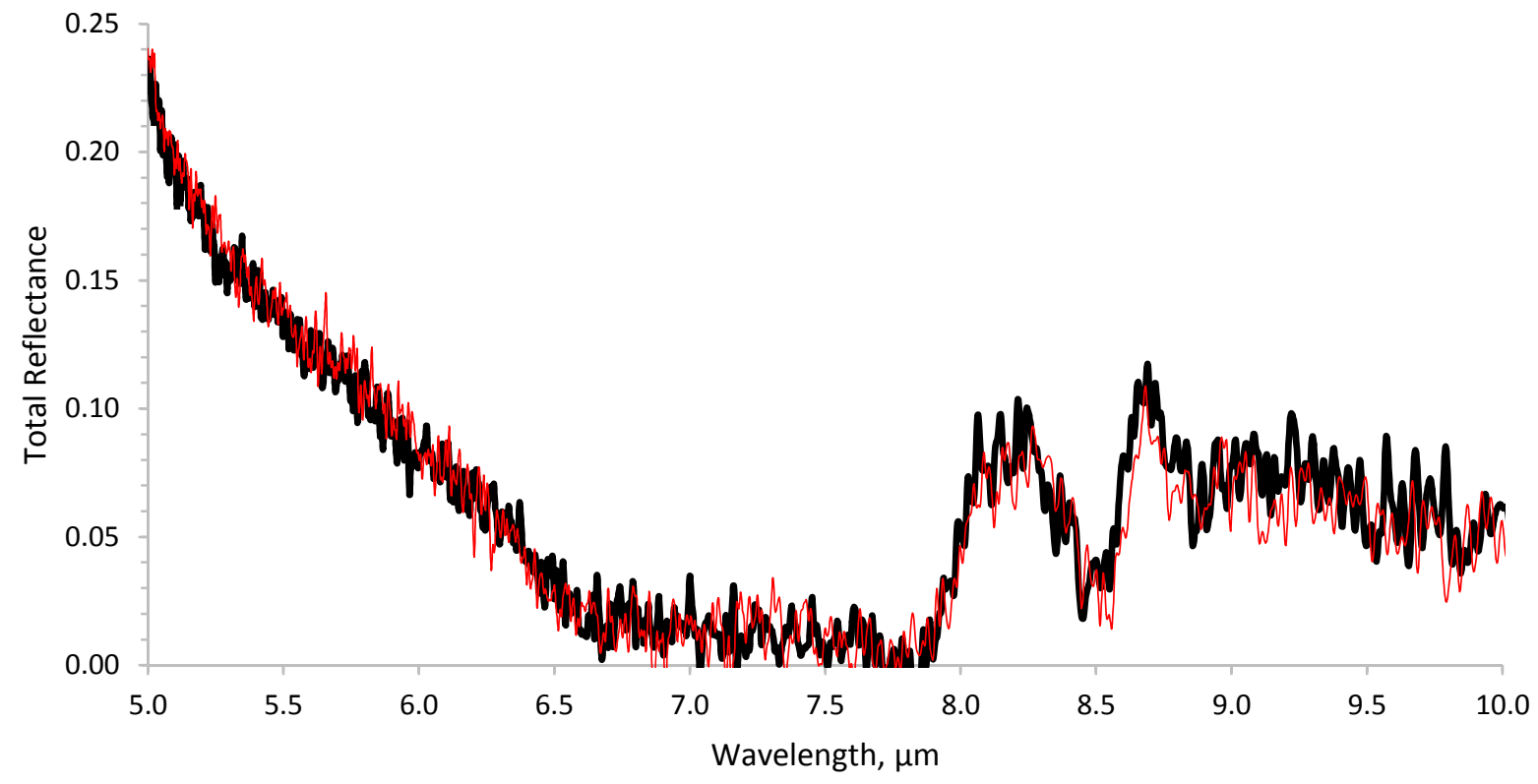

- back front 


\section{A2}

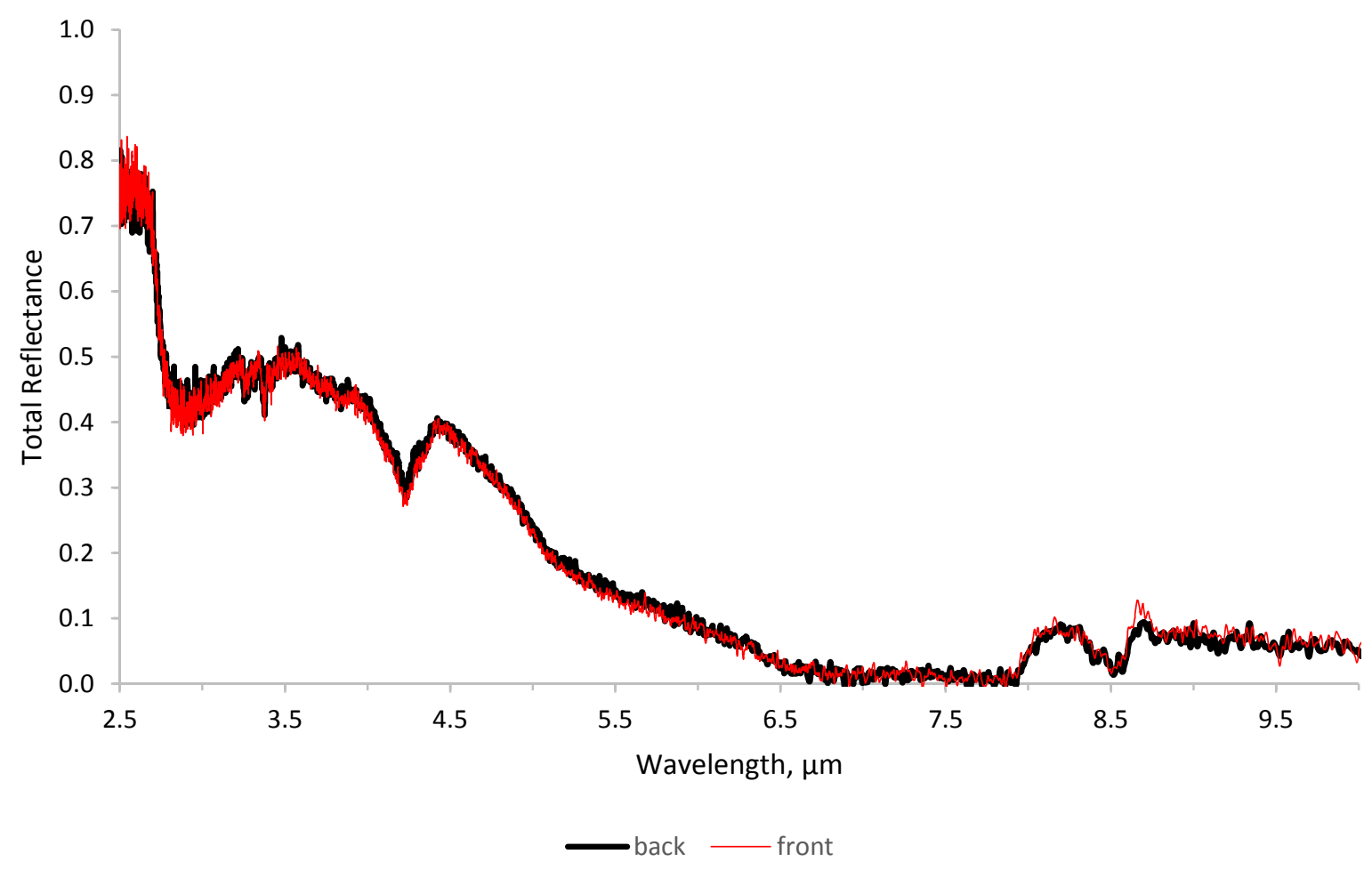

A2

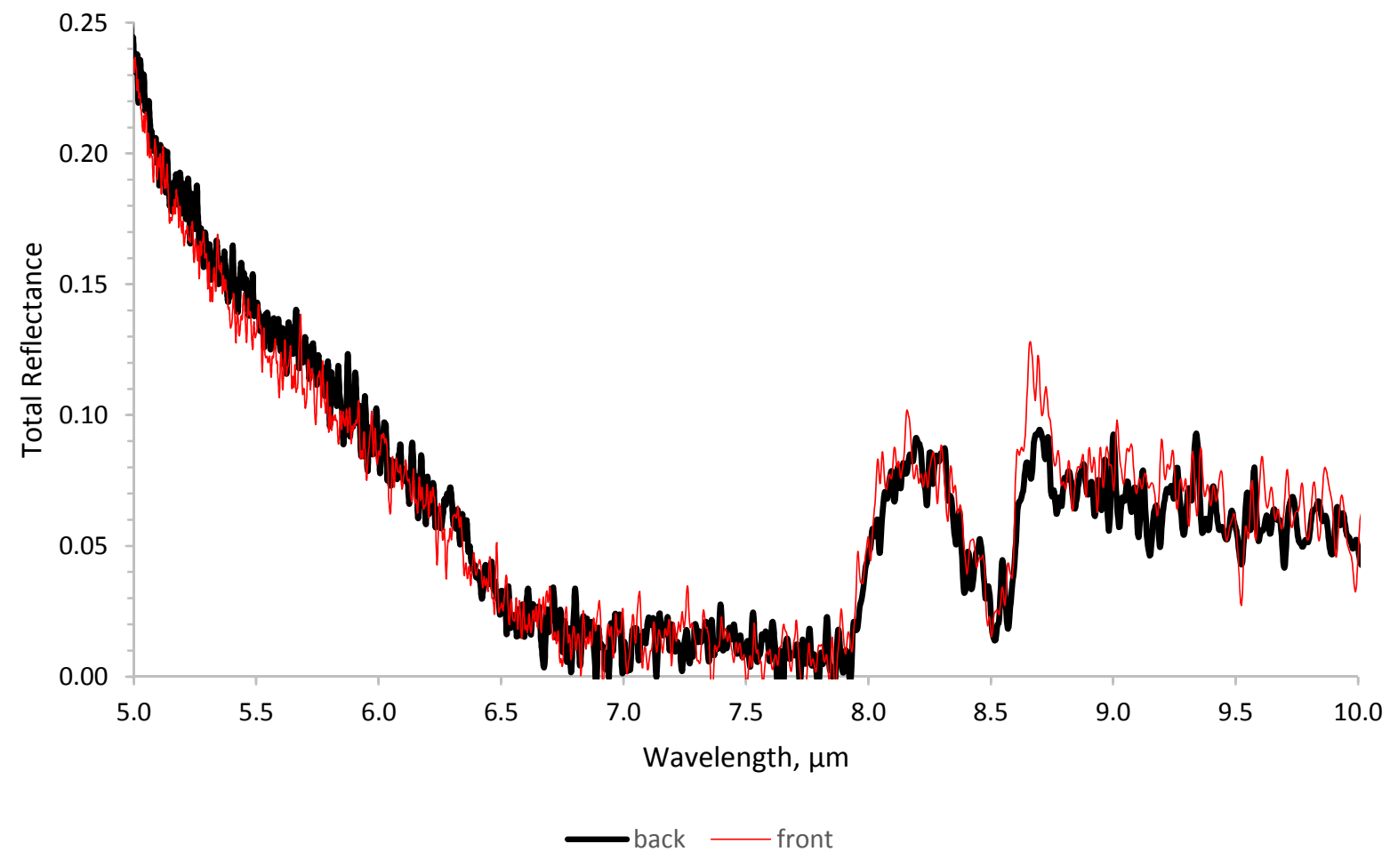




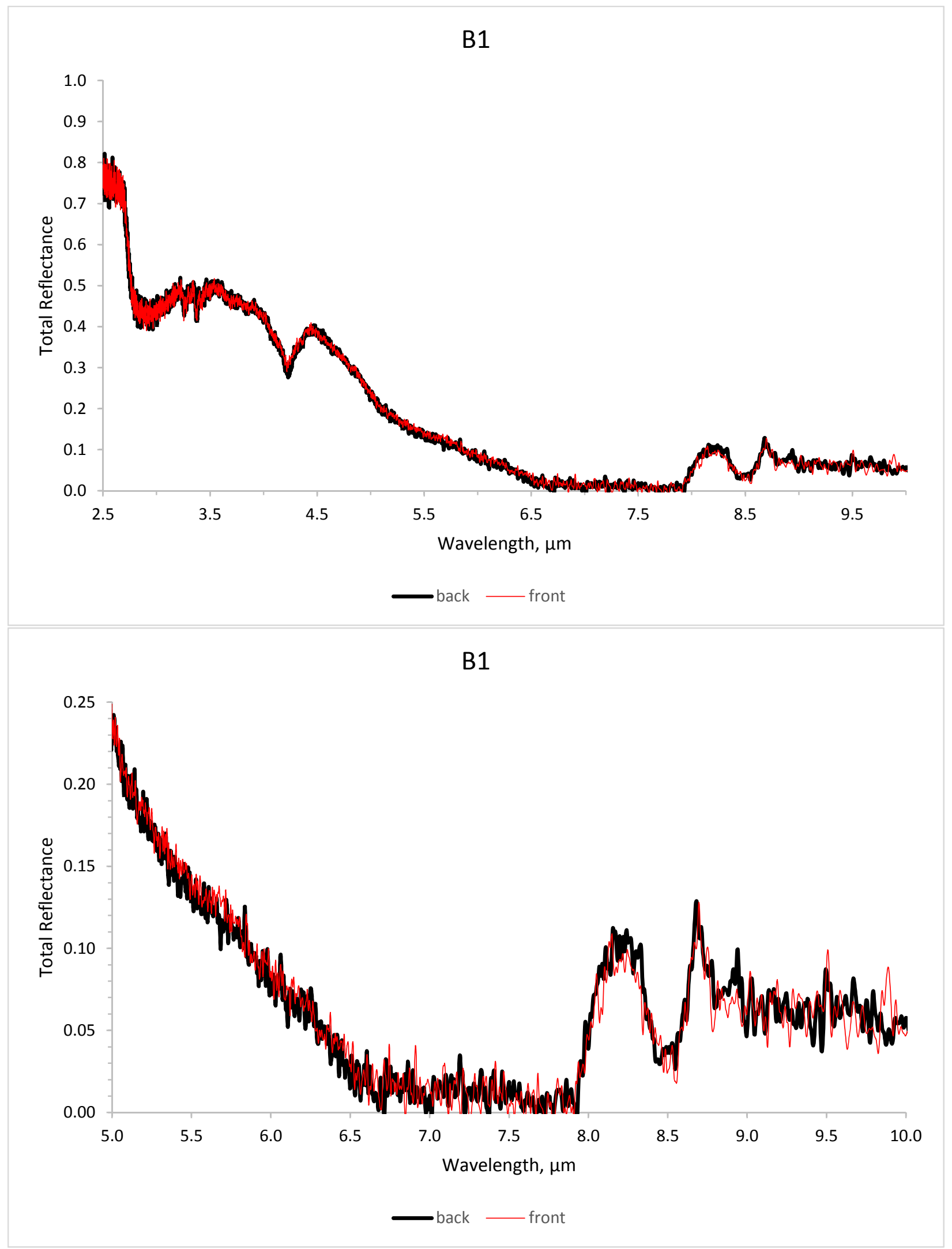


B2

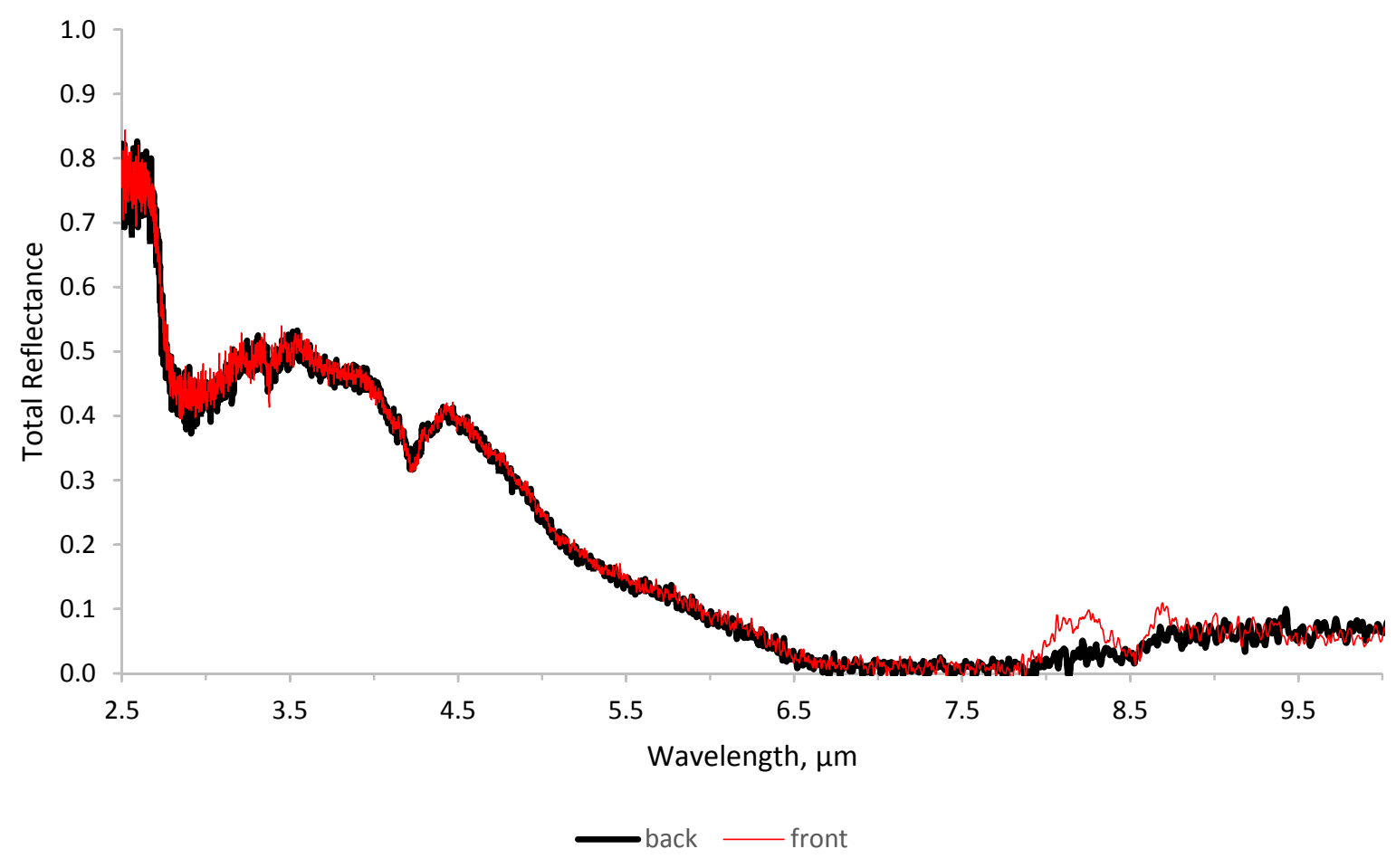

B2

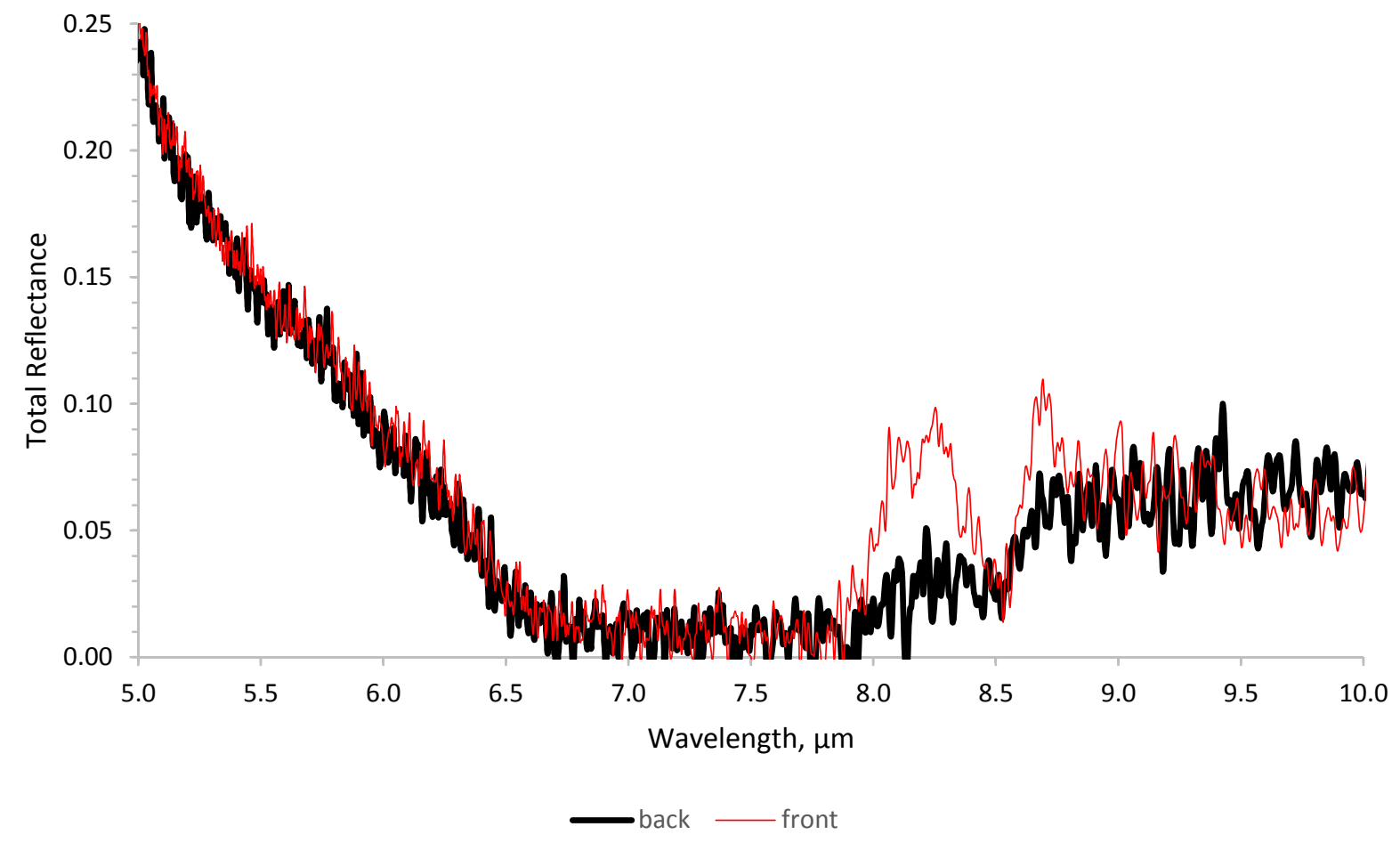




\section{C1}

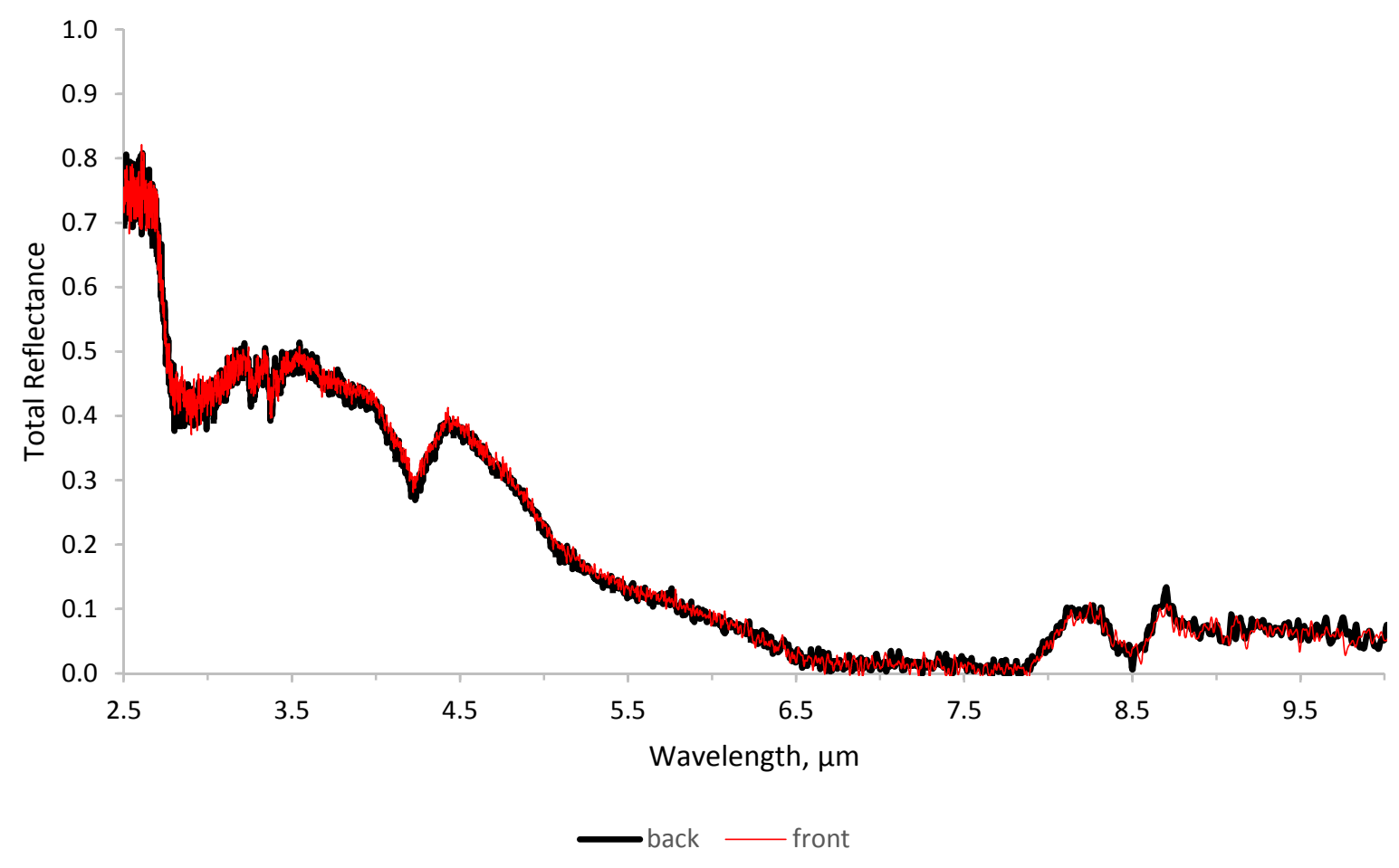

\section{C1}

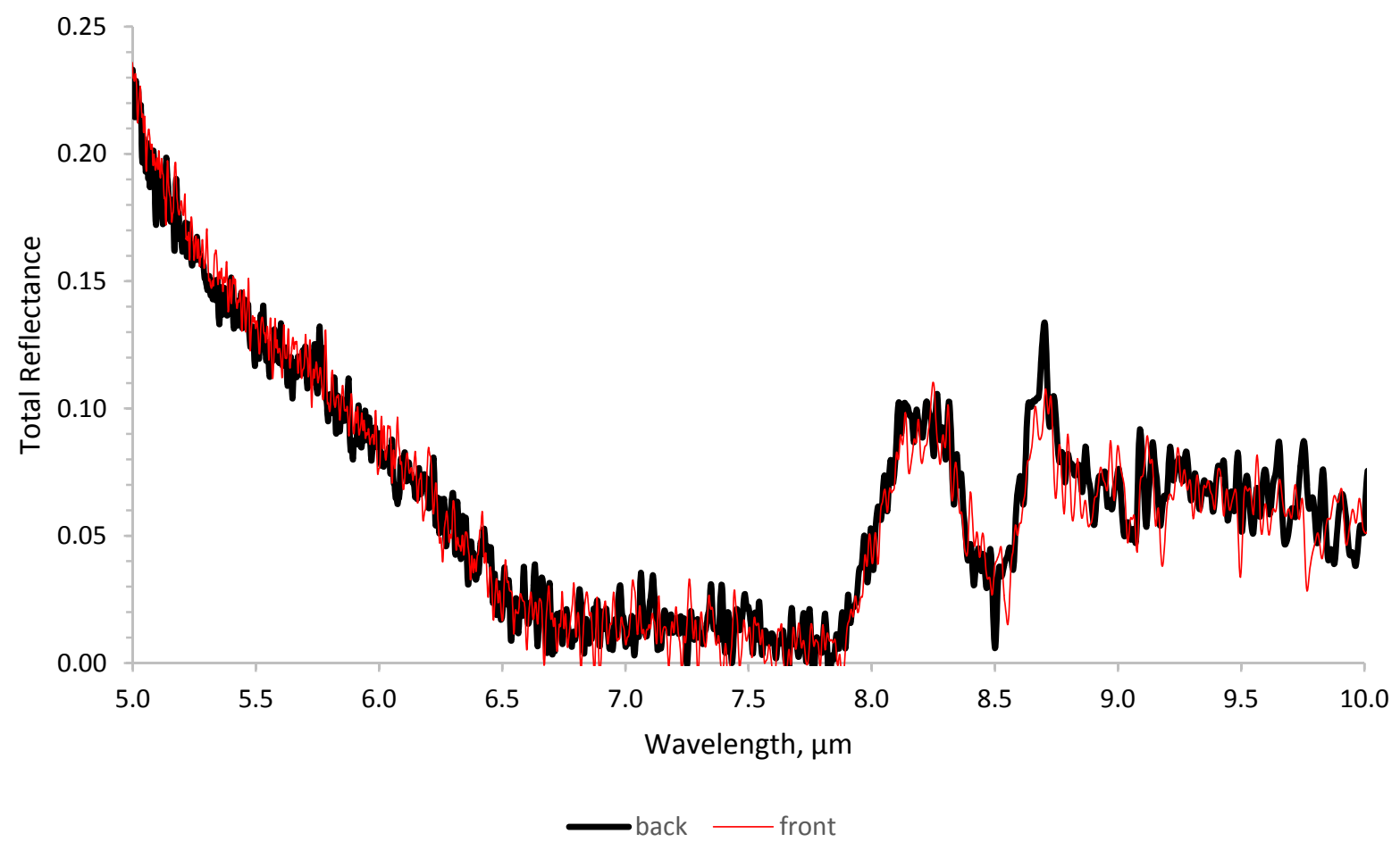




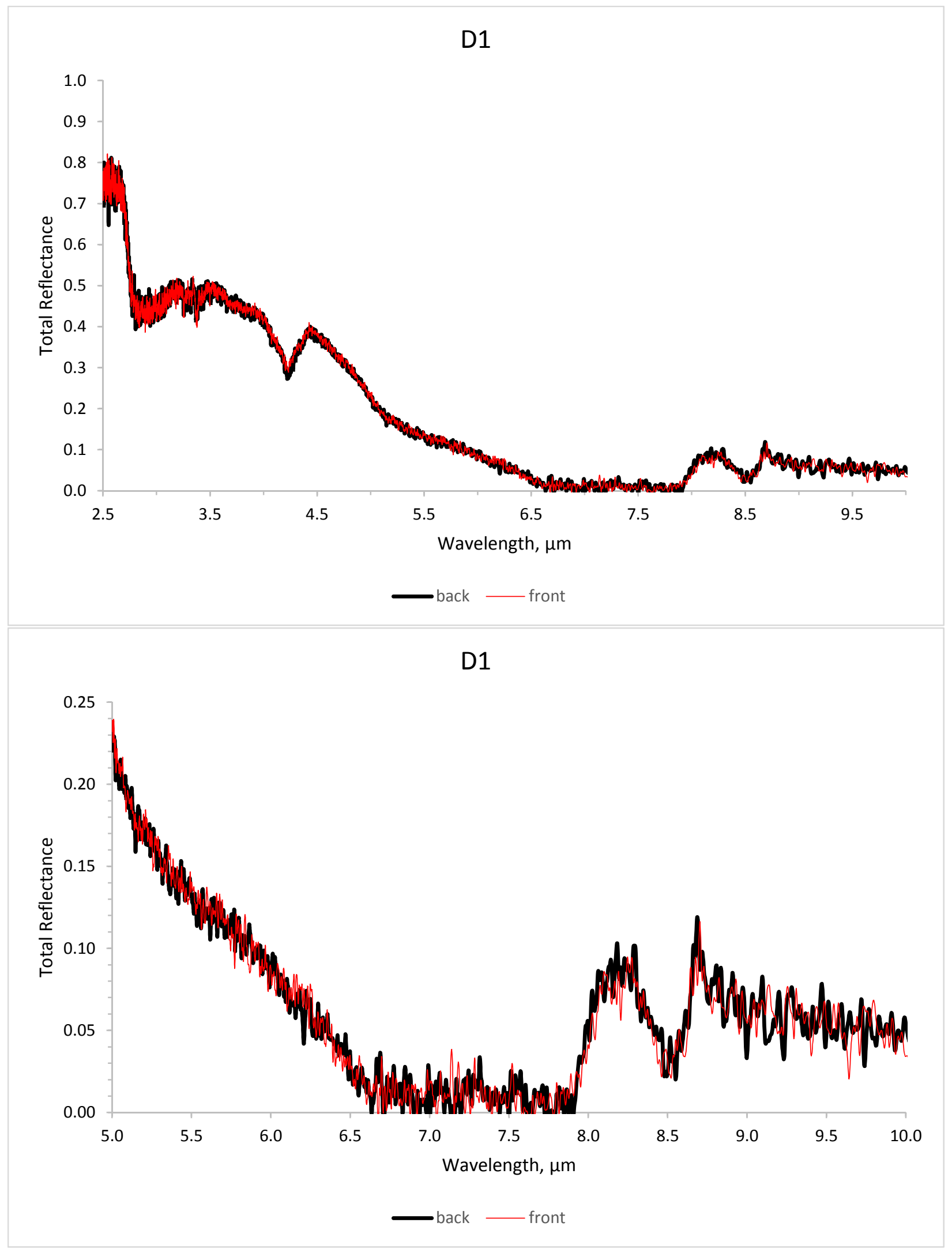


E1

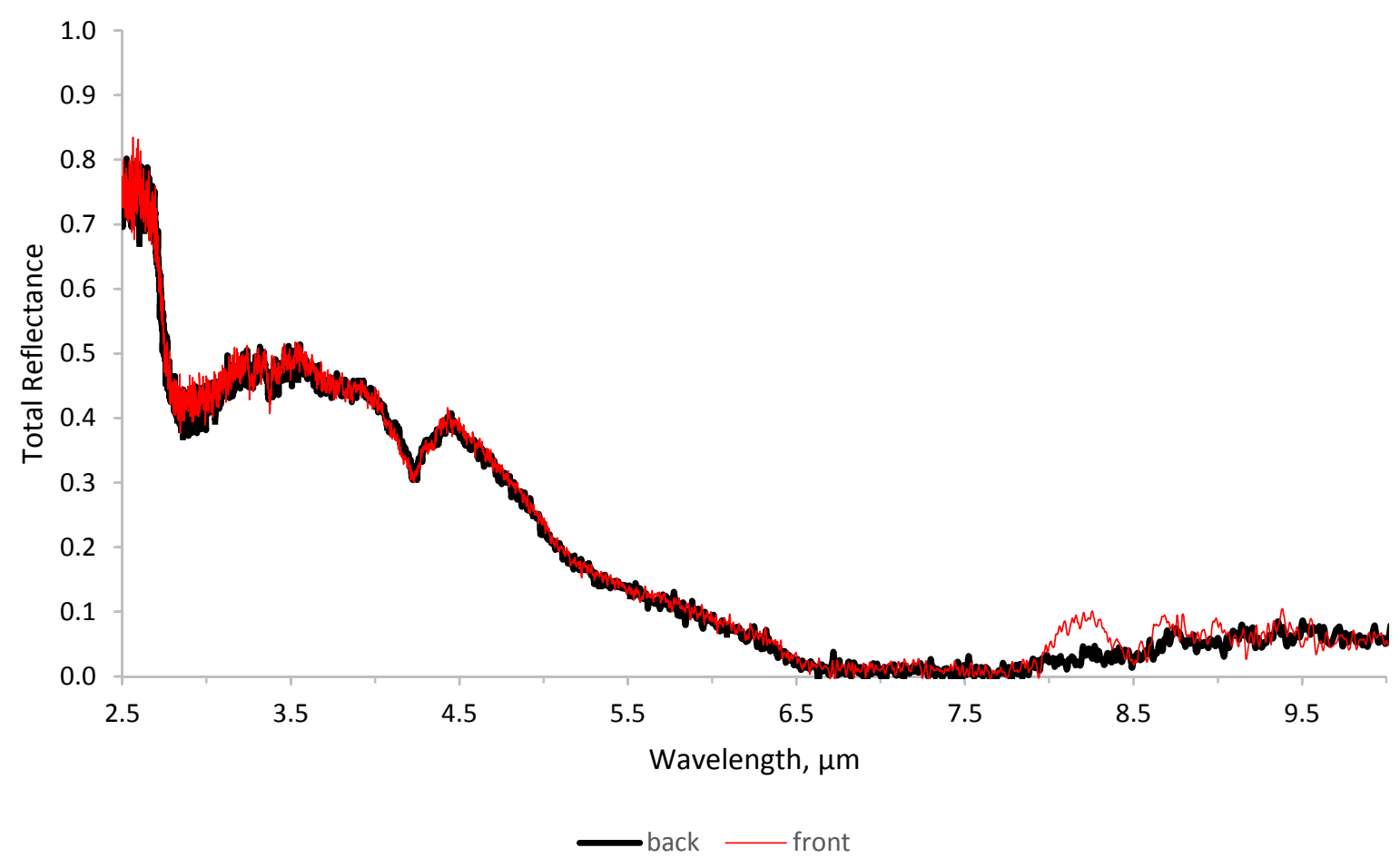

E1

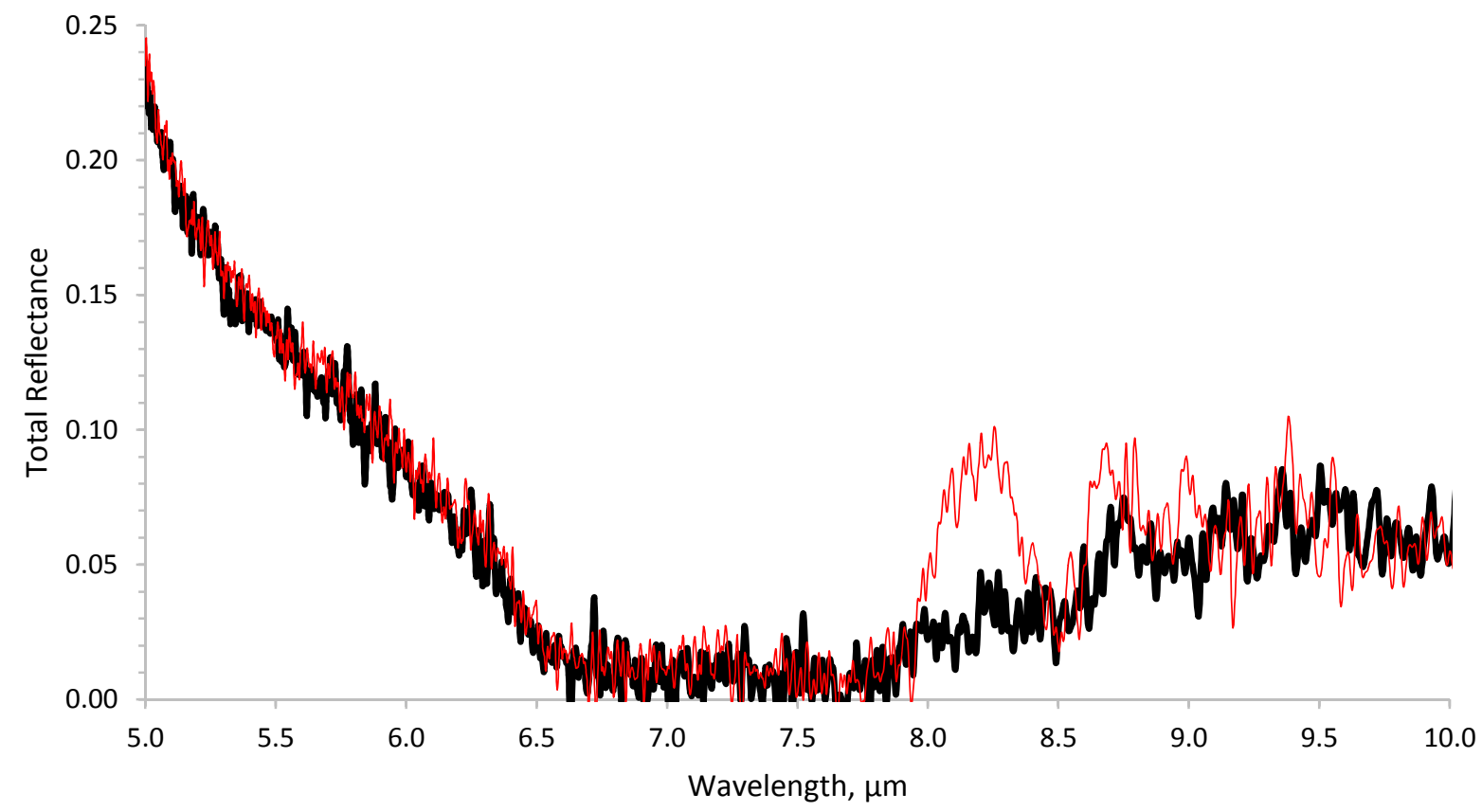

- back front 


\section{References}

1. J.R. Gaier, et al., "Degradation of Space Suit Fabrics in Low Earth Orbit," International Conference on Environmental Systems 2012, AIAA-2012-3573.

2. R.C. Linton, A.F. Whitaker, and M.M. Finckenor, "Space Environment Durability of Beta Cloth in LDEF Thermal Blankets," LDEF Materials Results for Spacecraft Applications, NASA CP-3257 (1994), 31-45.

3. K.K. deGroh, B.A. Banks, and C.E. McCarthy, "Spacecraft Polymers Atomic Oxygen Durability Handbook DBK-6024," Approved and published by the NASA Office of the Chief Engineer, June 27, 2014 and K.K. de Groh, et al., "Analyses of Hubble Space Telescope-Teflon Multilayer Insulation Blankets Retrieved After 19 Years of Space Exposure,” NASA/TM-2015-218476, February, 2015.

4. J.R. Gaier et al., "Post-Flight Characterization of Samples for the MISSE-7 Spacesuit Fabric Exposure Experiment," NASA/TM-2012-217651.

5. Dever, J.A., de Groh, K.K., Banks, B.A., and Townsend, J.A., "Effects of radiation and thermal cycling on Teflon ${ }^{\circledR}$ FEP," High Performance Polymers, Vol. 11, No. 1, Mar. 1999, pp. 123-140. 


